\title{
The inflamed liver
}

Citation for published version (APA):

Bijnen, M. (2019). The inflamed liver: RAGE and Gluttony. [Doctoral Thesis, Maastricht University]. Gildeprint Drukkerijen. https://doi.org/10.26481/dis.20190222mb

Document status and date:

Published: 01/01/2019

DOI:

10.26481/dis.20190222mb

Document Version:

Publisher's PDF, also known as Version of record

\section{Please check the document version of this publication:}

- A submitted manuscript is the version of the article upon submission and before peer-review. There can be important differences between the submitted version and the official published version of record.

People interested in the research are advised to contact the author for the final version of the publication, or visit the DOI to the publisher's website.

- The final author version and the galley proof are versions of the publication after peer review.

- The final published version features the final layout of the paper including the volume, issue and page numbers.

Link to publication

\footnotetext{
General rights rights.

- You may freely distribute the URL identifying the publication in the public portal. please follow below link for the End User Agreement:

www.umlib.nl/taverne-license

Take down policy

If you believe that this document breaches copyright please contact us at:

repository@maastrichtuniversity.nl

providing details and we will investigate your claim.
}

Copyright and moral rights for the publications made accessible in the public portal are retained by the authors and/or other copyright owners and it is a condition of accessing publications that users recognise and abide by the legal requirements associated with these

- Users may download and print one copy of any publication from the public portal for the purpose of private study or research.

- You may not further distribute the material or use it for any profit-making activity or commercial gain

If the publication is distributed under the terms of Article $25 \mathrm{fa}$ of the Dutch Copyright Act, indicated by the "Taverne" license above, 


\section{The inflamed liver: RAGE and Gluttony}


(C) Mitchell Bijnen, Maastricht, 2019

No part of this book may be reproduced or transmitted in any form or by any means, without prior permission in writing by the author, or when appropriate, by the publishers of the publications.

\section{Paranimfen:}

N. van Beurden-Simons

M. Van den Eynde

Cover design: Jean Scheijen

Printed by: Gildeprint

ISBN: 978-94-6323-489-4 


\section{The inflamed liver: RAGE and Gluttony}

\section{PROEFSCHRIFT}

Ter verkrijging van de graad van doctor aan de Universiteit Maastricht, op gezag van de Rector Magnificus, Prof. dr. Rianne M. Letschert, volgens het besluit van het College van Decanen, in het openbaar te verdedigen op vrijdag 22 februari 2019 om 14.00 uur

door

Mitchell Bijnen 


\section{Promotor}

Prof. dr. C.G. Schalkwijk

\section{Copromotor}

Dr. K. Wouters

\section{Beoordelingscommissie}

Prof. dr. J. Plat (Chairman)

Prof. dr. R. Shiri-Sverdlov

Dr. G.H. Koek

Prof. dr. ir. A.H. Kersten (Wageningen University \& Research)

Prof. dr. B. Staels (Université de Lille, France)

\section{Hartstichting}

The research described in this thesis was supported by a grant of the Dutch Heart Foundation (2013T143) and financial support by the Dutch Heart Foundation for the publication of this thesis is gratefully acknowledged. 


\section{Contents}

Chapter 1 General introduction 7

\section{Part 1:}

Chapter 2 Hepatic fat content and liver enzymes are associated with circulating free and protein-bound advanced glycation endproducts, which are associated with low-grade inflammation: The CODAM study

Chapter 3 Higher dietary advanced glycation endproduct intake increases circulating advanced glycation endproducts, hepatic advanced glycation endproducts and hepatic inflammation

Chapter 4 RAGE deficiency does not affect non-alcoholic steatohepatitis and atherosclerosis in Western type diet-fed $\mid \mathrm{dll} \mathrm{r}^{-/}$mice

\section{Part 2:}

Chapter 5 Characterization of immune cells in human adipose tissue by using flow cytometry

Chapter 6 Circulating classical monocytes are associated with CD11 $\mathrm{c}^{+}$macrophages in human visceral adipose tissue

Chapter 7 Adipose tissue macrophages induce hepatic neutrophil recruitment and macrophage accumulation in mice

Chapter 8 Adipose tissue macrophages do not affect atherosclerosis development in mice

Chapter 9 Summary and general discussion 
Valorisation

Dankwoord

Curriculum Vitae

Scientific output

251

Abbreviations

257 
Chapter 1

General introduction 


\section{The inflamed liver: RAGE and Gluttony}

The prevalence of obesity has greatly increased in the last decades contributing to a rise in a plethora of diseases like diabetes, non-alcoholic fatty liver disease (NAFLD) and cardiovascular disease (CVD) $)^{1,2}$. These comorbidities are presumably caused by the elevated circulating lipids and chronic inflammatory status that is associated with obesity. Next to the accumulation of lipids in the expanding adipose tissue (AT) and subsequent release of lipids into the circulation, obese individuals have higher levels of immune cells, mainly macrophages, within the AT. These adipose tissue macrophages (ATMs) secrete many pro-inflammatory cytokines maintaining not only an inflammatory state of the AT, but also a low-grade systemic inflammation affecting other organs and tissues ${ }^{3}$. Despite the clear associations between obesity and both NAFLD and CVD, it is not yet fully understood how AT expansion and the accompanying low-grade inflammation affect progression of liver disease and the development of atherosclerosis, a main cause of CVD.

\section{Obesity}

Over the last decades, obesity prevalence has nearly tripled. In 2016, nearly $40 \%$ of the global adult population was overweight and $13 \%$ was considered obese $^{4}$. Obesity is characterized by excessive fat accumulation in many organs, mainly the AT. This is typically caused by an imbalance between energy expenditure and intake resulting in the AT being overloaded with lipids and therefore an impaired lipid buffering capacity ${ }^{5,6}$. Consequently, circulating lipids are elevated and end up in many tissues including the liver, contributing to hepatic fat accumulation i.e. steatosis ${ }^{7,8}$. AT is a major endocrine organ and particularly obese AT produces many inflammatory cytokines, e.g. TNF $\alpha$, MCP-1, IFN- $\gamma$ and IL- $6^{9}$. These cytokines are released into the circulation contributing to the low-grade inflammation, which often accompanies obesity. During chronic low-grade inflammation, levels of proinflammatory cytokines and circulating immune cells such as monocytes are increased, which can affect other tissues and organs as well ${ }^{3}$. In addition, due to venous drainage from AT through the portal system, inflammatory 
mediators from the AT can directly end up in the liver, potentially contributing to the progression of NAFLD to the detrimental inflammatory stage ${ }^{10,11}$. Important producers of these inflammatory proteins in the AT are the ATMs. Studies have also connected increasing degrees of obesity with increasing rates of coronary artery disease. In addition, it has been shown that AT inflammation contributes to atherosclerosis in mice ${ }^{12,13}$.

\section{Atherosclerosis}

Cardiovascular disease (CVD) is the number one cause of death worldwide with over approximately $30 \%$ of all deaths ${ }^{14}$. An important cause of CVDrelated death is a myocardial infarction or stroke, often the end result of atherosclerosis. In atherosclerosis, oxidized cholesterol and macrophage accumulate in the vessel wall causing an inflammatory response. This initial lesion will expand and develop into a plaque as more lipids and inflammatory cells accumulate. Other cells such as vascular smooth muscle cells will start to produce extracellular matrix proteins (e.g. collagen) forming a fibrous cap, which further expands the plaque and occludes the lumen of the artery. Plaques can be stable for many years, but can also rupture resulting in occlusion of the vessel triggering a cardiovascular event such as a myocardial infarction or stroke ${ }^{15}$. It is not fully understood which factors determine the stability of a plaque and make a plaque either stable or rupture-prone. Stable plaques typically contain less macrophages and fewer dead cells inside the plaque (necrotic core), but a larger fibrous cap due to more collagen deposition by smooth muscle cells, while rupture-prone plaques are characterized by more inflammation, a high metabolic activity, intraplaque angiogenesis (due to hypoxia), a thin fibrous cap and large necrotic core ${ }^{16-18}$. A plaque rupture often takes place at the shoulder area of the plaque, which is rich in macrophages suggesting macrophages play a role in plaque stability and not only in plaque development ${ }^{16}$. An important source of these plaque macrophages are circulating monocytes that have entered the vessel wall and differentiate into macrophages ${ }^{15}$. Circulating monocyte levels are higher in the obese and have been associated with atherosclerosis development ${ }^{19}$. A possible explanation for this association is the elevated monocyteendothelium interaction allowing more monocytes to enter the intima, 
followed by initiation or progression of plaque development ${ }^{20,}{ }^{21}$. Furthermore, a pro-inflammatory subset of monocytes i.e. Ly6C $^{+}$(or $\mathrm{CD} 14^{+} \mathrm{CD} 16^{+}$) monocytes, are recruited during obesity due to high circulating lipid levels. These monocytes tend to adhere stronger to the vessel wall endothelium and are more prone to infiltrate atherosclerotic lesions ${ }^{22}$. Other important circulating cells in obesity and reported to play a role in atherogenesis are the neutrophils ${ }^{23}$. These cells are important for both plaque initiation as well as plaque stability. Neutrophils can worsen endothelial dysfunction by facilitating immune cell, e.g. monocyte, infiltration into the vessel wall. In the plaque, they stimulate lipid uptake by macrophages contributing to plaque progression, while also producing proteases and ROS, which affects plaque stability ${ }^{24}$.

\section{Non-alcoholic fatty liver disease}

The liver is of great importance in human metabolism. It plays a key role in lipid, protein and carbohydrate homeostasis making it the central organ in metabolic regulation. Other important functions include detoxification of harmful substances, the synthesis and breakdown of several hormones (Angiotensinogen, Thrombopoietin and IGF-1) and synthesis of proteins such as coagulation factors, albumin, complement factors and acute phase proteins. Both complement factors and acute phase proteins play an important role in the immune system throughout the body ${ }^{25,26}$. Due to disturbances in the hepatic regulation of lipid synthesis and secretion, possibly as a consequence of hyperinsulinemia or hepatic insulin resistance, and/or due to increased influx of fatty acids derived from AT, the liver may accumulate excessive amounts of lipids, termed steatosis ${ }^{8}$. The development of steatosis is a primary hallmark of NAFLD, a spectrum of liver diseases ranging from steatosis only ( $>5 \%$ of hepatocytes contain fat) to the inflammatory non-alcoholic steatohepatitis (NASH), fibrosis and ultimately cirrhosis. The latter stages are characterized by inflammation in addition to steatosis ${ }^{27}$. Hepatic inflammation causes several histological features allowing distinction from steatosis only. Liver cell injury can be observed due to ballooning of hepatocytes, while lobular inflammation can be recognized by accumulation of several different immune cells, such as lymphocytes, 
macrophages and neutrophils. An important feature is fibrosis as a result of liver damage caused by inflammation ${ }^{28}$.

NAFLD is seen as the hepatic component of the metabolic syndrome, often accompanied by concomitant metabolic disorders such as insulin resistance, dyslipidemia, central obesity and hypertension. Therefore, it is no surprise that with the rise in obesity, the occurrence of NAFLD has increased. In the general Western population, the prevalence of NAFLD is estimated to be 20 $30 \%$ while it is much higher in diabetic patients (30-50\%) and even has a prevalence of $90 \%$ in patients with hyperlipidemia ${ }^{29}$. At the steatosis only stage of NAFLD, the liver disease is considered to be benign and reversible (e.g. by losing weight). However, hepatic steatosis sensitizes the liver to hepatic inflammation. The inflammatory state due to NASH causes damage to the liver resulting in hepatocellular carcinoma or liver fibrosis and ultimately liver failure ${ }^{8}$. Moreover, NASH is linked to cardiovascular disease with many NASH patients dying from CVD, often atherosclerosis ${ }^{30}$. Seemingly, NASH patients have increased early and subclinical atherosclerosis independent of classical risk factors, insulin resistance or metabolic syndrome ${ }^{31}$. A long-term follow up study suggested that the presence of hepatic inflammation plays a key role in modulating CVD risk as a lower survival of CVD-related diseases was only observed when a patient had NASH and not when a patient had hepatic steatosis only ${ }^{30}$. Therefore, the inflammatory component of NAFLD is an important target for CVD therapy. Many possible causes of hepatic inflammation have been described, but it is still not clear which (if any) is the most important contributor in the progression from simple steatosis to full blown NASH. Possible mechanisms include oxidative stress, lipid peroxidation, ER stress, intrahepatic ceramide levels, increased extrahepatic fatty acids or cytokines and accumulation of advanced glycation endproducts $(A G E)^{32,33}$. In this thesis, I have further studied the role of 1 . AGEs via the receptor of advanced glycation endproducts (RAGE) and 2. release of inflammatory mediators by obese adipose tissue as proposed causes of hepatic inflammation and atherosclerosis. 


\section{Advanced glycation endproducts}

AGEs are glycated proteins that are formed non-enzymatically and have various pathological effects. They can disturb cell signaling by modification of intracellular proteins, stimulate inflammation or reactive oxygen species (ROS) production via interaction with the receptor for AGEs (RAGE), increase apoptosis and stiffen arteries by crosslinking extracellular matrix components $^{34,35}$. AGEs can be formed in several ways (Fig. 1.1). In the classic Maillard reaction, the carbonyl group of reducing sugars reacts with free amino groups of proteins resulting in a Schiff-base. Over time, this Schiff-base is rearranged into a more stable product, named Amadori product. Some of these products will undergo further reactions such as dehydration, oxidation and condensation resulting in AGEs that are irreversibly bound to proteins ${ }^{36}$, 37. This is a slow process and mainly effects long lasting proteins such as collagen, complement $\mathrm{C} 3$ and tubulin ${ }^{34}$. In addition to the Maillard reaction, AGEs can be formed more rapidly via AGE precursors, thereby affecting short-living proteins ${ }^{34}$. AGE precursors are reactive $\alpha$-dicarbonyls derived from glucose and lipid metabolism ${ }^{38}$. Important AGE precursors are methylglyoxal (MGO), glyoxal (GO) and 3-deoxyglucosone (3-DG) with MGO recognized as the most reactive $\alpha$-dicarbony $\left.\right|^{35}$. These AGE precursors bind to amino groups of proteins resulting in AGEs such as $\mathrm{N}^{\varepsilon}$ (carboxymethyl)lysine $(\mathrm{CML}), \mathrm{N}^{\varepsilon}$-(1-carboxyethyl)lysine (CEL), and $\mathrm{N}^{\delta}-(5-$ hydro-5-methyl-4-imidazolon-2-yl)-ornithine (MG-H1) (Fig. 1.1) 34, 39, 40. AGEs can be present in both the free (modified amino acid) and protein-bound (modified amino acid as part of a protein) form. Since a substantial part of the amino acids in the circulation are derived from the degradation of proteins, it is likely that free AGEs are derived from previously protein-bound AGEs $^{41}$.

AGE formation is increased in the presence of hyperglycemia, oxidative stress and lipid peroxidation ${ }^{39}$. Therefore, it is thought that due to high plasma and/or intracellular glucose and lipid levels, more AGE precursors and thus more AGEs are formed ${ }^{38,42}$. These ideal conditions for rapid AGE formation are most prominent in obese and diabetic patients and high levels of AGEs are found in these individuals ${ }^{43,44}$. Potentially, AGEs may contribute to the 
development of obesity-related and diabetic complications such as NAFLD and CVD.

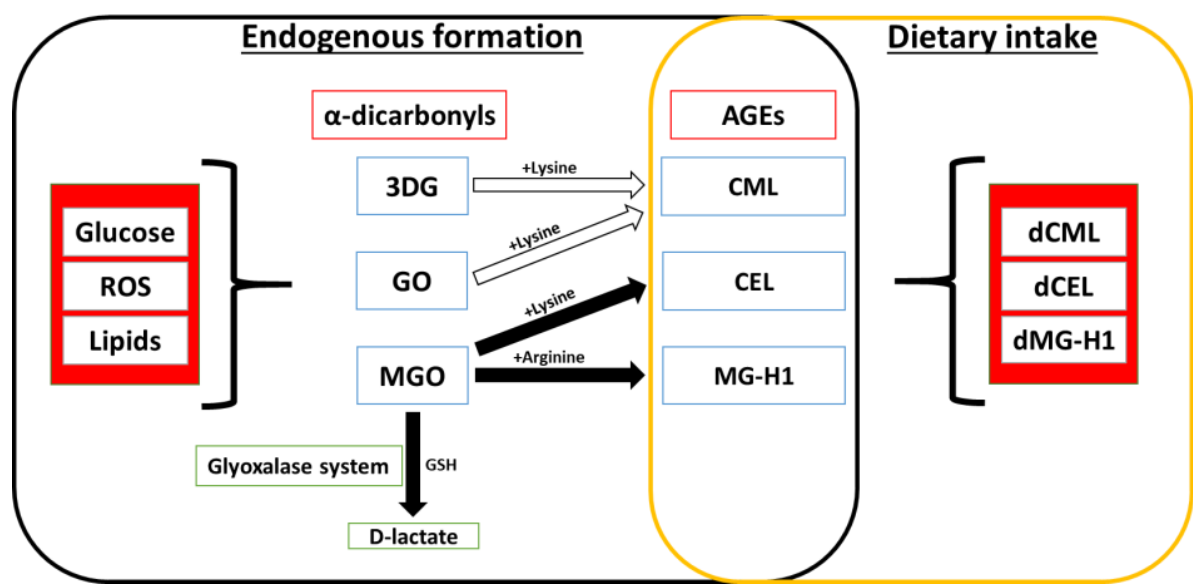

Figure 1.1. Main sources of in vivo AGE accumulation.

AGEs can be endogenously formed or be derived from the diet. Endogenous formation occurs via a non-enzymatic reaction of $\alpha$-dicarbonyls with amino-acids of proteins. This reaction occurs more frequently in the presence of high glucose, lipid or reactive oxygen species (ROS) levels. The most reactive AGE-precursor, MGO, can be detoxified by the glyoxalase system.

\section{Dietary AGEs}

Besides the endogenous formation of AGEs, AGEs can form exogenously and can be taken up by the body after consumption (Fig. 1.1) (5) $^{4}$ The Maillard reaction also occurs in (protein-rich) food products generating dietary AGEs (dAGEs). This exogenous AGE formation in food is accelerated at higher temperatures. Therefore, food products with high dAGE levels are typically highly processed and heated food products ${ }^{46}$.

The high sugar (glucose and fructose) and fat content of the Western diet in combination with popular preparation methods such as baking, grilling, frying and toasting has resulted in high levels of dAGEs in the diet ${ }^{47}$. These dAGEs are absorbed by the intestines and our group has recently demonstrated that a higher dietary AGE intake is associated with higher levels of free AGEs in plasma and urine ${ }^{45}$. Moreover, accumulation of dietary CML was observed in many organs including the liver of mice ${ }^{48}$. 
(Soluble) RAGE

RAGE is a transmembrane pattern recognition receptor consisting of three immunoglobulin-like regions: the characteristic one " $\mathrm{V}$ "-type and two " $\mathrm{C}$ "type domains, a small transmembrane domain and an amino acid long tail in the cytoplasm ${ }^{49}, 50$. The cytoplasmic tail is of great importance for intracellular signaling, while the " $\mathrm{V}$ "-type domain is responsible for ligand recognition and binding. Soluble RAGE (sRAGE) consists of only the extracellular " $\mathrm{V}$ " - and " $\mathrm{C}$ "-type domain and lacks the transmembrane domain and cytoplasmic tail ${ }^{50}$. RAGE is not exclusively a receptor of AGEs, but can bind and be activated by several ligands as it recognizes $3 D$ structures. The following factors have been shown to bind RAGE: amyloid- $\beta$ and amyloid- $A$, S100/calgranulins, High-mobility group protein B1 (HMGB1) and even LPS ${ }^{50,}$ ${ }^{51}$. All of these proteins and AGEs have been associated with inflammatory diseases and therefore it is not surprising that binding of these proteins to RAGE results in an inflammatory response, commonly via the NF-KB pathway ${ }^{52}$. NF-KB target genes include mostly genes coding for cytokines, adhesion molecules, immunoreceptors and genes important in antigen presentation. Other target genes are involved in apoptosis, the cellular stress response and RAGE and NF-KB themselves ${ }^{53}$. Transcription of RAGE and NF$K B$ is important to maintain and amplify the signaling and explains why RAGEmediated NF-KB activation is long lasting and can overrule autoregulatory inhibition $^{38}$. RAGE is expressed by many cell types and can be both constitutive and inducible. In immune cells such as monocytes and macrophages, but also in most other non-haematopoietic cell types (endothelial cells, smooth muscle cells and fibroblasts), RAGE expression needs to be stimulated to be expressed at significant levels ${ }^{50}$. This occurs in pathological conditions wherein RAGE ligands accumulate or when RAGE targeting transcription factors are activated. Previous findings show that lipid accumulation in hepatocytes is associated with higher levels of RAGE expression ${ }^{33}$. In addition, high fat diet feeding of rats, which causes hepatic steatosis, resulted in elevated levels of hepatic RAGE expression ${ }^{54}$. Together, these findings suggest that steatosis may sensitize the liver to inflammatory stimuli at least in part via RAGE. 
Glyoxalase

The glyoxalase system counteracts the rapid endogenous formation of methylglyoxal-derived AGEs within cells. This system consists of two enzymes, glyoxalase-1 (GLO-1) and GLO-2 ${ }^{55}$. The glyoxalase system detoxifies the main AGE-precursor MGO into D-lactate thereby preventing AGE formation (Fig. 1.1) ${ }^{56}$. The glyoxalase system has been shown to be of importance in several pathologies including diabetes and CVD. Overexpression of GLO-1, the rate limiting enzyme of the glyoxalase system, prevented accumulation of AGEs in endothelial cells and has been shown to have beneficial effects on the vasculature of diabetic rats ${ }^{57,58}$. GLO-1 expression was decreased in ruptured plaques, indicating a potential role in plaque stability ${ }^{59}$. The effect of GLO-1 overexpression on fatty liver disease is unknown. GLO-1 requires the anti-oxidant glutathione (GSH) to function and therefore the glyoxalase system is less effective during oxidative stress, a condition often present in the inflammatory liver of NASH patients ${ }^{56,60}$. Moreover, TNF, a pro-inflammatory cytokine secreted by hepatocytes and Kupffer cells in the liver, is able to reduce GLO-1 activity in both monocytes and macrophages ${ }^{59,61}$. Consequently, the endogenous protection system against AGE formation might be impaired in NAFLD. RAGE also seems to be involved in the regulation of GLO-1 activity as the expression of GLO-1 was reduced in the kidney of RAGE-deficient mice ${ }^{62}$. Binding of RAGE ligands to their receptor has also been shown to suppress levels of anti-oxidants such as GSH and ascorbic acid resulting in increased reactive oxygen species and reduced GLO-1 activity ${ }^{50}$. Interestingly, formation of AGEs in NAFLD and consequent activation of RAGE might therefore further impair the protective function of GLO-1.

\section{RAGE and hepatic inflammation}

RAGE is present on many different cell types including endothelial and immune cells ${ }^{50}$. Several studies have shown that deletion or blocking of RAGE leads to attenuation of vascular inflammation, in part by affecting inflammatory activation of endothelial cells ${ }^{63}$. AGEs have been shown to stimulate RAGE on endothelial cells resulting in enhanced NF-KB mediated expression of adhesion molecules and other inflammatory factors. 
Moreover, on endothelial cells, RAGE facilitates immune cell recruitment resulting in elevated immune cell infiltration when RAGE is more expressed ${ }^{64}$. Innate immune cells such as monocytes and macrophages are known to express RAGE, particularly under pathological conditions ${ }^{50}$. Important players in hepatic inflammation are the liver-resident macrophages (Kupffer cells) located in the hepatic sinusoids, which comprise a substantial amount (80-90\%) of all tissue-resident macrophages ${ }^{65}$. During pathological conditions monocytes infiltrate the liver, which will differentiate into macrophages providing an additional source of hepatic macrophages ${ }^{66}$. RAGE activation on macrophages skews the macrophage phenotype towards more pro-inflammatory, which is characterized by secretion of pro-inflammatory cytokines such as TNF- $\alpha$ and IL-1 $1 \beta^{67}$. These cytokines can trigger and propagate hepatic inflammation.

Other cells expressing RAGE and capable of producing inflammatory mediators are hepatocytes and hepatic stellate cells ${ }^{68}$. In these cell types, AGE-RAGE interaction can also contribute to oxidative stress, an important factor in the progression of NAFLD ${ }^{69,70}$. Considering the abundance of cells expressing RAGE in the liver, especially during pathological conditions, such as steatosis, it is likely that endogenously formed or dietary AGEs stimulate hepatic inflammation ${ }^{69}$. Indeed, our group previously reported accumulation of AGEs in NAFLD patients with higher levels of AGEs present in patients with more hepatic steatosis and inflammation ${ }^{33}$. Potentially, AGEs cause hepatic inflammation via RAGE as we also showed expression of inflammatory cytokines by hepatocytes upon stimulation with AGEs and this was RAGE dependent ${ }^{33}$.

\section{AGEs and atherosclerosis}

Due to the inflammatory processes in the atherosclerotic plaque, the plaque is hypoxic and levels of lipids and oxidative stress are high ${ }^{15,18}$. In particular the most dangerous plaques, i.e. rupture-prone plaques with a thin fibrotic cap are rich in macrophages and are highly metabolically active ${ }^{16,71}$. These are conditions favorable for AGE formation ${ }^{38}$. AGEs have previously been linked to CVD due to their ability to stiffen arteries by cross-linking extracellular matrix components ${ }^{72}$. Indeed, an AGE cross-link breaker was 
capable of reducing diabetes-accelerated atherosclerosis ${ }^{42}$. As addressed above, AGEs can also disrupt intracellular protein function or cause inflammation via RAGE ${ }^{35}$. We previously reported higher AGE levels in hazardous more inflammatory rupture-prone plaques compared to stable plaques $^{59}$. Moreover, the observed AGE accumulation in atherosclerotic plaque macrophages was associated with inflammatory markers such as IL-8 and MCP-1 in the plaque ${ }^{59}$. Previous studies have suggested that these effects in atherosclerosis lesions are in part via their receptor, RAGE. RAGEdeficient mice develop smaller and less inflammatory plaques, especially in diabetes-accelerated atherosclerosis ${ }^{73}$. These findings suggest a direct contribution of AGEs to CVD risk by affecting atherosclerosis.

\section{Adipose tissue inflammation}

Besides storing lipids, AT is an important endocrine organ secreting many socalled adipokines. Adipokines range from hormones and growth factors to cytokines and chemokines ${ }^{7,9}$. They can have local effects in the AT itself or systemic effects when they are released into the circulation. During obesity, many adipokines are produced by the visceral AT (VAT), which is located around organs in the abdominal cavity ${ }^{74}$. The changes in types of adipokines being produced and their elevated levels is a consequence of changes in VAT immune cell composition caused by obesity ${ }^{75}$. Important producers of inflammatory adipokines are ATMs, which are strongly increased in the VAT of obese mice and humans ${ }^{3,76}$. Local proliferation of ATMs and infiltration followed by differentiation of bone marrow-derived monocytes both contribute to these elevated levels of ATMs ${ }^{77,78}$. Although it is not yet fully understood what triggers the increased infiltration and proliferation of ATMs during obesity, AT hypertrophy during AT expansion causes hypoxia and adipocyte cell death, both capable of triggering AT inflammation ${ }^{7,79}$. ATMs are needed to phagocytose dead adipocytes generating the typical crown like structures (CLS), i.e. death adipocytes surrounded by macrophages ${ }^{79}$. AT from lean individuals usually contains mostly "alternatively activated" antiinflammatory M2 macrophages, distinguishable by their expression of Mannose Receptor C-type 1 (MRC1). These M2 ATMs produce mostly antiinflammatory cytokines such as IL-10 and arginase and contribute to tissue 
repair and angiogenesis ${ }^{80}$. In parallel with the AT expansion, a shift of the ATMs towards "classically activated" pro-inflammatory M1 macrophages occurs $^{81}$. These ATMs are recognized by expression of $\mathrm{CD} 11 \mathrm{c}$ and production of high levels of TNF, iNOS and IL12 contributing to systemic chronic inflammation and insulin resistance ${ }^{3}$. Moreover, the produced iNOS generates reactive oxygen species (ROS) elevating oxidative stress in the $A T^{81}$. The aforementioned CLS contain mainly $C D 11 c^{+} M 1$ macrophages and are positively associated with insulin resistance, chronic low-grade inflammation as well as hepatic lipid accumulation ${ }^{3,82}$.

Characterization of adipose tissue macrophages

Macrophages are complex innate immune cells with a great variety of (tissuespecific) functions. To fulfill all these different functions, macrophages have many different phenotypes between which they can even switch when appropriately stimulated by their environment ${ }^{83,84}$. The frequently described subtypes, $\mathrm{M} 1$ or $\mathrm{M} 2$, are therefore the extremes employed for simplicity and at least provide distinction between pro-inflammatory and antiinflammatory macrophages. Flow cytometry allows the use of multiple markers per cell permitting the distinction and relative quantification of macrophage subsets within the AT. Markers employed for this purpose are typically CD11C or CD86 for M1 macrophages and lack of CD11C or high MRC1 expression for M2 macrophages ${ }^{3,85}$.

Adipose tissue inflammation and the liver

The prevalence of NAFLD is extremely high in obese subjects as the majority of them has steatosis and $30 \%$ has biopsy-proven $\mathrm{NASH}^{86}$. In comparison to other ATs, expansion and inflammation of VAT has the largest impact on the liver. The main reasons for this close association are probably the anatomic proximity of the VAT to the liver and venous drainage. Venous drainage is the direct delivery of fatty acids and inflammatory mediators to the liver via the portal vein ${ }^{10,11}$. Indeed, portal drainage from transplanted AT has been demonstrated to influence insulin sensitivity and thereby predisposing to NAFLD development ${ }^{11}$. In addition, vAT greatly contributes to a chronic systemic inflammatory state, which could affect hepatic inflammation. 
Illustrating the importance of inflammation in AT for the development of comorbidities, a positive association between visceral ATM numbers and characteristics of NAFLD (hepatic steatosis, inflammation and fibrosis) was demonstrated ${ }^{87}$. Moreover, transplanting VAT to high fat diet fed mice caused increased hepatic triglyceride accumulation and circulating levels of the pro-inflammatory cytokine IL-6 ${ }^{88}$. In humans, the increased expression of inflammatory genes in vAT (and subcutaneous AT) was associated with progression and severity of NAFLD with the highest levels of AT inflammatory gene expression in NASH patients. Furthermore, this study showed that ATMs were likely responsible for the elevated levels of circulating cytokines and chemokines observed in NASH patients ${ }^{76}$.

\section{ATMs and atherosclerosis}

It is well accepted that obesity is a major risk factor for CVD. Studies have even determined that rates of coronary artery disease increase with higher degrees of obesity ${ }^{89}$. A potential link between obesity and atherosclerosis could be the low-grade inflammation caused by secretion of proinflammatory cytokines by ATMs. Inflammatory mediators derived from the ATMs can directly affect atherosclerosis and blocking circulating cytokines has a beneficial effect on atherosclerotic disease ${ }^{90,91}$. In mice, it has been shown that VAT inflammation contributes to atherosclerosis ${ }^{12}$. Importantly, these effects were dependent on MCP-1 implying the involvement of monocyte recruitment ${ }^{12,}$ 92. Indeed, ATMs can cause monocytosis and neutrophilia, again by release of inflammatory mediators into the circulation ${ }^{93}$. As previously described, elevated monocyte levels can contribute to atherosclerosis development due to a higher monocyteendothelium interaction resulting in more monocytes infiltrating the vessel wall ${ }^{20-22}$. Neutrophils can aggravate endothelial dysfunction enhancing immune cell infiltration into the intima and they produce proteases and ROS, which both contribute to plaque instability ${ }^{24}$. 


\section{Outline of this thesis}

In the first part of this thesis, we have evaluated the effects of AGEs and their receptor, RAGE, on hepatic inflammation and atherosclerosis. In the second part, we have investigated the contribution of ATMs to hepatic inflammation and atherosclerosis, independent from the AGE-RAGE axis (Fig. 1.2).

In Chapter 2, the association between NAFLD and AGEs or sRAGE in a human cohort study is described. In Chapter 3, we investigated the contribution of dietary AGEs to circulating and hepatic AGE levels and hepatic inflammation in mice. Next, Chapter $\mathbf{4}$ describes the role of RAGE in the development of $\mathrm{NASH}$ and atherosclerosis.

Chapter 5, describes a protocol (including a video) for isolation and characterization of ATMs from human AT, an important method used in the following chapters. In Chapter 6, we investigated the relationship between circulating monocytes and ATM subsets in humans. In Chapter 7, we addressed whether and how ATMs can influence circulating immune cell recruitment and how this affects hepatic inflammation. Next, we investigated in chapter 8 the role of ATMs on atherosclerosis development. Lastly, Chapter 9 summarizes the results and provides a discussion of all findings of this thesis and the implications of our findings for the field of hepatology and cardiovascular disease.

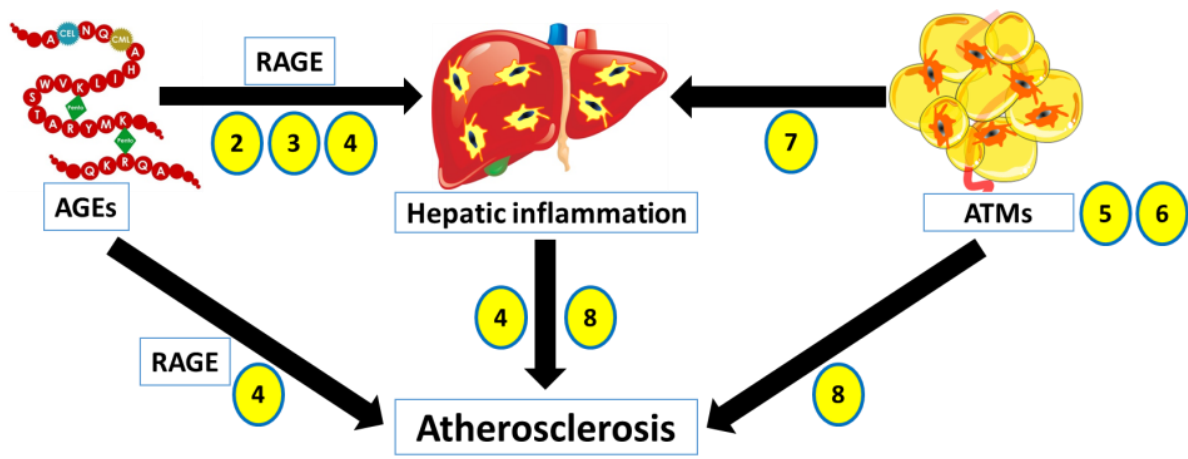

Figure 1.2. Overview of thesis.

Chapters 2, 3 and 4 of this thesis address the impact of AGEs and their receptor, RAGE, on hepatic inflammation and atherosclerosis. In chapters 5, 6, 7 and 8, we focus on the contribution of ATMs to hepatic inflammation and atherosclerosis. 


\section{References}

1. Nguyen DM, El-Serag HB. The epidemiology of obesity. Gastroenterol Clin North Am 2010;39:1-7.

2. Wild $\mathrm{SH}$, Byrne $\mathrm{CD}$. $\mathrm{ABC}$ of obesity. Risk factors for diabetes and coronary heart disease. BMJ 2006;333:1009-11.

3. Boutens L, Stienstra R. Adipose tissue macrophages: going off track during obesity. Diabetologia 2016;59:879-94.

4. WHO. Obesity and overweight. http://www.who.int/en/news-room/factsheets/detail/obesity-and-overweight: WHO, 2017.

5. (WHO) WHO. Obesity: Preventing and managing the global epidemic. Geneva: World Health Organization, 2000.

6. Frayn KN. Adipose tissue and the insulin resistance syndrome. Proc Nutr Soc 2001;60:375-80.

7. Goossens $\mathrm{GH}$. The role of adipose tissue dysfunction in the pathogenesis of obesityrelated insulin resistance. Physiol Behav 2008;94:206-18.

8. Than NN, Newsome PN. A concise review of non-alcoholic fatty liver disease. Atherosclerosis 2015;239:192-202.

9. Calder PC, Ahluwalia N, Brouns F, et al. Dietary factors and low-grade inflammation in relation to overweight and obesity. Br J Nutr 2011;106 Suppl 3:S5-78.

10. Mirza MS. Obesity, Visceral Fat, and NAFLD: Querying the Role of Adipokines in the Progression of Nonalcoholic Fatty Liver Disease. ISRN Gastroenterol 2011;2011:592404.

11. Rytka JM, Wueest S, Schoenle EJ, et al. The portal theory supported by venous drainage-selective fat transplantation. Diabetes 2011;60:56-63.

12. Ohman $\mathrm{MK}$, Shen $\mathrm{Y}$, Obimba $\mathrm{Cl}$, et al. Visceral adipose tissue inflammation accelerates atherosclerosis in apolipoprotein E-deficient mice. Circulation 2008;117:798-805.

13. Lakka HM, Lakka TA, Tuomilehto J, et al. Abdominal obesity is associated with increased risk of acute coronary events in men. Eur Heart J 2002;23:706-13.

14. Mendis S. Global Atlas on cardiovascular disease prevention and control: WHO, 2011:4.

15. Lusis AJ. Atherosclerosis. Nature 2000;407:233-41.

16. Virmani R, Burke AP, Farb A, et al. Pathology of the vulnerable plaque. Journal of the American College of Cardiology 2006;47:C13-8.

17. Rudd JH, Narula J, Strauss HW, et al. Imaging atherosclerotic plaque inflammation by fluorodeoxyglucose with positron emission tomography: ready for prime time? Journal of the American College of Cardiology 2010;55:2527-35.

18. Sluimer JC, Gasc JM, van Wanroij JL, et al. Hypoxia, hypoxia-inducible transcription factor, and macrophages in human atherosclerotic plaques are correlated with intraplaque angiogenesis. Journal of the American College of Cardiology 2008;51:1258-65.

19. Poitou C, Dalmas E, Renovato M, et al. CD14dimCD16+ and CD14+CD16+ monocytes in obesity and during weight loss: relationships with fat mass and subclinical atherosclerosis. Arterioscler Thromb Vasc Biol 2011;31:2322-30.

20. Chistiakov DA, Grechko AV, Myasoedova VA, et al. The role of monocytosis and neutrophilia in atherosclerosis. J Cell Mol Med 2018;22:1366-1382. 
21. Mestas J, Ley K. Monocyte-endothelial cell interactions in the development of atherosclerosis. Trends Cardiovasc Med 2008;18:228-32.

22. Swirski FK, Libby P, Aikawa E, et al. Ly-6Chi monocytes dominate hypercholesterolemia-associated monocytosis and give rise to macrophages in atheromata. J Clin Invest 2007;117:195-205.

23. Herishanu Y, Rogowski O, Polliack A, et al. Leukocytosis in obese individuals: possible link in patients with unexplained persistent neutrophilia. Eur J Haematol 2006;76:516-20.

24. Soehnlein O. Multiple roles for neutrophils in atherosclerosis. Circ Res 2012;110:875-88.

25. Rui L. Energy metabolism in the liver. Compr Physiol 2014;4:177-97.

26. Rensen SS, Slaats Y, Driessen A, et al. Activation of the complement system in human nonalcoholic fatty liver disease. Hepatology 2009;50:1809-17.

27. Stankovic MN, Mladenovic DR, Duricic I, et al. Time-dependent changes and association between liver free fatty acids, serum lipid profile and histological features in mice model of nonalcoholic fatty liver disease. Arch Med Res 2014;45:116-24.

28. Brunt EM. Pathology of nonalcoholic steatohepatitis. Hepatol Res 2005;33:68-71.

29. Bellentani S, Scaglioni F, Marino M, et al. Epidemiology of non-alcoholic fatty liver disease. Dig Dis 2010;28:155-61.

30. Ekstedt M, Franzen LE, Mathiesen UL, et al. Long-term follow-up of patients with NAFLD and elevated liver enzymes. Hepatology 2006;44:865-73.

31. Mavrogiannaki AN, Migdalis IN. Nonalcoholic Fatty liver disease, diabetes mellitus and cardiovascular disease: newer data. Int J Endocrinol 2013;2013:450639.

32. Tailleux A, Wouters K, Staels B. Roles of PPARs in NAFLD: potential therapeutic targets. Biochim Biophys Acta 2012;1821:809-18.

33. Gaens KH, Niessen PM, Rensen SS, et al. Endogenous formation of Nepsilon(carboxymethyl)lysine is increased in fatty livers and induces inflammatory markers in an in vitro model of hepatic steatosis. J Hepatol 2012;56:647-55.

34. Singh $\mathrm{R}$, Barden $\mathrm{A}, \mathrm{Mori} \mathrm{T}$, et al. Advanced glycation end-products: a review. Diabetologia 2001;44:129-46.

35. Brownlee M. Biochemistry and molecular cell biology of diabetic complications. Nature 2001;414:813-20.

36. Brownlee $M$, Vlassara $H$, Cerami A. Nonenzymatic glycosylation and the pathogenesis of diabetic complications. Annals of internal medicine 1984;101:52737.

37. Brownlee M. Advanced protein glycosylation in diabetes and aging. Annual review of medicine 1995;46:223-34.

38. Gaens KH, Stehouwer CD, Schalkwijk CG. Advanced glycation endproducts and its receptor for advanced glycation endproducts in obesity. Current opinion in lipidology 2013;24:4-11.

39. Casper GS. Therapeutic Interventions in the Glyc(oxid)ation Pathway. Immunology, Endocrine \& Metabolic Agents in Medicinal Chemistry 2007;7:57-68.

40. Brouwers $\mathrm{O}$, Niessen PM, Ferreira I, et al. Overexpression of glyoxalase-I reduces hyperglycemia-induced levels of advanced glycation end products and oxidative stress in diabetic rats. The Journal of biological chemistry 2011;286:1374-80.

41. Tai ES, Tan ML, Stevens RD, et al. Insulin resistance is associated with a metabolic profile of altered protein metabolism in Chinese and Asian-Indian men. Diabetologia 2010;53:757-67. 
42. Forbes JM, Yee LT, Thallas V, et al. Advanced glycation end product interventions reduce diabetes-accelerated atherosclerosis. Diabetes 2004;53:1813-23.

43. Singh VP, Bali A, Singh N, et al. Advanced glycation end products and diabetic complications. Korean J Physiol Pharmacol 2014;18:1-14.

44. Uribarri J, Cai W, Woodward $M$, et al. Elevated serum advanced glycation endproducts in obese indicate risk for the metabolic syndrome: a link between healthy and unhealthy obesity? J Clin Endocrinol Metab 2015;100:1957-66.

45. Scheijen J, Hanssen NMJ, van Greevenbroek MM, et al. Dietary intake of advanced glycation endproducts is associated with higher levels of advanced glycation endproducts in plasma and urine: The CODAM study. Clin Nutr 2017.

46. Scheijen J, Clevers E, Engelen L, et al. Analysis of advanced glycation endproducts in selected food items by ultra-performance liquid chromatography tandem mass spectrometry: Presentation of a dietary AGE database. Food Chem 2016;190:11451150.

47. N AL, Carbonero F. Impact of Maillard reaction products on nutrition and health: Current knowledge and need to understand their fate in the human digestive system. Crit Rev Food Sci Nutr 2017:1-14.

48. Tessier FJ, Niquet-Leridon C, Jacolot P, et al. Quantitative assessment of organ distribution of dietary protein-bound 13 C-labeled Nvarepsilon carboxymethyllysine after a chronic oral exposure in mice. Mol Nutr Food Res 2016;60:2446-2456.

49. Neeper M, Schmidt AM, Brett J, et al. Cloning and expression of a cell surface receptor for advanced glycosylation end products of proteins. J Biol Chem 1992;267:14998-5004.

50. Bierhaus A, Humpert PM, Morcos M, et al. Understanding RAGE, the receptor for advanced glycation end products. Journal of molecular medicine 2005;83:876-86.

51. Wang L, Wu J, Guo X, et al. RAGE Plays a Role in LPS-Induced NF-kappaB Activation and Endothelial Hyperpermeability. Sensors (Basel) 2017;17.

52. Ott $\mathrm{C}$, Jacobs $\mathrm{K}$, Haucke $\mathrm{E}$, et al. Role of advanced glycation end products in cellular signaling. Redox Biol 2014;2:411-29.

53. Pahl HL. Activators and target genes of Rel/NF-kappaB transcription factors. Oncogene 1999;18:6853-66.

54. Pereira E, Silvares RR, Flores EEl, et al. Hepatic microvascular dysfunction and increased advanced glycation end products are components of non-alcoholic fatty liver disease. PLoS One 2017;12:e0179654.

55. Thornalley PJ. Glyoxalase I--structure, function and a critical role in the enzymatic defence against glycation. Biochemical Society transactions 2003;31:1343-8.

56. Hanssen NM, Brouwers O, Gijbels MJ, et al. Glyoxalase 1 overexpression does not affect atherosclerotic lesion size and severity in ApoE-/- mice with or without diabetes. Cardiovasc Res 2014;104:160-70.

57. Brouwers O, Niessen PM, Haenen G, et al. Hyperglycaemia-induced impairment of endothelium-dependent vasorelaxation in rat mesenteric arteries is mediated by intracellular methylglyoxal levels in a pathway dependent on oxidative stress. Diabetologia 2010;53:989-1000.

58. Shinohara M, Thornalley PJ, Giardino I, et al. Overexpression of glyoxalase-I in bovine endothelial cells inhibits intracellular advanced glycation endproduct formation and prevents hyperglycemia-induced increases in macromolecular endocytosis. The Journal of clinical investigation 1998;101:1142-7. 
59. Hanssen NM, Wouters K, Huijberts MS, et al. Higher levels of advanced glycation endproducts in human carotid atherosclerotic plaques are associated with a rupture-prone phenotype. Eur Heart J 2014;35:1137-46.

60. Takaki A, Kawai D, Yamamoto K. Multiple hits, including oxidative stress, as pathogenesis and treatment target in non-alcoholic steatohepatitis (NASH). Int J Mol Sci 2013;14:20704-28.

61. Braunersreuther V, Viviani GL, Mach F, et al. Role of cytokines and chemokines in non-alcoholic fatty liver disease. World J Gastroenterol 2012;18:727-35.

62. Reiniger N, Lau K, McCalla D, et al. Deletion of the receptor for advanced glycation end products reduces glomerulosclerosis and preserves renal function in the diabetic OVE26 mouse. Diabetes 2010;59:2043-54.

63. Goldin A, Beckman JA, Schmidt AM, et al. Advanced glycation end products: sparking the development of diabetic vascular injury. Circulation 2006;114:597-605.

64. Chavakis T, Bierhaus A, Al-Fakhri N, et al. The pattern recognition receptor (RAGE) is a counterreceptor for leukocyte integrins: a novel pathway for inflammatory cell recruitment. J Exp Med 2003;198:1507-15.

65. Alisi A, Carpino G, Oliveira FL, et al. The Role of Tissue Macrophage-Mediated Inflammation on NAFLD Pathogenesis and Its Clinical Implications. Mediators of Inflammation 2017;2017:8162421.

66. Zigmond E, Samia-Grinberg S, Pasmanik-Chor M, et al. Infiltrating monocyte-derived macrophages and resident kupffer cells display different ontogeny and functions in acute liver injury. J Immunol 2014;193:344-53.

67. Kierdorf $\mathrm{K}$, Fritz G. RAGE regulation and signaling in inflammation and beyond. J Leukoc Biol 2013;94:55-68.

68. Yamagishi S, Matsui T. Role of receptor for advanced glycation end products (RAGE) in liver disease. Eur J Med Res 2015;20:15.

69. Takeuchi M, Takino J, Sakasai-Sakai A, et al. Involvement of the TAGE-RAGE system in non-alcoholic steatohepatitis: Novel treatment strategies. World J Hepatol 2014;6:880-93.

70. Santos JC, Valentim IB, de Araujo OR, et al. Development of nonalcoholic hepatopathy: contributions of oxidative stress and advanced glycation end products. Int J Mol Sci 2013;14:19846-66.

71. Yilmaz A, Lochno $M$, Traeg $F$, et al. Emergence of dendritic cells in rupture-prone regions of vulnerable carotid plaques. Atherosclerosis 2004;176:101-10.

72. van Eupen MG, Schram MT, van Sloten TT, et al. Skin Autofluorescence and Pentosidine Are Associated With Aortic Stiffening: The Maastricht Study. Hypertension 2016;68:956-63.

73. Jandeleit-Dahm K, Watson A, Soro-Paavonen A. The AGE/RAGE axis in diabetesaccelerated atherosclerosis. Clin Exp Pharmacol Physiol 2008;35:329-34.

74. Rosell $M$, Kaforou M, Frontini $A$, et al. Brown and white adipose tissues: intrinsic differences in gene expression and response to cold exposure in mice. Am J Physiol Endocrinol Metab 2014;306:E945-64.

75. Hamdy O, Porramatikul S, Al-Ozairi E. Metabolic obesity: the paradox between visceral and subcutaneous fat. Curr Diabetes Rev 2006;2:367-73.

76. du Plessis J, van Pelt J, Korf H, et al. Association of Adipose Tissue Inflammation With Histologic Severity of Nonalcoholic Fatty Liver Disease. Gastroenterology 2015;149:635-48 e14. 
77. Amano SU, Cohen JL, Vangala $\mathrm{P}$, et al. Local proliferation of macrophages contributes to obesity-associated adipose tissue inflammation. Cell Metab 2014;19:162-171.

78. Olefsky JM, Glass CK. Macrophages, inflammation, and insulin resistance. Annu Rev Physiol 2010;72:219-46.

79. Surmi BK, Hasty AH. Macrophage infiltration into adipose tissue: initiation, propagation and remodeling. Future Lipidol 2008;3:545-556.

80. Martinez FO, Gordon S. The M1 and M2 paradigm of macrophage activation: time for reassessment. F1000Prime Rep 2014;6:13.

81. Lumeng CN, Bodzin JL, Saltiel AR. Obesity induces a phenotypic switch in adipose tissue macrophage polarization. J Clin Invest 2007;117:175-84.

82. Alkhouri N, Gornicka A, Berk MP, et al. Adipocyte apoptosis, a link between obesity, insulin resistance, and hepatic steatosis. J Biol Chem 2010;285:3428-38.

83. Harford KA, Reynolds CM, McGillicuddy FC, et al. Fats, inflammation and insulin resistance: insights to the role of macrophage and T-cell accumulation in adipose tissue. Proc Nutr Soc 2011;70:408-17.

84. T'Jonck W, Guilliams M, Bonnardel J. Niche signals and transcription factors involved in tissue-resident macrophage development. Cell Immunol 2018.

85. Morris DL, Singer K, Lumeng CN. Adipose tissue macrophages: phenotypic plasticity and diversity in lean and obese states. Curr Opin Clin Nutr Metab Care 2011;14:3416.

86. Festi D, Colecchia A, Sacco T, et al. Hepatic steatosis in obese patients: clinical aspects and prognostic significance. Obes Rev 2004;5:27-42.

87. Tordjman J, Poitou C, Hugol D, et al. Association between omental adipose tissue macrophages and liver histopathology in morbid obesity: influence of glycemic status. J Hepatol 2009;51:354-62.

88. Hocking SL, Stewart RL, Brandon $A E$, et al. Subcutaneous fat transplantation alleviates diet-induced glucose intolerance and inflammation in mice. Diabetologia 2015.

89. Grundy SM. Obesity, metabolic syndrome, and coronary atherosclerosis. Circulation 2002;105:2696-8.

90. Ridker PM, Everett BM, Thuren $\mathrm{T}$, et al. Antiinflammatory Therapy with Canakinumab for Atherosclerotic Disease. N Engl J Med 2017;377:1119-1131.

91. McKellar GE, McCarey DW, Sattar N, et al. Role for TNF in atherosclerosis? Lessons from autoimmune disease. Nat Rev Cardiol 2009;6:410-7.

92. Ohman MK, Wright AP, Wickenheiser KJ, et al. Monocyte chemoattractant protein1 deficiency protects against visceral fat-induced atherosclerosis. Arterioscler Thromb Vasc Biol 2010;30:1151-8.

93. Nagareddy PR, Kraakman M, Masters SL, et al. Adipose tissue macrophages promote myelopoiesis and monocytosis in obesity. Cell Metab 2014;19:821-35. 
Part 1

$\underline{\text { RAGE }}$ 


\section{Chapter 2}

Hepatic fat content and liver enzymes are associated with circulating free and protein-bound advanced glycation endproducts, which are associated with low-grade inflammation: The CODAM study

Mitchell Bijnen, Marleen van Greevenbroek, Carla van der Kallen, Jean L. Scheijen, Marjo P.H. van de Waarenburg, Coen D.A. Stehouwer, Kristiaan Wouters and Casper G. Schalkwijk 


\section{$\underline{\text { Abstract }}$}

\section{Background}

Advanced glycation endproducts (AGEs) accumulate in fatty livers and may contribute to low-grade inflammation (LGI), potentially via their receptor, RAGE. It is unknown if the accumulation of AGEs in fatty livers results in higher levels of circulating AGEs. In a human cohort study, we investigated the association of liver fat and related hepatocellular damage with circulating AGEs and soluble RAGE (sRAGE), and subsequently the association of circulating AGEs and sRAGE with LGI.

\section{Materials and methods}

Cross-sectional associations of liver fat and liver enzymes with AGEs and SRAGE and additionally of AGEs and SRAGE with LGI were determined by multiple linear regression analyses (adjusted for age, sex, prior CVD, alcohol consumption, smoking, medication, kidney function and BMI) in the CODAM study ( $n=505$ included in this analysis). Liver fat percentage (eLF, Intransformed) was estimated using a previously MRI-validated equation. The liver enzymes, i.e. ALAT, ASAT and GGT, were In-transformed, standardized and combined into a standardized score (LE score). Plasma levels of free CML, $\mathrm{CEL}$, and MG-H1 (all $\mathrm{nM}$ ) and protein-bound CML, CEL and pentosidine (all $\mathrm{nmol} / \mathrm{mmol}$ lysine) were measured using HPLC-MS/MS and sRAGE $(\mathrm{pg} / \mathrm{ml})$ with use of ELISA, all were In-transformed. LGI plasma markers (IL-6, IL-8, TNF- $\alpha$, CRP, SAA, and sICAM1) were measured using an MSD multiplex assay, In-transformed, standardized and combined into a standardized score.

\section{Results}

eLF\% was positively associated with circulating free CEL $(\beta=0.090 ; 95 \% \mathrm{Cl}$ $0.041 ; 0.139)$, but inversely with protein-bound $\mathrm{CML}(\beta=-0.071 ; 95 \% \mathrm{Cl}-$ $0.108 ;-0.034)$. Similarly, the LE score was positively associated with free CML $(\beta=0.044 ; 95 \% \mathrm{Cl} 0.012 ; 0.076)$ and $\mathrm{CEL}(\beta=0.040 ; 95 \% \mathrm{Cl} 0.009 ; 0.072)$, but inversely with protein-bound $\mathrm{CML}(\beta=-0.037 ; 95 \% \mathrm{Cl}-0.060 ;-0.013)$. Free $\mathrm{CML}(\beta=0.297 ; 95 \% \mathrm{Cl} 0.049 ; 0.545)$ was positively associated with LGI, while protein-bound $\mathrm{CML}(\beta=-0.547 ; 95 \% \mathrm{Cl}-0.888 ;-0.207)$ was inversely associated with this estimate of systemic inflammation, although this 
association was no longer present after adjustment for BMI. eLF\% and LEscore were not associated with SRAGE and SRAGE was not associated with LGI after adjustment for BMI.

\section{Conclusion}

Liver fat and liver enzymes were positively associated with the plasma level of free AGEs, which, in turn, were associated with LGI. In contrast, inverse relations were observed of liver fat and liver enzymes with plasma levels of protein-bound AGEs and of protein-bound AGEs with LGI. These data suggest that hepatic steatosis and inflammation affect the formation and degradation of hepatic protein-bound AGEs resulting in elevated circulating free AGE levels. These alterations in AGE levels might influence $L G I$, but this is most likely independent of RAGE. 


\section{Introduction}

Non-alcoholic fatty liver disease (NAFLD) is a spectrum of liver abnormalities ranging from steatosis (fatty liver) to non-alcoholic steatohepatitis (NASH), fibrosis and ultimately cirrhosis. NASH is characterized by both steatosis and inflammation, of which the latter causes hepatocellular injury and over time irreversible liver damage (cirrhosis) ${ }^{1}$. Moreover, NASH is associated with $C V D$, seemingly due to hepatic inflammation considering long-term survival of CVD-related diseases is lower in NASH patients than in NAFLD patients with steatosis only ${ }^{2,3}$. Therefore, it is highly relevant to investigate the causes of hepatic inflammation and how these might affect CVD risk.

Fat accumulation in the liver, i.e. steatosis, can cause oxidative stress, increased lipid peroxidation and release of inflammatory cytokines ${ }^{4,5}$. Higher levels of oxidative stress and lipid peroxidation, accompanied by inflammation-induced elevated metabolic rate, stimulate the formation of advanced glycation endproducts (AGEs) ${ }^{6}$. These sugar-modified proteins are capable of disturbing intracellular protein function, cross-linking extracellular matrix (ECM) proteins and activating the receptor of advanced glycation endproducts, $\mathrm{RAGE}^{7}$. AGEs can be present in both the free (glycated free amino acids) and protein-bound (glycated amino acids within a protein) form. Considering that many of the amino acids in the circulation are derived from degraded proteins, free AGEs are likely also derived from proteinbound $\mathrm{AGEs}^{8}$. Major AGEs include $\mathrm{N}^{\varepsilon}$-(carboxymethyl)lysine $(\mathrm{CML}), \mathrm{N}^{\varepsilon}-(1-$ carboxyethyl)lysine (CEL), $\quad \mathrm{N}^{\delta}$-(5-hydro-5-methyl-4-imidazolon-2-yl)ornithine (MG-H1) and pentosidine. Binding and stimulation of the receptor for advanced glycation endproducts (RAGE) by protein-bound CML (PB-CML), protein-bound CEL (PB-CEL) and MG-H1 can increase oxidative stress and upregulate transcription of NF-KB dependent genes, i.e. inflammatory genes $^{9-11}$. Furthermore, our group demonstrated that RAGE can trap the protein-bound form of AGEs in obese adipose tissue thereby inducing adipose tissue inflammation ${ }^{12}$. Besides as a cell membrane-bound form that stimulates inflammation, RAGE can also be present as soluble RAGE (sRAGE) in plasma due to alternative splicing (i.e. esRAGE) or cleavage of the already cell-bound form ${ }^{13}$. The functional role of sRAGE has not yet been fully elucidated, but it is thought to act as a decoy receptor for its ligands ${ }^{14}$. 
Alternatively, it might simply be an indication of RAGE activity as it has been associated with CVD and diabetes ${ }^{13}$.

We previously showed that CML accumulates in human fatty livers. This accumulation was more pronounced in livers with more severe steatosis and inflammation ${ }^{15}$. In addition, we demonstrated that PB-CML exerts proinflammatory effects on hepatocytes via RAGE, resulting in the production of inflammatory cytokines ${ }^{15}$. We now hypothesize that AGEs accumulated in the fatty liver are released into the circulation, but also activate RAGE in the liver, thereby contributing to low-grade inflammation (LGI). In a human cohort study, we investigated the association of 1 . liver fat and liver enzymes with circulating AGEs or SRAGE and 2. the association of circulating AGEs and sRAGE with LGI.

\section{Materials and methods}

\section{Subjects and study design}

The Cohort on Diabetes and Atherosclerosis Maastricht (CODAM) is a cohort study of 574 subjects, selected based on a moderately increased risk of cardiometabolic disease from a large cohort in the general population as previously described ${ }^{16}$. The current cross-sectional analyses were performed in 505 subjects as subjects with missing data (either input or output variable or important covariate) were excluded. The study protocol was approved by the Medical Ethical Committee of the Maastricht University Medical Centre, and all subjects gave written informed consent.

\section{Liver fat estimation}

Liver fat percentage (eLF\%) was estimated using a magnetic resonance spectroscopy (MRS)-validated equation developed by Kotronen et al. ${ }^{17}$. Briefly, liver fat content is estimated based on liver enzymes (ASAT (aspartate amino transferase) and ASAT / alanine transaminase (ALAT) ratio), fasting insulin levels, presence of the metabolic syndrome and presence of type 2 diabetes. In addition, the fatty liver index (FLI) as described by Bedogni et al. was used, which is based on an algorithm using BMI, waist circumference, triglycerides and gamma-glutamyl transferase (GGT) levels and was validated using ultrasound and MRS ${ }^{18-20}$. 


\section{Liver enzymes and inflammatory markers}

ASAT, ALAT and GGT were measured in EDTA plasma as previously described ${ }^{21}$. Plasma markers of low-grade inflammation (IL-6, IL-8, TNF- $\alpha$, CRP, SAA, and sICAM1) were measured using an MSD multiplex assay ${ }^{21}$.

\section{Measurement of advanced glycation endproducts}

Free CML, CEL, and MG-H1 and PB-CML, PB-CEL and protein bound pentosidine (PB-pentosidine) were analyzed in EDTA plasma by ultraperformance liquid chromatography tandem mass spectrometry (UPLC MS/MS). Detailed descriptions of the measurement of plasma AGEs have been previously described ${ }^{22,23}$.

\section{Measurement of sRAGE}

SRAGE (esRAGE and shed forms of RAGE) levels were determined in EDTA plasma using a human RAGE quantikine ELISA (R\&D Systems) according to the manufacturer's instructions. Intra- and interassay coefficients of variation were 7.6 and $2.6 \%$, respectively ${ }^{13}$.

\section{Other covariates}

Body mass index (BMI), smoking status, mean alcohol consumption, medication use and prior CVD were determined as described elsewhere ${ }^{24}$. Glomerular filtration rate (eGFR) was estimated using the short Modification of Diet in Renal Disease equation ${ }^{25}$, as reported previously ${ }^{21}$.

\section{Statistical analysis}

Study population characteristics were compared across tertiles of liver fat percentage using standard One-way ANOVA for normally distributed variables, Kruskal-Wallis One-way ANOVA for non-normally distributed variables and Chi-square test for categorical variables. A combined liver enzyme (LE) or low-grade inflammation (LGI) score was calculated as previously described ${ }^{21}$. In brief, all LEs or LGI plasma markers were Intransformed to obtain a normal distribution. For each individual, these Intransformed values were transformed into Z-scores (i.e. standardized values) using SPSS. Next, the three standardized LEs and six inflammation markers, respectively, were averaged to obtain a composite score, which was again 
standardized. The resulting LE-score and LGI-score were used in subsequent analyses. All AGEs, eLF\% and SRAGE were also In-transformed prior to analyses. FLI was standardized before analyses.

The cross-sectional associations of liver fat and liver enzymes (main independent variables) with AGEs and SRAGE (outcomes) and additionally of AGEs and sRAGE (main independent variables) with LGI (outcome) were examined with the use of multiple linear regression analyses with adjustments for the following potential confounders: age (years), sex (male/female), alcohol consumption (g/day), current smoker $(\mathrm{Y} / \mathrm{N})$, prevalent CVD $(\mathrm{Y} / \mathrm{N})$, use of medication (glucose-lowering $[\mathrm{Y} / \mathrm{N}]$, lipidmodifying $[\mathrm{Y} / \mathrm{N}]$, antihypertensive $[\mathrm{Y} / \mathrm{N}])$, eGFR $\left(\mathrm{ml} / \mathrm{min} / 1.73 \mathrm{~m}^{2}\right)$ and $\mathrm{BMI}$ $\left(\mathrm{kg} / \mathrm{m}^{2}\right)$. All analyses were performed using SPSS for Windows, version 25.0 (IBM Corp.) and all data were considered statistically significant at $\mathrm{P} \leq 0.05$.

\section{Results}

\section{Study population}

In table 2.1, the study population is presented according to tertiles of eLF\%. Subjects with more severe steatosis in general had a higher prevalence of type 2 diabetes and CVD and accordingly used more medication. Moreover, individuals in the highest liver fat tertile had the highest BMI, fasting glucose, triglyceride and HbA1c levels, but the lowest HDL level. These worse metabolic characteristics were accompanied by higher levels of low-grade inflammation markers and liver enzymes. PB-Pentosidine, PB-CML and sRAGE were lower, while free CEL was higher in those in the highest tertile of liver fat.

\section{Association of liver fat with free and protein-bound AGEs and SRAGE}

In linear regression analyses, eLF\% was positively associated with free CML $(\beta=0.042 ; 95 \% \mathrm{Cl} 0.002 ; 0.082)$ and $\mathrm{CEL}(\beta=0.096 ; 95 \% \mathrm{Cl} 0.058 ; 0.135)$, but inversely with PB-pentosidine $(\beta=-0.059 ; 95 \% \mathrm{Cl}-0.1 ;-0.018), \mathrm{PB}-\mathrm{CML}(\beta=-$ $0.115 ; 95 \% \mathrm{Cl}-0.143 ;-0.087)$ and sRAGE $(\beta=-0.097 ; 95 \% \mathrm{Cl}-0.146 ;-0.048)$. Adjustment for age, sex, alcohol consumption, smoking, prior CVD, 
The CODAM study

Table 2.1. General characteristics of the study population $(n=505)$ according to tertiles of eLF\%

\begin{tabular}{|c|c|c|c|c|c|}
\hline & \multirow{2}{*}{ All participants } & \multicolumn{4}{|c|}{ Liver fat according to tertiles of eLF\% } \\
\hline & & Lowest $(n=168)$ & Middle $(n=169)$ & Highest $(n=168)$ & P-value \\
\hline Age (years) & $59.5 \pm 7.0$ & $58.5 \pm 7.3$ & $59.8 \pm 7.4$ & $60.3 \pm 6.3$ & 0.057 \\
\hline Male sex (\%) & 62.4 & 54.2 & 60.9 & 72 & 0.003 \\
\hline NGM/IGM/T2DM (\%) & $53.5 / 22.6 / 24.0$ & $83.3 / 15.5 / 1.2$ & $56.8 / 30.2 / 13.0$ & $20.2 / 22.0 / 57.7$ & $<0.001$ \\
\hline CVD (\%) & 26.9 & 19.6 & 23.7 & 37.5 & 0.001 \\
\hline Current smoker (\%) & 20.8 & 22.6 & 21.9 & 17.9 & 0.853 \\
\hline Alcohol (g/day) & $8.6(1.3-22.8)$ & $8.5(2.4-22.7)$ & $9.9(1.4-24.2)$ & $7.1(0.5-21.2)$ & 0.311 \\
\hline Antihypertensive medication (\%) & 37.4 & 23.2 & 35.5 & 53.6 & $<0.001$ \\
\hline Lipid modifying medication (\%) & 18.2 & 12.5 & 16.6 & 25.6 & 0.006 \\
\hline Glucose lowering medication (\%) & 12.1 & 0.6 & 5.3 & 30.4 & $<0.001$ \\
\hline Body mass index $\left(\mathrm{kg} / \mathrm{m}^{2}\right)$ & $28.4 \pm 4.2$ & $25.8 \pm 3.1$ & $28.4 \pm 3.4$ & $31.0 \pm 4.4$ & $<0.001$ \\
\hline Waist circumference $(\mathrm{cm})$ & $98.9 \pm 11.9$ & $90.3 \pm 9.0$ & $99.1 \pm 9.2$ & $107.4 \pm 10.6$ & $<0.001$ \\
\hline Fasting glucose (mM) & $5.58(5.20-6.34)$ & $5.20(4.94-5.44)$ & $5.57(5.22-6.00)$ & $6.57(5.84-7.62)$ & $<0.001$ \\
\hline Triglycerides (mM) & $1.4(1-1.9)$ & $1(0.8-1.4)$ & $1.5(1.1-2.0)$ & $1.8(1.4-2.2)$ & $<0.001$ \\
\hline Cholesterol (mM) & $5.21 \pm 0.93$ & $5.14 \pm 0.90$ & $5.31 \pm 0.94$ & $5.17 \pm 0.95$ & 0.197 \\
\hline LDL-cholesterol (mM) & $3.32 \pm 0.87$ & $3.24 \pm 0.86$ & $3.43 \pm 0.88$ & $3.29 \pm 0.87$ & 0.120 \\
\hline HDL-cholesterol (mM) & $1.20 \pm 0.35$ & $1.41 \pm 0.35$ & $1.16 \pm 0.32$ & $1.03 \pm 0.25$ & $<0.001$ \\
\hline $\mathrm{HbA1c}(\%)$ & $5.8(5.5-6.2)$ & $5.6(5.3-5.8)$ & $5.8(5.5-6.1)$ & $6.2(5.8-6.9)$ & $<0.001$ \\
\hline HOMA2-IR & $1.58(1.09-2.51)$ & $1.02(0.80-1.26)$ & $1.56(1.21-2.00)$ & $3.21(2.37-4.55)$ & $<0.001$ \\
\hline $\mathrm{IL}-6$ (pg/ml) & $1.56(1.12-2.28)$ & $1.25(0.96-2.18)$ & $1.60(1.17-2.20)$ & $1.80(1.33-2.57)$ & $<0.001$ \\
\hline IL-8 (pg/ml) & $4.34(3.58-5.53)$ & $4.18(3.44-5.23)$ & $4.30(3.50-5.13)$ & $4.78(3.83-6.30)$ & $<0.001$ \\
\hline TNF- $\alpha(\mathrm{pg} / \mathrm{ml})$ & $6.25(5.23-7.61)$ & $5.94(5.02-7.01)$ & $6.34(5.30-7.51)$ & $6.60(5.43-7.96)$ & 0.002 \\
\hline CRP (mg/L) & $2.04(0.92-3.97)$ & $1.07(0.59-2.72)$ & $2.20(1.20-4.33)$ & $2.71(1.46-5.00)$ & $<0.001$ \\
\hline $\mathrm{SAA}(\mathrm{mg} / \mathrm{L})$ & $1.42(0.98-2.27)$ & $1.20(0.87-2.16)$ & $1.52(1.02-2.41)$ & $1.52(1.05-2.33)$ & 0.004 \\
\hline sICAM-1 (ng/ml) & $212.5(186.8-242.7)$ & $195.4(177.8-221.5)$ & $211.0(189.1-236.5)$ & $231.8(204.9-257.8)$ & $<0.001$ \\
\hline Low-grade inflammation score & $0.00 \pm 1$ & $-0.42 \pm 0.97$ & $0.026 \pm 0.89$ & $0.38 \pm 0.98$ & $<0.001$ \\
\hline PB-Pentosidine ( $\mathrm{nmol} / \mathrm{mmol}$ lysine) & $0.43(0.36-0.53)$ & $0.46(0.39-0.55)$ & $0.44(0.36-0.52)$ & $0.41(0.35-0.50)$ & 0.015 \\
\hline PB-CML (nmol/mmol lysine) & $34.6(29.6-41.0)$ & $37.1(32.3-44.9)$ & $35.2(31.1-40.6)$ & $31.1(26.4-38.0)$ & $<0.001$ \\
\hline PB-CEL (nmol/mmol lysine) & $23.3(19.0-29.2)$ & $22.8(19.5-26.9)$ & $24.2(19.0-30.3)$ & $22.9(18.6-29.5)$ & 0.250 \\
\hline Free $\mathrm{CML}(\mathrm{nM})$ & $79.5(61.2-98.6)$ & $76.0(60.3-92.9)$ & $80.4(61.0-100.1)$ & $82.2(64.1-102.5)$ & 0.144 \\
\hline Free CEL (nM) & $45.5(37.0-58.0)$ & $42.7(34.8-52.4)$ & $45.9(38.7-56.7)$ & $51.0(38.2-63.0)$ & $<0.001$ \\
\hline Free MG-H1(nM) & $123.8(87.5-176.6)$ & $127.2(90.8-168.1)$ & $121.0(85.6-172.5)$ & $119.6(85.0-198.3)$ & 0.810 \\
\hline SRAGE (pg/ml) & $1250(893-1604)$ & $1402.3(1112-1756)$ & $1229.1(838-1567)$ & $1154.7(850-1440)$ & $<0.001$ \\
\hline ALAT U/L & $22.2(17.2-27.9)$ & $17.1(14.3-21.2)$ & $22.4(18.0-26.7)$ & $28.6(23.2-36.3)$ & $<0.001$ \\
\hline ASAT (U/L) & $19.8(16.5-24.2)$ & $18.2(14.7-21.4)$ & $19.3(16.6-23.3)$ & $22.7(19.0-27.6)$ & $<0.001$ \\
\hline GGT (U/L) & $24.0(17.0-37.0)$ & $18.0(13.0-23.8)$ & $26.0(18.0-37.5)$ & $34.0(24.0-48.8)$ & $<0.001$ \\
\hline Liver enzyme score & $0.00 \pm 1$ & $-0.643 \pm 0.72$ & $-0.02 \pm 0.81$ & $0.66 \pm 1.00$ & $<0.001$ \\
\hline eLF\% (\%) & $4.79(2.35-8.62)$ & $2.11(1.79-2.35)$ & $4.79(3.80-5.89)$ & $10.64(8.60-14.53)$ & $<0.001$ \\
\hline FLI & $55.7 \pm 27.8$ & $30.6 \pm 19.3$ & $57.8 \pm 22.4$ & $78.7 \pm 16.8$ & $<0.001$ \\
\hline eGFR (ml/min/1.73 m2) & $91.5 \pm 18.6$ & $89.3 \pm 15.1$ & $90.8 \pm 17.9$ & $94.5 \pm 21.9$ & 0.028 \\
\hline
\end{tabular}

Data are expressed as mean $\pm \mathrm{SD}$, median [interquartile range] or percentages; the minimum and maximum of eLF\% tertiles were [0.85 - 2.91], [2.92 - 6.97] and [6.98 - 36.65] \%, respectively. eLF\%: estimated liver fat \%; NGM: normal glucose metabolism; IGM, impaired glucose metabolism; T2DM: type 2 diabetes mellitus; CVD: cardiovascular disease; LDL: low-density lipoprotein; HDL: high-density lipoprotein; HbA1c: hemoglobin A1c; HOMA2-IR: homeostasis model assessment insulin resistance; IL; interleukin; TNF- $\alpha$ : tumour necrosis factor- $\alpha$; CRP: C-reactive protein; SAA: Serum amyloid A; sICAM1: soluble intercellular adhesion molecule 1; ALAT: alanine aminotransferase; ASAT: aspartate amino transferase; GGT: $\gamma$-glutamyl transferase; FLI: fatty liver index; eGFR: estimated glomerular filtration rate. 
medication use and eGFR (model 3) mainly affected the positive association of eLF\% with free $C M L$, which was no longer significant $(\beta=0.041 ; 95 \% \mathrm{Cl}$ $0.002 ; 0.084$ ). After additional adjustment for BMI (model 4 ), eLF\% was still positively associated with free CEL and inversely with $\mathrm{PB}-\mathrm{CML}$, but the association with free CML, PB-pentosidine or SRAGE was no longer significant. eLF\% was not associated with PB-CEL or MG-H1 (Table 2.2). Additional analyses were performed with FLI instead of the eLF\% as measure of liver fat and yielded comparable results (Suppl. Table 2.1). However, the positive association between $\mathrm{FLI}$ and free $\mathrm{CML}$ now remained significant after adjustment of several confounders (model 3 ) and the association between FLI and PB-pentosidine was retained also after adjustment for BMI (model 4).

\section{Association of liver enzymes with free and protein-bound AGEs and SRAGE} Next, we investigated the association of the LE-score (as a measure of hepatocellular injury) with AGEs and sRAGE (Table 2.2). The LE-score was positively associated with free $\mathrm{CML}(\beta=0.030 ; 95 \% \mathrm{Cl} 0 ; 0.060)$ and free CEL $(\beta=0.047 ; 95 \% \mathrm{Cl} 0.018 ; 0.077)$, but an inverse association between the LEscore and PB-CML ( $\beta=-0.061 ; 95 \% \mathrm{Cl}-0.083 ;-0.039)$ or LE-score and SRAGE $(\beta=-0.072 ; 95 \% \mathrm{Cl}-0.109 ;-0.034)$ was observed. The positive associations with free CML $(\beta=0.046 ; 95 \% \mathrm{Cl} 0.015 ; 0.077)$ and free CEL $(\beta=0.049 ; 95 \% \mathrm{Cl}$ $0.019 ; 0.079$ ) were stronger after additional adjustment (model 3 ), while the association with PB-CML ( $\beta=-0.054 ; 95 \% \mathrm{Cl}-0.077 ;-0.031$ ) was slightly weaker and the association with sRAGE was no longer significant $(\beta=-0.027$; $95 \% \mathrm{Cl}-0.067 ; 0.012)$. Adjustment for BMI did not alter these associations substantially. The LE-score was not associated with PB-CEL or MG-H1.

\section{Association of liver fat and liver enzymes with LGI}

NAFLD is typically accompanied by low-grade systemic inflammation. In our cohort, we investigated the associations between liver fat or liver enzymes and the LGI score (Table 2.3). As expected, there was a strong association of eLF\% ( $\beta=0.494 ; 95 \% \mathrm{Cl} 0.387 ; 0.601)$ and the LE-score $(\beta=0.310 ; 95 \% \mathrm{Cl}$ $0.226 ; 0.393)$ with LGI. Additional adjustment did not substantially affect these associations. Moreover, when employing the FLI instead of eLF\%, the results were highly comparable (Suppl. Table 2.2). 
Table 2.2. Cross-sectional associations of liver fat and liver enzymes with free and proteinbound AGEs and SRAGE

\begin{tabular}{|c|c|c|c|c|c|c|c|c|c|}
\hline \multirow[b]{2}{*}{ Outcome } & \multicolumn{3}{|c|}{ eLF\% (\%) } & \multicolumn{6}{|c|}{ Liver enzyme score } \\
\hline & Model & & $95 \% \mathrm{Cl}$ & & P-value & $\beta$ & $95 \% \mathrm{Cl}$ & & P-value \\
\hline Free CML & 1 & 0.042 & 0.002 & 0.082 & 0.038 & 0.030 & 0.000 & 0.060 & 0.052 \\
\hline \multirow[t]{3}{*}{$(\mathrm{nM})$} & 2 & 0.031 & -0.008 & 0.070 & 0.122 & 0.030 & -0.001 & 0.061 & 0.055 \\
\hline & 3 & 0.041 & -0.002 & 0.084 & 0.061 & 0.046 & 0.015 & 0.077 & 0.004 \\
\hline & 4 & 0.037 & -0.014 & 0.088 & 0.151 & 0.044 & 0.012 & 0.076 & 0.008 \\
\hline Free CEL & 1 & 0.096 & 0.058 & 0.135 & $<0.001$ & 0.047 & 0.018 & 0.077 & 0.002 \\
\hline \multirow[t]{3}{*}{$(\mathrm{nM})$} & 2 & 0.083 & 0.045 & 0.121 & $<0.001$ & 0.037 & 0.007 & 0.067 & 0.016 \\
\hline & 3 & 0.095 & 0.054 & 0.136 & $<0.001$ & 0.049 & 0.019 & 0.079 & 0.001 \\
\hline & 4 & 0.090 & 0.041 & 0.139 & $<0.001$ & 0.040 & 0.009 & 0.072 & 0.012 \\
\hline Free MG-H1 & 1 & 0.043 & -0.019 & 0.105 & 0.170 & -0.009 & -0.056 & 0.038 & 0.719 \\
\hline \multirow[t]{3}{*}{$(\mathrm{nM})$} & 2 & 0.023 & -0.038 & 0.084 & 0.464 & -0.019 & -0.067 & 0.028 & 0.423 \\
\hline & 3 & 0.024 & -0.042 & 0.090 & 0.481 & 0.006 & -0.042 & 0.053 & 0.820 \\
\hline & 4 & 0.036 & -0.042 & 0.115 & 0.367 & 0.007 & -0.043 & 0.057 & 0.789 \\
\hline PB-Pentosidine & 1 & -0.059 & -0.100 & -0.018 & 0.005 & -0.150 & -0.047 & 0.016 & 0.342 \\
\hline \multirow[t]{3}{*}{ (nmol/mmol lysine) } & 2 & -0.076 & -0.117 & -0.035 & $<0.001$ & -0.028 & -0.060 & 0.004 & 0.088 \\
\hline & 3 & -0.102 & -0.146 & -0.058 & $<0.001$ & -0.032 & -0.064 & 0.001 & 0.055 \\
\hline & 4 & -0.051 & -0.102 & 0.001 & 0.055 & -0.007 & -0.040 & 0.026 & 0.676 \\
\hline PB-CML & 1 & -0.115 & -0.143 & -0.087 & $<0.001$ & -0.061 & -0.083 & -0.039 & $<0.001$ \\
\hline \multirow[t]{3}{*}{ (nmol/mmol lysine) } & 2 & -0.122 & -0.150 & -0.093 & $<0.001$ & -0.067 & -0.090 & -0.044 & $<0.001$ \\
\hline & 3 & -0.105 & -0.136 & -0.074 & $<0.001$ & -0.054 & -0.077 & -0.031 & $<0.001$ \\
\hline & 4 & -0.071 & -0.108 & -0.034 & $<0.001$ & -0.037 & -0.060 & -0.013 & 0.002 \\
\hline PB-CEL & 1 & 0.000 & -0.036 & 0.036 & 0.992 & 0.003 & -0.025 & 0.031 & 0.828 \\
\hline \multirow[t]{3}{*}{ (nmol/mmol lysine) } & 2 & -0.002 & -0.039 & 0.035 & 0.911 & -0.002 & -0.030 & 0.027 & 0.919 \\
\hline & 3 & 0.013 & -0.028 & 0.055 & 0.527 & 0.007 & -0.023 & 0.037 & 0.652 \\
\hline & 4 & -0.003 & -0.052 & 0.047 & 0.920 & 0.001 & -0.0300 & 0.033 & 0.939 \\
\hline sRAGE & 1 & -0.097 & -0.146 & -0.048 & $<0.001$ & -0.072 & -0.109 & -0.034 & $<0.001$ \\
\hline \multirow[t]{3}{*}{$(\mathrm{pg} / \mathrm{ml})$} & 2 & -0.076 & -0.125 & -0.028 & 0.002 & -0.040 & -0.078 & -0.002 & 0.039 \\
\hline & 3 & -0.076 & -0.130 & -0.023 & 0.005 & -0.027 & -0.067 & 0.012 & 0.169 \\
\hline & 4 & -0.039 & -0.102 & 0.025 & 0.232 & -0.010 & -0.050 & 0.031 & 0.642 \\
\hline
\end{tabular}

$\beta$-values are unstandardized regression coefficients and represent the change in AGEs and SRAGE (all In-transformed) per one unit increase in eLF\% (In-transformed) or the LE-score. Model 1: Crude model. Model 2: Model $1+$ adjustment for age and sex. Model 3: Model $2+$ adjustment for alcohol, smoking, CVD, medication, eGFR. Model 4: Model $3+$ adjustment for BMI. 95\% Cl: 95\% confidence interval. 
Table 2.3. Associations of liver fat and liver enzymes with low-grade inflammation

\begin{tabular}{|c|c|c|c|c|c|c|c|c|c|}
\hline \multirow[b]{2}{*}{ Outcome } & \multicolumn{4}{|c|}{ eLF\% (\%) } & \multicolumn{5}{|c|}{ Liver enzyme score } \\
\hline & Model & $\beta$ & $95 \% \mathrm{Cl}$ & & P-value & $\beta$ & $95 \% \mathrm{Cl}$ & & P-value \\
\hline \multirow[t]{4}{*}{ LGI } & 1 & 0.494 & 0.387 & 0.601 & $<0.001$ & 0.310 & 0.226 & 0.393 & $<0.001$ \\
\hline & 2 & 0.493 & 0.386 & 0.599 & $<0.001$ & 0.347 & 0.262 & 0.431 & $<0.001$ \\
\hline & 3 & 0.533 & 0.415 & 0.650 & $<0.001$ & 0.356 & 0.270 & 0.442 & $<0.001$ \\
\hline & 4 & 0.429 & 0.290 & 0.568 & $<0.001$ & 0.292 & 0.205 & 0.380 & $<0.001$ \\
\hline
\end{tabular}

$\beta$-values are unstandardized regression coefficients and represent the change in the LGI score per one unit increase in eLF\% (In-transformed) or LE-score. Model 1: Crude model. Model 2: Model $1+$ adjustment for age and sex. Model 3: Model $2+$ adjustment for alcohol, smoking, CVD, medication, eGFR. Model 4: Model 3 + adjustment for BMI. 95\% Cl: 95\% confidence interval.

\section{Association of free and protein-bound AGEs and SRAGE with LGI}

AGEs can trigger inflammation via RAGE, potentially contributing to $L G I$ and could thereby explain, at least in part, the association of liver fat and liver enzymes with LGI. Therefore, we investigated the association of AGEs and sRAGE with the LGI score. Free CML $(\beta=0.443 ; 95 \% \mathrm{Cl} 0.194 ; 0.692)$ and free $\operatorname{CEL}(\beta=0.359 ; 95 \% \mathrm{Cl} 0.103 ; 0.616)$ were positively associated with $\mathrm{LGI}$, while PB-CML ( $\beta=-0.631 ; 95 \% \mathrm{Cl}-0.965 ;-0.298$ ) was inversely associated with this estimate of systemic inflammation. After adjustment for age, sex, alcohol consumption, smoking, prior CVD, medication use and eGFR (model 3), the positive association between free $C E L$ and $L G I$ was borderline non-significant ( $\beta=0.259 ; 95 \% \mathrm{Cl}-0.006 ; 0.525$ ), while the associations of free $\mathrm{CML}$ (positive) and PB-CML (inverse) with LGI remained significant. Adjustment for BMI (model 4) strongly attenuated the inverse association between PB-CML and LGI. This association was no longer significant $(\beta=-0.251 ; 95 \% \mathrm{Cl}-0.592$; 0.090 ) and only the positive association between free $C M L$ and $L G I$ remained (Table 2.4). To examine if free CML indeed contributes to the abovedescribed strong association of eLF\% or LE-score with LGI, we performed an additional analysis in which we adjusted that association for free CML. Adjustment for free CML reduced the association between eLF\% and $\mathrm{LGI}$ slightly from $\beta=0.429(95 \% \mathrm{Cl} 0.290 ; 0.568)$ to $\beta=0.420(95 \% \mathrm{Cl} 0.281 ; 0.558)$ and the association between LE-score and LGI from $\beta=0.292(95 \% \mathrm{Cl} 0.205$; $0.380)$ to $\beta=0.283(95 \% \mathrm{Cl} 0.195 ; 0.371)$. No association was observed between SRAGE, PB-CEL, PB-Pentosidine or MG-H1 and LGI (Table 2.4). 


\section{Discussion}

The present study revealed that liver fat and liver enzymes were positively associated with circulating free AGEs, while inverse associations were observed with circulating protein-bound AGEs. In addition, free AGEs were positively associated with LGI, but an inverse association was determined between protein-bound AGEs and LGI, albeit this latter association was explained by BMI. Lastly, there was no association observed of liver fat and liver enzymes with sRAGE or between sRAGE and LGI after adjustment for BMI. We demonstrated that a higher hepatic fat content, a hallmark of NAFLD, is associated with AGEs and SRAGE, but a key role is played by obesity and adipose tissue as adjustment for BMI attenuated these associations. However, even after adjustment for this potential confounder, a positive association between liver fat and free AGEs (only CEL and not CML) and an inverse association of protein-bound AGEs (pentosidine and PB-CML) was still observed. Lipid peroxidation contributes to CEL formation making its generation likely in metabolically active and lipid rich environments such as the fatty liver ${ }^{26}$. Indeed, levels of other lipid peroxidation products (e.g. malondialdehyde and 8-isoprostane) are elevated in the circulation of NAFLD patients ${ }^{27,28}$. Moreover, hepatic steatosis was shown to lead to lipid peroxidation in mice ${ }^{29}$. In line with our data, Palma-Duran et al. recently reported elevated levels of circulating CEL and not CML in NAFLD patients in a case-control study ${ }^{30}$.

The inverse relationship between hepatic steatosis and circulating proteinbound AGEs suggests either trapping of AGEs in the liver or an elevated breakdown of (modified) proteins in fatty livers. We previously reported trapping of specifically PB-CML in adipose tissue of obese mice and reduced levels of circulating PB-CML in obese subjects ${ }^{12}$. In the liver, we also observed trapping of CML-modified albumin, although the amount of trapped PB-CML in the liver was not compared between healthy and steatotic livers ${ }^{12}$. Therefore, it is possible that a higher amount of PB-CML is trapped in fatty livers, which could explain the inverse direction of the association between liver fat and circulating PB-CML. Another explanation could be alterations in protein metabolism, specifically an enhanced protein breakdown, in NAFLD. A recent study indeed reported elevated levels of plasma amino acids, 


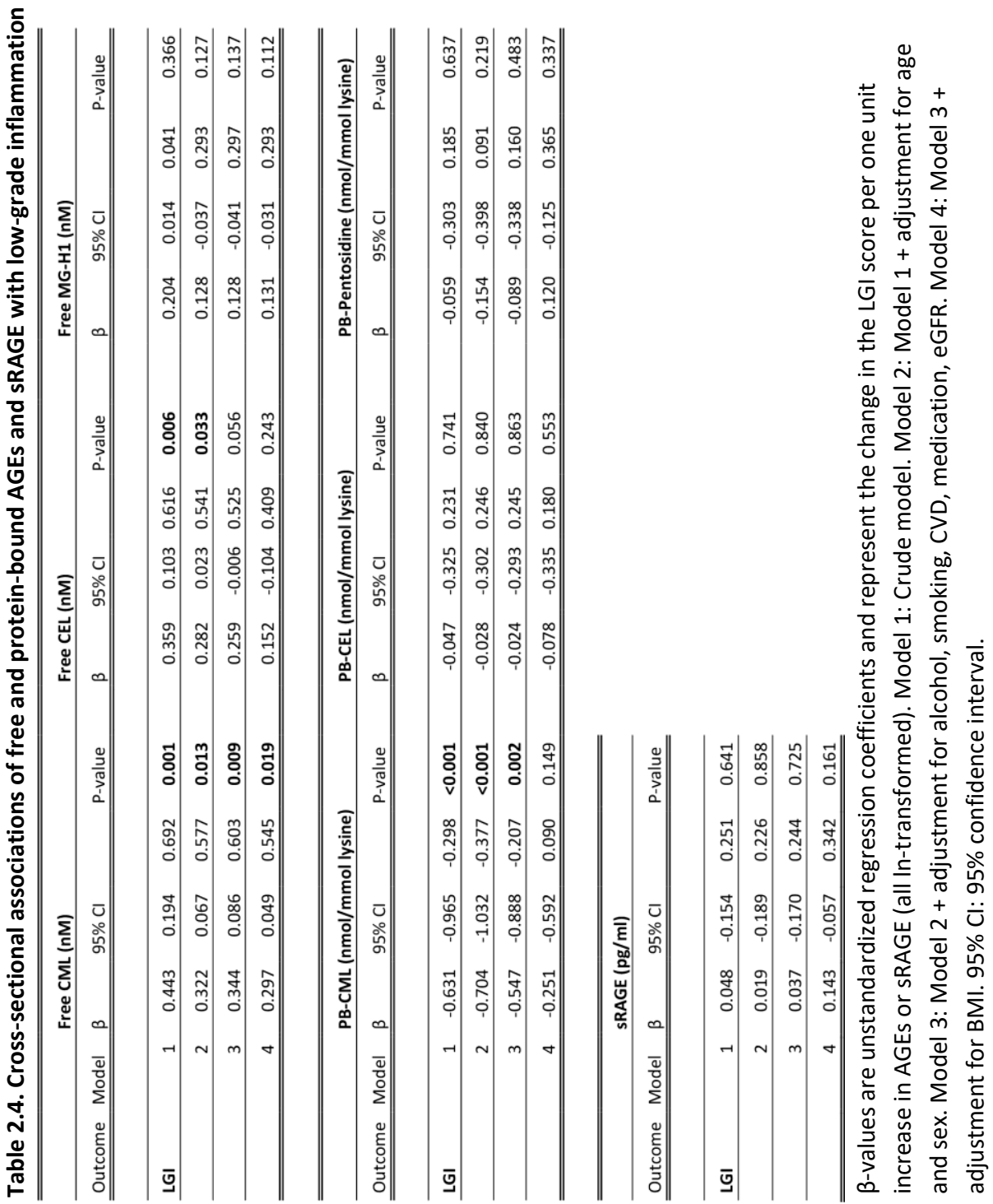

including leucine, a marker of protein breakdown, in NAFLD patients ${ }^{31,32}$. This could also explain the inverse relationship between liver fat and pentosidine. Pentosidine is formed through the slow Maillard reaction and therefore mainly affects long-living proteins, which are typically ECM components such as collagen ${ }^{33}$. In contrast to enhanced protein breakdown, Munsterman et al. reported inhibition of hepatic ECM degradation by hepatic stellate cells in NAFLD $^{34}$. Reduced ECM degradation could explain the observed lower 
circulating pentosidine levels as less modified proteins are released from the ECM, albeit Munsterman et al. reported this in a more advanced stage of NAFLD ${ }^{34}$.

We found a strong inverse association between liver fat and SRAGE, but this association was largely dependent on BMI. Several studies have shown that obesity is a strong determinant of sRAGE levels explaining why the association is no longer present after adjustment for this confounder ${ }^{35,36}$. In accordance with our data, Palma-Duran et al. reported a decrease of sRAGE in NAFLD patients ${ }^{30}$. Interestingly, this difference between cases and controls in their study was observed despite matching for BMI. However, their study used diagnosed NAFLD patients in whom the liver status might be worse than our population. Possibly, sRAGE levels are influenced more by the liver and independently from the obese adipose tissue in patients with worse NALFD. Hepatocellular injury as a result of hepatic inflammation is reflected by elevated liver enzymes. As such, our study implies that hepatic injury is associated with higher levels of circulating free AGEs (CML and CEL), but lower levels of protein-bound AGEs (PB-CML). These findings are in agreement with our previous study revealing elevated levels of $\mathrm{CML}$ in livers with more severe steatosis and inflammation ${ }^{15}$. Furthermore, hepatic inflammation is accompanied by oxidative stress given that hepatic immune cells are an important producer of reactive oxygen species (ROS) ${ }^{37}$. High oxidative stress causes lipid peroxidation and contributes to AGE formation, mainly CML and $\mathrm{CEL}^{26}$. The association of hepatocellular injury with elevated circulating free CML, but lower circulating PB-CML suggests enhanced breakdown of proteins by liver injury and the accompanying hepatic inflammation. As previously described, protein degradation is enhanced in NAFLD patients ${ }^{32}$. Moreover, circulating levels of free amino acid correlated strongly with liver enzymes and even hepatic injury and inflammation ${ }^{32}$. These findings make it likely that more intrahepatic PB-CML is degraded to circulating free $\mathrm{CML}$ in subjects with more hepatocellular injury.

Our analyses confirmed that liver disease might contribute to elevated inflammatory cytokines and thereby maintenance of low-grade inflammation ${ }^{38-40}$.

The observed positive association of free CML and CEL with LGI suggests that these plasma free AGEs might influence LGI. However, the association of CEL 
with LGI disappeared after adjustment for BMI implying that this association depends more on adiposity and the adipose tissue inflammation that accompanies it. Free CML remained associated with $L G I$ even after adjustment for BMI. However, the very modest effect of additional adjustment for free CML suggested that the strong association of hepatic steatosis and injury with LGI was not mediated by circulating free CML levels. Indeed, it has been described that free CML is unable to stimulate RAGE and cause inflammation ${ }^{10}$. Therefore, any effects on LGI by free CML are likely to be indirect or due to disturbance of intracellular function and not via RAGE ${ }^{7}$. In line with this notion, we observed that SRAGE was not associated with LGI despite its potential role as a decoy receptor for its ligands or as indicator of AGE-RAGE axis activity ${ }^{13}{ }^{14}$. In contrast, Palma-Duran et al. did report an inverse correlation between SRAGE and either TNF- $\alpha$ and CRP, two components of our LGI-score ${ }^{30}$. This discrepancy could be explained by the other markers used to calculate our LGI-score as these markers might not correlate well with SRAGE. Indeed, when performing a similar analysis, we observed a significant inverse correlation between sRAGE and CRP as well, but the correlation between SRAGE and TNF- $\alpha$ was not present (data not shown). However, we believe that our LGI-score is a representative measure of low-grade inflammation preferable over a few single markers. Another explanation for discrepancies can be found in the difference in severity of liver disease between the studies. As previously mentioned, Palma-Duran et al. used diagnosed NAFLD patients in comparison to our population without diagnosis of NAFLD ${ }^{30}$.

Interestingly, the inverse association between PB-CML and $\mathrm{LGI}$ also disappeared after adjustment for BMI. Likely, this has to do with the aforementioned trapping of PB-CML in the adipose tissue ${ }^{12}$.

Our study has some limitations. Given our cross-sectional study design, we cannot draw causal conclusions on the investigated relationships. Prospective studies are required to better understand the contribution of liver disease to AGE formation and subsequently circulating AGEs and lowgrade inflammation. Another important consideration is the estimation of liver fat employed in the study. We used two different equations to estimate liver fat content, but did not measure liver fat content using imaging techniques or quantify hepatic steatosis or inflammation in liver biopsies. 
These procedures were not feasible in our large human cohort due to cost or ethical concerns. However, the two measures of liver fat (eLF\% and FLI) used in this study have been validated in previous studies and revealed similar associations in the present study ${ }^{17,18}$.

In conclusion, our findings suggest an elevated formation of AGEs in fatty and injured livers accompanied with an enhanced breakdown of the formed protein-bound AGEs resulting in altered levels of circulating AGEs.

Potentially, these alterations can contribute to LGI. 


\section{References}

1. Tailleux A, Wouters K, Staels B. Roles of PPARs in NAFLD: potential therapeutic targets. Biochim Biophys Acta 2012;1821:809-18.

2. Ekstedt M, Franzen LE, Mathiesen UL, et al. Long-term follow-up of patients with NAFLD and elevated liver enzymes. Hepatology 2006;44:865-73.

3. Festi D, Colecchia A, Sacco T, et al. Hepatic steatosis in obese patients: clinical aspects and prognostic significance. Obes Rev 2004;5:27-42.

4. Than NN, Newsome PN. A concise review of non-alcoholic fatty liver disease. Atherosclerosis 2015;239:192-202.

5. Angulo P. Nonalcoholic fatty liver disease. N Engl J Med 2002;346:1221-31.

6. Maessen DE, Stehouwer CD, Schalkwijk CG. The role of methylglyoxal and the glyoxalase system in diabetes and other age-related diseases. Clin Sci (Lond) 2015;128:839-61.

7. Brownlee M. Biochemistry and molecular cell biology of diabetic complications. Nature 2001;414:813-20.

8. Tai ES, Tan ML, Stevens RD, et al. Insulin resistance is associated with a metabolic profile of altered protein metabolism in Chinese and Asian-Indian men. Diabetologia 2010;53:757-67.

9. Bierhaus $A$, Humpert PM, Morcos $M$, et al. Understanding RAGE, the receptor for advanced glycation end products. Journal of molecular medicine 2005;83:876-86.

10. Kislinger T, Fu C, Huber B, et al. N(epsilon)-(carboxymethyl)lysine adducts of proteins are ligands for receptor for advanced glycation end products that activate cell signaling pathways and modulate gene expression. J Biol Chem 1999;274:31740-9.

11. Xue J, Ray $R$, Singer $D$, et al. The receptor for advanced glycation end products (RAGE) specifically recognizes methylglyoxal-derived AGEs. Biochemistry 2014;53:3327-35.

12. Gaens KH, Goossens GH, Niessen PM, et al. Nepsilon-(carboxymethyl)lysinereceptor for advanced glycation end product axis is a key modulator of obesityinduced dysregulation of adipokine expression and insulin resistance. Arterioscler Thromb Vasc Biol 2014;34:1199-208.

13. Gaens KH, Ferreira I, van der Kallen CJ, et al. Association of polymorphism in the receptor for advanced glycation end products (RAGE) gene with circulating RAGE levels. J Clin Endocrinol Metab 2009;94:5174-80.

14. Lopez-Diez R, Shekhtman A, Ramasamy R, et al. Cellular mechanisms and consequences of glycation in atherosclerosis and obesity. Biochim Biophys Acta 2016;1862:2244-2252.

15. Gaens KH, Niessen PM, Rensen SS, et al. Endogenous formation of Nepsilon(carboxymethyl)lysine is increased in fatty livers and induces inflammatory markers in an in vitro model of hepatic steatosis. J Hepatol 2012;56:647-55.

16. Jacobs $\mathrm{M}$, van Greevenbroek MM, van der Kallen $\mathrm{CJ}$, et al. Low-grade inflammation can partly explain the association between the metabolic syndrome and either coronary artery disease or severity of peripheral arterial disease: the CODAM study. Eur J Clin Invest 2009;39:437-44.

17. Kotronen A, Peltonen M, Hakkarainen A, et al. Prediction of non-alcoholic fatty liver disease and liver fat using metabolic and genetic factors. Gastroenterology 2009;137:865-72. 
18. Bedogni G, Bellentani S, Miglioli L, et al. The Fatty Liver Index: a simple and accurate predictor of hepatic steatosis in the general population. BMC Gastroenterol 2006;6:33.

19. Yang BL, Wu WC, Fang KC, et al. External validation of fatty liver index for identifying ultrasonographic fatty liver in a large-scale cross-sectional study in Taiwan. PLoS One 2015;10:e0120443.

20. Cuthbertson DJ, Weickert MO, Lythgoe $D$, et al. External validation of the fatty liver index and lipid accumulation product indices, using $1 \mathrm{H}$-magnetic resonance spectroscopy, to identify hepatic steatosis in healthy controls and obese, insulinresistant individuals. Eur J Endocrinol 2014;171:561-9.

21. Wlazlo N, van Greevenbroek MM, Ferreira I, et al. Activated complement factor 3 is associated with liver fat and liver enzymes: the CODAM study. Eur J Clin Invest 2013;43:679-88.

22. Scheijen J, Clevers E, Engelen L, et al. Analysis of advanced glycation endproducts in selected food items by ultra-performance liquid chromatography tandem mass spectrometry: Presentation of a dietary AGE database. Food Chem 2016;190:11451150.

23. Hanssen NM, Engelen L, Ferreira I, et al. Plasma levels of advanced glycation endproducts Nepsilon-(carboxymethyl)lysine, Nepsilon-(carboxyethyl)lysine, and pentosidine are not independently associated with cardiovascular disease in individuals with or without type 2 diabetes: the Hoorn and CODAM studies. J Clin Endocrinol Metab 2013;98:E1369-73.

24. Wlazlo N, van Greevenbroek MM, Ferreira I, et al. Iron metabolism is associated with adipocyte insulin resistance and plasma adiponectin: the Cohort on Diabetes and Atherosclerosis Maastricht (CODAM) study. Diabetes Care 2013;36:309-15.

25. Levey AS, Bosch JP, Lewis JB, et al. A more accurate method to estimate glomerular filtration rate from serum creatinine: a new prediction equation. Modification of Diet in Renal Disease Study Group. Ann Intern Med 1999;130:461-70.

26. Gaens KH, Stehouwer CD, Schalkwijk CG. Advanced glycation endproducts and its receptor for advanced glycation endproducts in obesity. Current opinion in lipidology 2013;24:4-11.

27. Yesilova Z, Yaman H, Oktenli C, et al. Systemic markers of lipid peroxidation and antioxidants in patients with nonalcoholic Fatty liver disease. Am J Gastroenterol 2005;100:850-5.

28. Konishi M, Iwasa M, Araki J, et al. Increased lipid peroxidation in patients with nonalcoholic fatty liver disease and chronic hepatitis $\mathrm{C}$ as measured by the plasma level of 8-isoprostane. J Gastroenterol Hepatol 2006;21:1821-5.

29. Letteron P, Fromenty B, Terris B, et al. Acute and chronic hepatic steatosis lead to in vivo lipid peroxidation in mice. J Hepatol 1996;24:200-8.

30. Palma-Duran SA, Kontogianni MD, Vlassopoulos A, et al. Serum levels of advanced glycation end-products (AGEs) and the decoy soluble receptor for AGEs (sRAGE) can identify non-alcoholic fatty liver disease in age-, sex- and BMI-matched normoglycemic adults. Metabolism 2018;83:120-127.

31. Charlton MR. Protein metabolism and liver disease. Baillieres Clin Endocrinol Metab 1996;10:617-35.

32. Gaggini M, Carli F, Rosso $C$, et al. Altered amino acid concentrations in NAFLD: Impact of obesity and insulin resistance. Hepatology 2018;67:145-158. 


\section{Chapter 2}

33. Sell DR, Monnier VM. Structure elucidation of a senescence cross-link from human extracellular matrix. Implication of pentoses in the aging process. J Biol Chem 1989;264:21597-602.

34. Munsterman ID, Kendall T, Khelil N, et al. Extracellular matrix components indicate remodelling activity in different fibrosis stages of human non-alcoholic fatty liver disease. Histopathology 2018.

35. Koborova I, Gurecka R, Csongova M, et al. Association between metabolically healthy central obesity in women and levels of soluble receptor for advanced glycation end products, soluble vascular adhesion protein-1, and the activity of semicarbazide-sensitive amine oxidase. Croat Med J 2017;58:106-116.

36. Guclu M, Ali A, Eroglu DU, et al. Serum Levels of sRAGE Are Associated with Body Measurements, but Not Glycemic Parameters in Patients with Prediabetes. Metab Syndr Relat Disord 2016;14:33-9.

37. Reyes-Gordillo K, Shah R, Muriel P. Oxidative Stress and Inflammation in Hepatic Diseases: Current and Future Therapy. Oxid Med Cell Longev 2017;2017:3140673.

38. Tarantino G, Savastano S, Colao A. Hepatic steatosis, low-grade chronic inflammation and hormone/growth factor/adipokine imbalance. World J Gastroenterol 2010;16:4773-83.

39. Haukeland JW, Damas JK, Konopski Z, et al. Systemic inflammation in nonalcoholic fatty liver disease is characterized by elevated levels of CCL2. J Hepatol 2006;44:1167-74.

40. Gaudio E, Nobili V, Franchitto A, et al. Nonalcoholic fatty liver disease and atherosclerosis. Intern Emerg Med 2012;7 Suppl 3:S297-305. 


\section{Supplementary tables}

Suppl. table 2.1. Associations of FLI with free and protein-bound AGEs and SRAGE

\begin{tabular}{|c|c|c|c|c|c|}
\hline \multicolumn{6}{|c|}{ FLI } \\
\hline Outcome & Model & $\beta$ & $95 \% \mathrm{Cl}$ & & P-value \\
\hline Free CML & 1 & 0.031 & 0.001 & 0.062 & 0.043 \\
\hline \multirow[t]{3}{*}{$(\mathrm{nM})$} & 2 & 0.027 & -0.004 & 0.057 & 0.083 \\
\hline & 3 & 0.033 & 0.002 & 0.064 & 0.038 \\
\hline & 4 & 0.048 & -0.004 & 0.099 & 0.068 \\
\hline Free CEL & 1 & 0.064 & 0.034 & 0.093 & $<0.001$ \\
\hline \multirow[t]{3}{*}{$(\mathrm{nM})$} & 2 & 0.053 & 0.023 & 0.083 & $<0.001$ \\
\hline & 3 & 0.058 & 0.029 & 0.088 & $<0.001$ \\
\hline & 4 & 0.069 & 0.019 & 0.119 & 0.007 \\
\hline Free MG-H1 & 1 & 0.013 & -0.034 & 0.060 & 0.590 \\
\hline \multirow[t]{3}{*}{$(\mathrm{nM})$} & 2 & 0.000 & -0.047 & 0.047 & 0.990 \\
\hline & 3 & -0.001 & -0.048 & 0.047 & 0.976 \\
\hline & 4 & 0.004 & -0.076 & 0.083 & 0.930 \\
\hline PB-Pentosidine & 1 & -0.070 & -0.101 & -0.039 & $<0.001$ \\
\hline \multirow[t]{3}{*}{ (nmol/mmol lysine) } & 2 & -0.086 & -0.117 & -0.055 & $<0.001$ \\
\hline & 3 & -0.093 & -0.124 & -0.062 & $<0.001$ \\
\hline & 4 & -0.061 & -0.113 & -0.009 & 0.022 \\
\hline PB-CML & 1 & -0.089 & -0.110 & -0.067 & $<0.001$ \\
\hline \multirow[t]{3}{*}{ (nmol/mmol lysine) } & 2 & -0.096 & -0.117 & -0.074 & $<0.001$ \\
\hline & 3 & -0.081 & -0.103 & -0.058 & $<0.001$ \\
\hline & 4 & -0.063 & -0.100 & -0.025 & 0.001 \\
\hline PB-CEL & 1 & 0.026 & -0.002 & 0.053 & 0.067 \\
\hline \multirow[t]{3}{*}{ (nmol/mmol lysine) } & 2 & 0.024 & -0.005 & 0.003 & 0.621 \\
\hline & 3 & 0.033 & 0.003 & 0.063 & 0.031 \\
\hline & 4 & 0.046 & -0.004 & 0.096 & 0.069 \\
\hline sRAGE & 1 & -0.090 & -0.127 & -0.053 & $<0.001$ \\
\hline \multirow[t]{3}{*}{$(\mathrm{pg} / \mathrm{ml})$} & 2 & -0.066 & -0.103 & -0.029 & 0.001 \\
\hline & 3 & -0.063 & -0.102 & -0.025 & 0.001 \\
\hline & 4 & -0.030 & -0.095 & 0.034 & 0.354 \\
\hline
\end{tabular}

$\beta$-values are unstandardized regression coefficients and represent the change in AGEs and SRAGE (all In-transformed) per one unit increase in FLI (standardized). Model 1: Crude model. Model 2: Model $1+$ adjustment for age and sex. Model 3: Model $2+$ adjustment for alcohol, smoking, CVD, medication, eGFR. Model 4: Model 3 + adjustment for BMI. 95\% Cl: 95\% confidence interval; FLI: fatty liver index. 
Suppl. table 2.2. Associations of FLI with low-grade inflammation

\begin{tabular}{|c|c|c|c|c|c|}
\hline & & FLI & & & \\
\hline Outcome & Model & $\beta$ & $95 \% \mathrm{Cl}$ & & P-value \\
\hline \multirow[t]{4}{*}{ LGI } & 1 & 0.325 & 0.242 & 0.408 & $<0.001$ \\
\hline & 2 & 0.343 & 0.260 & 0.427 & $<0.001$ \\
\hline & 3 & 0.329 & 0.243 & 0.416 & $<0.001$ \\
\hline & 4 & 0.234 & 0.090 & 0.378 & 0.002 \\
\hline
\end{tabular}

$\beta$-values are unstandardized regression coefficients and represent the change in the LGI score per one unit increase in FLI (standardized). Model 1: Crude model. Model 2: Model $1+$ adjustment for age and sex. Model 3: Model $2+$ adjustment for alcohol, smoking, CVD, medication, eGFR. Model 4: Model 3 + adjustment for BMI. $95 \% \mathrm{Cl}$ : $95 \%$ confidence interval; FLI: fatty liver index. 


\section{Chapter 3}

Higher dietary advanced glycation endproduct intake increases circulating advanced glycation endproducts, hepatic advanced glycation endproducts and hepatic inflammation

Mitchell Bijnen, Suzan Wetzels, Jean L. Scheijen, Marjo P.H. van de Waarenburg, Coen D.A. Stehouwer, Kristiaan Wouters and Casper G. Schalkwijk

In preparation 


\section{Abstract}

\section{Background}

Non-alcoholic fatty liver disease ranges from steatosis only to non-alcoholic steatohepatitis (NASH). The latter is characterized by lipid accumulation and inflammation associated with liver damage. We previously found that advanced glycation endproducts (AGEs) accumulate in livers of NASH patients, which may trigger hepatic inflammation. The major source of hepatic AGEs is unknown. We hypothesize that dietary AGEs accumulate in the liver and contribute to hepatic inflammation.

\section{Methods}

C57BL/6 mice were fed standard chow, baked chow or a low fat diet for 5 weeks. The protein-bound (PB) forms of the major AGEs $N^{\varepsilon_{-}}$ (carboxymethyl)lysine (CML), $\mathrm{N}^{\varepsilon}$-(1-carboxyethyl)lysine $(\mathrm{CEL})$, and $\mathrm{N}^{\delta}-(5-$ hydro-5-methyl-4-imidazolon-2-yl)-ornithine (MG-H1) were analyzed in diets and the free forms of $\mathrm{CML}, \mathrm{CEL}$ and $\mathrm{MG}-\mathrm{H} 1$ were determined in murine plasma and liver homogenates by ultra-performance liquid chromatographytandem mass spectrometry. Hepatic inflammatory gene expression was examined using qPCR.

\section{Results}

Baking the standard chow strongly increased PB-AGE content (3- to 10-fold higher). Feeding mice with baked chow increased circulating free CEL (119 \pm 3 vs $247 \pm 23 n M, p=0.002$ and MG-H1 (120 \pm 3 vs $505 \pm 80 n M ; p=0.003)$ and hepatic free CML ( $41 \pm 2$ vs $54 \pm 4 \mathrm{nmol} / \mathrm{L} ; \mathrm{p}=0.03$ ) and MG-H1 (3.7 \pm 0.1 vs $9.9 \pm 2.0 \mathrm{nmol} / \mathrm{L} ; \mathrm{p}=0.02$ ) in comparison to standard chow-fed mice. Compared to standard chow, baked chow feeding increased hepatic gene expression of Tumor necrosis factor alpha ( $1 \pm 0.2$ vs $1.6 \pm 0.25 ; p=0.057$ ) and C-reactive protein ( $1 \pm 0.13$ vs $1.37 \pm 0.06 ; p=0.04$ ). A low fat diet contains up to 6-fold less PB-AGEs as compared to standard chow. Switching the diet from standard chow to a low fat diet, resulted in a reduction of circulating concentrations of free CML (from $791 \pm 79 n M$ to $248 \pm 39 n M ; p=0.001$ ), free CEL (from $212 \pm 28 \mathrm{nM}$ to $39 \pm 5 \mathrm{nM}$; p=0.001) and free MG-H1 (from $175 \pm$ $50 \mathrm{nM}$ to $17 \pm 4 \mathrm{nM} ; \mathrm{p}=0.02$ ) and hepatic free CML (from $5.61 \pm 0.41 \mathrm{nmol} / \mathrm{g}$ 
to $3.33 \pm 0.11 \mathrm{nmol} / \mathrm{g} ; \mathrm{p}=0.002$ ) and MG-H1 (from $0.51 \pm 0.09 \mathrm{nmol} / \mathrm{g}$ to $0.33 \pm 0.02 \mathrm{nmol} / \mathrm{g} ; \mathrm{p}=0.10$ ). The reduction of hepatic AGEs was accompanied by a decrease in hepatic inflammatory gene expression.

\section{Conclusion}

Dietary AGEs contribute to circulating and hepatic AGEs and higher dietary AGE intake results in increased hepatic inflammation. Both AGE accumulation and inflammation can be reduced by a switch to low dietary AGE intake. 


\section{Introduction}

In line with the rise in the prevalence of obesity, the occurrence of nonalcoholic fatty liver disease (NAFLD) has increased ${ }^{1}$. NAFLD is a progressive liver disease starting with hepatic lipid accumulation (steatosis), advancing to inflammatory liver disease (non-alcoholic steatohepatitis; NASH) and eventually resulting in irreversible liver damage (liver cirrhosis) or liver cancer (hepatocellular carcinoma) ${ }^{2}$. The inflammatory phase of NAFLD, NASH, has also been associated with cardiovascular disease ${ }^{3,4}$. Therefore, the prevention and treatment of hepatic inflammation is highly relevant. However, it is not yet fully understood which factors contribute to the progression of NAFLD and more importantly, cause hepatic inflammation. A potentially important trigger might be the accumulation of advanced glycation endproducts (AGE) $)^{5,6}$. AGEs are sugar-modified proteins that are formed by the non-enzymatic reaction of carbonyl groups with amino acids of proteins ${ }^{7}$. We previously showed the presence of a major AGE, $\mathrm{N}^{\varepsilon}$ (carboxymethyl)lysine (CML), in the liver of NASH patients ${ }^{6}$. Moreover, hepatic CML content was higher in patients with more severe hepatic steatosis and inflammation ${ }^{6}$. In addition, we showed that CML triggers an inflammatory response in human hepatocytes which was dependent on their proinflammatory receptor, the receptor for AGEs (RAGE) ${ }^{6}$. Furthermore, it has been shown that CML activates human monocyte-derived macrophages and causes tumor necrosis factor alpha (TNF $\alpha$ ) production ${ }^{6,8}$. These data suggest that AGEs contribute to hepatic inflammation and could be relevant therapeutic targets to stop the NAFLD progression towards NASH.

AGEs can either be formed endogenously in the body or ingested and taken up when present in food ${ }^{9}$. Endogenous formation of AGEs can occur slowly via the Maillard reaction or rapidly due to the binding of highly reactive dicarbonyls, such as methylglyoxal, to amino acids. The latter process is thought to be the main contributor to endogenously formed AGEs and is stimulated by metabolic factors such as hyperglycemia, inflammation, hypoxia and oxidative stress ${ }^{10}$. Exogenous AGE formation in food products is mainly driven by the slow Maillard reaction. This reaction is accelerated at higher temperatures. Therefore, highly processed and heated food products are rich in AGEs. Considering the high sugar (glucose and fructose) content 
and popular preparation methods such as baking, grilling, frying and toasting of the Western diet, this diet contains a high concentration of $\mathrm{AGEs}^{11}$. We have recently demonstrated in humans, that higher intake of dietary AGEs is associated with higher levels of free AGEs in plasma and urine ${ }^{12}$. However, it is unknown whether the accumulated AGEs in organs, such as the liver, are derived from the diet. Therefore, the aim was to investigate the influence of dietary AGEs on AGE levels in the circulation and consequently in the liver. Moreover, we investigated whether dietary AGEs contribute to hepatic inflammation in mice.

\section{Materials and methods}

\section{Animal studies}

The standard chow diet (ssniff, Germany) was heated at $160^{\circ} \mathrm{C}$ for two hours to increase AGE levels (i.e. baked chow). 5 weeks old female C57BL/6 mice were fed standard chow or baked chow for 5 weeks.

Male C57BL/6 Idlr ${ }^{-/-}$mice (30 weeks old) were fed standard chow from birth before receiving a low fat diet (10 kcal\% fat; D12450J, Research Diets, New Brunswick) for 5 weeks. Blood was taken from the vena saphena using EDTA lined Microvette tubes (Sarstedt) at 3 time points, i.e. before switching the standard chow diet to the low fat diet ( $t=0 \mathrm{wks}$ ) and after 3 weeks ( $t=3 \mathrm{wks}$ ) and 5 weeks ( $t=5 \mathrm{wks}$ ) of low fat diet feeding. The low fat diet is the matched control diet for the high fat diet (60 kcal\% fat; D12492, Research Diets, New Brunswick), commonly used to induce obesity in rodents. All performed experiments were approved by the Animal Experiments Committee of Maastricht University or by the local ethical committee for animal experiments of Hasselt University.

\section{Cholesterol and triglyceride measurements}

Cholesterol and triglycerides circulating levels were determined with use of a colorimetric test (Cholesterol FS'10 and Triglycerides FS 5'ecoline, Diagnostic System $\mathrm{GmbH}$, Holzheim, Germany) as previously described ${ }^{13}$. 


\section{Advanced glycation endproducts measurements}

Livers were homogenized using a Mini-bead beater homogenizer (Biospec) and $250 \mu \mathrm{l}$ sodium phosphate buffer $(0,1 \mathrm{M})$ supplemented with protease inhibitor (Roche) and 0,02\% Triton-x (Sigma-Aldrich). Free or protein-bound (PB) $\mathrm{N}^{\varepsilon}$-(carboxymethyl)lysine (CML), $\mathrm{N}^{\varepsilon}$-(1-carboxyethyl)lysine (CEL), and $\mathrm{N}^{\delta}$ (5-hydro-5-methyl-4-imidazolon-2-yl)-ornithine (MG-H1) were analyzed by ultra-performance liquid chromatography-tandem mass spectrometry in plasma, liver homogenates and pulverized animal diets. Detailed descriptions of the measurement of plasma, hepatic and diet AGEs has been described previously ${ }^{14,15}$.

\section{Hepatic gene expression analysis}

Trizol reagent (Ambion) was used to isolate RNA from the liver before synthesis to cDNA using the iScript cDNA synthesis kit (170-8891; Bio-Rad, Hercules, USA) following manufacturer's instructions. The IQ SensiMix SYBR master mix (Bioline, London, UK) was used to determine hepatic gene expression on the CFX96 Touch with CFX manager software (Biorad) according to manufacturer's instructions. Expression levels were calculated with the $\Delta \Delta C T$ method and the geometric mean of two reference genes, Cyclophillin and Beta2-microglobulin ${ }^{16}$. All primers (Eurogentec) are given in supplementary table 3.1 .

\section{Statistical Analysis}

Unpaired data was tested for significance using a two-tailed Student's T-test. Repeated measure ANOVA with Tuckey's multiple comparison post-hoc test was performed on paired data. All data analyses were performed using GraphPad Prism 5.01 (La Jolla California, USA), all data was expressed as the mean \pm SEM and were considered statistically significant at $P \leq 0.05$.

\section{Results}

\section{Higher dietary AGE intake increases circulating and hepatic free AGEs}

To generate a diet high in AGEs, the standard chow was baked $160^{\circ} \mathrm{C}$ for two hours. The resulting baked chow contained considerably more PB-CML, PBCEL and PB-MG-H1 when compared to standard chow (Fig. 3.1A-C). Feeding 
the baked chow for five weeks increased circulating free CEL and MG-H1 levels, but not free CML levels, compared to standard chow-fed mice (Fig. 3.2A). In the liver, free $\mathrm{CML}$ and MG-H1, but not CEL, were higher in baked chow-fed mice compared to standard chow-fed mice (Fig. 3.2B).

Food intake seemed to be reduced the first few days after switching to the baked chow diet, but after the mice familiarized themselves with the diet, food consumption was comparable between groups (Suppl. Fig. 3.1A). Consequently, weight gain was not different between standard chow and baked chow-fed mice (Suppl. Fig. 3.1B).
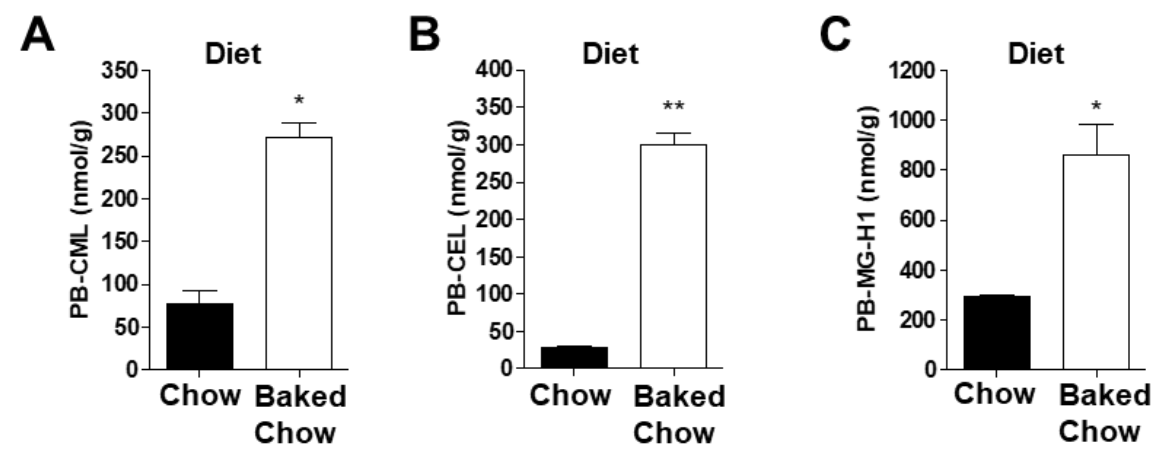

Figure 3.1. Baking chow diet increases dietary protein-bound advanced glycation endproducts

(A-C) Levels of PB-CML, PB-CEL and PB-MG-H1 in the standard chow and baked chow. All data are means $\pm S E M . * P \leq 0.05,{ }^{* *} P \leq 0.01$ vs standard chow.

\section{Higher dietary AGE intake increases hepatic inflammation}

To evaluate effects of AGE intake on hepatic inflammation, hepatic inflammatory gene expression was measured. Levels of the proinflammatory cytokine, Tnf $\alpha$, tended to be higher $(\mathrm{p}=0.057)$, while the acute phase protein, $C$-reactive protein (Crp), was significantly higher in the mice fed baked chow when compared to standard chow-fed mice. However, the general macrophage marker, $F 4 / 80$, and the proinflammatory marker, monocyte chemoattractant protein 1 (Mcp1), expression levels were comparable between groups. The acute phase protein, Serum amyloid A (Saa), neutrophil activation marker, Myeloperoxidase ( $\mathrm{Mpo}$ ), and the oxidative stress related transcription factor, nuclear factor (erythroid-derived 2)-like 2 (Nrf2) were 
higher in baked chow-fed mice compared to standard chow-fed mice, but these differences did not reach statistical significance (Fig. 3.2C).

A

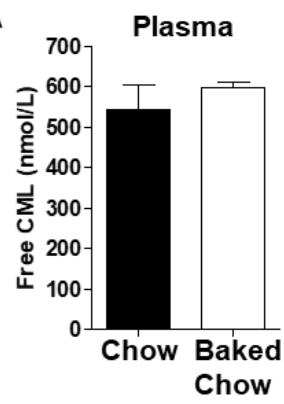

B

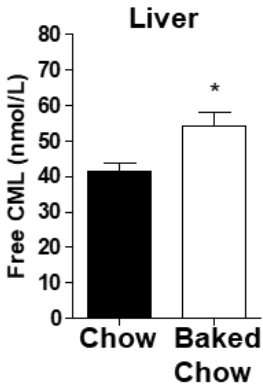

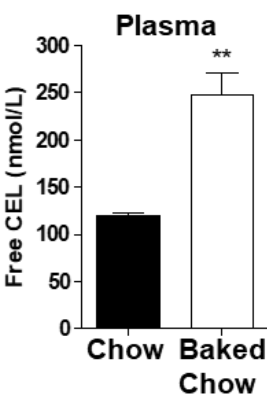

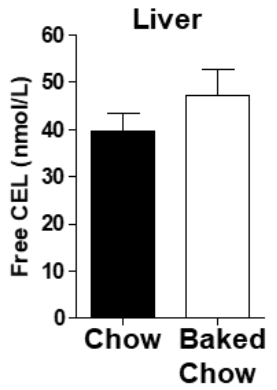

Plasma
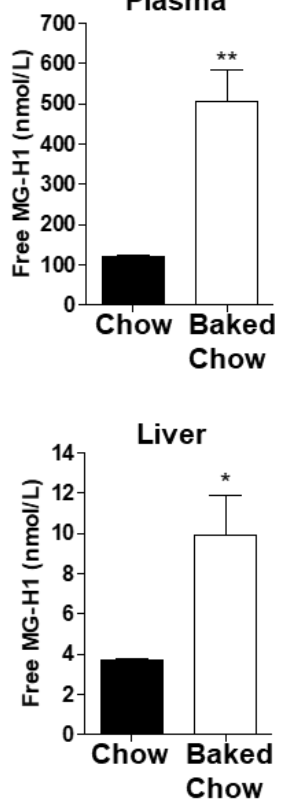

C

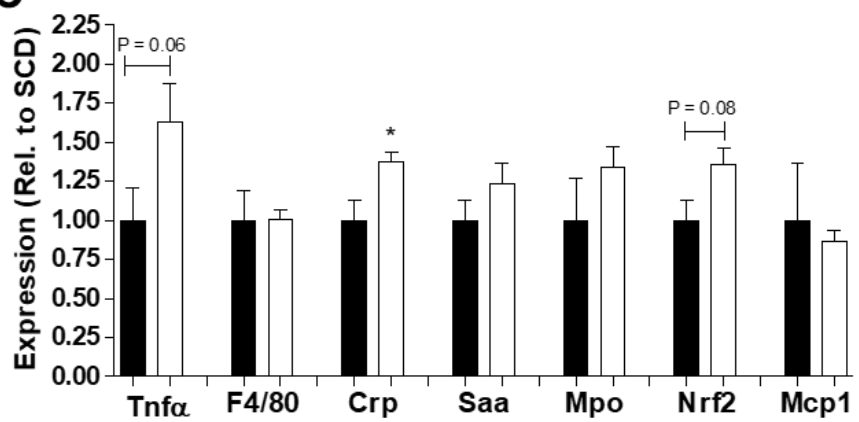

Chow $\square$ Baked chow

Figure 3.2. Increasing dietary advanced glycation endproduct intake elevates plasma and hepatic advanced glycation endproducts

(A, B) Circulating (A) and hepatic (B) free CML, CEL and MG-H1 levels after 5 weeks of standard chow or baked chow feeding. (C) Gene expression in the liver after 5 weeks of standard chow or baked chow feeding. All data are means \pm SEM. ${ }^{*} \mathrm{P} \leq 0.05,{ }^{* *} \mathrm{P} \leq 0.01$ vs standard chow. $\mathrm{n}=$ 4. 


\section{Switching to a diet low in AGEs reduces circulating free AGEs within 3 weeks} In order to investigate if lowering dietary AGE intake reduces circulating and hepatic AGEs, we first analyzed the AGE levels in different animal diets. In animal models for obesity, a high fat diet and a matched control diet referred to as low fat diet is frequently used. We determined the PB-AGE levels in both diets and found them to be comparable to each other. Moreover, all PB-AGEs were substantially lower in the low fat diet than in the standard chow diet (Table 3.1).

To determine if circulating AGEs, hepatic AGEs and hepatic inflammation can be reduced by lowering dietary AGE content, we switched the diet from standard chow to the low fat diet, i.e from a diet high in AGEs to a diet low in AGEs (Fig. 3.3A). After switching to a diet low in AGEs, circulating free AGEs strongly decreased within 3 weeks and no further reduction was observed after 5 weeks (Fig. 3.3B).

Table 3.1. Advanced glycation endproducts in a variety of animal diets

\begin{tabular}{|l||l|l|l|}
\hline Diet & $\begin{array}{l}\text { PB-CML } \\
\text { (Average } \pm \text { SEM) }\end{array}$ & $\begin{array}{l}\text { PB-CEL } \\
\text { (Average } \pm \text { SEM) }\end{array}$ & $\begin{array}{l}\text { PB-MG-H1 } \\
\text { (Average } \pm \text { SEM) }\end{array}$ \\
\hline \hline Standard chow & $77.5 \pm 15.5$ & $28.5 \pm 1.5$ & $297 \pm 4$ \\
\hline Baked chow & $271 \pm 18$ & $299.5 \pm 15.5$ & $863.5 \pm 120.5$ \\
\hline Low fat diet & $12.5 \pm 0.9$ & $5.9 \pm 0.4$ & $180.1 \pm 13.2$ \\
\hline High fat diet & $13.2 \pm 1$ & $6.4 \pm 0.2$ & $224.2 \pm 35.8$ \\
\hline
\end{tabular}

PB-CML, PB-CEL and PB-MG-H1 levels in standard chow, baked chow, low fat diet and high fat diet.

\section{A diet low in AGEs reduces hepatic AGEs and hepatic inflammation}

AGE levels in the liver were compared between standard chow and low fat diet-fed mice. Feeding mice a low fat diet strongly reduced hepatic free CML, while free MG-H1 showed a tendency towards a decrease when compared to standard chow-fed mice. Hepatic free CEL was comparable between both groups (Fig. 3.3C). Next, dietary AGE effects on hepatic gene expression was investigated to determine effects on hepatic inflammation. Levels of Tnf $\alpha$ ( $p$ $=0.08)$ and Saa $(p=0.06)$ tended to be decreased, while F4/80 and Mpo were strongly reduced by low fat diet feeding when compared to standard chow feeding. Crp and Nrf2 were comparable between both groups and Mcp1 was 
slightly reduced by low fat diet feeding when compared to standard chow feeding (Fig. 3.3D).

A

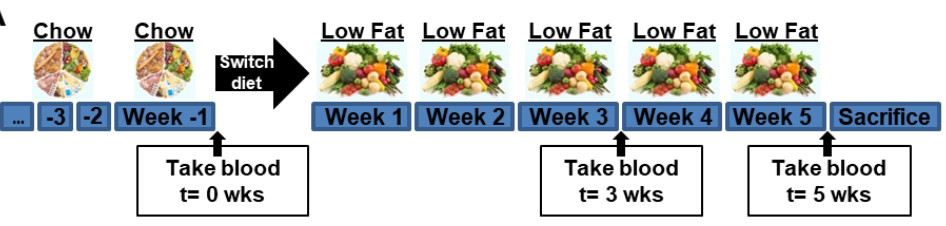

B
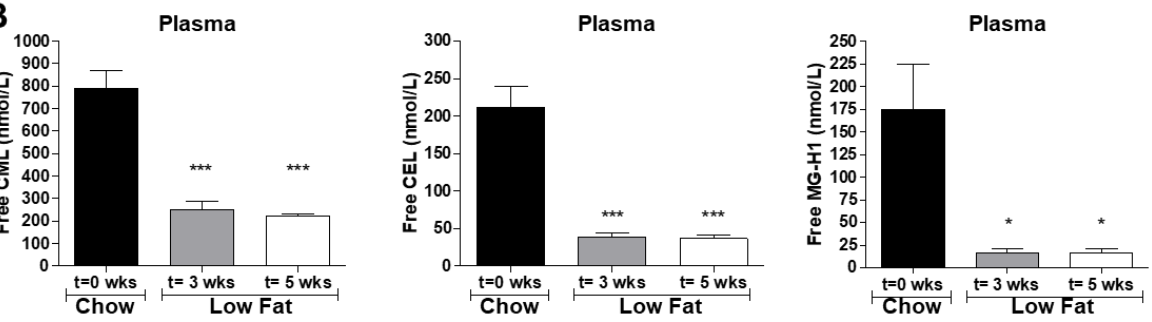

C
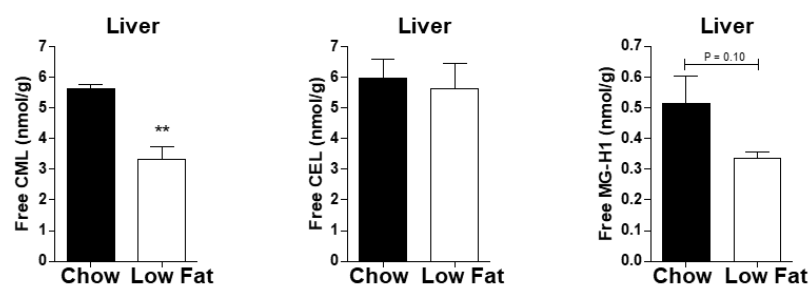

D

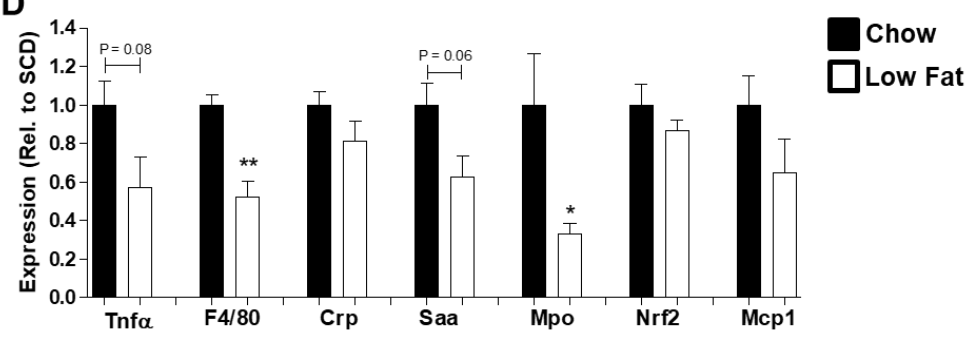

Figure 3.3. Reduction of dietary advanced glycation endproducts intake reduces circulating free advanced glycation endproducts within the same mice

(A) Setup of the intervention experiment in which standard chow-fed mice were taken off standard chow and fed low fat diet for 5 weeks. (B) Circulating levels of free CML, CEL and MG$\mathrm{H} 1$ after 0,3 or 5 weeks of low fat diet feeding. (C) Hepatic free CML, CEL and MG-H1 after standard chow or 5 weeks of low fat diet feeding. (D) Hepatic gene expression after standard chow or low fat diet feeding. All data are means \pm SEM. ${ }^{*} P \leq 0.05,{ }^{* *} P \leq 0.01,{ }^{* * *} \mathrm{P} \leq 0.001$ vs standard chow or $* \mathrm{p} \leq 0.05,{ }^{* * *} \mathrm{P} \leq 0.001$ vs $\mathrm{t}=0$ wks standard chow. $\mathrm{n}=4$. 


\section{Discussion}

Our data demonstrates that a higher dietary AGE intake increases circulating and hepatic AGEs. Importantly, the higher dietary AGE intake induces hepatic inflammatory gene expression.

Considering that exogenous AGE formation is strongly increased during the heating and processing of foods, the standard chow diet was baked to generate a diet high in AGEs. Indeed, after the baking procedure the PB-CML levels in the standard chow diet were increased 4-fold. This is in line with previous studies using baked animal diets (same baking temperature) reporting 4-6 fold increases in $\mathrm{CML}^{17,18}$. Next to the substantial increase in $\mathrm{CML}$, we observed a 10-fold and a 3-fold increase in CEL and MG-H1, respectively, by baking a standard chow diet. These data imply that in addition to $\mathrm{CML}$, heating animal diets elevates other major AGEs including MG-H1.

Feeding this baked diet increased plasma AGEs, which is in line with our previous work in humans ${ }^{12}$. There, we showed that dietary AGE intake, quantified using a validated food intake questionnaire, is associated with free AGEs but not with PB-AGEs in plasma and urine, implying that degradation of dietary AGEs into single (modified) amino acids in the intestine is necessary before they can enter the circulation. In the current animal study, we showed that a higher dietary AGE intake is associated with strong increases of hepatic AGEs, mainly CML and MG-H1. These findings suggest accumulation of dietary AGEs in tissues after transportation via the circulation. Tessier et al. previously investigated the biodistribution of specifically CML by carbon labeling, allowing a distinction between dietary and endogenous CML. They observed an accumulation of dietary CML in many organs including the liver of mice ${ }^{19}$. We now show that in addition to $\mathrm{CML}, \mathrm{MG}-\mathrm{H} 1$ also accumulates in the liver by increasing dietary AGE intake. The observed elevated hepatic AGE levels caused by increased dietary AGE intake were accompanied by induction of hepatic inflammatory gene expression. In agreement, feeding AGE-rich formula or diet has been shown to induce proinflammatory gene expression in piglet kidney cells or murine adipocytes, respectively ${ }^{20,21}$. Expression of proinflammatory cytokines can be induced by the binding of AGEs to their receptor, RAGE, as this leads to NF- 
$\mathrm{KB}$ activation, a key regulator in inflammatory gene expression ${ }^{7}$. In line, Leung et al. showed RAGE-dependent induction of hepatic inflammation after high dietary AGE feeding of mice ${ }^{17}$. Many studies have reported detrimental effects of high dietary AGEs on a wide variety of pathologies including liver disease ${ }^{17,22,23}$. Leung et al. induced NAFLD by feeding mice a high fat, high fructose, high cholesterol (HFHC) diet and demonstrated exacerbation of hepatic inflammation, but not steatosis when feeding mice a baked form of the HFHC diet ${ }^{17}$. However, circulating and hepatic AGEs were not determined in that study. We now show elevated levels of circulating and hepatic AGEs upon high dietary AGE feeding accompanied by enhanced hepatic inflammation.

In our follow-up experiment, we found a reduction of circulating and hepatic AGEs by lowering the dietary AGE intake. In parallel, hepatic inflammatory gene expression was reduced. These data further substantiate that dietary AGEs are important contributors to AGE levels in plasma and the liver. Moreover, this observation indicates that circulating and even tissue AGE levels can be reduced quite quickly by reducing dietary AGE intake. Considering the close association between dietary AGEs and plasma AGEs in humans, an intervention aimed at reducing AGEs could lower circulating and presumably tissue AGEs in humans as well. Previous human studies using such interventions have already shown beneficial effects of an AGE restricted diet on nephropathy, insulin sensitivity and systemic inflammation ${ }^{24-26}$. However, the effect of an AGE restricted diet on human liver disease has not yet been reported. Moreover, liver-centered animal studies have focused on increasing dietary AGE content instead of a further reduction ${ }^{17,22,23}$. To our knowledge, our study is the first to compare hepatic inflammation in standard chow fed mice with mice fed a diet low in AGEs. In line with the increase in hepatic inflammation after higher dietary intake observed by us and others ${ }^{22}$, we demonstrated for the first time a decrease in hepatic inflammatory gene expression upon low AGE diet feeding. Therefore, AGElowering therapies might be a promising treatment to tackle the inflammatory component of NAFLD.

It should be emphasized that frequently used animal diets (standard chow, high fat and Western type diet) differ substantially in AGE levels (Table 1). Because of the strong contribution of dietary AGEs to circulating and tissue 
(e.g. liver) AGEs, this can have a major impact on the results. Therefore, a specialized control diet with comparable AGE levels should be used, especially when investigating the AGE-RAGE axis. This is exemplified by the equal levels of dietary AGEs in the matched low and high fat specialized diets used for obesity studies.

The main limitation of our study is the inability to only alter AGE content in the diets. Baking does not only increase AGEs, but can affect nutritional value, vitamins, minerals and other diet components ${ }^{27,}{ }^{28}$. Therefore, we cannot conclusively prove that the changes in dietary AGEs causes the alterations in circulating AGEs, hepatic AGEs and hepatic inflammation. However, it is unlikely that the observed strong effects would be explained indirectly by other factors such as minerals.

Moreover, weight gain was similar between groups indicating comparable food intake and implying nutritional value was not impacted significantly by baking. Only a slight difference in food intake between standard chow and baked chow-fed mice was observed in the first few days, after which the mice familiarized themselves. In line, Leung et al. reported no effects of baked chow diet feeding on food intake and weight gain ${ }^{17}$.

Although the low fat diet differs substantially from the standard chow diet, with higher amounts of sucrose and starch and less energy derived from proteins in the low fat diet, the observed decrease in AGEs and hepatic inflammation support the main conclusions, i.e. that dietary AGEs impact circulating and hepatic AGEs and hepatic inflammation. Nevertheless, we cannot exclude potential effects of diet composition on hepatic inflammation independent from AGEs.

In summary, alterations in dietary AGE intake result in changed levels of free AGEs in both plasma and liver affecting hepatic inflammatory gene expression. Therefore, dietary AGEs might contribute to the progression of NAFLD towards irreversible liver damage. Future interventions could be aimed at reducing dietary AGE intake or reduction of circulating and thereby hepatic AGEs. 


\section{Acknowledgements}

We would like to thank José van de Gaar and Maria Vroomen (MUMC, Maastricht, The Netherlands) for their support and expertise regarding the animal experiments. 


\section{References}

1. Li L, Liu DW, Yan HY, et al. Obesity is an independent risk factor for non-alcoholic fatty liver disease: evidence from a meta-analysis of 21 cohort studies. Obes Rev 2016;17:510-9.

2. Than NN, Newsome PN. A concise review of non-alcoholic fatty liver disease. Atherosclerosis 2015;239:192-202.

3. Festi D, Colecchia A, Sacco T, et al. Hepatic steatosis in obese patients: clinical aspects and prognostic significance. Obes Rev 2004;5:27-42.

4. Ekstedt M, Franzen LE, Mathiesen UL, et al. Long-term follow-up of patients with NAFLD and elevated liver enzymes. Hepatology 2006;44:865-73.

5. Tilg $\mathrm{H}$, Moschen AR. Evolution of inflammation in nonalcoholic fatty liver disease: the multiple parallel hits hypothesis. Hepatology 2010;52:1836-46.

6. Gaens KH, Niessen PM, Rensen SS, et al. Endogenous formation of Nepsilon(carboxymethyl)lysine is increased in fatty livers and induces inflammatory markers in an in vitro model of hepatic steatosis. J Hepatol 2012;56:647-55.

7. Singh $\mathrm{R}$, Barden $\mathrm{A}$, Mori $\mathrm{T}$, et al. Advanced glycation end-products: a review. Diabetologia 2001;44:129-46.

8. Pertynska-Marczewska M, Kiriakidis S, Wait R, et al. Advanced glycation end products upregulate angiogenic and pro-inflammatory cytokine production in human monocyte/macrophages. Cytokine 2004;28:35-47.

9. Aragno M, Mastrocola R. Dietary Sugars and Endogenous Formation of Advanced Glycation Endproducts: Emerging Mechanisms of Disease. Nutrients 2017;9.

10. Hanssen NM, Stehouwer CD, Schalkwijk CG. Methylglyoxal and glyoxalase I in atherosclerosis. Biochem Soc Trans 2014;42:443-9.

11. N AL, Carbonero F. Impact of Maillard reaction products on nutrition and health: Current knowledge and need to understand their fate in the human digestive system. Crit Rev Food Sci Nutr 2017:1-14.

12. Scheijen J, Hanssen NMJ, van Greevenbroek MM, et al. Dietary intake of advanced glycation endproducts is associated with higher levels of advanced glycation endproducts in plasma and urine: The CODAM study. Clin Nutr 2017.

13. Shiri-Sverdlov R, Wouters K, van Gorp PJ, et al. Early diet-induced non-alcoholic steatohepatitis in APOE2 knock-in mice and its prevention by fibrates. J Hepatol 2006;44:732-41.

14. Scheijen J, Clevers E, Engelen L, et al. Analysis of advanced glycation endproducts in selected food items by ultra-performance liquid chromatography tandem mass spectrometry: Presentation of a dietary AGE database. Food Chem 2016;190:11451150.

15. Hanssen NM, Wouters K, Huijberts MS, et al. Higher levels of advanced glycation endproducts in human carotid atherosclerotic plaques are associated with a rupture-prone phenotype. Eur Heart J 2014;35:1137-46.

16. Livak KJ, Schmittgen TD. Analysis of relative gene expression data using real-time quantitative PCR and the 2(-Delta Delta C(T)) Method. Methods 2001;25:402-8.

17. Leung $\mathrm{C}$, Herath $\mathrm{CB}$, Jia $\mathrm{Z}$, et al. Dietary advanced glycation end-products aggravate non-alcoholic fatty liver disease. World J Gastroenterol 2016;22:8026-40.

18. Sourris KC, Harcourt BE, Penfold SA, et al. Modulation of the cellular expression of circulating advanced glycation end-product receptors in type 2 diabetic nephropathy. Exp Diabetes Res 2010;2010:974681. 
19. Tessier FJ, Niquet-Leridon C, Jacolot P, et al. Quantitative assessment of organ distribution of dietary protein-bound 13 C-labeled Nvarepsilon carboxymethyllysine after a chronic oral exposure in mice. Mol Nutr Food Res 2016;60:2446-2456.

20. Elmhiri G, Mahmood DF, Niquet-Leridon C, et al. Formula-derived advanced glycation end products are involved in the development of long-term inflammation and oxidative stress in kidney of IUGR piglets. Mol Nutr Food Res 2015;59:939-47.

21. Cai W, Ramdas M, Zhu L, et al. Oral advanced glycation endproducts (AGEs) promote insulin resistance and diabetes by depleting the antioxidant defenses AGE receptor1 and sirtuin 1. Proc Natl Acad Sci U S A 2012;109:15888-93.

22. Leung $C$, Herath $C B$, Jia $Z$, et al. Dietary glycotoxins exacerbate progression of experimental fatty liver disease. J Hepatol 2014;60:832-8.

23. Zhuang A, Yap FY, Bruce C, et al. Increased liver AGEs induce hepatic injury mediated through an OST48 pathway. Sci Rep 2017;7:12292.

24. Luevano-Contreras C, Garay-Sevilla ME, Wrobel K, et al. Dietary advanced glycation end products restriction diminishes inflammation markers and oxidative stress in patients with type 2 diabetes mellitus. J Clin Biochem Nutr 2013;52:22-6.

25. Uribarri J, Cai W, Ramdas $\mathrm{M}$, et al. Restriction of advanced glycation end products improves insulin resistance in human type 2 diabetes: potential role of AGER1 and SIRT1. Diabetes Care 2011;34:1610-6.

26. Uribarri J, He JC. The low AGE diet: a neglected aspect of clinical nephrology practice? Nephron 2015;130:48-53.

27. Friedman M. Nutritional consequences of food processing. Forum Nutr 2003;56:350-2.

28. Reddy $M B$, Love $M$. The impact of food processing on the nutritional quality of vitamins and minerals. Adv Exp Med Biol 1999;459:99-106. 


\section{Supplementary figures and tables}

A

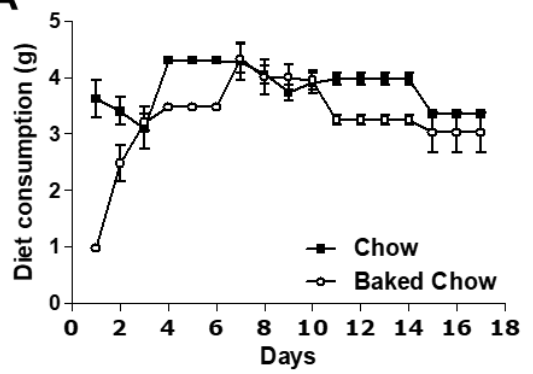

B

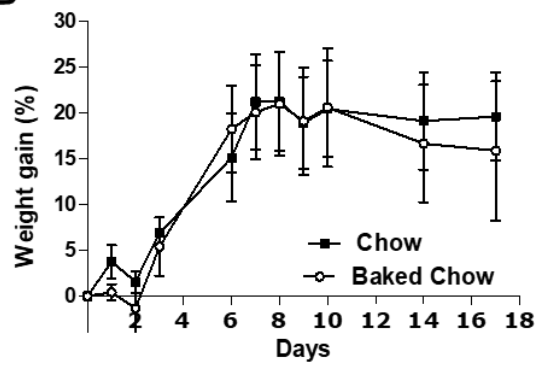

Suppl. Figure 3.1. Feeding mice a baked chow diet does not impact food intake or weight gain

(A) Amount of diet consumed in grams by the standard chow and baked chow-fed mice. (B) Percentage of bodyweight gain of the standard chow and baked chow-fed mice. All data are means \pm SEM. $n=4$.

Suppl. Table 3.1. Primer sequences

\begin{tabular}{lll}
\hline Gene & FW primer & RV primer \\
\hline Tnfa & TGGGAGTAGACAAGGTACAACCC & CATCTTCTCAAAATTCGAGTGACAA \\
\hline Crp & AGATCCCAGCAGCATCCATA & GGTGTTCAGTGGCTTCTTTGA \\
\hline Saa & ATTTTTCACGAGGCTTCC & CCCGAGCATGGAAGTATTTG \\
\hline Mpo & GGGCTGCTGGCTATCAATAC & TAGAGCTTCTCCCCATTCCA \\
\hline Nrf2 & CTTAGTCAGCGACAGAAGGAC & AGGCATCTTGTTTGGGATGTG \\
\hline F4/80 & GGATGTACAGATGGGGGATG & TCTGTGGTGTCAGTGCAGGT \\
\hline Mcp1 & TTAAAACCTGGATCGGAACCAA & GCATTAGCTTCAGATTTACGGGT \\
\hline Cyclophilin & TTCCTCCTTTCACAGAATTATTCCA & CCGCCAGTGCCATTATGG \\
\hline B2-Micro & CTTTCTGGTGCTTGTCTCACTGA & GTATGTTCGGCTTCCCATTCTC \\
\hline
\end{tabular}

Primer sequences used for hepatic gene expression analysis. 


\section{Chapter 4}

\section{RAGE deficiency does not affect non-alcoholic steatohepatitis and atherosclerosis in Western type diet- fed Idlr-/- mice}

Mitchell Bijnen, Nicky Beelen, Suzan Wetzels, José van de Gaar, Maria Vroomen, Erwin Wijnands, Jean L. Scheijen, Marjo P.H. van de Waarenburg, Marion J. Gijbels, Jack P. Cleutjens, Erik A.L. Biessen, Coen D.A. Stehouwer, Casper G. Schalkwijk and Kristiaan Wouters

Sci Rep. 2018 Oct 15;8(1):15256 


\section{Abstract}

Non-alcoholic fatty liver disease is a spectrum of liver diseases ranging from steatosis only to non-alcoholic steatohepatitis (NASH). The latter is characterized by hepatic inflammation, which increases the risk of cardiovascular disease. It is poorly understood which factors contribute to the onset of hepatic inflammation characterizing the progression from steatosis to NASH. Previously, we demonstrated increased advanced glycation endproducts (AGEs) in the livers of NASH patients. We hypothesise that AGEs play a key role in NASH development by activating their proinflammatory receptor, RAGE.

RAGE-deficient mice and wildtype littermates, both on Idlr $^{-/}$background, were fed a Western type diet (WTD) for 3 or 12 weeks. Flow cytometry, histology, gene expression and AGE measurements were performed to evaluate the effects of RAGE deficiency.

RAGE-deficient mice displayed reduced weight gain and visceral fat expansion compared to control mice. No difference in adipose tissue inflammation was observed between groups. RAGE deficiency did not affect WTD-induced monocytosis, circulating lipids or hepatic steatosis. WTDinduced hepatic neutrophil and macrophage accumulation and atherosclerotic plaque development was comparable between control and RAGE-deficient mice. No difference in AGE levels was observed.

RAGE does not seem to play a major role in the development of NASH or atherosclerosis in a hyperlipidemic mouse model. 


\section{Introduction}

Non-alcoholic fatty liver disease (NAFLD) is the most common liver disease, affecting $20-30 \%$ of the general population of the western world ${ }^{1}$. Its prevalence has risen in tandem with obesity, which is a key risk factor for NAFLD. Obesity increases the risk of developing NAFLD 3.5-fold and was shown to contribute to hepatic inflammation ${ }^{2-5}$. This higher risk is attributed to alterations in glucose and lipid metabolism as well as lipid-induced chronic systemic inflammation ${ }^{4}$. A more advanced and severe form of NAFLD is nonalcoholic steatohepatitis (NASH), which is characterized by hepatic lipid accumulation (steatosis) in combination with hepatic inflammation ${ }^{3}$. NASH can cause extensive hepatic fibrosis and cirrhosis, leaving only liver transplantation as an option for these patients ${ }^{6}$. In addition, NASH is linked to cardiovascular disease (CVD) with over five times as many NASH patients dying from CVD instead of liver-related causes $^{6,7}$. Furthermore, long-term survival of CVD-related diseases is lower in NASH patients compared to NAFLD patients with steatosis only ${ }^{7}$. Therefore, it is of great importance to identify the triggers involved in the progression of simple hepatic steatosis to NASH.

Liver-resident macrophages, the Kupffer cells, play an important role in liver injury, pathogen defence and thus hepatic inflammation. Many factors may contribute to hepatic inflammation and Kupffer cell activation, such as an abundance of liver fat and cholesterol, circulating inflammatory cytokines, oxidative stress and advanced glycation endproducts (AGEs) ${ }^{8,9}$. AGEs are formed by the reaction of reduced sugars with amino groups of proteins and their formation is a consequence of normal metabolism ${ }^{10}$. Hyperlipidaemia, hyperglycaemia, and (inflammation induced) oxidative stress can all contribute to the formation of AGEs. Indeed, AGE accumulation in plasma and tissue is associated with obesity, diabetes and atherosclerosis, an important cause of $C^{11-13}$. We previously showed that $\mathrm{N}^{\varepsilon_{-}}$ (carboxymethyl)lysine (CML), an important AGE, accumulates in human livers and is linked to $\mathrm{NASH}^{9}$. In addition, we demonstrated that CML exerts proinflammatory effects on hepatocytes via the receptor of AGEs, RAGE' . RAGE is a cell surface receptor capable of recognizing multiple ligands (AGEs, HMGB1, S100 proteins), it is expressed on hepatocytes, stellate cells, 
lymphocytes, endothelial cells, monocytes and macrophages including Kupffer cells ${ }^{14,15}$. Therefore, AGE-induced activation of RAGE potentially contributes to the onset of inflammation in NASH. Previous studies have shown reduced inflammation, reduced atherosclerotic plaque size and improvement of insulin sensitivity in RAGE-deficient mice ${ }^{16-18}$. In the current study, we investigated whether RAGE is causally linked to hepatic inflammation and atherosclerosis development during Western type diet (WTD)-induced NASH development by comparing control Idlr ${ }^{-/-}$mice with RAGE-deficient $\mid \mathrm{dll}^{-1}$ mice.

\section{Materials and methods}

\section{Animal study}

Female 9-11 week old C57BL/6 $\mathrm{Idlr}^{-1-}$ (henceforth referred to as WT) and

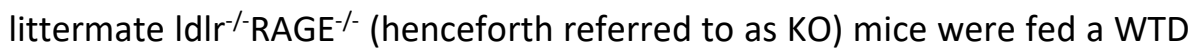
(21\% milk butter, $0.2 \%$ cholesterol, $46 \%$ carbohydrates (of which $40,5 \%$ sucrose) and $17 \%$ casein; SDSdiets \#824171) for $3(n=7)$ or 12 weeks $(n=11$ 12) after which they were sacrificed using $\mathrm{CO}_{2} / \mathrm{O}_{2}$ inhalation followed by exsanguination via cardiac puncture. WTD feeding strongly and rapidly induces hepatic steatosis and inflammation, main hallmarks of $\mathrm{NASH}$, and atherosclerosis in $\mathrm{Idll}^{-/-}$mice ${ }^{19,20}$. Considering the abundance of previous studies using this model show that this model displays hepatic steatosis and inflammation, we only investigated the role of RAGE in WTD-fed mice ${ }^{5,19-22}$. Standard chow fed mice, which develop neither atherosclerosis nor NASH, were therefore not included due to ethical reasons ${ }^{5,19-22}$. The RAGE ${ }^{-1}$ mice used for breeding were a generous gift from Prof. Dr. P. P. Nawroth (Heidelberg University). All performed experiments were approved by the Animal Experiments Committee of Maastricht University and in compliance with the relevant guidelines from the Directive 2010/63/EU of the European Parliament on the protection of animals used for scientific purposes.

\section{Flow cytometry}

During the study, blood was taken from the hind limb using EDTA lined Microvette tubes (Sarstedt) and at sacrifice by cardiac puncture. Blood was transferred to a Trucount absolute count tube (BD) containing FC-receptor 
block (anti-CD16/CD32) before adding a cocktail of antibodies (Suppl. table 4.1). Hereafter, erythrocytes were lysed using lysisbuffer (8.4 g/L NH${ }_{4} \mathrm{CL}$ and $0.84 \mathrm{~g} / \mathrm{L} \mathrm{NaHCO}_{3}$ in $\mathrm{H}_{2} \mathrm{O}, \mathrm{pH} 7.4$ ) before measurement. Flow cytometry was performed using a BD FACSCANTO II running FACS Diva 8.0.1 software which was also used for all analyses. The FACS gating strategy can be found in the supplementary materials (Suppl. Fig. 4.1).

\section{RNA Isolation, cDNA Synthesis and qRT-PCR}

RNA was isolated from liver, visceral fat and aortic arch tissue using Trizol reagent (Ambion) before CDNA synthesis using the iScript CDNA synthesis kit (170-8891; Bio-Rad, Hercules, USA) following manufacturer's instructions. Gene expression was determined using IQ SensiMix SYBR master mix (Bioline, London, UK) on a CFX96 Touch with CFX manager software (Biorad). The geometric mean of two reference genes, Cyclophillin and Beta2microglobulin, was used as reference and the $\Delta \Delta C T$ method was employed to calculate expression levels ${ }^{23}$. Primer sequences are given in supplementary table 4.2 .

\section{Histology}

Frozen liver sections $(7 \mu \mathrm{m})$ were stained using antibodies against macrophages (rat anti-mouse F4/80, clone Cl:A3-1; Acris antibodies) and neutrophils (custom antibody; clone NIMP-R14) as previously described ${ }^{20,24}$. As negative controls, the primary antibody was omitted. Photographs were captured using a Zeiss microscope (Axioskop 40) with a Jenoptik camera and Progress Capture Pro 2.8.8 software. Neutrophils were counted in 6 microscopical views (200x magnification) of the liver while hepatic macrophage content was quantified as percentage of $\mathrm{F} 4 / 80^{+}$pixels of the total area using Photoshop CS3 (v10.0). Liver paraffin sections $(4 \mu \mathrm{m})$ were stained for Haematoxylin and Eosin (H\&E; Sigma-Aldrich) and photos were taken (200x magnification) using the setup described above. General hepatic inflammation (immune cell count and clustering, hepatocyte injury) was scored in masked fashion by an experienced mouse pathologist using the H\&E-stained sections. Aortic roots were cryosectioned $(7 \mu \mathrm{m})$ and stained with H\&E or Sirius Red for plaque area and collagen content quantification, respectively. These sections were analysed blindly using computerized 
morphometry to determine plaque size and collagen content (Leica QWin V3, Cambridge, UK). Atherosclerotic plaque phenotype was rated small, moderate or advanced based on fibroblasts, necrosis, foam cells, general inflammation, endothelial adhesion, granulocytes, adventitia influx and calcification by an experienced mouse pathologist using the H\&E sections as previously described ${ }^{25}$.

\section{Hepatic and plasma cholesterol and triglyceride measurements}

Livers were homogenized in $250 \mu$ SET buffer ( 250 mM sucrose, 2 mM EDTA and $10 \mathrm{mM}$ Tris) using a Mini-bead beater homogenizer (Biospec). Hepatic and plasma levels of cholesterol and triglycerides were measured using a colourimetric test (Cholesterol FS'10 and Triglycerides FS 5'ecoline, Diagnostic System $\mathrm{GmbH}$, Holzheim, Germany) as described previously ${ }^{26}$. Liver lipid levels were corrected for protein content by performing a BCA assay (BCA kit, Sigma-Aldrich, Germany) according to the manufacturer's instructions.

\section{$\alpha$-dicarbonyls and AGE measurements}

Livers were homogenized in SET buffer as described above. Methylglyoxal (MGO), glyoxal (GO), 3-deoxyglucosone (3-DG) and free $\mathrm{N}^{\varepsilon}$ (carboxymethyl)lysine (CML), $\mathrm{N}^{\varepsilon}$-(1-carboxyethyl)lysine (CEL), and $\mathrm{N}^{\delta}-(5-$ hydro-5-methyl-4-imidazolon-2-yl)-ornithine (MG-H1) were analysed in plasma and liver homogenates by ultra-performance liquid chromatography tandem mass spectrometry (UPLC MS/MS) as previously described ${ }^{27,28}$.

\section{Bone marrow-derived macrophages (BMDMs) culturing}

Femur and tibia were obtained from C57BL/6 Idlr ${ }^{-/-}$(WT) and littermate $\mathrm{Idl} \mathrm{r}^{-/}$ $\mathrm{RAGE}^{-/-}(\mathrm{KO})$ mice and bone marrow was flushed using PBS. The bone marrow was filtered into a single cell suspension before centrifuging and resuspending the cells in RPMI 1640 (Greiner 31870-074) medium containing 15\% L929 cell conditioned medium, 10\% Fetal Calf Serum (Hyclone) and 1\% Glutamine pen/strep (Greiner). The cells were then plated and cultured for 7 days, necessary to allow complete differentiation to BMDMs before discarding all non-adherent cells. BMDMs were incubated for 24 hours before stimulation with TNF (500 U/ml), Lipopolysaccharide (LPS; $10 \mathrm{ng} / \mathrm{ml}$ ) 
or IFN-y $(100 \mathrm{U} / \mathrm{ml})$ for 2 hours. After stimulation, BMDMs were washed with PBS and harvested using Tri reagent (Sigma-Aldrich) for RNA isolation. Experiments were performed in triplicate.

\section{Statistical Analysis}

Data was tested for significance using a two-tailed Student's T-test when comparing two groups or a one-way ANOVA with Tukey's multiple comparison post-hoc test when comparing multiple groups. GraphPad Prism 5.01 (La Jolla California, USA) was used to perform all data analyses, all data was expressed as the mean \pm SEM and were considered statistically significant at $P \leq 0.05$.

\section{Results}

RAGE deficiency leads to reduced weight gain and visceral adipose tissue without affecting circulating lipids or monocytosis

WTD-induced weight gain was markedly reduced in RAGE-deficient mice in comparison to control mice (Fig. 4.1A). Visceral adipose tissue (vAT) expansion was reduced in RAGE-deficient mice, while subcutaneous adipose tissue was not different between control mice and mice lacking RAGE (Fig. 4.1B, C). RAGE deficiency did not impact plasma cholesterol and triglyceride levels (Fig. 4.1D). WTD feeding triggers monocytosis increasing circulating monocyte levels ${ }^{29}$. However, flow cytometry revealed no difference between control and RAGE-deficient mice in total circulating monocytes or "proinflammatory" Ly6c ${ }^{+}$and "patrolling" Ly6c" monocyte subsets (Fig. 4.1E). All other circulating immune cells were comparable between the groups (Suppl. Table 4.3). Similar results were obtained after 3 weeks of WTD feeding (Suppl. Fig. 4.2A-C, Suppl. Table 4.4).

\section{RAGE deficiency does not affect hepatic steatosis or inflammation}

WTD feeding strongly and rapidly induces hepatic steatosis and inflammation, main hallmarks of NASH, in Idlr ${ }^{-1-}$ mice $^{19,}{ }^{20}$. Indeed, after 12 weeks of WTD feeding, the liver was very steatotic and contained high, but 
A

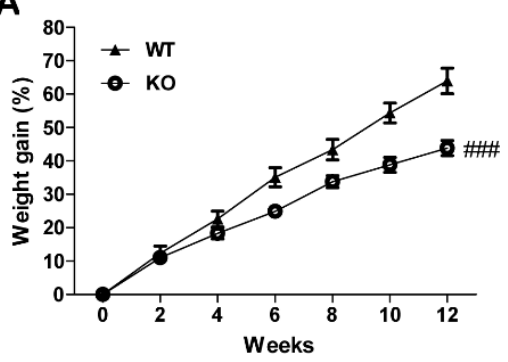

D

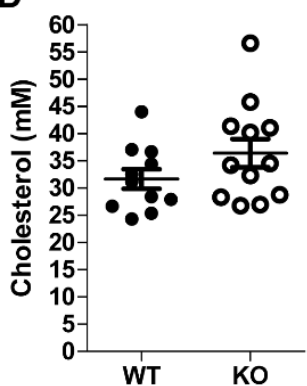

B

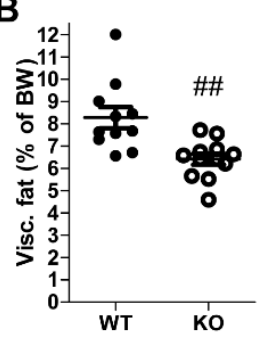

C

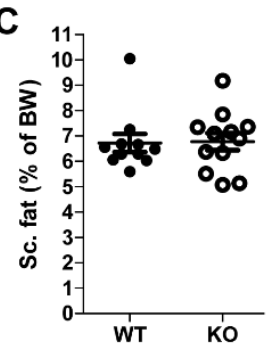

Figure 4.1. RAGE deficiency reduced weight gain and visceral adipose tissue but did not affect circulating lipids or monocytosis

(A-C) Bodyweight gain over time in the 12 weeks WTD-feeding experiment (A) and VAT (B) or SAT (C) as percentage of bodyweight. (D) Plasma cholesterol and triglyceride levels after 12 weeks of WTD feeding. (E) Total circulating monocyte levels and subdivision in Ly6c+ and Ly6cmonocytes measured by flow cytometry and presented as cells $/ \mu$ lafter 12 weeks of WTD feeding. All data are means \pm SEM. \#\#P $<0.01$, \#\#\# $<0.001$ vs WT. $n=11-12$.

similar levels of cholesterol and triglycerides in control and RAGE-deficient mice (Fig. 4.2A, B). RAGE deficiency was confirmed by measurement of RAGE hepatic gene expression, which was not detectable in the RAGE-deficient mice (Suppl. Fig. 4.3A). Lobular inflammation and immune cell presence was comparable in control and RAGE-deficient mice after 12 weeks of WTD (Fig. 4.2C). Hepatic neutrophil infiltration and macrophage accumulation was clearly present after WTD feeding, but similar in control and RAGE-deficient mice (Fig. 4.2D-E). Correspondingly, total liver F4/80 (general macrophage marker) and $C d 11 b$ (marker of monocytes/macrophages and neutrophils) gene expression levels were comparable between groups (Fig. 4.2F). To further phenotype the 

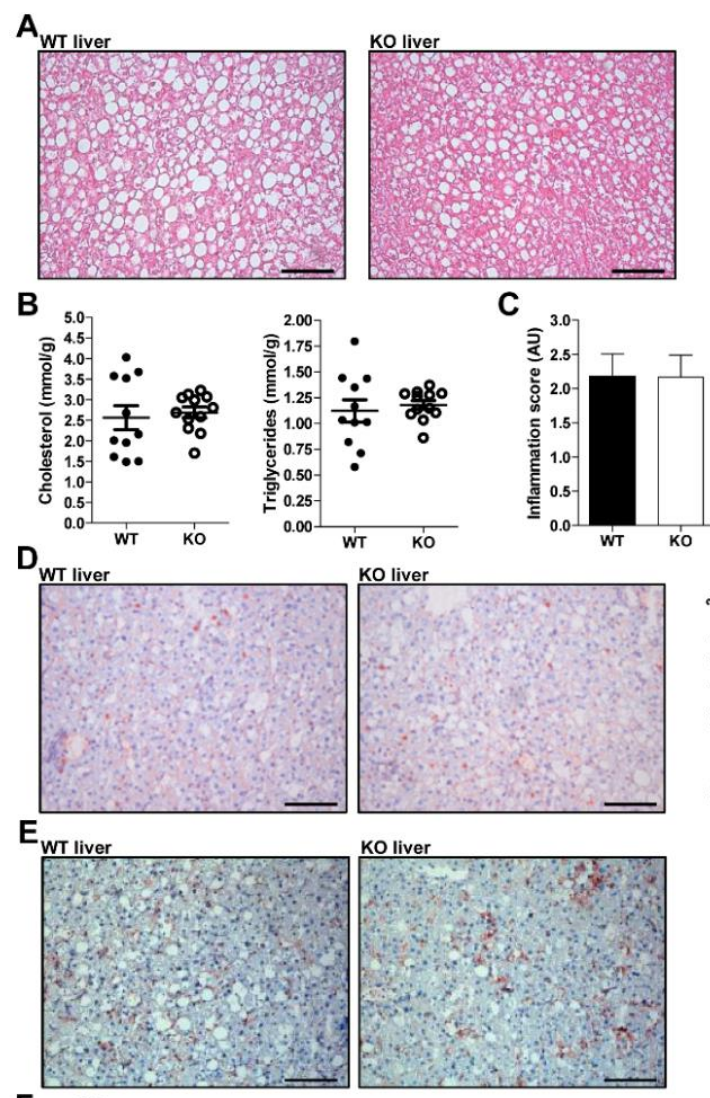

KO liver
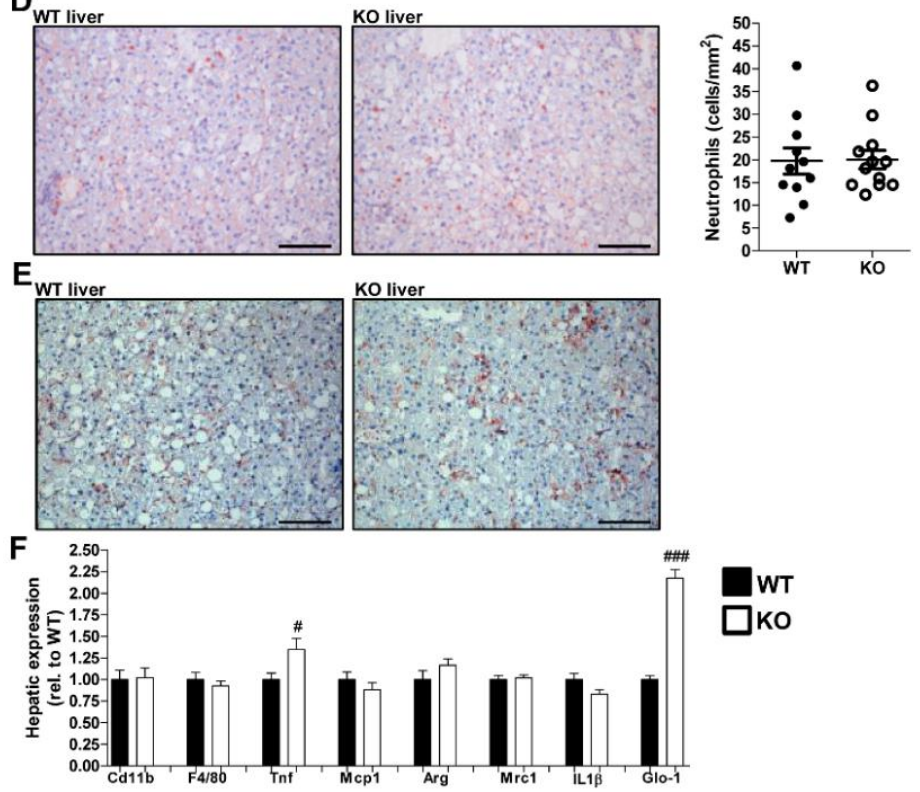

Figure 4.2. RAGE deficiency does not affect hepatic steatosis, neutrophil infiltration or macrophage accumulation

(A, B) Representative images of the liver stained with H\&E (A; 200x magnification) and hepatic cholesterol and triglyceride levels after 12 weeks of WTD feeding (B). (C) Hepatic inflammation scored (1, 2, 3 or 4) by an experienced pathologist based on lobular inflammation and immune cell numbers after 12 weeks of WTD feeding. (D) Representative photos and quantification of immunohistochemical neutrophil staining (NIMP-R14 antibody; 200x magnification) in the liver after 12 weeks of WTD. (E) Representative images of hepatic macrophage staining (F4/80 antibody; 200x magnification) after 12 weeks of WTD feeding. (F) Total hepatic gene expression levels measured of inflammatory and immune cell specific markers after 12 weeks 
of WTD feeding. All data are means \pm SEM. \#P $<0.05$, \#\#\#P<0.001 vs WT. $n=11-12$. Scalebars $100 \mu \mathrm{m}$.

accumulated macrophages, Tnf and Mcp1 (proinflammatory markers) and Arg1 and Mrc1 (markers of anti-inflammatory macrophages) were measured. Tnf expression was significantly higher in RAGE-deficient mice compared to control mice while the other markers were not affected by RAGE deficiency. Expression of Glyoxalase-1 (Glo-1), the rate-limiting enzyme in the detoxification of the major AGE precursor $\mathrm{MGO}^{30}$, was clearly higher in RAGE-deficient mice (Fig. 4.2F). After 3 weeks of WTD feeding, all expression levels were similar between groups except for Glo-1 expression, which was again twice as high in the RAGE-deficient mice compared to the control mice (Suppl. Fig. 4.3B-F).

\section{RAGE does not affect visceral adipose tissue inflammation}

RAGE deficiency affected weight gain and visceral fat expansion after 12 weeks of WTD feeding (Fig. 4.1A, B). Therefore, we investigated whether a general macrophage marker, F4/80, as well as a proinflammatory, Cd11c, and anti-inflammatory, Mrc1, macrophage marker were different between control and RAGE-deficient mice in vAT. All these markers were similar between groups. In line, the expression of Mcp1 and Tnf, two inflammatory cytokines, was comparable between both groups of mice (Suppl. Fig. 4.4A).

\section{Atherosclerosis development is not affected by the presence of RAGE}

WTD feeding does not only induce hepatic steatosis and inflammation in Idlr /- mice, but also atherosclerosis development, which was assessed after 12 weeks of diet. Both the control and RAGE-deficient mice developed significant plaques in the aortic root, but they did not differ in plaque size (Fig. 4.3A, B). In line, plaque phenotype (based on fibroblasts, necrosis, foam cells, general inflammation, endothelial adhesion, granulocytes, adventitia influx and calcification) and collagen content were comparable between both groups (Fig. 4.3C, D). F4/80 expression in the aortic arch did not differ between control and RAGE-deficient mice, suggesting equal macrophage content. Proinflammatory markers, such as Mcp1, Tnf, IL6, IL1 $\beta$ and $C d 11 c$, were also similar between control and RAGE-deficient mice. Aortic 
expression of Col1a1 was comparable between the groups as expected based on the plaque collagen content (Fig. 4.3E).
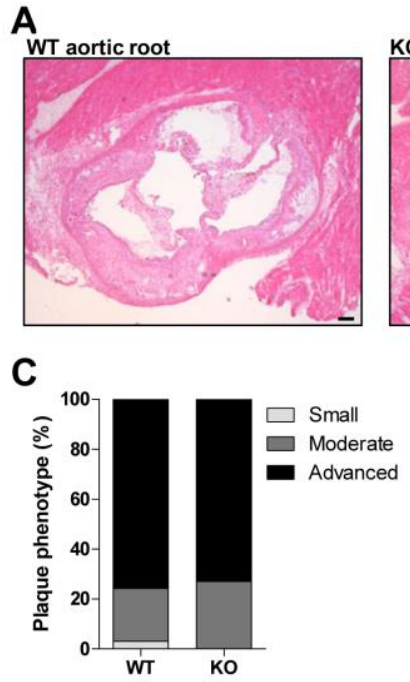
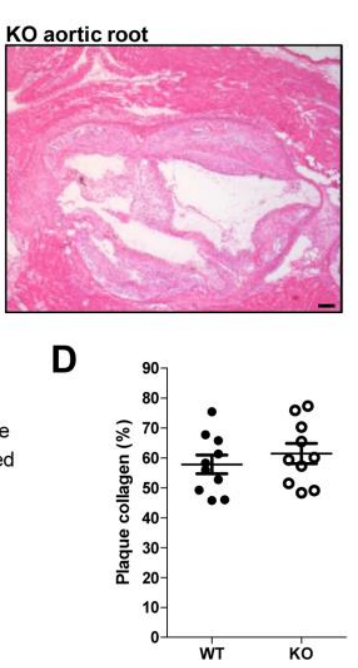

B

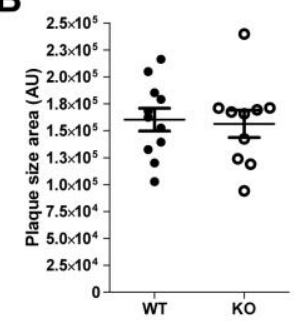

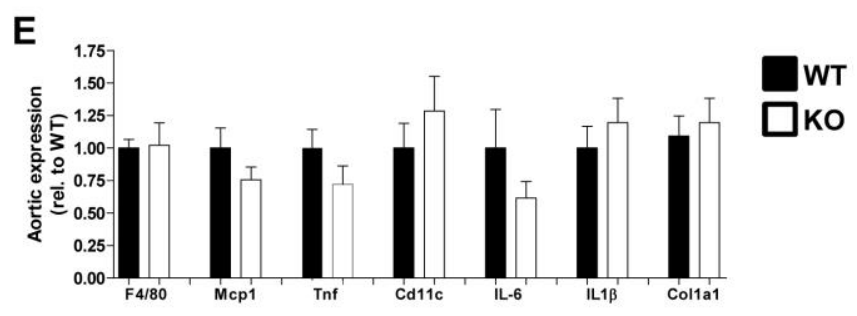

Figure 4.3 Atherosclerotic plaque size and inflammatory state is unaffected by RAGE

(A, B) Representative pictures (A) of H\&E-stained aortic root plaques (40x magnification) and corresponding quantification of plaque size (B) after 12 weeks of WTD feeding. (C) Plaque phenotype score presented as percentage of each score. (D) Quantification of plaque collagen content presented as percentage of plaque size area. (E) Aortic arch gene expression levels of inflammatory and immune cell specific markers. All data are means \pm SEM. $n=11-12$. Scalebars $100 \mu \mathrm{m}$.

\section{RAGE does not contribute to inflammatory signalling in macrophages}

As we were unable to detect any differences between control and RAGEdeficient mice in NASH development, we investigated the contribution of RAGE to general macrophage inflammation. When stimulating both control (Idlr ${ }^{-/}$mice derived) and RAGE-deficient (Idlr ${ }^{-/} \mathrm{RAGE}^{-/-}$mice derived) macrophages with IFNy, TNF or LPS for 2 hours, expression of Tnf increased 
in a RAGE-independent manner (Fig. 4.4A). IL16 only increased after stimulation with TNF and LPS, but not IFNy and this increase was also comparable between control and RAGE-deficient macrophages (Fig. 4.4B). Lastly, inducible nitric oxide synthase (iNOS) expression was increased by all stimuli, but the increase due to TNF was only minor compared to IFNy or LPS stimulation. There was no difference between control and $\mathrm{RAGE}^{-/-}$-derived macrophages (Fig. 4.4C). RAGE expression was unaffected by all stimuli and was nearly undetectable in RAGE-deficient BMDMs (Fig. 4.4D).
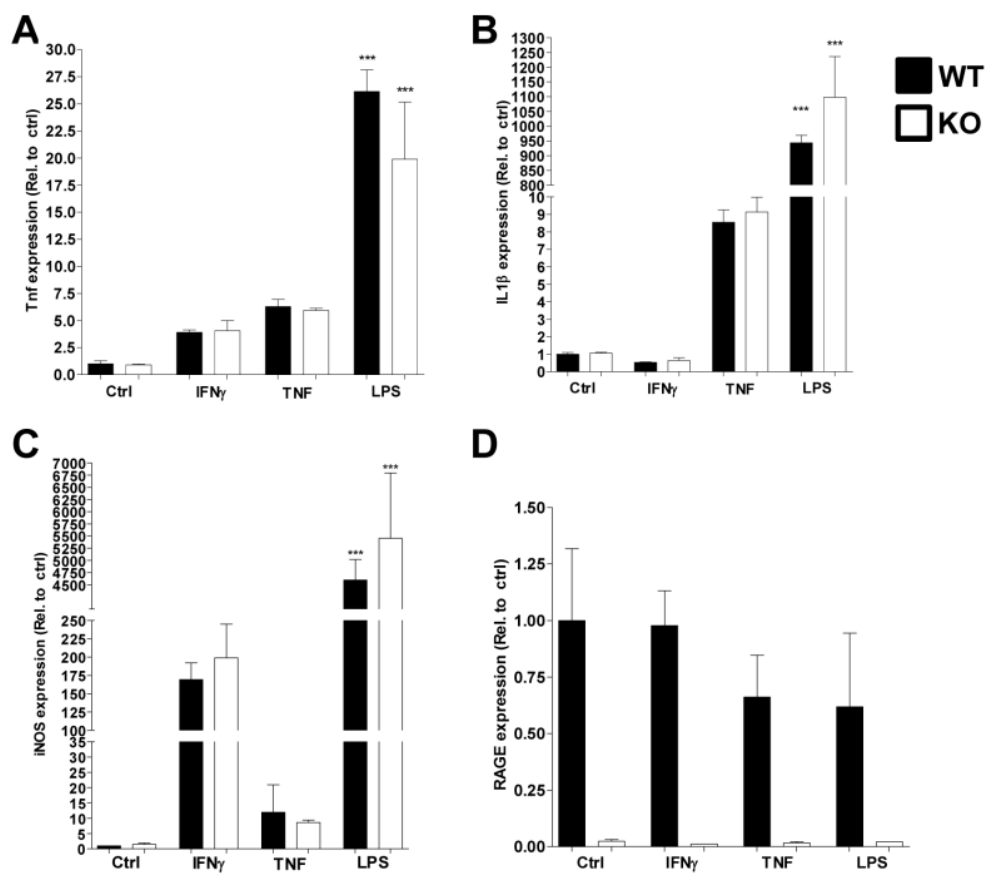

D

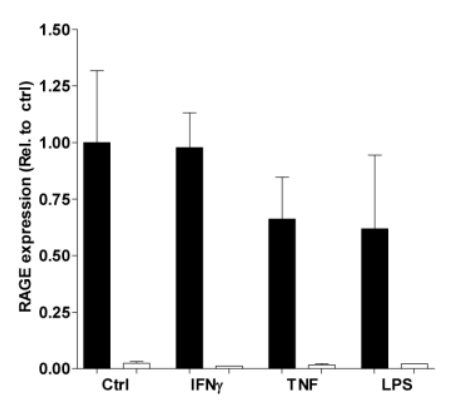

Figure 4.4. RAGE does not contribute to inflammatory signalling in macrophages

(A-D) Gene expression levels of $\operatorname{Tnf}(A), \operatorname{IL} 1 \beta(B)$, iNOS (C) and RAGE (D) after stimulation of

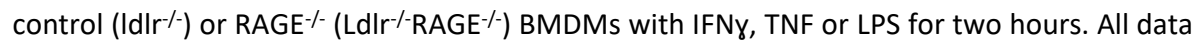
are means \pm SEM. ${ }^{* * *} \mathrm{P}<0.001$ vs control. $\mathrm{n}=3$.

\section{RAGE deficiency does not affect circulating and hepatic free AGEs}

Previous research showed RAGE-mediated trapping of CML in visceral adipose tissue of obese mice, which could induce inflammatory cytokine secretion $^{18}$. To explore whether RAGE deficiency affects hepatic AGE trapping, we measured circulating and hepatic $\alpha$-dicarbonyls and free AGE 
levels after 12 weeks of WTD feeding. Circulating and hepatic levels of MGO, GO and 3-DG were all comparable between control and RAGE-deficient mice. Plasma and liver free AGE levels were also unaffected by RAGE (Table 4.1). These results suggest RAGE-mediated trapping of CML, or other AGEs, does not occur in the liver.

Table 4.1. Circulating and hepatic $\alpha$-dicarbonyls and free AGEs are not affected by RAGE

\begin{tabular}{|l||c|c|}
\hline & WT (Mean \pm SEM) & KO (Mean \pm SEM) \\
\hline \hline Plasma MGO (nmol/L) & $1267 \pm 238$ & $853 \pm 125$ \\
\hline Plasma GO (nmol/L) & $4953 \pm 424$ & $5507 \pm 266$ \\
\hline Plasma 3-DG (nmol/L) & $2595 \pm 147$ & $2757 \pm 176$ \\
\hline & & \\
\hline Hepatic MGO (nmol/g) & $2987 \pm 169$ & $2930 \pm 200$ \\
\hline Hepatic GO (nmol/g) & $4676 \pm 380$ & $4923 \pm 477$ \\
\hline Hepatic 3-DG (nmol/g) & $11336 \pm 1553$ & $9980 \pm 1404$ \\
\hline & & \\
\hline Plasma CML (nmol/L) & $86,6 \pm 6,5$ & $74,6 \pm 5,6$ \\
\hline Plasma CEL (nmol/L) & $21,5 \pm 1,1$ & $22,7 \pm 0,9$ \\
\hline Plasma MG-H1 (nmol/L) & $8,4 \pm 1,7$ & $8,9 \pm 1,2$ \\
\hline & & \\
\hline Hepatic CML (nmol/g) & $2,53 \pm 0,11$ & $2,49 \pm 0,08$ \\
\hline Hepatic CEL(nmol/g) & $5,28 \pm 0,44$ & $4,49 \pm 0,17$ \\
\hline Hepatic MG-H1 (nmol/g) & $0,72 \pm 0,06$ & $0,63 \pm 0,06$ \\
\hline
\end{tabular}

The $\alpha$-dicarbonyls MGO, GO and 3-DG measured in plasma and liver after 12 weeks of WTD feeding. In addition, the free CML, CEL and MG-H1 levels in the circulation and the liver after 12 weeks of WTD. $n=11-12$.

\section{Discussion}

Our study showed no key role of RAGE in the development of NASH or atherosclerosis in hyperlipidemic mice. No effects of RAGE deficiency on systemic or hepatic inflammation or on hepatic steatosis were observed. In addition, RAGE deficiency did not impact inflammatory gene expression in the adipose tissue or aorta and there was no effect on atherosclerotic plaque 
size or phenotype. Lastly, RAGE deficiency did not affect circulating or hepatic levels of AGEs.

RAGE-deficient mice exhibited reduced weight gain, likely as a result of a slight difference in visceral fat expansion. A similar finding was reported by Ueno et al. in a different model of atherosclerosis development (apoE $\left.{ }^{-/}\right)$ showing reduced weight gain and reduced visceral fat expansion in RAGEdeficient mice ${ }^{31}$. Song et al. also showed this effect in high fat diet-induced obesity in RAGE-deficient mice and linked it to increased energy expenditure and a reduction of $\mathrm{CD} 11 \mathrm{C}^{+}$macrophages in $\mathrm{VAT}^{32}$. We did not observe such a clear effect of RAGE deficiency on adipose tissue inflammation, possibly due to the difference in diets. The high fat diet used by Song et al. consists of $60 \%$ lard designed to greatly expand adipose tissue mass and cause recruitment of macrophages causing inflammation ${ }^{32,33}$. In contrast, we used WTD with $21 \%$ fat (milk butter) and $0.2 \%$ cholesterol, which induces mild obesity ${ }^{20,34}$. Therefore, any effects of RAGE on adipose tissue inflammation could differ between these models depending on the diets.

RAGE deficiency did not affect WTD-induced monocytosis. This is consistent with a study performed by Nagareddy et al. showing no effects on leukocytosis and also specifically monocytosis after transplanting RAGE ${ }^{-1}$ bone marrow to obese mice ${ }^{35}$. Without a clear effect on hyperlipidemiaassociated monocytosis, a role for RAGE on monocyte-derived macrophages in tissues such as the liver is less likely.

RAGE deficiency did not affect WTD-induced hepatic steatosis, neutrophil recruitment or macrophage accumulation. Comparable levels of steatosis were expected as no effects of RAGE on hepatic cholesterol or triglycerides storage have been described and RAGE has mainly been described as a protein important in inflammation ${ }^{36}$. Nonetheless, Daffu et al. did report a role for RAGE in macrophage cholesterol efflux via suppression of ABCG-1, leaving room for speculation on roles of RAGE outside of inflammatory signalling ${ }^{37}$.

Unexpectedly, we did not observe any effects of RAGE on hepatic inflammation at two different time points ( 3 and 12 weeks) and NASH development was unaltered by RAGE deficiency. Previous studies revealed a potential role of RAGE in several other immune-driven liver pathologies such as acetaminophen-induced liver injury, ischemic liver injury and cholestatic 
liver disease $\mathrm{e}^{38-40}$. Furthermore, our group and others showed an accumulation of AGEs and the presence of RAGE in murine and human livers and associations between serum AGE levels and liver pathology have been described $^{9,41,42}$. In addition, Leung et al. reported exacerbation of fatty liver disease including inflammatory markers when feeding rats a high AGE diet and these effects could be RAGE-dependent ${ }^{42}$. In spite of this previous research suggesting a potential role of RAGE in NAFLD and in particular $\mathrm{NASH}$, we did not find any clear effects of RAGE deficiency on NASH development in our model. However, there is a major distinction between the inflammatory responses when comparing models of liver injury with a model causing hepatic inflammation due to dietary cholesterol. In the first, major damage-associated molecular patterns (DAMPs) are released upon cell injury and death, triggering a strong and fast inflammatory response ${ }^{43}$. HMGB1, an important DAMP released upon cell damage, is known to bind and activate RAGE signalling and consequently trigger inflammation ${ }^{44,45}$. In the WTD-feeding (rich in cholesterol) model, hepatocytes are sensitized to TNF and FAS by cholesterol loading of the mitochondria ${ }^{46}$. In addition, Kupffer cells take up cholesterol and trap oxidized LDL triggering an immune response $^{20,47}$. Therefore, in WTD-induced NASH, DAMPs might be of less importance and are likely not released in high amounts due to a lack of substantial liver damage in this model ${ }^{19}$. Therefore, any role of RAGE in our model would likely be via effects of AGEs on RAGE. In agreement, Leung et al. showed no effects of RAGE deficiency on NAFLD unless hepatic AGEs were strongly increased by feeding mice a baked diet which contained an increased amount of CML, a proven ligand of RAGE ${ }^{48}$.

We previously reported involvement of RAGE in trapping CML in visceral adipose tissue of obese mice resulting in inflammation and in reduced circulating CML levels ${ }^{18}$. In the current study using WTD-fed mice, circulating and hepatic CML levels were unaffected by RAGE deficiency. These observations indicate that $\mathrm{CML}$ trapping does not occur in the liver during NASH development, possibly explaining why we find no role for RAGE in the development of hepatic inflammation. RAGE-mediated trapping and inflammation appears to be confined to expanding adipose tissue during the development of obesity ${ }^{18}$. 
RAGE-deficient mice displayed a twofold higher expression level of Glo-1 in the liver corresponding with an earlier finding by Reiniger et al. showing a higher level of Glo- 1 in the kidney of RAGE-deficient diabetic mice ${ }^{49}$. Glo- 1 is the rate-limiting enzyme in the detoxification of the major AGE precursor MGO. However, the observed higher levels of Glo-1 expression did not impact hepatic MGO levels in our study. In contrast, Reiniger et al. showed a decrease of MGO levels in the kidney of RAGE-deficient mice, but the observed decrease by Reiniger et al. was only observed in diabetic mice and not in their non-diabetic control mice ${ }^{49}$. Previous work by our group showed no effects of Glo-1 overexpression on atherosclerosis ${ }^{30}$. In line, the elevated Glo-1 expression induced by RAGE deficiency as observed in the current study did not impact atherosclerosis.

Corresponding with our observation that monocytosis and hepatic inflammation were unaffected by RAGE deficiency, we did not observe an effect of RAGE on atherosclerotic plaque size or plaque inflammatory gene expression. Previous research did report effects of RAGE on atherosclerosis, mainly in diabetes-induced atherosclerosis in which the pathogenesis is different from the WTD-driven atherosclerosis ${ }^{50}$. However, Sun et al. investigated the effects of RAGE deficiency on atherosclerosis in a similar model, the Idlr $^{-/}$mouse fed a high fat diet containing cholesterol ${ }^{17}$. A main difference between the used diets is cholesterol levels $(0.15 \%$ in their study instead of the $0.20 \%$ in our study) and fat content (36.2\% in their study and not $21 \%$ as in our study). Alternatively, discrepancies might also be explained by other diet components (vitamins, minerals, etc.), genetic background, health status and even microflora.

In the Idlr-- mouse fed a WTD, the model for NASH used in this study, hepatic steatosis and inflammation occurs rapidly. Other, mainly late stage aspects of NASH, such as fibrosis and liver damage characterised by hepatocyte ballooning are mild ${ }^{19,20}$. When liver damage does occur in NASH and DAMPs, e.g. HMGB1, are released, RAGE could have a superior role to play in aggravating hepatic inflammation.

In conclusion, RAGE does not seem to play a major role in the development of NASH in hyperlipidemic mice. However, we cannot rule out that AGEs, via other mechanisms, play a role in NAFLD. Their effect on the inflammatory 
aspect of NAFLD needs to be further investigated, preferably by inhibiting AGE formation or altering dietary AGE intake.

\section{Acknowledgements}

We would like to thank Prof. Dr. P. P. Nawroth (Heidelberg University, Heidelberg, Germany) for generously providing the RAGE ${ }^{-/}$mice used for breeding and generating the $\mathrm{Idl} \mathrm{r}^{-/} \mathrm{RAGE}^{-/}$mice. 


\section{References}

1. Williams CD, Stengel J, Asike MI, et al. Prevalence of nonalcoholic fatty liver disease and nonalcoholic steatohepatitis among a largely middle-aged population utilizing ultrasound and liver biopsy: a prospective study. Gastroenterology 2011;140:12431.

2. Nguyen DM, El-Serag HB. The epidemiology of obesity. Gastroenterol Clin North Am 2010;39:1-7.

3. Than NN, Newsome PN. A concise review of non-alcoholic fatty liver disease. Atherosclerosis 2015;239:192-202.

4. Li L, Liu DW, Yan HY, et al. Obesity is an independent risk factor for non-alcoholic fatty liver disease: evidence from a meta-analysis of 21 cohort studies. Obes Rev 2016;17:510-9.

5. Bijnen M, Josefs T, Cuijpers I, et al. Adipose tissue macrophages induce hepatic neutrophil recruitment and macrophage accumulation in mice. Gut 2017.

6. Festi D, Colecchia A, Sacco T, et al. Hepatic steatosis in obese patients: clinical aspects and prognostic significance. Obes Rev 2004;5:27-42.

7. Ekstedt $M$, Franzen LE, Mathiesen UL, et al. Long-term follow-up of patients with NAFLD and elevated liver enzymes. Hepatology 2006;44:865-73.

8. Tailleux A, Wouters $K$, Staels B. Roles of PPARs in NAFLD: potential therapeutic targets. Biochim Biophys Acta 2012;1821:809-18.

9. Gaens KH, Niessen PM, Rensen SS, et al. Endogenous formation of Nepsilon(carboxymethyl)lysine is increased in fatty livers and induces inflammatory markers in an in vitro model of hepatic steatosis. J Hepatol 2012;56:647-55.

10. Schalkwijk CG, Miyata T. Early- and advanced non-enzymatic glycation in diabetic vascular complications: the search for therapeutics. Amino Acids 2012;42:1193-204.

11. Gaens KH, Stehouwer CD, Schalkwijk CG. Advanced glycation endproducts and its receptor for advanced glycation endproducts in obesity. Current opinion in lipidology 2013;24:4-11.

12. Hanssen NM, Beulens JW, van Dieren S, et al. Plasma advanced glycation end products are associated with incident cardiovascular events in individuals with type 2 diabetes: a case-cohort study with a median follow-up of 10 years (EPIC-NL). Diabetes 2015;64:257-65.

13. Hanssen NM, Wouters K, Huijberts MS, et al. Higher levels of advanced glycation endproducts in human carotid atherosclerotic plaques are associated with a rupture-prone phenotype. Eur Heart J 2014;35:1137-46.

14. Ramasamy R, Yan SF, Herold K, et al. Receptor for advanced glycation end products: fundamental roles in the inflammatory response: winding the way to the pathogenesis of endothelial dysfunction and atherosclerosis. Ann N Y Acad Sci 2008;1126:7-13.

15. Yue $\mathrm{S}$, Zhou HM, Zhu JJ, et al. Hyperglycemia and liver ischemia reperfusion injury: a role for the advanced glycation endproduct and its receptor pathway. Am J Transplant 2015;15:2877-87.

16. Soro-Paavonen A, Watson AM, Li J, et al. Receptor for advanced glycation end products (RAGE) deficiency attenuates the development of atherosclerosis in diabetes. Diabetes 2008;57:2461-9. 
17. Sun L, Ishida $T$, Yasuda $T$, et al. RAGE mediates oxidized LDL-induced proinflammatory effects and atherosclerosis in non-diabetic LDL receptor-deficient mice. Cardiovasc Res 2009;82:371-81.

18. Gaens KH, Goossens GH, Niessen PM, et al. Nepsilon-(carboxymethyl)lysinereceptor for advanced glycation end product axis is a key modulator of obesityinduced dysregulation of adipokine expression and insulin resistance. Arterioscler Thromb Vasc Biol 2014;34:1199-208.

19. Bieghs V, Van Gorp PJ, Wouters K, et al. LDL receptor knock-out mice are a physiological model particularly vulnerable to study the onset of inflammation in non-alcoholic fatty liver disease. PLoS One 2012;7:e30668.

20. Wouters K, van Gorp PJ, Bieghs V, et al. Dietary cholesterol, rather than liver steatosis, leads to hepatic inflammation in hyperlipidemic mouse models of nonalcoholic steatohepatitis. Hepatology 2008;48:474-86.

21. Subramanian S, Goodspeed L, Wang S, et al. Dietary cholesterol exacerbates hepatic steatosis and inflammation in obese LDL receptor-deficient mice. J Lipid Res 2011;52:1626-35.

22. Depner CM, Philbrick KA, Jump DB. Docosahexaenoic acid attenuates hepatic inflammation, oxidative stress, and fibrosis without decreasing hepatosteatosis in a Ldlr(-/-) mouse model of western diet-induced nonalcoholic steatohepatitis. J Nutr 2013;143:315-23.

23. Livak KJ, Schmittgen TD. Analysis of relative gene expression data using real-time quantitative PCR and the 2(-Delta Delta C(T)) Method. Methods 2001;25:402-8.

24. Huugen $\mathrm{D}$, Xiao $\mathrm{H}$, van Esch $\mathrm{A}$, et al. Aggravation of anti-myeloperoxidase antibodyinduced glomerulonephritis by bacterial lipopolysaccharide: role of tumor necrosis factor-alpha. Am J Pathol 2005;167:47-58.

25. van Vlijmen BJ, van den Maagdenberg AM, Gijbels MJ, et al. Diet-induced hyperlipoproteinemia and atherosclerosis in apolipoprotein E3-Leiden transgenic mice. J Clin Invest 1994;93:1403-10.

26. Shiri-Sverdlov R, Wouters K, van Gorp PJ, et al. Early diet-induced non-alcoholic steatohepatitis in APOE2 knock-in mice and its prevention by fibrates. J Hepatol 2006;44:732-41.

27. Hanssen NM, Engelen L, Ferreira I, et al. Plasma levels of advanced glycation endproducts Nepsilon-(carboxymethyl)lysine, Nepsilon-(carboxyethyl)lysine, and pentosidine are not independently associated with cardiovascular disease in individuals with or without type 2 diabetes: the Hoorn and CODAM studies. J Clin Endocrinol Metab 2013;98:E1369-73.

28. Scheijen JL, Schalkwijk CG. Quantification of glyoxal, methylglyoxal and 3deoxyglucosone in blood and plasma by ultra performance liquid chromatography tandem mass spectrometry: evaluation of blood specimen. Clinical chemistry and laboratory medicine : CCLM / FESCC 2013:1-7.

29. Swirski FK, Libby P, Aikawa E, et al. Ly-6Chi monocytes dominate hypercholesterolemia-associated monocytosis and give rise to macrophages in atheromata. J Clin Invest 2007;117:195-205.

30. Hanssen NM, Brouwers O, Gijbels MJ, et al. Glyoxalase 1 overexpression does not affect atherosclerotic lesion size and severity in ApoE-/- mice with or without diabetes. Cardiovasc Res 2014;104:160-70.

31. Ueno $\mathrm{H}$, Koyama $\mathrm{H}$, Shoji $\mathrm{T}$, et al. Receptor for advanced glycation end-products (RAGE) regulation of adiposity and adiponectin is associated with atherogenesis in apoE-deficient mouse. Atherosclerosis 2010;211:431-6. 
32. Song $F$, Hurtado del Pozo $C$, Rosario R, et al. RAGE regulates the metabolic and inflammatory response to high-fat feeding in mice. Diabetes 2014;63:1948-65.

33. van der Heijden RA, Sheedfar F, Morrison MC, et al. High-fat diet induced obesity primes inflammation in adipose tissue prior to liver in C57BL/6j mice. Aging (Albany NY) 2015;7:256-68.

34. Machado MV, Michelotti GA, Xie G, et al. Mouse models of diet-induced nonalcoholic steatohepatitis reproduce the heterogeneity of the human disease. PLoS One 2015;10:e0127991.

35. Nagareddy PR, Kraakman M, Masters SL, et al. Adipose tissue macrophages promote myelopoiesis and monocytosis in obesity. Cell Metab 2014;19:821-35.

36. Bierhaus $A$, Humpert PM, Morcos $M$, et al. Understanding RAGE, the receptor for advanced glycation end products. Journal of molecular medicine 2005;83:876-86.

37. Daffu G, Shen X, Senatus L, et al. RAGE Suppresses ABCG1-Mediated Macrophage Cholesterol Efflux in Diabetes. Diabetes 2015;64:4046-60.

38. Zeng S, Feirt N, Goldstein M, et al. Blockade of receptor for advanced glycation end product (RAGE) attenuates ischemia and reperfusion injury to the liver in mice. Hepatology 2004;39:422-32.

39. Ekong $\mathrm{U}$, Zeng $\mathrm{S}$, Dun $\mathrm{H}$, et al. Blockade of the receptor for advanced glycation end products attenuates acetaminophen-induced hepatotoxicity in mice. J Gastroenterol Hepatol 2006;21:682-8.

40. Goodwin M, Herath C, Jia Z, et al. Advanced glycation end products augment experimental hepatic fibrosis. J Gastroenterol Hepatol 2013;28:369-76.

41. Hyogo H, Yamagishi S, Iwamoto K, et al. Elevated levels of serum advanced glycation end products in patients with non-alcoholic steatohepatitis. J Gastroenterol Hepatol 2007;22:1112-9.

42. Leung $C$, Herath $C B$, Jia $Z$, et al. Dietary glycotoxins exacerbate progression of experimental fatty liver disease. J Hepatol 2014;60:832-8.

43. Huebener $P$, Pradere JP, Hernandez $C$, et al. The HMGB1/RAGE axis triggers neutrophil-mediated injury amplification following necrosis. J Clin Invest 2015;125:539-50.

44. Chen $R$, Hou $W$, Zhang $Q$, et al. Emerging role of high-mobility group box 1 (HMGB1) in liver diseases. Mol Med 2013;19:357-66.

45. Asavarut $P, \mathrm{Zhao} \mathrm{H}, \mathrm{Gu}$ J, et al. The role of HMGB1 in inflammation-mediated organ injury. Acta Anaesthesiol Taiwan 2013;51:28-33.

46. Mari M, Caballero F, Colell A, et al. Mitochondrial free cholesterol loading sensitizes to TNF- and Fas-mediated steatohepatitis. Cell Metab 2006;4:185-98.

47. Bieghs V, Walenbergh SM, Hendrikx T, et al. Trapping of oxidized LDL in lysosomes of Kupffer cells is a trigger for hepatic inflammation. Liver Int 2013;33:1056-61.

48. Leung C, Herath CB, Jia Z, et al. Dietary advanced glycation end-products aggravate non-alcoholic fatty liver disease. World J Gastroenterol 2016;22:8026-40.

49. Reiniger N, Lau K, McCalla D, et al. Deletion of the receptor for advanced glycation end products reduces glomerulosclerosis and preserves renal function in the diabetic OVE26 mouse. Diabetes 2010;59:2043-54.

50. Barlovic DP, Soro-Paavonen A, Jandeleit-Dahm KA. RAGE biology, atherosclerosis and diabetes. Clin Sci (Lond) 2011;121:43-55. 


\section{Supplementary figures and tables}

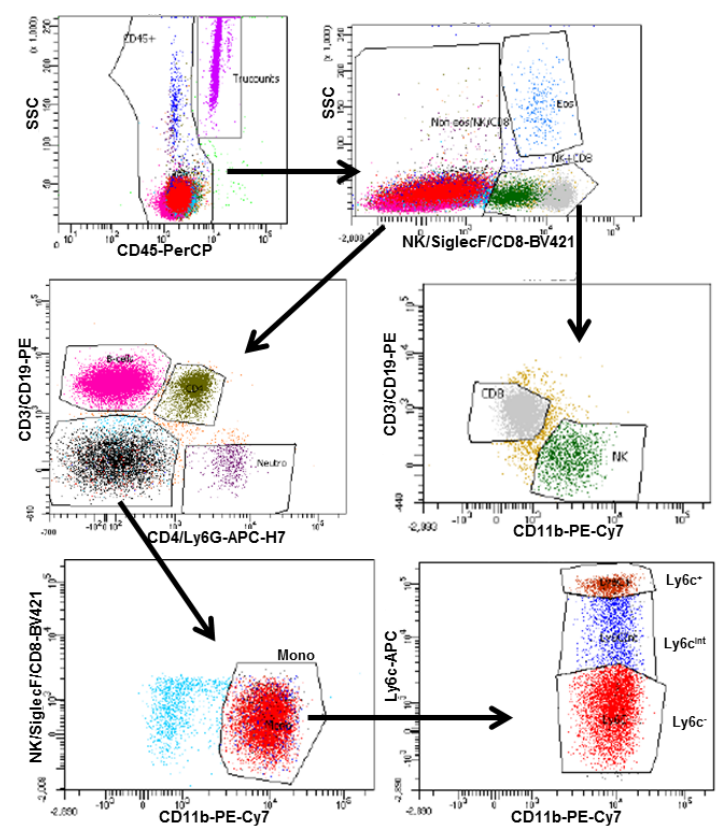

\section{Suppl. Figure 4.1. Gating strategy used for flow cytometry}

FACS plots showing gating strategy used for circulating cells starting from CD45+ cells. First, eosinophils (SSC+, SiglecF+), NK (SSC-, NK1.1+) and CD8+ T-cells (SSC-, CD8+) were separated and further divided into $\mathrm{CD} 8+\mathrm{T}$-cells $(\mathrm{CD} 3+)$ and NK-cells $(\mathrm{CD} 11 \mathrm{~b}+)$. All other cells were divided into B-cells (CD19+, CD4-, Ly6G-), CD4+ cells (CD3+, CD4+), neutrophils (CD3-, Ly6G+) and remaining cells. Monocytes were separated from these remaining cells using $C D 11 b$ before splitting all monocytes into Ly6c- (patrolling monocytes), Ly6cint and Ly6c+ (proinflammatory) monocytes based on their Ly6c expression. SSC, sidescatter.
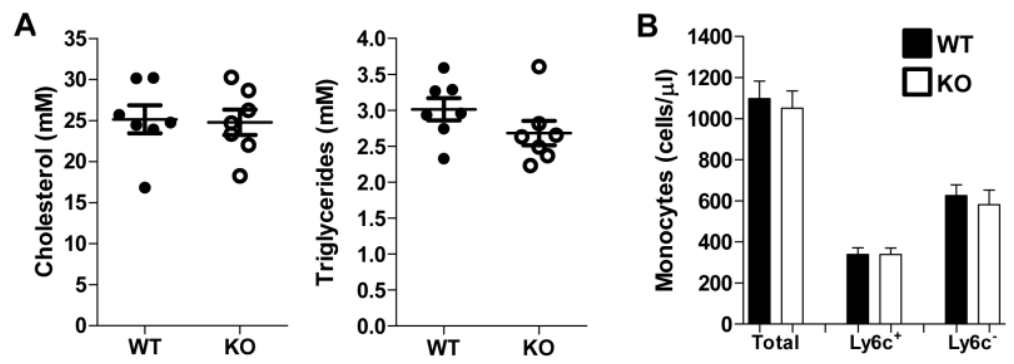

Suppl. Figure 4.2. RAGE does not affect plasma lipid levels or monocytosis

(A) Plasma cholesterol and triglyceride levels after 3 weeks of WTD feeding. (B) Total circulating monocyte levels and subdivision in Ly6C+ and Ly6C-monocytes measured by flow cytometry and presented as cells/ $\mu$ l after 3 weeks of WTD feeding. All data are means \pm SEM. $\mathrm{n}=7$. 

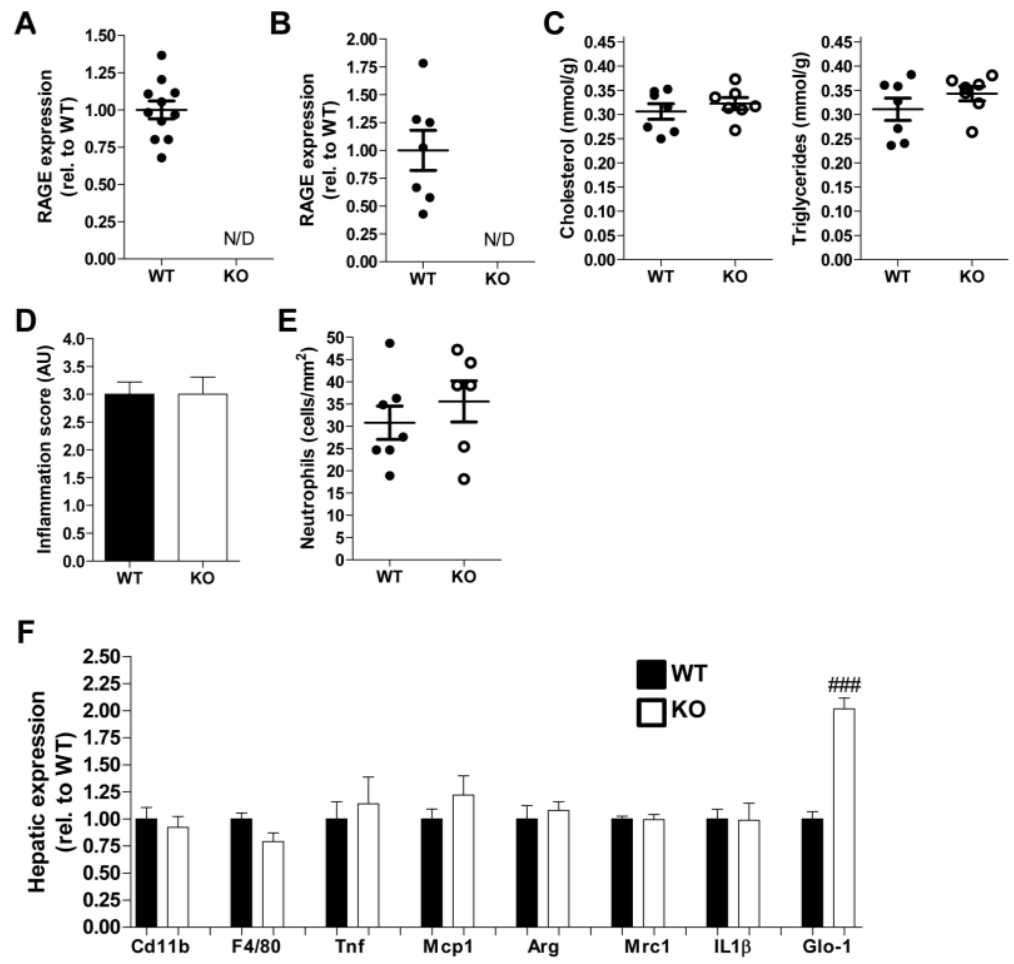

Suppl. Figure 4.3. Hepatic steatosis, neutrophil infiltration and macrophage accumulation were unaffected by RAGE

(A, B) Hepatic RAGE expression levels after $12(A ; n=11-12)$ and 3 weeks $(B ; n=7)$ of WTD feeding. (C) Hepatic cholesterol and triglycerides levels after 3 weeks of WTD feeding. (D) Hepatic inflammation score $(1,2,3$ or 4 based on lobular inflammation and immune cell numbers) after 3 weeks of WTD feeding. (E) Quantification of neutrophils in the liver after 3 weeks of WTD. (F) Hepatic gene expression levels of inflammatory and immune cell specific markers after 3 weeks of WTD feeding. N/D = not detectable. All data are means \pm SEM. \#\#\#P $<0.001$ vs WT. $\mathrm{n}=7$.

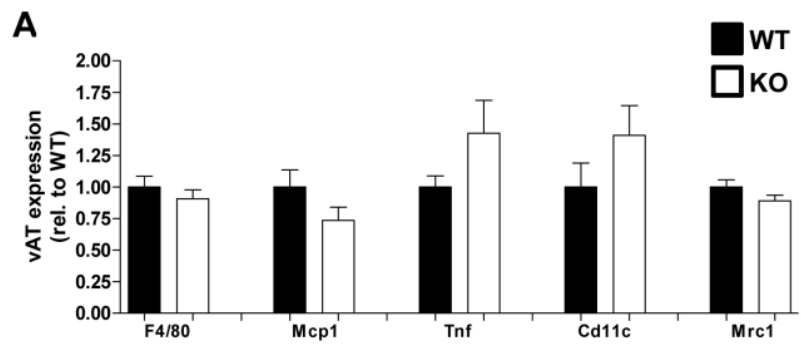

Suppl. Figure 4.4. RAGE deficiency does not influence visceral adipose tissue inflammation (A) Gene expression levels of inflammatory and immune cell specific markers in vAT after 12 weeks of WTD feeding. All data are means \pm SEM. $n=7$. 
Suppl. Table 4.1. Antibodies used for flow cytometry of circulating cells

\begin{tabular}{lll}
\hline Antibody & Label & Manufacturer \\
\hline \hline & & \\
\hline Blood mix & & \\
\hline CD16/32 & - & eBioscience \\
\hline CD45 & PerCP & Biolegend \\
\hline CD3 & PE & eBioscience \\
\hline NK1.1 & BV421 & Biolegend \\
\hline LY6G & APC-H7 & BD \\
\hline CD11B & PE-Cy7 & BD \\
\hline LY6C & APC & Miltenyi \\
\hline CD4 & APC-H7 & BD \\
\hline CD8 & eFluor450 & eBioscience \\
\hline CD19 & PE & eBioscience \\
\hline SIGLECF & BV421 & BD \\
\hline
\end{tabular}

Flow cytometry antibodies with fluorescent label and manufacturer.

Suppl. Table 4.2. Primer sequences

\begin{tabular}{lll}
\hline Gene & FW primer & RV primer \\
\hline \hline Mcp1 & TTAAAAACCTGGATCGGAACCAA & GCATTAGCTTCAGATTTACGGGT \\
\hline Tnf & CATCTTCTCAAAATTCGAGTGACAA & TGGGAGTAGACAAGGTACAACCC \\
\hline $\mathbf{F} \mathbf{4} \mathbf{8 0}$ & GGATGTACAGATGGGGGATG & TCTGTGGTGTCAGTGCAGGT \\
\hline IL1 $\boldsymbol{\beta}$ & CTGCAGCTGGAGAGTGTGGAT & CACTTTGCTCTTGACTTCTATCTTGTTG \\
\hline Cd11b & ATGGACGCTGATGGCAATACC & TCCCCATTCACGTCTCCCA \\
\hline Mrc1 & TGCCAAAAATTATTGATCCTGTAACT & CGCCGGCACCTATCACA \\
\hline Arg1 & CATGGGCAACCTGTGTCCTT & CGATGTCTTTGGCAGATATGCA \\
\hline Glo1 & ATGACGAGACTCAGAGTTACCACAA & TAGACATCAGGAACGGCAAATCC \\
\hline RAGE & GCTCGAATCCTCCCCAATG & TCCCCTCATCGACAATTCCA \\
\hline Cd11c & CTGGATAGCCTTTCTTCTGCTG & GCACACTGTGTCCGAACTCA \\
\hline IL-6 & TTCAACCAAGAGGTAAAAGATTTACATAA & CACTCCTTCTGTGACTCCAGCTT \\
\hline iN0S & GCCCCTGGAAGTTTCTCTTC & TTCTGTGCTGTCCCAGTGAG \\
\hline Col1a1 & TGTTCAGCTTTGTGGACCTC & TCAAGCATACCTCGGGTTTC \\
\hline Cyclophilin & TTCCTCCTTTCACAGAATTATTCCA & CCGCCAGTGCCATTATGG \\
\hline B2-Micro & CTTTCTGGTGCTTGTCTCACTGA & GTATGTTCGGCTTCCCATTCTC \\
\hline
\end{tabular}

Forward and reverse qPCR primer sequences of all measured genes. 
Suppl. Table 4.3. RAGE deficiency does not affect circulating immune cells

\begin{tabular}{|l|l|l|}
\hline Cell type & WT (Mean \pm SEM) & KO (Mean \pm SEM) \\
\hline \hline All immune cells $($ cells/ $\mu \mathrm{l})$ & $6268 \pm 499$ & $7309 \pm 824$ \\
\hline CD4 T-cells $($ cells $/ \mu \mathrm{l})$ & $590 \pm 53$ & $731 \pm 86$ \\
\hline CD8 T-cells $($ cells $/ \mu \mathrm{l})$ & $591 \pm 37$ & $625 \pm 72$ \\
\hline B-cells $($ cells $/ \mu \mathrm{l})$ & $2744 \pm 303$ & $3741 \pm 471$ \\
\hline Neutrophils $($ cells $/ \mu \mathrm{l})$ & $911 \pm 289$ & $1075 \pm 245$ \\
\hline NK-cells $($ cells $/ \mu \mathrm{l})$ & $425 \pm 77$ & $296 \pm 26$ \\
\hline Eosinophils $($ cells $/ \mu \mathrm{l})$ & $63,8 \pm 11,2$ & $109,3 \pm 27,3$ \\
\hline
\end{tabular}

Levels of circulating T-cells, B-cells, neutrophils, NK-cells and eosinophils measured by flow cytometry in cells/ $\mu$ lafter 12 weeks of WTD feeding. $n=11-12$.

Suppl. Table 4.4. Circulating immune cells are not affected by RAGE

\begin{tabular}{|l|l|l|}
\hline Cell type & WT (Mean \pm SEM) & KO (Mean \pm SEM) \\
\hline \hline All immune cells $($ cells/ $\mu \mathrm{l})$ & $10969 \pm 393$ & $12570 \pm 723$ \\
\hline CD4 T-cells (cells/ $\mu \mathrm{l})$ & $1656 \pm 124$ & $1832 \pm 139$ \\
\hline CD8 T-cells $($ cells/ $\mu \mathrm{l})$ & $1204 \pm 79$ & $1221 \pm 76$ \\
\hline B-cells $($ cells $/ \mu \mathrm{l})$ & $5448 \pm 213$ & $6929 \pm 456^{\#}$ \\
\hline Neutrophils $($ cells/ $\mu \mathrm{l})$ & $657 \pm 70$ & $684 \pm 97$ \\
\hline NK-cells $($ cells $/ \mu \mathrm{l})$ & $257 \pm 21$ & $230 \pm 18$ \\
\hline Eosinophils $(\mathrm{cells} / \mu \mathrm{l})$ & $138 \pm 16$ & $177 \pm 20$ \\
\hline
\end{tabular}

Levels of circulating T-cells, B-cells, neutrophils, NK-cells and eosinophils measured by flow cytometry in cells $/ \mu$ l after 3 weeks of WTD feeding. \#P $<0.05$ vs WT. $n=7$. 


\section{Part 2}

Gluttony 


\section{Chapter 5}

\section{Characterization of immune cells in human adipose tissue by using flow cytometry}

Mitchell Bijnen*, Suzan Wetzels*, Erwin Wijnands, Erik A.L. Biessen, Casper G. Schalkwijk and Kristiaan Wouters *These authors contributed equally

J Vis Exp. 2018 Mar 6;(133)

Video link: https://www.jove.com/video/57319/characterization-immunecells-human-adipose-tissue-using-flow 


\section{Abstract}

Infiltration of immune cells in the subcutaneous and visceral adipose tissue (AT) deposits leads to a low-grade inflammation contributing to the development of obesity-associated complications such as type 2 diabetes. To quantitatively and qualitatively investigate the immune cell subsets in human AT deposits, we have developed a flow cytometry approach. The stromal vascular fraction (SVF), containing the immune cells, is isolated from subcutaneous and visceral AT biopsies by collagenase digestion. Adipocytes are removed after centrifugation. The SVF cells are stained for multiple membrane-bound markers selected to differentiate between immune cell subsets and analyzed using flow cytometry. As a result of this approach, pro- and anti-inflammatory macrophage subsets, dendritic cells (DCs), B-cells, CD4 ${ }^{+}$and $\mathrm{CD} 8^{+} \mathrm{T}$-cells, and NK cells can be detected and quantified. This method gives detailed information about immune cells in AT and the amount of each specific subset. Since there are numerous fluorescent antibodies available, our flow cytometry approach can be adjusted to measure various other cellular and intracellular markers of interest. 


\section{Introduction}

Obesity is characterized with low-grade AT inflammation ${ }^{1}$ and infiltration of pro-inflammatory immune cells in both visceral and subcutaneous AT (vAT, sAT). Accumulation of pro-inflammatory immune cells in the VAT leads to insulin resistance which is a primary risk factor for developing type 2 diabetes ${ }^{2}$. Immune cells of both the innate and adaptive immune system are found in the obese AT, such as macrophages, mast cells, neutrophils, CD4 ${ }^{+}$ and $\mathrm{CD} 8^{+} \mathrm{T}$-cells, and $\mathrm{B}$-cells ${ }^{3-7}$. These immune cells, together with endothelial cells, stromal cells, adipocyte progenitors, fibroblasts and pericytes, constitute the $\mathrm{SVF}^{8}$ and are the main source of pro-inflammatory substances in the $\mathrm{AT}^{9}$.

The inflammatory status of AT is commonly investigated by techniques including Western blot $^{10}, \mathrm{qPCR}^{11}$, and immunohistochemistry ${ }^{11}$. However, when using these techniques, the entire AT, adipocytes, and SVF, is used. This makes it difficult to determine the amount and subsets of immune cells present in the AT. Immune cells have various cell markers to define and categorize them, such as macrophages. Macrophages show significant heterogeneity in both function and cell surface marker expression ${ }^{12}$. Therefore, they are often categorized into two macrophage populations: M1 and M2. M2 macrophages are usually called alternatively activated macrophages $^{12,13}$ and reside in the AT of lean, metabolically normal humans ${ }^{14}$. However, during obesity, a phenotypic switch occurs from M2 macrophages to M1 macrophages. These classically activated M1 macrophages express $\mathrm{CD} 11 \mathrm{C}^{12}$ and accumulate around dead adipocytes to form crown-like structures ${ }^{13}$. It has been shown that $\mathrm{CD} 11 \mathrm{C}^{+}$macrophages in the AT impair insulin action and are associated with insulin resistance in obese humans ${ }^{15}$. To identify $M 1$ and $M 2$ macrophages in the AT, immunohistochemistry is an option. This technique gives information about the location of the macrophages in the tissue. However, it will limit the number of markers that can be used in one staining. Moreover, it is also difficult to quantify. Therefore, to investigate the different immune cell subsets in the VAT and SAT deposits, we have developed a flow cytometry approach. This approach gives us the opportunity to use multiple markers 
per cell with one flow cytometry analysis to define cell subsets and count the numbers of each subset present in the AT deposits.

\section{Protocol}

Video protocol:

https://www.jove.com/video/57319/characterization-immune-cellshuman-adipose-tissue-using-flow

Visceral and subcutaneous AT samples were taken from subjects enrolled in the study approved by the Medical Ethical committee Jessa Hospital, Hasselt, and Hasselt University, Belgium, in accordance with the Declaration of Helsinki.

\section{Preparation of Reagents}

\subsection{Collagenase solution}

1.1.1. Dissolve $1 \mathrm{~g}$ of Collagenase $\mathrm{I}$ in $10 \mathrm{~mL}$ of phosphate buffered saline (PBS, without calcium and magnesium) to make a 100 $\mathrm{mg} / \mathrm{mL}$ stock solution. Prepare $200 \mu \mathrm{L}$ aliquots and store at -20 ${ }^{\circ} \mathrm{C}$.

1.1.2. Dissolve $1 \mathrm{~g}$ of Collagenase $\mathrm{XI}$ in $10 \mathrm{~mL}$ of PBS to make a 100 $\mathrm{mg} / \mathrm{mL}$ stock solution. Prepare $200 \mu \mathrm{L}$ aliquots and store at -20 ${ }^{\circ} \mathrm{C}$.

1.1.3. Dissolve $10 \mathrm{mg}$ of DNase I in $10 \mathrm{~mL}$ of PBS to make a 10 $\mathrm{mg} / \mathrm{mL}$ stock solution. Prepare $180 \mu \mathrm{L}$ aliquots and store at -20 ${ }^{\circ} \mathrm{C}$.

1.1.4. Add $100 \mu \mathrm{L}$ Collagenase I $(100 \mathrm{mg} / \mathrm{mL}), 100 \mu \mathrm{L}$ Collagenase $\mathrm{XI}(100 \mathrm{mg} / \mathrm{mL})$, and $90 \mu \mathrm{L}$ DNase I $(10 \mathrm{mg} / \mathrm{mL})$ to $10 \mathrm{~mL}$ of DMEM Ham's F12. Make collagenase solution fresh for each isolation. 
1.2. Erythrocyte lysis buffer

1.2.1 Dissolve $0.84 \mathrm{~g} \mathrm{NH}_{4} \mathrm{Cl}$ in $100 \mathrm{~mL}$ of ultrapure water.

1.2.2 Set the $\mathrm{pH}$ at 7.4 before use. Store in a glass flask at $4{ }^{\circ} \mathrm{C}$.

1.2.3 Place the erythrocyte lysis buffer on ice before use.

1.3. FACS buffer

1.3.1 Dissolve $0.5 \mathrm{~g}$ bovine serum albumin (BSA) in $100 \mathrm{~mL}$ of PBS to obtain $0.5 \%$ BSA PBS.

1.3.2 Dissolve $65 \mathrm{mg}$ of $\mathrm{NaN}_{3}$ in $100 \mathrm{~mL} 0.5 \%$ BSA PBS to obtain $10 \mathrm{mM} \mathrm{NaN}_{3} 0.5 \%$ BSA PBS. Store solution in a glass flask at $4{ }^{\circ} \mathrm{C}$.

1.3.3 Place FACS buffer on ice before use.

CAUTION: $\mathrm{NaN}_{3}$ is highly toxic. Work in a fume hood and wear safety glasses and gloves for protection while handling $\mathrm{NaN}_{3}$.

1.4. Human IgG block

1.4.1 Dissolve $10 \mathrm{mg}$ of human IgG in $10 \mathrm{~mL}$ PBS to obtain $1 \mathrm{mg} / \mathrm{mL}$. Prepare $100 \mu \mathrm{L}$ aliquots and store at $-20^{\circ} \mathrm{C}$.

1.4.2 Place the human IgG block on ice before use.

\section{Isolation of SVF from AT}

2.1 Cut $1 \mathrm{~g}$ of AT biopsy into small pieces $\left( \pm 2 \mathrm{~mm}^{2}\right)$ with a scalpel and transfer to a $50-\mathrm{mL}$ centrifuge tube (e.g., Falcon tube). Add $10 \mathrm{~mL}$ of collagenase solution to each AT sample. 
Note: Close the lid of the tube completely and turn the lid $1 / 4$ turn back.

2.2 Incubate for $60 \mathrm{~min}$ at $37^{\circ} \mathrm{C}$ in a water-bath under gentle shaking (60 cycles/min).

2.3 Filter the resulting suspension with a $200 \mu \mathrm{M}$ filter and collect the sample in a new 50-mL centrifuge tube. Add $7 \mathrm{~mL}$ PBS on top of the filter to rinse the filter and obtain all the cells.

2.4 Centrifuge the sample at $280 \times \mathrm{g}$ for $5 \mathrm{~min}$ at $4{ }^{\circ} \mathrm{C}$.

2.5 Remove the floating adipocyte fraction by pipetting. The cell pellet is the SVF.

Note: Remove the adipocyte fraction to obtain SVF. Avoid submerging the entire tip in the sample because this will only remove the PBS and not the floating adipocytes.

2.6 Resuspend the SVF in $5 \mathrm{~mL}$ of PBS to remove collagenase, filter the suspension with a $70 \mu \mathrm{M}$ filter, rinse the filter with $5 \mathrm{~mL}$ PBS, and centrifuge the sample at $280 \times \mathrm{g}$ for $5 \mathrm{~min}$ at $4{ }^{\circ} \mathrm{C}$.

2.7 Remove the supernatant and resuspend the pellet in $3 \mathrm{~mL}$ of erythrocyte lysis buffer.

2.8 Incubate for 5 min on ice. Add $7 \mathrm{~mL}$ of PBS after incubation.

2.9 Centrifuge the sample at $280 \times \mathrm{g}$ for $5 \mathrm{~min}$ at $4{ }^{\circ} \mathrm{C}$.

\section{Staining of SVF for Flow Cytometry Analysis}

3.1 Dissolve the cell pellet in $90 \mu \mathrm{L} 4{ }^{\circ} \mathrm{C}$ FACS buffer and add $10 \mu \mathrm{L}$ of $1 \mathrm{mg} / \mathrm{mL}$ human IgG block. Divide the cell suspension in 2 wells of a $96 \mathrm{v}$-shape well plate. Place the plate on ice and let the human IgG block incubate 
for $15 \mathrm{~min}$.

3.2 Add $100 \mu \mathrm{L}$ FACS buffer to each sample to wash and centrifuge the plate for $5 \mathrm{~min}$ with $280 \mathrm{xg}$ at $4{ }^{\circ} \mathrm{C}$. Remove the supernatant by tipping the plate upside down in one smooth movement without tapping the plate.

Note: Make sure to remove any remaining liquid from the top of the plate with a tissue while keeping the plate upside down.

3.3 Prepare antibody cocktails for macrophage and DC subsets (FACS panel 1) and for T- and B-cell subsets (FACS panel 2) as described in Table 5.1 and Table 5.2. The volumes described in Table 5.1 and Table 5.2 are selected after optimizing the antibody concentrations and are sufficient for one VAT or SAT sample.

Note: In FACS panel 1, use the markers CD303 and CD141 to confirm that $\mathrm{CD}_{11 C^{+}} \mathrm{CD} 11 \mathrm{~B}^{\text {low }}$ cells are DCs. However, it is recommended to exclude these markers from the panel to include a live/dead staining. Both FACS panel 1 and 2 can be combined with the LIVE/DEAD Fixable Red Dead Cell Stain Kit viability staining when excluding CD303 in panel 1 as the PE channel will be unused. Perform viability staining according to the manufacturer's instructions.

3.4 Resuspend the pellet in $29.5 \mu \mathrm{L}$ antibody cocktail for FACS panel 1 , and $23 \mu \mathrm{L}$ antibody cocktail for FACS panel 2 . Incubate for $30 \mathrm{~min}$ in the dark on ice.

3.5 Add $150 \mu \mathrm{L}$ FACS buffer to each well and resuspend the cell pellet to perform a second wash step. Centrifuge the plate for 5 min at $280 \times \mathrm{g}$ and $4{ }^{\circ} \mathrm{C}$. Remove the supernatant by tipping the plate upside down.

3.6 Add $150 \mu \mathrm{L} 1 \%$ formaldehyde solution to each well to fix the cells. Transfer the cell suspension from each well to the corresponding FACS tube by pipetting with a P200 pipette. Store FACS tubes at $4{ }^{\circ} \mathrm{C}$ in the dark up to 7 days. 
Note: Direct measurement is also possible. Add $150 \mu \mathrm{L}$ FACS buffer to each well instead of $1 \%$ formaldehyde, transfer the cells by pipetting with a P200 pipette to the corresponding FACS tubes, and analyze the cells.

CAUTION: Formaldehyde is very toxic. Prepare formaldehyde solutions while working in a fume hood to avoid inhalation and wear gloves and safety glasses for protection.

Table 5.1. Antibody cocktail for FACS panel 1 to identify macrophage subsets and dendritic cell populations

\begin{tabular}{|c|c|c|c|c|c|}
\hline Target & Definition target & Present on & Fluorochrome & Quantity & Clone \\
\hline CD11B & $\begin{array}{l}\text { myeloid integrin } \\
\text { marker }\end{array}$ & $\begin{array}{l}\text { granulocytes, } \\
\text { monocytes/ } \\
\text { macrophages, } \\
\text { dendritic cells }^{\text {low }} \text { and } \\
\text { natural killer cells }\end{array}$ & BV421 & $2.5 \mu \mathrm{L}$ & ICRF44 \\
\hline CD19 & common B cell antigen & $\begin{array}{l}\text { B cell development } \\
\text { from pro-B cell to } \\
\text { blastoid B cell and } \\
\text { plasma B cell } \\
\end{array}$ & Fitc & $3 \mu \mathrm{L}$ & HIB19 \\
\hline CD3 & common T cell antigen & \begin{tabular}{|l|} 
T lymphocytes, natural \\
killer T cells and \\
thymocytes
\end{tabular} & Fitc & $3 \mu \mathrm{L}$ & UCHT1 \\
\hline CD66B & $\begin{array}{l}\text { member of the } \\
\text { carcinoembryonic } \\
\text { antigen (CEA)-like } \\
\text { glycoprotein family }\end{array}$ & granulocytes & Fitc & $5 \mu \mathrm{L}$ & G10F5 \\
\hline CD56 & $\begin{array}{l}\text { heavily glycosylated } \\
\text { adhesion protein }\end{array}$ & $\begin{array}{l}\text { natural killer cells and } \\
\text { natural killer T cells }\end{array}$ & Fitc & $5 \mu \mathrm{L}$ & B159 \\
\hline CD303 & \begin{tabular}{l|} 
type II transmembrane \\
glycoprotein
\end{tabular} & $\begin{array}{l}\text { plasmacytoid dendritic } \\
\text { cells }\end{array}$ & PE & $1 \mu \mathrm{L}$ & $201 \mathrm{~A}$ \\
\hline CD141 & thrombomodulin & $\begin{array}{l}\text { monocytes/ } \\
\text { macrophages }{ }^{\text {low }}, \\
\text { subpopulation of } \\
\text { dendritic cells }\end{array}$ & APC & $1 \mu \mathrm{L}$ & M80 \\
\hline CD11C & $\begin{array}{l}\text { type I transmembrane } \\
\text { glycoprotein; integrin } \\
\text { ax }\end{array}$ & $\begin{array}{l}\text { monocytes/ } \\
\text { macrophages, } \\
\text { dendritic cells, } \\
\text { granulocytes, natural } \\
\text { killer cells, nubset of B } \\
\text { and T cells } \\
\end{array}$ & APC-Сy7 & $0.5 \mu \mathrm{L}$ & Bu15 \\
\hline CD45 & $\begin{array}{l}\text { common leukocyte } \\
\text { antigen }\end{array}$ & $\begin{array}{l}\text { all human leukocytes } \\
\text { including lymphocytes, } \\
\text { monocytes, } \\
\text { granulocytes, } \\
\text { eosinophils, and } \\
\text { thymocytes }\end{array}$ & PE-Сy7 & $1 \mu \mathrm{L}$ & $\mathrm{HI} 30$ \\
\hline FACS buffer & - & - & - & $7.5 \mu \mathrm{l}$ & - \\
\hline
\end{tabular}

Amount of antibody described is for the analysis of one sample.

\section{Flow Cytometry Analysis}

4.1 Before the first measurement, use an unstained negative control to set the forward scatter (FSC) and side scatter (SSC). Adjust the 
voltages of the flow cytometer according to the manufacturer's instructions so that all populations of interest are visible in the FSC and SSC graph and a distinction between debris and live cells can be made.

4.2 Perform multi-color compensation analysis with antibody capture beads following the manufacturer's protocol.

4.3 Prepare fluorescence minus one (FMO) controls by making the antibody mix but exclude one antibody from the mix. Do this for every antibody, creating 8 antibody mixes for FACS panel 1, and 6 antibody mixes for FACS panel 2. These FMO antibody mixes are used to stain SVF as described previously in this protocol.

4.4 Measure all FMO controls and set the gating strategy based on FMO controls. Use the FMO controls to detect possible auto-fluorescence of the cells.

Note: By removing one antibody from the mix, any fluorescence level detected in this channel is a background/autofluorescent signal. Hence, by comparing the different FMO control FACS results, gates can be drawn on specific populations ensuring that the gatings are based on positive cells and not based on auto-fluorescence.

4.5 Vortex the FACS tubes at $800 \mathrm{rpm}$ before placing them in the flow cytometer and starting the measurement.

Note: A minimum of 50,000 events in the live gate is recommended to ensure enough cells are measured from each subpopulation. 
Table 5.2. Antibody cocktail for FACS panel 2 to identify T- and B-cell populations

\begin{tabular}{|c|c|c|c|c|c|}
\hline Target & Definition target & Present on & Fluorochrome & Quantity & Clone \\
\hline CD19 & common B cell antigen & $\begin{array}{l}\text { B cell development } \\
\text { from pro-B cell to } \\
\text { blastoid B cell and } \\
\text { plasma B cell }\end{array}$ & BV421 & $1 \mu \mathrm{L}$ & HIB19 \\
\hline CD3 & common $\mathrm{T}$ cell antigen & $\begin{array}{l}\text { T lymphocytes, natural } \\
\text { killer T cells and } \\
\text { thymocytes }\end{array}$ & v500 & $3 \mu \mathrm{L}$ & UCHT1 \\
\hline CD56 & $\begin{array}{l}\text { heavily glycosylated } \\
\text { adhesion protein }\end{array}$ & $\begin{array}{l}\text { natural killer cells and } \\
\text { natural killer T cells }\end{array}$ & APC & $5 \mu \mathrm{L}$ & HCD56 \\
\hline CD4 & $\begin{array}{l}\text { Ig superfamily, type } \\
\text { I transmembrane } \\
\text { glycoprotein }\end{array}$ & \begin{tabular}{|l} 
T helper cell, \\
thymocytes, \\
monocytes/ \\
macrophages, type II \\
natural killer T cells
\end{tabular} & PerCP-Cy5.5 & $1 \mu \mathrm{L}$ & RPA-T4 \\
\hline CD8 & $\begin{array}{l}\text { Q-subunit of a } \\
\text { disulfide-linked } \\
\text { bimolecular complex }\end{array}$ & $\begin{array}{l}\text { cytotoxic T cells, } \\
\text { thymocytes, subset of } \\
\text { natural killer cells }\end{array}$ & APC-H7 & $2 \mu \mathrm{L}$ & SK1 \\
\hline CD45 & $\begin{array}{l}\text { common leukocyte } \\
\text { antigen }\end{array}$ & \begin{tabular}{|l|} 
all human leukocytes \\
including lymphocytes, \\
monocytes, \\
granulocytes, \\
eosinophils, and \\
thymocytes
\end{tabular} & PE-Cy7 & $1 \mu \mathrm{L}$ & $\mathrm{H} \mid 30$ \\
\hline FACS buffer & - & - & - & $10 \mu \mathrm{l}$ & - \\
\hline
\end{tabular}

Amount of antibody described is for the analysis of one sample.

\section{Representative Results}

The SVF isolated from vAT and SAT was measured using flow cytometry. Flow cytometry measurements generate plots showing different cell populations based on cellular markers (Figures 5.1A and 5.1B). First, by plotting the forward scatter width (FSC-W) and forward scatter area (FSC-A), cell aggregates can be eliminated from further analysis by gating the single cells as low FSC-W. Next, live cells are selected, and cellular debris is excluded by gating the cells of the correct size and complexity using FSC-A and the side scatter area (SSC-A), respectively. Dead cells are small and therefore visible as a distinct population with a small FSC-A. Next, immune cells were selected by use of the pan-leukocyte marker CD45 (Panel 1 and 2, Figure 5.1A). To analyze macrophages, other immune cells such as T-cells (CD3), B-cells (CD19), neutrophils (CD66 $b^{+}$CD11 $b^{+}$), and NK-cells (CD56) were excluded from further analysis by using distinct antibodies targeting these cells, but with the same fluorochrome. Further subdivision of the remaining cells was based on $\mathrm{CD} 11 \mathrm{~b}$ and $\mathrm{CD} 11 \mathrm{c}$ expression. This resulted in the following populations: $\mathrm{CD}_{11} \mathrm{~b}^{+} \mathrm{CD} 11 \mathrm{c}^{+}$macrophages, $\mathrm{CD} 11 \mathrm{~b}^{+} \mathrm{CD} 11 \mathrm{c}^{-}$macrophages, and CD11 bow/- CD11c $\mathrm{b}^{+}$DCs (FACS panel 1, Figure 5.1B). Measurement of mean fluorescence intensity $(\mathrm{MFI})$ allowed the quantification of the 
expression of CD303 (plasmacytoid DC marker) and CD141 (DC marker), on $\mathrm{CD} 11 \mathrm{~b}^{+} \mathrm{CD} 11 \mathrm{c}^{+}$macrophages and $\mathrm{CD} 11 \mathrm{~b}^{\text {low/- }} \mathrm{CD} 11 \mathrm{c}^{+} \mathrm{DC}$. Expression of both these markers were higher in $\mathrm{CD} 11 \mathrm{~b}^{\text {low/ }} \mathrm{CD} 11 \mathrm{c}^{+}$cells confirming that CD11 b $\mathrm{b}^{\text {low } /-} \mathrm{CD} 11 \mathrm{c}^{+}$cells were DCs (Figure 5.1C).

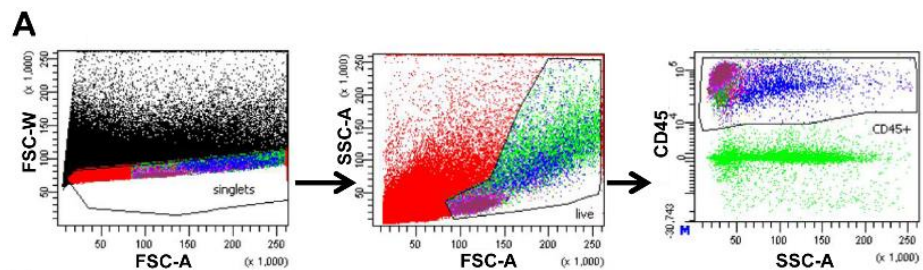

B

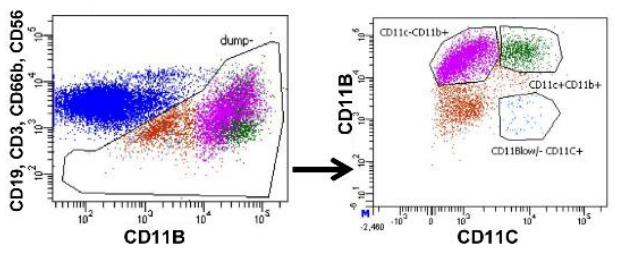

C
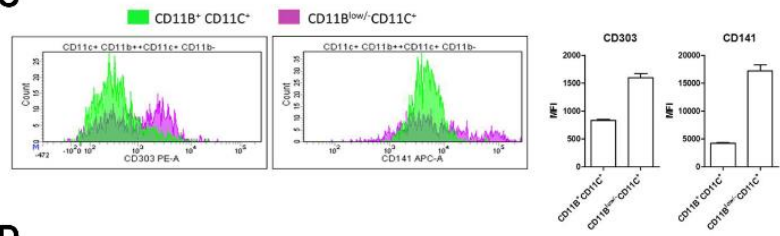

D

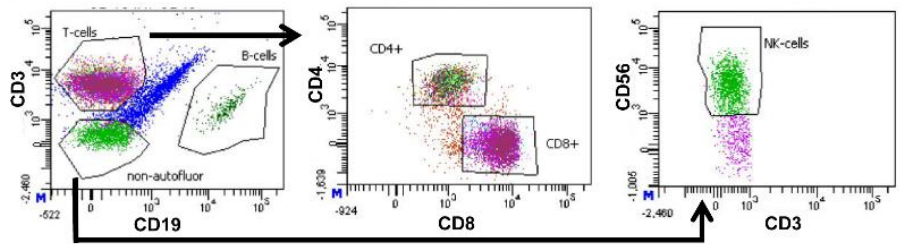

Figure 5.1. FACS gating strategy of visceral adipose tissue.

(A) FACS plot of all events (black) with forward scatter width intensity (FSC-W) and forward scatter area intensity (FSC-A) containing a gate to select only single cells (red) followed by a FACS plot based on FSC-A and side scatter area intensity (SSC-A) containing a gate selecting live cells (light green). Next plot with SSC-A and CD45 fluorescence intensity contains a gate selecting all CD45+ (immune) cells (blue). (B) FACS plot of CD19, CD3, CD66b, and CD56 fluorescence intensity versus CD11b fluorescence intensity, and a gate selecting all cells that are CD19, CD3, CD66b, and CD56 negative (brown) for further division into populations. Further subdivision in the next plot based on CD11b and CD11c fluorescence intensity. Gates are displayed containing $\mathrm{CD}_{11} \mathrm{~b}^{+} \mathrm{CD} 11 \mathrm{c}^{+}$macrophages (dark green), $\mathrm{CD} 11 \mathrm{~b}^{+} \mathrm{CD} 11 \mathrm{c}^{-}$ macrophages (purple), and CD11blow/- CD11 $\mathrm{c}^{+}$dendritic cells (blue). (C) Amount of CD11 $\mathrm{b}^{+}$, $\mathrm{CD}_{11} \mathrm{c}^{+}$, or $\mathrm{CD} 11 \mathrm{~b}^{\text {low/- }} \mathrm{CD} 11 \mathrm{c}^{+}$cells (Y-axis) displaying their levels of fluorescence intensity (Xaxis) for CD303 and CD141, and the corresponding quantification of the mean fluorescence 
intensity (MFI). (D) FACS plot displaying the previous $\mathrm{CD} 45^{+}$population (blue) based on CD3 and CD19 fluorescence intensity containing gates selecting T-cells (magenta), B-cells (dark green), and non-autofluorescent cells (green) negative for both CD3 and CD19. The following plot is based on CD4 and CD8 fluorescence with gates selecting CD4 (light green) and CD8 ${ }^{+}$ (magenta) T-cells. An identical gating strategy is used for subcutaneous adipose tissue. An identical gating strategy is used for subcutaneous adipose tissue. This figure has been modified from Wouters et al. ${ }^{16}$

The $\mathrm{CD} 45^{+}$cells (Figure 5.1A) were divided into T-cells and B-cells using CD3 and $C D 19$, respectively. T-cells were subdivided into T-helper cells (CD4 ${ }^{+}$) and cytotoxic T-cells (CD8 ${ }^{+}$). Lastly, $\mathrm{CD}^{-}{ }^{-} \mathrm{CD} 19^{-}$cells were plotted to quantify NKcells using the marker CD56 (FACS panel 2, Figure 5.1D). The number of cells in each gate is quantified and can be used to calculate the percentage of this cell type of all living cells (Table 5.3).

Table 5.3. Immune cell abundance of different cell types in vAT

\begin{tabular}{|c|c|c|}
\hline Macrophage panel & & \\
\hline Gate name & \# Cells & $\%$ of live \\
\hline Single cells & 183054 & \\
\hline live & 10477 & 100 \\
\hline CD45 & 4100 & 39.13 \\
\hline dump & 771 & 7.36 \\
\hline $\mathrm{CD}_{11 \mathrm{C}^{-} \mathrm{CD} 11 \mathrm{~B}^{+}}$ & 430 & 4.1 \\
\hline $\mathrm{CD}_{11 \mathrm{C}^{+} \mathrm{CD} 11 \mathrm{~B}^{+}}$ & 104 & 0.99 \\
\hline $\mathrm{CD} 11 \mathrm{C}^{+} \mathrm{CD} 11 \mathrm{~B}^{\mathrm{low} / \mathrm{-}}$ & 15 & 0.14 \\
\hline \multicolumn{3}{|c|}{ T-cell, B-cell, NK-cell panel } \\
\hline Gate name & \#Cells & $\%$ of live \\
\hline Single cells & 34616 & \\
\hline Live & 3728 & 100 \\
\hline $\mathrm{CD} 45^{+}$ & 1589 & 42.62 \\
\hline NK-cells & 29 & 0.78 \\
\hline $\mathrm{CD}^{+}$ & 953 & 25.56 \\
\hline $\mathrm{CD4}^{+}$ & 601 & 16.12 \\
\hline $\mathrm{CD}^{+}$ & 328 & 8.8 \\
\hline $\mathrm{CD} 19^{+}$ & 20 & 0.54 \\
\hline
\end{tabular}

Number of cells in each gate and the percentage of the different cell types based on the total amount of living cells.

The percentage of living cells can be calculated for each subject allowing the calculation of an average of all subjects in a group of for example lean or obese men displaying the abundance of a specific immune cell, i.e., the proinflammatory $\mathrm{CD} 11 \mathrm{~b}^{+} \mathrm{CD} 11 \mathrm{c}^{+}$macrophage in visceral $\mathrm{AT}$ (Figure 5.2). 


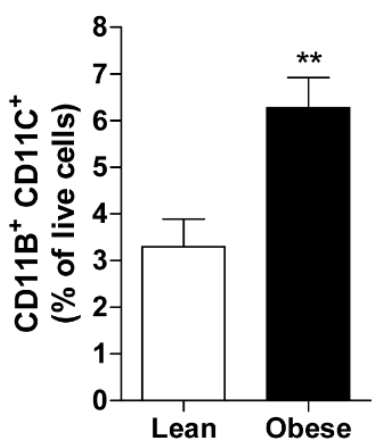

Figure 5.2. Obese VAT contains more pro-inflammatory macrophages

The amount of $\mathrm{CD} 11 \mathrm{~b}^{+} \mathrm{CD} 11 \mathrm{c}^{+}$macrophages presented as percentage of all living cells in vAT of lean and obese men. All data are means \pm SEM; $n=20$ for lean and $n=31$ for obese. ${ }^{* *} p \leq$ 0.01 vs. lean.

\section{Discussion}

These methods describe how to isolate the SVF from VAT and SAT and quantify the relative amounts of immune cells within these tissues. Furthermore, the methods state how to determine the expression of markers on specific cell types.

Flow cytometry of tissue immune cells is a powerful technique to phenotype the immunological state of tissues. The quantification of tissue immune cells can have many applications. As described in the results, it is possible to compare the presence of specific immune cells between groups of patients (e.g., lean vs. obese). In addition, by also performing flow cytometry on blood of the same patients, associations between circulating cells and tissue cells can be investigated. With this application we were able to determine that a specific subset of circulating monocytes is associated with pro-inflammatory $\mathrm{CD}_{11 \mathrm{C}^{+}}$adipose tissue macrophages ${ }^{16}$.

Adjustments to the described protocol will expand its applications as numerous available fluorescent antibodies make flow cytometry very versatile. With different antibodies nearly all cell types can be distinguished and the expression of many markers can be detected. Furthermore, it is possible to stain markers intracellularly by permeabilizing the cell membrane to allow intracellular binding of the fluorescent antibodies.

These characteristics allow distinction of the very diverse macrophage 
populations beyond the overly simplified $\mathrm{M} 1$ and $\mathrm{M} 2$ macrophage subtypes. Besides measurement of surface marker expression, proteins (e.g. cytokines) can be stained intracellularly providing information on macrophage functionality. In addition, proliferation markers such as Ki67 are used to quantify proliferation rates. As described, distinction between macrophages and DCs was based on MFI levels of DC markers. A general macrophage marker, such as CD68 can be incorporated into the macrophage panel (FACS panel 1). However, CD68 needs to be stained intracellularly requiring permeabilization of the cell membrane which is not preferable and would extend the protocol. Other macrophage markers are subset markers such as CD163 and CD206 or CD11c, the latter being integrated in the macrophage panel presented here.

In our FACS panels, a marker to distinguish live and dead cells was not included, which would be preferable because it allows a more accurate exclusion of dead cells than the use of FSC and SSC. Frequently used are the DNA staining viability dyes propidium iodide (PI) or 4',6-diamidino-2phenylindole (DAPI) as well as free amine reacting dyes such as the LIVE/DEAD Fixable Dead Cell Stain Kit, which is available in different dye colors. However, PI and DAPI cannot be used when fixing the cells. As described in the protocol, the LIVE/DEAD Fixable Red Dead Cell viability staining can be integrated into both panels without affecting the overall FACS gating strategy.

In addition, the data are expressed as a percentage of live cells meaning all data are relative. Only by entering an exact, known number of cells into the flow cytometer, would it be possible to determine the exact numbers of each cell type. An approximate number of cells could be calculated after counting the cells in the SVF fraction by using a counting chamber. However, this number would have to be adjusted for the amount of biopsy tissue used to isolate the SVF, but this has limitations when comparing lean to obese AT. A similar mass of obese AT consists of less adipocytes as they are filled with lipids and have expanded greatly. This could lead to an underestimation of immune cell number if presented as number of immune cells per gram of AT or per adipocyte.

In human studies, inclusion of patients is usually done over a longer period 
of time making standardization of experimental procedures of great importance. For comparison of flow cytometry data between patients, there are several options. As described in this protocol, cells can be fixed before measurement allowing analysis of several samples on the same day. This can also be achieved by freezing the SVF before staining them, which allows the staining procedure to be equal between all samples, but the viability of cells might be affected. Lastly, also employed in this study, are fluorescent beads to install compensation levels, and cytometer tracking beads were used biweekly to standardize daily measurements of the cytometer. This last option is the most efficient when measuring samples from a study spanning a long period of time.

A limiting factor for flow cytometry in general is the use of fluorescence. The number of fluorescent labels that can be detected simultaneously is limited due to overlap in emission spectra. However, with smart FACS panel development and the use of several antibody cocktails per VAT or SAT sample, this issue can be overcome as described in this protocol. An important aspect of FACS panel development is FMO controls. By using all antibodies of the panel except for one, potential autofluorescence levels can be appreciated when comparing the FMO with the full panel. This allows accurate gating of populations and these procedures should be performed when setting up a new FACS panel. In addition, new generations of FACS devices can detect up to 50 parameters allowing simultaneous detection of many characteristics per cell. Another issue related to the fluorescence aspect is the autofluorescence of cells, particularly macrophages. After excitation of the cells with the FACS laser (mainly with $488 \mathrm{~nm}$ wavelength excitation), these cells emit a fluorescent signal (mainly $<640 \mathrm{~nm}$ ) that can overlap with the emission spectra of the antibody labels ${ }^{17,18}$. To account for this, unstained cells should be measured to determine the autofluorescence in each channel. With this knowledge, fluorochromes should be selected that display a signal strength that exceeds the autofluorescent signal. This autofluorescent background signal should be taken into account when determining the gating strategy of the populations. Therefore, by application of this protocol and intelligent FACS panel design it is possible to in depth phenotype macrophage subtypes. New distinct AT macrophages and their function can be characterized. 


\section{Chapter 5}

\section{Acknowledgements}

We would like to thank J. van de Gaar and M. Vroomen (Maastricht University, The Netherlands) for their technical support. In addition, we would like to thank K. Verboven, D. Hansen, J. Jocken, and E. Blaak for providing the blood and tissue biopsies used for setting up this protocol and the subsequent experiments. 


\section{References}

1. McNelis JC, Olefsky JM. Macrophages, immunity, and metabolic disease. Immunity 2014;41:36-48.

2. Makki K, Froguel P, Wolowczuk I. Adipose tissue in obesity-related inflammation and insulin resistance: cells, cytokines, and chemokines. ISRN Inflamm 2013;2013:139239.

3. DeFuria J, Belkina AC, Jagannathan-Bogdan $\mathrm{M}$, et al. B cells promote inflammation in obesity and type 2 diabetes through regulation of T-cell function and an inflammatory cytokine profile. Proc Natl Acad Sci U S A 2013;110:5133-8.

4. Elgazar-Carmon V, Rudich A, Hadad N, et al. Neutrophils transiently infiltrate intraabdominal fat early in the course of high-fat feeding. J Lipid Res 2008;49:1894-903.

5. Han JM, Levings MK. Immune regulation in obesity-associated adipose inflammation. J Immunol 2013;191:527-32.

6. Liu J, Divoux A, Sun J, et al. Genetic deficiency and pharmacological stabilization of mast cells reduce diet-induced obesity and diabetes in mice. Nat Med 2009;15:9405.

7. Nishimura S, Manabe I, Nagasaki M, et al. CD8+ effector T cells contribute to macrophage recruitment and adipose tissue inflammation in obesity. Nat Med 2009;15:914-20.

8. Koh YJ, Koh BI, Kim H, et al. Stromal vascular fraction from adipose tissue forms profound vascular network through the dynamic reassembly of blood endothelial cells. Arterioscler Thromb Vasc Biol 2011;31:1141-50.

9. Peinado JR, Jimenez-Gomez $Y$, Pulido MR, et al. The stromal-vascular fraction of adipose tissue contributes to major differences between subcutaneous and visceral fat depots. Proteomics 2010;10:3356-66.

10. Leggate M, Carter WG, Evans MJC, et al. Determination of inflammatory and prominent proteomic changes in plasma and adipose tissue after high-intensity intermittent training in overweight and obese males. Journal of Applied Physiology 2012;112:1353-1360.

11. Divoux A, Moutel S, Poitou C, et al. Mast cells in human adipose tissue: link with morbid obesity, inflammatory status, and diabetes. J Clin Endocrinol Metab 2012;97:E1677-85.

12. Harford KA, Reynolds CM, McGillicuddy FC, et al. Fats, inflammation and insulin resistance: insights to the role of macrophage and T-cell accumulation in adipose tissue. Proc Nutr Soc 2011;70:408-17.

13. Lumeng CN, Bodzin JL, Saltiel AR. Obesity induces a phenotypic switch in adipose tissue macrophage polarization. J Clin Invest 2007;117:175-84.

14. Morris DL, Singer K, Lumeng CN. Adipose tissue macrophages: phenotypic plasticity and diversity in lean and obese states. Curr Opin Clin Nutr Metab Care 2011;14:3416 .

15. Wentworth JM, Naselli G, Brown WA, et al. Pro-inflammatory CD11C+CD206+ adipose tissue macrophages are associated with insulin resistance in human obesity. Diabetes 2010;59:1648-56.

16. Wouters K, Gaens K, Bijnen M, et al. Circulating classical monocytes are associated with CD11c+ macrophages in human visceral adipose tissue. Sci Rep 2017;7:42665.

17. Duan M, Li WC, Vlahos $R$, et al. Distinct macrophage subpopulations characterize acute infection and chronic inflammatory lung disease. J Immunol 2012;189:946-55. 
18. Li F, Yang M, Wang L, et al. Autofluorescence contributes to false-positive intracellular Foxp3 staining in macrophages: a lesson learned from flow cytometry. $\mathrm{J}$ Immunol Methods 2012;386:101-7. 


\section{Chapter 6}

\section{Circulating classical monocytes are associated with CD11c ${ }^{+}$ macrophages in human visceral adipose tissue}

Kristiaan Wouters, Katrien Gaens, Mitchell Bijnen, Kenneth Verboven, Johan Jocken, Suzan Wetzels, Erwin Wijnands, Dominique Hansen, Marleen van Greevenbroek, Adriaan Duijvestijn, Erik A. L. Biessen, Ellen E. Blaak, Coen D.A. Stehouwer and Casper G. Schalkwijk

Sci Rep. 2017 Feb 15;7:42665 


\section{Abstract}

Immune cell accumulation in adipose tissue (AT) is associated with the development of AT inflammation, resulting in metabolic dysfunction. Circulating immune cell patterns may reflect immune cell accumulation in expanding AT. However, data linking human leukocytes in blood and AT is lacking. We investigated whether blood immune cell populations are associated with their counterparts in subcutaneous (scAT) or visceral AT (vAT).

Flow cytometry was performed on blood, scAT and vAT from 16 lean and 29 obese men. Circulating natural killer (NK)-cells, classical monocytes and nonclassical monocytes were higher in obese individuals. VAT, but not scAT, of obese individuals contained more inflammatory CD11c " $M 1$ " macrophages and NK cells compared to lean individuals. Blood classical monocytes were associated with $\mathrm{CD} 11 \mathrm{c}^{+}$macrophages in vAT but not SCAT. This association was unrelated to expression of the adhesion molecules CD11b and CD11c or of the chemokine receptor CX3CR1 on these monocytes. Other AT immune cells were not associated with their respective counterparts in blood. Finally, CD11 ${ }^{+}$macrophages and CD4 ${ }^{+}$T-cells in vAT were associated with their counterparts in scAT. In conclusion, blood classical monocytes reflect $\mathrm{CD} 11 \mathrm{c}^{+}$macrophages in vAT. 


\section{Introduction}

Adipose tissue (AT) inflammation is a key feature of obesity-associated metabolic dysfunction ${ }^{1,2}$. Pro-inflammatory so-called "M1" macrophages are thought to be recruited from the circulation to $\mathrm{AT}^{3}$, where they accumulate around dying adipocytes to form crown-like structures (CLS), and contribute to insulin resistance and the risk to develop type 2 diabetes ${ }^{4,5}$. The presence of CD11c on the surface of human AT macrophages was shown to be discriminative for these CLS-macrophages and the presence of $\mathrm{CD} 11 \mathrm{c}^{+}$ macrophages correlates with insulin resistance in humans ${ }^{5}$. Additionally, immune cells such as T-lymphocytes, dynamically change in AT during obesity, contributing to chronic inflammation ${ }^{6}$. Compared to subcutaneous AT (scAT), visceral AT (VAT) is thought to be the most inflammatory fat depot in obese people 7 . Unfortunately, VAT is not readily accessible for clinical assessment. Therefore, clinical research considers blood immune cells or scAT inflammatory status as a measure of AT inflammation. However, the validity of immune cells in blood or SCAT as surrogate readout for the VAT immune cell profile is unknown.

Circulating immune cells, including monocytes, granulocytes and lymphocytes, are associated with obesity and its complications ${ }^{8}$. Monocytes, the precursor cells of macrophages, are subdivided based on surface expression of the lipopolysaccharide receptor CD14 and the Fc gamma receptor $\mathrm{CD} 16$ into $\mathrm{CD} 14^{+} \mathrm{CD} 16^{-}$(classical), $\mathrm{CD} 14^{+} \mathrm{CD} 16^{+}$(intermediate), and CD14 ${ }^{\text {dim }} C D 16^{+}$(non-classical) monocytes, representing 75\%-85\%, 5\%-10\% and $5 \%-10 \%$ respectively of total blood monocytes ${ }^{9}$. Since at least part of ATcontained immune cells is recruited from the circulation, it seems plausible that blood immune cell patterns relate to inflammation in expanding VAT. Circulating $\mathrm{CD}_{16}{ }^{+}$monocytes (including both intermediate and non-classical) were shown to be associated with SCAT total macrophage content as assessed by immunohistochemical staining of $\mathrm{CD} 8^{10}$. However, data linking blood monocyte subtypes with specific macrophage subsets in VAT or SCAT is unavailable, as is information on other leukocyte subsets ${ }^{8}$. Therefore, we investigated the cross-association of relevant leukocyte subsets in blood, ScAT and VAT from lean and obese men using flow cytometry. Moreover, we 
investigated whether immune cells in accessible scAT reflect immune cell content in vAT.

\section{Research Design and Methods}

\section{Subjects}

Male subjects who were scheduled to undergo abdominal or bariatric surgery were recruited. The decision to undergo surgery was made independently of this research protocol, between patient and physician. The control group consisted of 16 lean male subjects. The obese group was composed of 29 male subjects. Within obese individuals there were 6 patients with type 2 diabetes (defined as having $\mathrm{HbA} 1 \mathrm{c}>6.5 \%$ or taking glucose-lowering medication). 4 obese individuals were on glucose-lowering medication, one of which in combination with lipid lowering medication and 6 patients were on lipid-lowering medication only. Lean individuals were included due to surgery of inguinal hernia, except for 1 patient who underwent sigmoidectomy due to diverticulitis and 1 patient who underwent cholecystectomy due to cholesterolosis. Both patients showed some degree of inflammation but with respect to the circulating or AT immune cells, these patients fell within the normal range of variability.

Clinical characteristics of the subjects included in the study are summarized in table 6.1. Major exclusion criteria were presence of a history of heart, lung or kidney disease and/or presence of endocrine anomalies. Lean controls were selected based on their age to obtain a group of which average age was not different from the obese group. The study protocol was approved by the Medical Ethical Committee Jessa hospital, Hasselt, and Hasselt University, Belgium, in accordance with the Declaration of Helsinki, and all subjects gave their written informed consent before participating in the study.

\section{Anthropometric measurements and blood sampling}

Body weight, height, waist/hip circumference and blood pressure were determined at the morning of surgery. Fat and lean body mass were estimated by bio-electrical impedance analyses (Bodystat 1500; Bodystat Ltd., Isle of Man, U.K.). Fasting venous blood samples were collected after an overnight fast for measurement of plasma glucose, serum insulin and 
glycated hemoglobin. Plasma glucose was measured by the glucose oxidase method using an AU2700 analyser (Beckman Coulter, Brea, CA, USA). Serum insulin was assessed by an immunoassay (ADVIA Centaur Insulin IRI; Siemens Medical Solutions Diagnostics, Tarrytown, NY, USA). Glycated hemoglobin was assessed by high performance liquid chromatography using a HA-8160 Hi-Auto A1C analyser (Menarini, Zaventem, Belgium). Blood cell counts were done with ADVIA 2120 Hematology System (Siemens) and are expressed as cells/L.

Table 6.1. Baseline parameters

\begin{tabular}{|l|c|c|c|}
\hline & Lean Subjects & Obese Subjects & P-value \\
\hline Age $($ years $)$ & $51.5(47.5-58.5)$ & $49.0(45.0-54.0)$ & 0.210 \\
\hline BMI $\left(\mathrm{kg} / \mathrm{m}^{2}\right)$ & $23.7(22.7-24.8)$ & $37.4(36.1-39.4)$ & $<0.001$ \\
\hline Waist-to-hip ratio & $0.98(0.96-0.99)$ & $1.09(1.06-1.11)$ & $<0.001$ \\
\hline Plasma glucose $(\mathrm{mM})$ & $5.6(5.2-5.9)$ & $5.8(5.5-7.2)$ & 0.014 \\
\hline Serum Insulin $(\mathrm{mU} / \mathrm{L})$ & $6.7(5.5-12.1)$ & $19.0(15.0-29.5)$ & $<0.001$ \\
\hline HOMA-IR & $1.71(1.3-3.2)$ & $5.7(3.6-8.3)$ & $<0.001$ \\
\hline HbA1C $(\%)$ & $5.2(5.1-5.5)$ & $6.0(5.4-6.8)$ & $<0.001$ \\
\hline Fat percentage $(\%)$ & $22.2(19.8-27.9)$ & $36.2(34.6-38.3)$ & $<0.001$ \\
\hline
\end{tabular}

Table shows baseline parameters from lean and obese individuals included in this study. Data are presented as median (interquartile range). Differences between lean and obese individuals are analysed with an independent student t-test. ${ }^{*}$ P-value $<0.05$ is considered statistically significant.

\section{Adipose tissue biopsies}

After an overnight fast, adipose tissue biopsies were taken from the abdominal subcutaneous adipose tissue depot (scAT) and the omentum majus (vAT). For each adipose tissue depot, approximately $1-3 \mathrm{~g}$ adipose tissue was collected. The tissue was immediately brought to the laboratory for further processing.

Stromal vascular Fraction (SVF) preparation

SVF cells were obtained by collagenase digestion of adipose tissue fragments in Dulbecco's Modified Eagle's Medium (DMEM)-Ham's F12 with Collagenase 
11 (Sigma Aldrich C7657, $0.0875 \mathrm{mg} / \mathrm{ml}$ ), collagenase 1 (Sigma Aldrich C0130, $1.216 \mathrm{mg} / \mathrm{ml}$ ) and DNAse 1 (Sigma Aldrich DN25, $0.09 \mathrm{mg} / \mathrm{ml}$ ) under gentle shaking $(60 \mathrm{cycles} / \mathrm{min})$ at $37^{\circ} \mathrm{C}$. The resulting suspension was filtered through a $200 \mu \mathrm{m}$ filter and fat cells were removed as floating fraction after centrifugation (5 min, $1250 \mathrm{rpm}$ ). SVF cells were washed once with DMEMHam's F12 to eliminate collagenase, filtered through a $70 \mu \mathrm{M}$ filter and stained for flow cytometry.

\section{Flow cytometry}

Isolated SVF cells were used for two antibody cocktails. Cocktail 1 included CD45-PE-Cy7 (BD 557748), CD3-fitc (BD 561807), CD19-fitc (BD 555412), CD56-fitc (BD 562794), CD66b-fitc (BD 555724), CD11b-BV421 (Biologend 301324), and CD11C-APC-Cy7 (Biolegend 337218). Cocktail 2 included CD45PE-Cy7 (BD 557748), CD3-V500 (BD 561416), CD4-PerCP (Biolegend 300528), CD8 APC-H7 (BD 641400), CD19-BV421 (Biolegend 302234), and CD56-APC (Biolegend 318310). Samples were measured with a FACS-Canto II (BD Biosciences). Results were analysed with FACSdiva (BD Biosciences) and FlowJo software. Gating strategy is shown in supplemental Figure 6.1. Since weight of the adipose tissues was unavailable, data are expressed as \% of cells relative to total cells (based on forward and side scatter plot).

Detailed characterization of blood cells was achieved using flow cytometry. Heparinized whole blood was used for staining for flow cytometry using two antibody cocktails ( $50 \mu$ l of whole blood for each staining). Cocktail 1 included CD3-fitc (BD 561807), CD19-fitc (BD 555412), CD66b-fitc (BD 555724), CD56PE (BD, 345810), HLA-DR-V500 (BD 561224), CD14-APC-H7 (BD 641394), CD16-PerCP (BD 560717), CD11b-BV421 (BD 562632), CD11C-PE-Cy7 (BD 561356), and CX3CR1-APC (Biolegend 341609). Cocktail 2 included CD3-V500 (BD 561416), CD4-APC-H7 (BD 560158), CD8-PerCP-Cy5.5 (BD 560662), CD25-PE-Cy7 (BD 335824), CD127-fitc (BD 560549) and CD19-PerCP-Cy5.5 (BD 332780). Since it was our goal to detect correlations between the different immune cell depots, data on circulating immune cells are expressed in the same manner as for tissue macrophages, i.e. as \% of total cells. Notably, white blood cell counts did not differ between the groups.

Analyses were performed on fresh blood samples. To standardize measurements, we used antibodies from a single batch during the whole 
study. Upon arrival, antibody solutions were aliquoted into small volumes to avoid frequent temperature changes or contamination. Furthermore, cytometer tracking beads were used bi-weekly to define a baseline and standardize daily measurements of the cytometer.

\section{Statistical analyses}

All analyses were performed with the Statistical Package for Social Sciences (SPSS) version 17.0 for Windows (SPSS Inc, Chicago, Illinois, USA). Depending on missing variables, data on $n=16$ for the lean and between 21 and 29 for the obese individuals were included in analyses. Variables with a skewed distribution (based on Shapiro-Wilk test) were In transformed prior to analysis. Comparison of baseline characteristics between lean and obese subjects was performed with an independent Student's t-test. Additionally, differences in immune cell populations between lean and obese subjects were analysed with linear regression analyses and were adjusted for age. Linear regression analyses were also used to investigate the associations between circulating immune cell populations and immune cell populations in scAT and VAT and between immune cell populations in VAT and SCAT.

\section{Results}

Immune cell profiles in blood, scAT and VAT of lean and obese men

Total circulating white blood cells, lymphocytes, monocytes, basophils, eosinophils and neutrophils did not differ between lean and obese individuals (Table 6.2). Multicolour flow cytometry showed that the percentage of blood nonclassical monocytes, classical monocytes, and NKcells out of total leukocytes was higher in obese individuals compared to lean controls. No significant differences were found between lean and obese men for circulating B-cells or T-cell subsets (Table 6.2). vAT from obese individuals was enriched in $\mathrm{CD}_{4} 5^{+}$immune cells, CD11 $\mathrm{c}^{+}$macrophages and NK cells relative to total stromal vascular cells. The relative abundance of $\mathrm{CD} 11 \mathrm{C}^{-}$ macrophages and B-cells tended to be higher in these subjects (Table 6.3). Interestingly, these differences were not observed in SCAT, confirming that SCAT is less prone to obesity-associated adipose inflammation than $\mathrm{VAT}^{7}$. 
Table 6.2. Immune cell populations in blood

\begin{tabular}{|c|c|c|c|}
\hline & Lean Subjects & Obese Subjects & P-value \\
\hline $\mathrm{WBC}(\times 10 * 9 / \mathrm{L})$ & $6.9(6.3-9.5)$ & $6.6(5.7-8.4)$ & 0.197 \\
\hline Lymphocytes $(\times 10 \star 9 / \mathrm{L})$ & $1.9(1.6-2.3)$ & $1.8(1.5-2.2)$ & 0.136 \\
\hline Monocytes $(\times 10 * 9 / \mathrm{L})$ & $0.5(0.4-0.7)$ & $0.5(0.4-0.6)$ & 0.416 \\
\hline Basophils $(\times 10 * 9 / \mathrm{L})$ & $0.05(0.04-0.07)$ & $0.04(0.02-0.05)$ & 0.060 \\
\hline Eosinophils $(\times 10 * 9 / \mathrm{L})$ & $0.22(0.16-0.37)$ & $0.15(0.08-0.26)$ & 0.065 \\
\hline Neutrophils $(\times 10 * 9 / \mathrm{L})$ & $4.3(3.0-6.0)$ & $3.7(3.2-5.4)$ & 0.533 \\
\hline B-cell (\% of total) & $3.5(2.0-5.0)$ & $3.7(2.7-4.7)$ & 0.786 \\
\hline T-cell (\% of total) & $58.5(55.2-62.8)$ & $52.8(46.4-60.3)$ & 0.371 \\
\hline $\mathrm{CD}^{+}{ }^{+}(\%$ of total $)$ & $13.5(10.5-18.8)$ & $16.1(12.1-18.6)$ & 0.304 \\
\hline $\mathrm{CD}^{+}$(\% of total) & $5.0(2.9-10.2)$ & $6.5(4.0-11.4)$ & 0.295 \\
\hline T-helper (\% of total) & $11.8(9.5-16.7)$ & $14.9(11.0-16.9)$ & 0.286 \\
\hline T-regulatory (\% of total) & $1.4(1.0-1.8)$ & $1.4(0.9-1.8)$ & 0.856 \\
\hline NK-cells (\% of total) & $2.9(1.8-4.7)$ & $4.9(3.1-6.5)$ & $0.016^{*}$ \\
\hline Classical Mono (\% of total) & $4.6(3.8-5.7)$ & $6.5(4.6-7.5)$ & $0.012^{*}$ \\
\hline CD11c $($ MFI $)\left(\times 10^{3}\right)$ & $5.1(4.1-5.9)$ & $6.3(4.8-7.4)$ & 0.242 \\
\hline CD11b (MFI) $\left(\times 10^{3}\right)$ & $20.5(17.9-25.0)$ & $27.8(24.6-31.3)$ & $0.008^{*}$ \\
\hline CX3CR1 (MFI) $\left(\times 10^{3}\right)$ & $4.6(3.8-5.5)$ & $5.4(4.1-6.6)$ & 0.097 \\
\hline Intermediate Mono (\% of total) & $0.2(0.2-0.3)$ & $0.3(0.2-0.5)$ & 0.077 \\
\hline CD11c (MFI) $\left(\times 10^{3}\right)$ & $17.4(16.0-19.1)$ & $17.4(16.3-21.2)$ & 0.803 \\
\hline CD11b (MFI) $\left(\times 10^{3}\right)$ & $23.2(20.7-30.6)$ & $30.7(26.8-35.7)$ & $0.022^{*}$ \\
\hline CX3CR1 (MFI) $\left(\times 10^{3}\right)$ & $12.7(9.7-15.8)$ & $14.2(11.9-16.0)$ & 0.153 \\
\hline Nonclassical Mono (\% of total) & $0.5(0.4-0.8)$ & $1.0(0.7-1.6)$ & $0.000^{*}$ \\
\hline CD11c $(\mathrm{MFI})\left(\times 10^{3}\right)$ & $12.2(9.8-13.5)$ & $15.1(12.8-16.8)$ & 0.098 \\
\hline CD11b (MFI) $\left(\times 10^{3}\right)$ & $5.3(3.2-6.6)$ & $6.5(4.7-7.3)$ & 0.066 \\
\hline CX3CR1 (MFI) $\left(\times 10^{3}\right)$ & $10.7(8.7-12.7)$ & $12.0(10.4-13.7)$ & $0.043^{*}$ \\
\hline
\end{tabular}

Blood cells were either measured by an automated clinical assay (x109 cells/L) or with flow cytometry (\% of total cells) in whole blood. Data are presented as median (interquartile range). Differences in immune cell populations were analysed with linear regression with adjustment for age. ${ }^{*}$ P-value $<0.05$ is considered significant.

Circulating classical monocytes are associated with $C D 11 c^{+}$macrophages in $V A T$, independent of surface integrin and CX3CR1 expression

We investigated whether blood immune cell profiles relative to total leukocytes are associated with corresponding immune cells relative to 
stromal vascular cells in both AT depots. We found a positive association of blood classical monocytes with $\mathrm{CD}_{11} \mathrm{c}^{+}$macrophages in vAT $(\beta=0.67$, $p=0.014$ ) (Fig. 6.1A). Neither intermediate $(\beta=2.61, p=0.40)$ (Fig. 6.1B), nor nonclassical circulating monocytes $(\beta=1.9, p=0.054$ ) (Fig. 6.1C) correlated with $\mathrm{CD} 11 \mathrm{c}^{+}$macrophages in vAT. None of the circulating blood monocytes were associated with CD11c vAT macrophages (Fig. 6.1 D-F). Analysing lean and obese groups separately no longer showed a significant association, probably due to lack of power. However, effect sizes remained similar.

Table 6.3. Immune cell populations in ScAT and vAT

\begin{tabular}{|c|c|c|c|c|}
\hline & & Lean Subjects & Obese Subjects & P-value \\
\hline Subcutaneous & $\mathrm{CD}_{4} 5^{+}(\%$ of total $)$ & $48.3(36.6-54.1)$ & $38.4(30.2-50.6)$ & 0.571 \\
\hline \multirow[t]{7}{*}{ Adipose Tissue } & $\mathrm{CD} 1 \mathrm{c}^{-} \mathrm{CD}^{-11 b^{+}}(\%$ of total $)$ & $3.8(0.9-7.2)$ & $2.6(1.7-5.1)$ & 0.873 \\
\hline & $\mathrm{CD} 1 \mathrm{c}^{+} \mathrm{CD} 1 \mathrm{~b} \mathrm{~b}^{+}(\%$ of total $)$ & $5.6(2.3-9.5)$ & $6.9(4.2-11.1)$ & 0.587 \\
\hline & NK-cells (\% of total) & $3.0(2.2-4.0)$ & $3.1(2.4-4.9)$ & 0.971 \\
\hline & T-cells (\% of total) & $24.4(18.7-33.0)$ & $24.7(21.4-27.6)$ & 0.971 \\
\hline & T-helper cells ( $\%$ of total) & $14.0(9.5-20.6)$ & $11.2(8.9-14.8)$ & 0.583 \\
\hline & Cytotoxic T-cells (\% of total & $7.6(5.6-9.6)$ & $8.7(6.0-10.4)$ & 0.375 \\
\hline & B-cells (\% of total) & $0.7(0.4-1.0)$ & $0.7(0.5-1.5)$ & 0.862 \\
\hline Visceral & $\mathrm{CD}^{2} 5^{+}(\%$ of total $)$ & $41.9(25.6-47.5)$ & $55.7(50.6-61.6)$ & $<0.001^{*}$ \\
\hline \multirow[t]{7}{*}{ Adipose Tissue } & $\mathrm{CD} 1 \mathrm{c}^{-} \mathrm{CD}^{-11 b^{+}}(\%$ of total$)$ & $4(1.4-4.5)$ & $5.0(3.6-7.8)$ & 0.066 \\
\hline & $\mathrm{CD} 1 \mathrm{c}^{+} \mathrm{CD} 1 \mathrm{~b}^{+}(\%$ of total $)$ & $2.3(1.5-3.5)$ & $5.8(2.3-8.2)$ & $0.009^{*}$ \\
\hline & NK-cells (\% of total) & $2.7(1.6-4.1)$ & $3.8(2.7-5.8)$ & $0.029^{*}$ \\
\hline & T-cells (\% of total) & $27.3(15.5-40,6)$ & $40.8(24.1-46.2)$ & 0.107 \\
\hline & T-helper cells (\% of total) & $12.9(9.8-25.1)$ & $16.6(12.4-25.2)$ & 0.786 \\
\hline & Cytotoxic T-cells (\% of total) & $8.8(6.1-16.5)$ & $14.8(6.7-21.8)$ & 0.173 \\
\hline & B-cells ( $\%$ of total) & $0.5(0.2-3.3)$ & $1.4(0.9-2.2)$ & 0.055 \\
\hline
\end{tabular}

Immune cells were measured with flow cytometry in SVF from scAT and vAT biopsies. Data (\% of total cells) are presented as median (interquartile range). Differences in immune cell populations were analysed with linear regression with adjustment for age. ${ }^{*} \mathrm{P}$-value $<0.05$ is considered significant. 
A
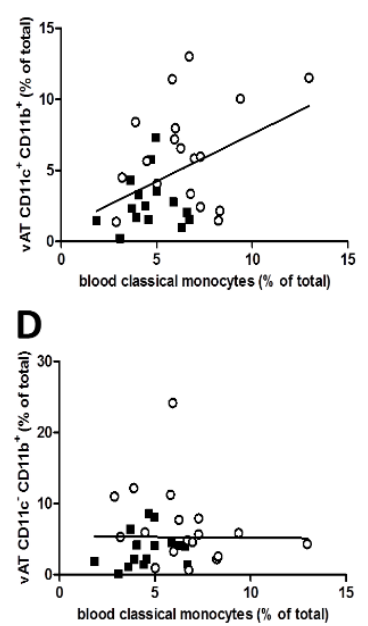

B

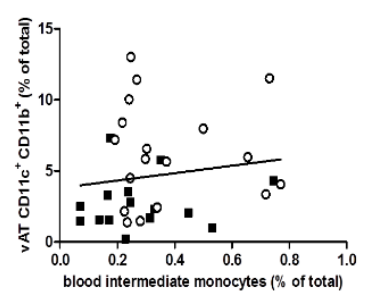

E

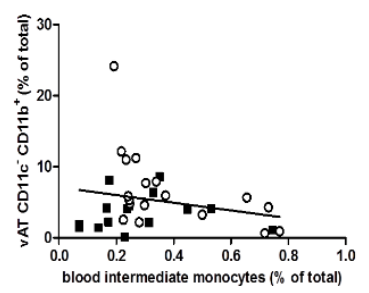

C

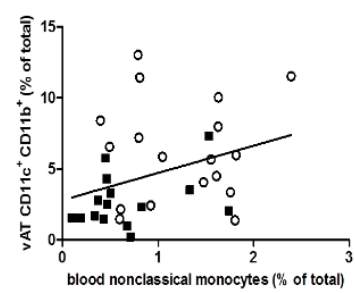

$\mathbf{F}$

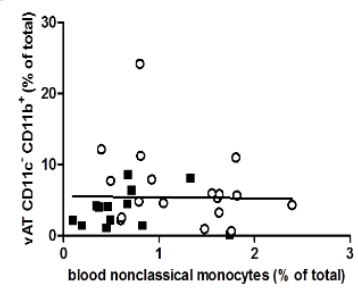

Figure 6.1. Leukocytes in vAT (represented as \% of stromal vascular cells on the Y-axis) were associated with circulating monocyte subsets (represented as \% of leukocytes on the $X$-axis) and with scAT leukocytes (represented as \% of stromal vascular cells on the $X$-axis) Squares represent data of lean individuals and open circles represent data from obese individuals. Regression analyses are shown for $C D 11 c+C D 11 b+M 1$ macrophages with (A) classical monocytes $(\beta=0.67, p=0.014)$, (B) intermediate monocytes $(\beta=2.61, p=0.40)$ and $(C)$ nonclassical monocytes $(\beta=1.90, p=0.054)$ and for CD11c-CD11b+M2 macrophages in vAT with circulating $(D)$ classical monocytes $(\beta=-0.023, p=0.95)$, $(E)$ intermediate monocytes $(\beta=-$ 5.54, $p=0.20)$ and $(F)$ nonclassical monocytes $(\beta=0.41, p=0.77)$.

Other blood immune cell types were not associated with their corresponding population in vAT (B-cells: $\beta=0.008, p=0.97$; $C D 4^{+}$T-cells: $\beta=0.136, p=0.67$; Th-cells: $\beta=0.149, p=0.67$; Treg-cells: $\beta=1.140, p=0.68 ; C D 8^{+}$Tc-cells: $\beta=0.064$, $p=0.82$; NK cells: $\beta=0.089, p=0.50$ ). In addition, blood monocyte subsets were not associated with either macrophage subset in scAT, nor were blood lymphocytes associated with their presence in SCAT (data not shown). Excluding obese patients with type 2 diabetes from these analyses did not materially alter these results (data not shown).

Integrins are involved in trafficking ${ }^{11}$, adhesion and transmigration of monocytes $^{12}$ and may be markers of cellular activation ${ }^{13}$. Therefore, we assessed whether surface integrin expression on blood monocytes, measured as the mean fluorescence intensity (MFI), was involved in the association found between blood monocyte and AT macrophage content. The expression of the integrin CD11b by classical monocytes was higher in 
obese individuals (Table 6.2). However, our analysis did not reveal any association between CD11b expression by monocyte subsets and CD11 $\mathrm{c}^{+}$ macrophage accumulation in vAT (classical: $\beta=0.018, p=0.81$; intermediate: $\beta=0.045, p=0.60$; nonclassical: $\beta=0.084, p=0.79$ ). Similar null-results were obtained for VAT CD11c macrophages (data not shown). Expression of the integrin CD11c on circulating monocytes did not differ between obese vs lean individuals (Table 6.2). In addition, the fractalkine receptor CX3CR1 has been suggested to be involved in monocyte recruitment during metabolic inflammation ${ }^{14}$. CX3CR1 expression on classical monocytes was not associated with $C D 11 c^{+}$macrophage accumulation in $\operatorname{VAT}(\beta=-0.09, p=0.80)$. CX3CR1 expression on intermediate monocytes however, did show a significant association with $\mathrm{CD} 11 \mathrm{c}^{+}$macrophage accumulation in VAT ( $\beta=$ $0.35 ; p=0.039$ ) and a similar trend was found for non-classical monocytes $(\beta=0.31 ; p=0.056)$. No associations were found for CX3CR1 expression with vAT CD11c macrophages (data not shown).

VAT CD11 $c^{+}$macrophage and Th-cell content is reflected by sCAT

We investigate whether immune cells in accessible scAT reflect immune cell distribution in VAT by determining their association between VAT and SCAT. A significant association was found for $C_{D} 11 c^{+}$macrophages $(\beta=0.37$; $p<0.001$ ) (Fig. 6.2A), but not for the CD11c subset $(\beta=0.26 ; p=0.12)$ (Fig. 6.2B). In addition, an association was found for $C D 4^{+}$T-helper cells $(\beta=0.61$; $\mathrm{p}=0.006$ ) (Fig. 6.2C), but not for other lymphocytes ( $C D 8^{+}$Tc-cells and B-cells) and NK cells (Fig. 6.2D-F). Excluding obese patients with diabetes from these analyses did not materially alter these results (data not shown). Finally, we performed these analyses separately in lean and obese individuals. The results show that obese individuals contributed most to the association of CD11 $c^{+}$macrophages between vAT and SCAT $(\beta=0.41, p=0.003)$; while lean individuals only retained a tendency $(\beta=0.18, p=0.096)$. Remarkably, the association between scAT and VAT Th-cells depended on lean individuals $(\beta=0.79, p=0.006)$; while this association was completely lost in the obese group $(\beta=0.31, p=0.42)$. 
A

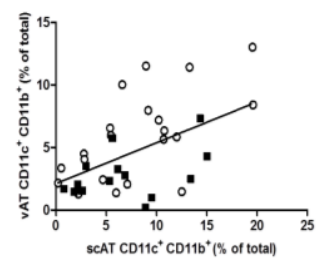

D

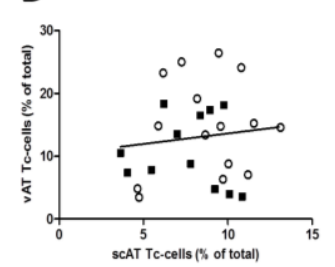

B

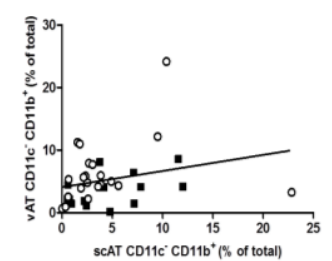

E

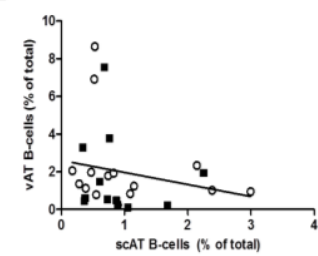

C

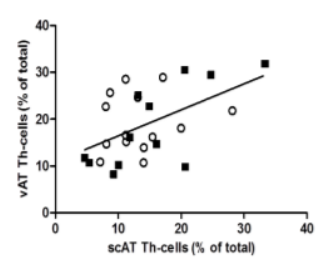

$\mathbf{F}$

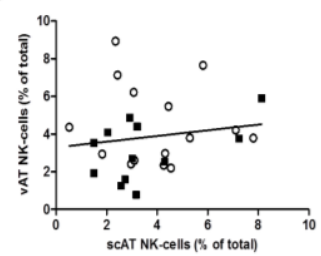

Figure 6.2.

Regression analyses between ScAT and VAT are shown for (A) CD11c+CD11b+M1 macrophages $(\beta=0.36, p<0.001)$, (B) CD11c-CD11b+M2 macrophages $(\beta=0.26, p=0.12)$, (C) CD4+ Th cells $(\beta=0.61, p=0.006)$, (D) CD8+ Tc cells $(\beta=0.33, p=0.55)$, (E) B-cells $(\beta=-0.64$, $p=0.31)$, and $(F)$ NK cells $(\beta=0.15, p=0.45)$.

\section{Discussion}

Our data delineate the associations between immune cell populations in human blood, vAT and scAT.

The flow cytometry data in blood of lean and obese individuals are in agreement with numerous studies showing positive associations between circulating nonclassical monocytes and obesity ${ }^{8,15}$. In contrast, data on classical monocytes seem inconsistent as not all studies find these cells to be increased in obese individuals ${ }^{7,10}$. In line with our data however, Schipper et al. showed that classical monocytes associate with $\mathrm{BMI}$ in obese children ${ }^{13}$. It should be noted that many studies report data on monocyte subsets either relative to the total monocyte pool, or as cell number. For the comparison with AT immune cell subsets, we have expressed our data as percentage of cells relative to total leukocytes, similar to the representation in AT (as \% of stromal vascular cells). Such different representation of data within the current literature may partially explain differences between studies.

Importantly, our analyses show that classical monocytes in blood reflect the accumulation of inflammatory $\mathrm{CD}_{11 \mathrm{c}^{+}}$macrophages in vAT. These 
correlations may indicate that the accumulation of VAT CD $11 \mathrm{c}^{+}$macrophages originates at least in part from blood monocytes. This observation seems at odds with recent cell tracking studies in mouse obesity models which show that, at least in the steady state, macrophages are seeded in AT during embryogenesis and are maintained by local self-renewal, independent of monocyte recruitment ${ }^{16}$. Interestingly, Haase et al. reported that local proliferation contributes mainly to $\mathrm{M} 2$ macrophages in murine adipose tissue ${ }^{17}$. In addition, $\mathrm{CD} 8^{+}$macrophages in human obese compared to lean AT showed increased expression of proliferation markers, but it remained unclear whether this was associated with a specific macrophage subset ${ }^{17}$. Our data corroborate the concept that $\mathrm{CD} 11 \mathrm{c}^{+}$"M1" macrophages in human VAT originate from circulating classical monocytes. In line, Pecht et al. recently showed that classical monocytes from healthy male donors displayed the highest migration toward conditioned medium from VAT compared to nonclassical and intermediated monocytes from the same donors ${ }^{18}$. Clearly, it is complicated to resolve these issues in humans. In mice, a recent elegant study using shielded irradiation followed by bone marrow transplantation showed that during obesity, monocyte influx and monocyteto-macrophage differentiation in AT becomes increasingly important. These newly arrived cells were found to proliferate in situ in crown-like structures 19. Unfortunately, we did not measure proliferation in our samples. However, based on our findings and current literature, we believe it is likely that both recruitment and local proliferation take part in human AT immune cell accumulation.

Integrins are involved in trafficking ${ }^{11}$, adhesion and transmigration of monocytes ${ }^{12}$ and expression of the integrin CD11b on total monocytes was shown to be associated with CD68 gene expression in SCAT biopsies ${ }^{20}$. However, our data did not reveal any association between integrin expression by separate monocyte subsets and macrophage subsets in VAT. These results thus argue against a need for CD11b and CD11c upregulation on monocytes for their recruitment to AT.

CX3CR1, which acts as a receptor for fractalkine (CX3CL1), has been shown to function as a chemoattractant and as an adhesion molecule ${ }^{21}$. In humans CX3CR1 has been implicated in obesity and type 2 diabetes ${ }^{22}$. However, there is conflicting data whether CX3CR1 is directly involved in monocyte 
recruitment to $A T, A T$ inflammation and insulin resistance ${ }^{23,24}$. Devevre et al. showed that CX3CR1 expression was increased in all three monocyte subsets of obese individuals ${ }^{25}$. Our data showed increased CX3CR1 expression only on non-classical monocytes although intermediate monocytes tended to show increased surface expression. Intriguingly, although intermediate monocytes were not associated with AT macrophages, we did found a positive association between CX3CR1 surface expression on these cells with CD11 ${ }^{+}$macrophages in vAT. Oppositely, classical monocytes did not show enhanced CX3CR1 surface expression, suggesting that CX3CR1 does not affect the relationship between classical monocytes and $\mathrm{CD}_{11 \mathrm{c}^{+}}$ macrophages in VAT.

Of interest is our observation that next to circulating monocytes and VAT macrophages, also circulating and VAT NK cells were higher in obese individuals. Recent observations in mice show that NK cells infiltrate VAT early during obesity development and contribute to the inflammatory environment causing insulin resistance ${ }^{26,27}$. It has been shown that blood NK cells are increased obese individuals but displayed decreased function ${ }^{28}$. However, we did not observe an association between blood and vAT NK cells. Further studies are thus needed to clarify the potential role of NK cells in obese humans.

Our results did not reveal associations between VAT or SCAT T-cell subsets and circulating T-cells. In contrast with these data, McLaughlin et al. reported significant correlations between $\mathrm{CD} 4^{+}$Th cells and $\mathrm{CD}^{+}$Tc cells in blood and scAT in humans ${ }^{29}$. McLaughlin et al. presented T-cell subsets as \% of total T cells while our data are presented relative to all circulating leukocytes or stromal vascular cells. While our data reflect a poor quantitative association between circulating and AT T-cell subsets, representing T-cell subsets as a fraction of total T-cells by McLaughlin et al. may reflect qualitative associations between blood and AT T-cell subsets. Thus, our data suggests that the predictive value of measuring circulating lymphocytes in blood as a reflection for immune cell infiltration in vAT is limited.

Finally, we analysed the association between immune cells in the two major AT depots. Since vAT is not readily accessible for research purposes, many studies use scAT biopsies as a marker for AT inflammation. Our data show that ScAT is a proxy for determining M1 macrophages and CD4 ${ }^{+} \mathrm{T}$-helper cells 
in human vAT. However, it should be kept in mind that inflammation is less pronounced in SCAT than in VAT. In addition, our results show that this association is stronger in obese individuals, implicating that using SCAT $\mathrm{CD}_{11 \mathrm{c}^{+}}$macrophages as a marker for vAT inflammation should be done cautiously. Intriguingly, the association between vAT and SCAT CD4 ${ }^{+}$T-helper cells depended completely on lean individuals as this relation was no longer present in obese men. It is known that obesity leads to a shift in the balance of Th2 and Th1 cells ${ }^{30}$. Since we did not include intracellular markers of Thelper cell polarization, it is possible that preferential recruitment of certain T-cell subsets negatively affected these associations in obese individuals.

Our study has some limitations. First, only male subjects were included. Therefore, future studies are needed to investigate whether current findings are also true for female individuals. Second, next to M1 adipose tissue macrophages, $C D 11 \mathrm{c}$ is considered to be a marker of dendritic cells ${ }^{31}$. Since most human DCs either express no CD11b or low levels of CD11b ${ }^{31}$ and since monocytes upregulate $\mathrm{CD} 11 \mathrm{~b}$ expression during their maturation into macrophages ${ }^{32}$, we identified adipose tissue macrophages as cells that express high levels of CD11b (see supplemental Fig. 6.1 for gating strategy). Comparing $\mathrm{CD} 11 \mathrm{c}^{+} \mathrm{CD} 11 \mathrm{~b}^{+}$adipose tissue macrophages with $\mathrm{CD} 11 \mathrm{~b}^{\text {low/ }}$

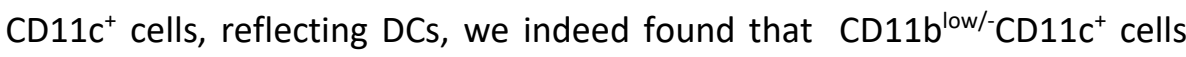
displayed higher expression levels of the DC markers CD141 and CD303 (suppl. Fig. 6.1c). Third, using biopsies from surgical procedures bears a risk of blood contamination of the tissue samples. Hence, part of the immune cells measured in these samples may be arising from residual blood. However, our data do not show any associations between the relative amount of T-cells, B-cells or NK cells between the circulation and adipose tissue, despite being identified by the same markers in blood and tissues. Therefore, we believe that the effects of blood contamination of the tissues used in this study are only minor. Finally, we did not correct our analyses for multiple testing. We acknowledge that this comprehensive evaluation of relations between different immune cell depots entailed multiple statistical tests, which may have increased the chance of false positive findings. On the other hand, rigorous adjustment for multiple testing would increase the chance that a real biological association is not detected. In this study, we explored hypotheses that were generated from basic science in order to 
provide a first line of human evidence as basis for further research. In the light of this aim, we argued that it would be undesirable to miss an association that does exist in the population. Therefore, and in agreement with current recommendations for observational studies, we did not formally adjust for multiple testing ${ }^{33}$.

In conclusion, our data show, independently from surface integrin expression, that blood classical monocytes are associated with $\mathrm{CD} 11 \mathrm{c}^{+}$ macrophages in vAT.

\section{Acknowledgements}

Maria Vroomen and José van de Gaar are greatly acknowledged for their technical support. 


\section{References}

1. Ohman MK, Wright AP, Wickenheiser KJ, et al. Visceral adipose tissue and atherosclerosis. Curr Vasc Pharmacol 2009;7:169-79.

2. Carvalheira JB, Qiu Y, Chawla A. Blood spotlight on leukocytes and obesity. Blood 2013;122:3263-7.

3. Lumeng CN, Bodzin JL, Saltiel AR. Obesity induces a phenotypic switch in adipose tissue macrophage polarization. J Clin Invest 2007;117:175-84.

4. Patsouris D, Li PP, Thapar D, et al. Ablation of CD11c-positive cells normalizes insulin sensitivity in obese insulin resistant animals. Cell Metab 2008;8:301-9.

5. Wentworth JM, Naselli G, Brown WA, et al. Pro-inflammatory CD11c+CD206+ adipose tissue macrophages are associated with insulin resistance in human obesity. Diabetes 2010;59:1648-56.

6. McNelis JC, Olefsky JM. Macrophages, immunity, and metabolic disease. Immunity 2014;41:36-48.

7. Harman-Boehm I, Bluher $\mathrm{M}$, Redel $\mathrm{H}$, et al. Macrophage infiltration into omental versus subcutaneous fat across different populations: Effect of regional adiposity and the comorbidities of obesity. Journal of Clinical Endocrinology \& Metabolism 2007; 92:2240-2247.

8. Pecht T, Gutman-Tirosh A, Bashan N, et al. Peripheral blood leucocyte subclasses as potential biomarkers of adipose tissue inflammation and obesity subphenotypes in humans. Obes Rev 2014;15:322-37.

9. Woollard KJ, Geissmann F. Monocytes in atherosclerosis: subsets and functions. Nat Rev Cardiol 2010;7:77-86.

10. Powell LA, Crowe $P$, Kankara $C$, et al. Restoration of adipose function in obese glucose-tolerant men following pioglitazone treatment is associated with CCAAT enhancer-binding protein beta up-regulation. Clin Sci (Lond) 2012;123:135-46.

11. Shi C, Pamer EG. Monocyte recruitment during infection and inflammation. Nat Rev Immunol 2011;11:762-74.

12. Zhang WY, Schwartz E, Wang Y, et al. Elevated concentrations of nonesterified fatty acids increase monocyte expression of $\mathrm{CD} 11 \mathrm{~b}$ and adhesion to endothelial cells. Arterioscler Thromb Vasc Biol 2006;26:514-9.

13. Lundahl J, Hallden G, Skold CM. Human blood monocytes, but not alveolar macrophages, reveal increased CD11b/CD18 expression and adhesion properties upon receptor-dependent activation. Eur Respir J 1996;9:1188-94.

14. Combadiere C, Potteaux S, Gao JL, et al. Decreased atherosclerotic lesion formation in CX3CR1/apolipoprotein E double knockout mice. Circulation 2003;107:1009-16.

15. Poitou C, Dalmas E, Renovato M, et al. CD14dimCD16+ and CD14+CD16+ monocytes in obesity and during weight loss: relationships with fat mass and subclinical atherosclerosis. Arterioscler Thromb Vasc Biol 2011;31:2322-30.

16. Amano SU, Cohen JL, Vangala $\mathrm{P}$, et al. Local proliferation of macrophages contributes to obesity-associated adipose tissue inflammation. Cell Metab 2014;19:162-171.

17. Haase J, Weyer $\mathrm{U}$, Immig $\mathrm{K}$, et al. Local proliferation of macrophages in adipose tissue during obesity-induced inflammation. Diabetologia 2014;57:562-71.

18. Pecht T, Haim Y, Bashan N, et al. Circulating Blood Monocyte Subclasses and LipidLaden Adipose Tissue Macrophages in Human Obesity. PLoS One 2016;11:e0159350. 
19. Zheng C, Yang Q, Cao J, et al. Local proliferation initiates macrophage accumulation in adipose tissue during obesity. Cell Death Dis 2016;7:e2167.

20. Boschmann M, Engeli S, Adams F, et al. Adipose tissue metabolism and CD11b expression on monocytes in obese hypertensives. Hypertension 2005;46:130-6.

21. Fong AM, Robinson LA, Steeber DA, et al. Fractalkine and CX3CR1 mediate a novel mechanism of leukocyte capture, firm adhesion, and activation under physiologic flow. J Exp Med 1998;188:1413-9.

22. Shah $\mathrm{R}$, Hinkle $\mathrm{CC}$, Ferguson JF, et al. Fractalkine is a novel human adipochemokine associated with type 2 diabetes. Diabetes 2011;60:1512-8.

23. Morris DL, Oatmen KE, Wang $\mathrm{T}$, et al. CX3CR1 deficiency does not influence trafficking of adipose tissue macrophages in mice with diet-induced obesity. Obesity (Silver Spring) 2012;20:1189-99.

24. Shah R, O'Neill SM, Hinkle C, et al. Metabolic Effects of CX3CR1 Deficiency in DietInduced Obese Mice. PLoS One 2015;10:e0138317.

25. Devevre EF, Renovato-Martins M, Clement K, et al. Profiling of the three circulating monocyte subpopulations in human obesity. J Immunol 2015;194:3917-23.

26. Lee BC, Kim MS, Pae M, et al. Adipose Natural Killer Cells Regulate Adipose Tissue Macrophages to Promote Insulin Resistance in Obesity. Cell Metab 2016;23:685-98.

27. Wensveen FM, Jelencic V, Valentic $S$, et al. NK cells link obesity-induced adipose stress to inflammation and insulin resistance. Nat Immunol 2015;16:376-85.

28. Viel S, Besson L, Charrier E, et al. Alteration of Natural Killer cell phenotype and function in obese individuals. Clin Immunol 2016.

29. McLaughlin T, Liu LF, Lamendola C, et al. T-cell profile in adipose tissue is associated with insulin resistance and systemic inflammation in humans. Arterioscler Thromb Vasc Biol 2014;34:2637-43.

30. Chatzigeorgiou A, Karalis KP, Bornstein SR, et al. Lymphocytes in obesity-related adipose tissue inflammation. Diabetologia 2012;55:2583-92.

31. Merad M, Sathe $P$, Helft J, et al. The dendritic cell lineage: ontogeny and function of dendritic cells and their subsets in the steady state and the inflamed setting. Annu Rev Immunol 2013;31:563-604.

32. Ammon C, Meyer SP, Schwarzfischer L, et al. Comparative analysis of integrin expression on monocyte-derived macrophages and monocyte-derived dendritic cells. Immunology 2000;100:364-9.

33. Vandenbroucke JP, von Elm E, Altman DG, et al. Strengthening the Reporting of Observational Studies in Epidemiology (STROBE): explanation and elaboration. Int J Surg 2014;12:1500-24. 


\section{Supplementary figures}

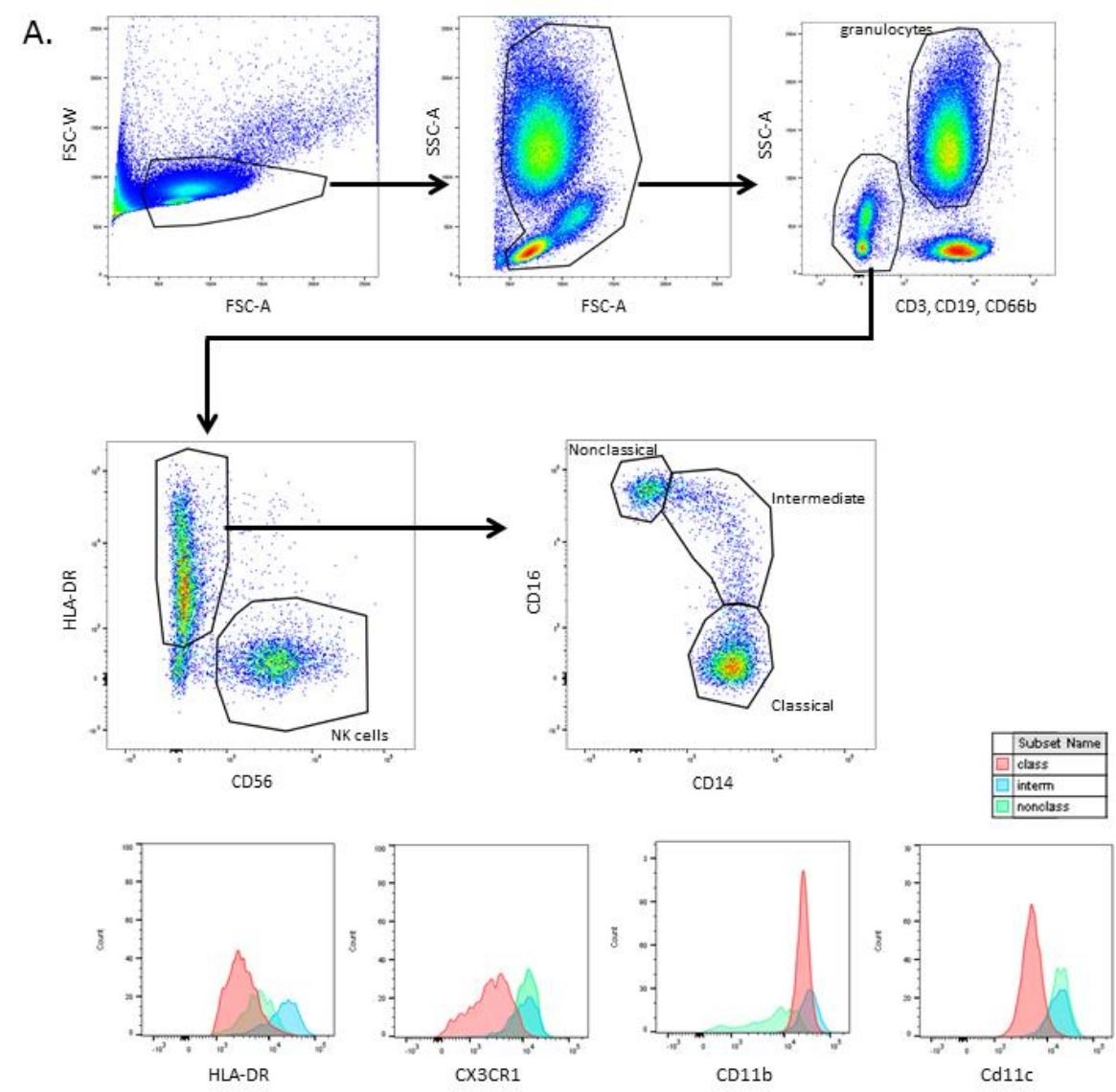

\section{Suppl. Figure 6.1A. Gating strategy}

From single blood cells, live cells were gated based on forward and side scatters. From live cells, negative (dump) selection was done based on CD3 (T cells), CD19 (B cells) and CD66b (granulocytes). Dump- cells were gated for CD56 (NK cells) and HLA-DR (monocytes). HLA-DRcells were over $95 \%$ negative for CD14 and CD16 (data not shown). From monocytes, subsets were identified based on CD14 and CD16 expression. The identity of the different monocyte subsets was validated using surface expression of CD11C, HLA-DR and CX3CR1. The boundaries of gates to differentiate between classical, intermediate and nonclassical monocytes were defined for each participant based on the expression of these markers. Classical monocytes: CD11clow, CX3CR1low and HLA-DRlow; intermediate monocytes: CD11chi, CX3CR1int and HLA-DRhi; nonclassical monocytes: CD11chi, CX3CR1hi and HLA-DRint. 
B.
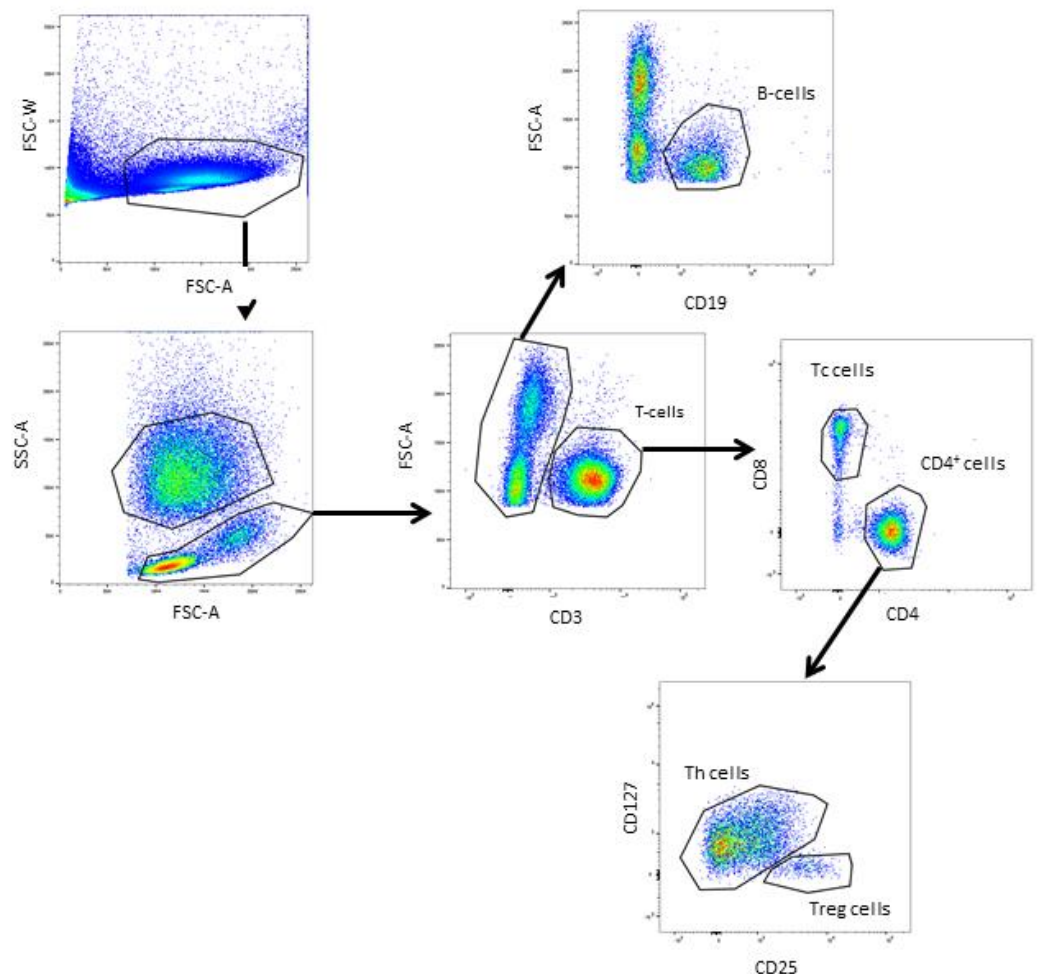

\section{Suppl. Figure 6.1B. Gating strategy}

From single blood cells, monocytes and lymphocytes were gated. B-cells were identified based on CD19 expression and T-cells by CD3. From total T cells, cytotoxic T cells were identified based on CD8 expression. From CD4-positive cells, Tregs (CD127low CD25high) and Thelper cells (CD127high CD25low) were identified. 
C.
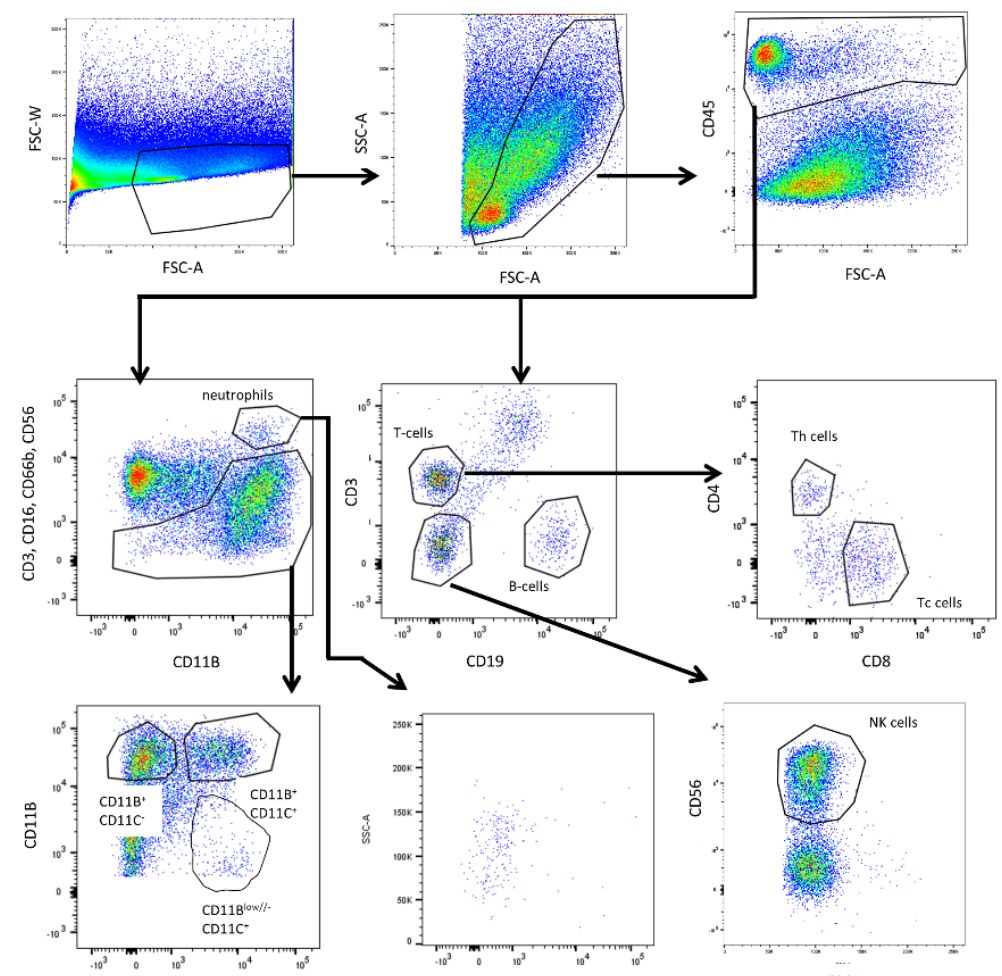

CD11C
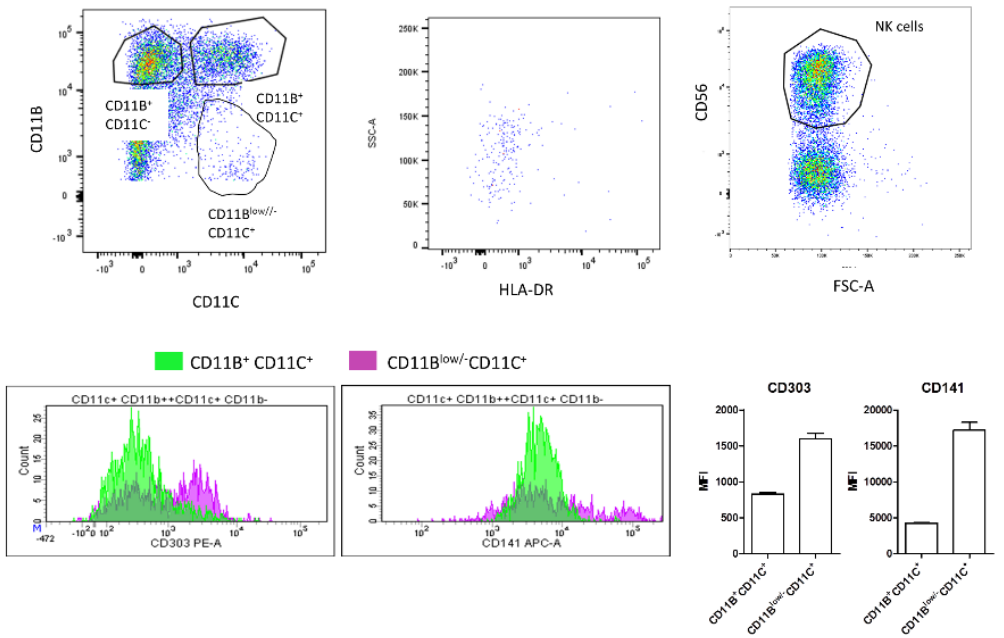

\section{Suppl. Figure 6.1C. Gating strategy}

SVF cells from VAT and SCAT were gated for live single cells based on forward and side scatters. Immune cells were selected based on CD45 expression. Lymphocyte populations in AT were identified based on CD19 for B-cells and CD3 for T-cells. T-cells were further subdivided in CD8 ${ }^{+}$Tc cells and CD4 ${ }^{+}$Th cells. Non-B- and T-cells were gated for CD56 to identify NK cells. From CD45+ cells B-cells (CD19), T-cells (CD3), NK cells (CD56) and granulocytes (CD66b) were excluded for the identification of macrophages (defined as CD11Bhi), which were subdivided in $\mathrm{CD}_{11} \mathrm{~B}^{+} \mathrm{CD} 11 \mathrm{C}^{-}$and $\mathrm{CD} 11 \mathrm{~B}^{+} \mathrm{CD} 11 \mathrm{C}^{+}$macrophages. The expression of the dendritic cell markers $C D C D 303$ and $C D 141$ was analyzed confirming that $C D 11 \mathrm{Blow} /$ - cells express dendritic

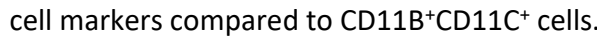


Chapter 6 


\section{Chapter 7}

Adipose tissue macrophages induce hepatic neutrophil recruitment and macrophage accumulation in mice

Mitchell Bijnen, Tatjana Josefs, Ilona Cuijpers, Constantijn J. Maalsen, José van de Gaar, Maria Vroomen, Erwin Wijnands, Sander S. Rensen, Jan Willem M. Greve, Marten H. Hofker, Erik A.L. Biessen, Coen D.A. Stehouwer, Casper G. Schalkwijk and Kristiaan Wouters 


\section{$\underline{\text { Abstract }}$}

\section{Objective}

Obesity is a risk factor for non-alcoholic steatohepatitis (NASH). This risk has been attributed to visceral adipose tissue (VAT) expansion associated with increased proinflammatory mediators. Accumulation of $\mathrm{CD}_{1} 1 \mathrm{c}^{+}$ proinflammatory adipose tissue macrophages (ATMs) is an important driver of VAT inflammation. We investigated the role of ATMs in hepatic inflammation during NASH development.

\section{Design}

VAT isolated from lean, obese, or ATM-depleted (using clodronate liposomes) obese mice was transplanted to lean Idlr $^{-1}$ acceptor mice. Systemic and hepatic inflammation was assessed either after 2 weeks on standard chow or after 8 weeks on high cholesterol diet (HCD) to induce NASH.

\section{Results}

Transplanting donor vAT from obese mice increased HCD-induced hepatic macrophage content compared to lean-transplanted mice, worsening liver damage. ATM depletion prior to VAT transplantation reduced this increased hepatic macrophage accumulation. On chow, VAT transplantation induced a more pronounced increase in circulating and hepatic neutrophil numbers in obese-transplanted than lean-transplanted mice, while ATM depletion prior to VAT transplantation reversed this effect. Microarray analysis of FACSsorted $\mathrm{CD} 11 \mathrm{C}^{+}$and $\mathrm{CD}_{11} \mathrm{c}^{-}$macrophages isolated from donor AT showed that obesity resulted in enhanced expression of neutrophil chemotaxis genes specifically in CD11 $\mathrm{C}^{+}$ATMs. Involvement of the neutrophil chemotaxis proteins, CXCL14 and CXCL16, was confirmed by culturing vAT. In humans, CD11c expression in VAT of obese individuals correlated with VAT expression of neutrophil chemotactic genes and with hepatic expression of neutrophil and macrophage marker genes.

\section{Conclusion}

ATMs from obese VAT induce hepatic macrophage accumulation during NASH development, possibly by enhancing neutrophil recruitment. 


\section{Summary box}

What is already known about this subject?

-Obesity is characterized by adipose tissue dysfunction resulting in increased adipose tissue inflammation, which can cause systemic inflammation.

-Obese adipose tissue is rich in $\mathrm{CD}_{11 \mathrm{c}^{+}}$macrophages which are proinflammatory and contribute to adipose tissue inflammation.

-A positive association between visceral adipose tissue macrophage numbers and liver histopathology (steatosis, fibrosis and inflammation score) has been shown in morbidly obese subjects.

\section{What are the new findings?}

-The proinflammatory $\mathrm{CD}_{11} \mathrm{C}^{+}$macrophages that accumulate in obese adipose tissue express high levels of neutrophil chemotaxis genes resulting in elevated secretion of neutrophil chemotaxis proteins, such as CXCL14 and CXCL16, by obese adipose tissue.

-The $\mathrm{CD} 11 \mathrm{C}^{+}$adipose tissue macrophages recruit neutrophils from bone marrow resulting in elevated circulating neutrophil levels and consequently increased hepatic neutrophil accumulation.

- In an experimental model of NASH, transplanting obese adipose tissue caused increased hepatic macrophage accumulation worsening liver damage.

- CD11c expression, as a marker of proinflammatory macrophages, was associated with neutrophil chemotaxis gene expression in human VAT biopsies. In addition, VAT CD11c expression also correlated with gene expression of neutrophil and macrophage markers in paired human liver biopsies.

\section{How might it impact on clinical practice in the foreseeable future?}

-Our data again shows the need to tackle adipose tissue inflammation as it seemingly contributes directly to complications such as NASH. More awareness regarding this subject is necessary and medication targeting systemic inflammation might be a treatment option.

-By revealing targetable proteins involved in the initiation of hepatic inflammation in obesity, such as the proposed neutrophil chemotaxis genes, 
specific inhibitors could be developed that might prevent effects of adipose tissue inflammation on systemic inflammation and thus the liver.

-For definitive diagnosis of NASH, an invasive liver biopsy is currently still required. Measuring a panel of circulating inflammatory proteins (chemokines) linked to hepatic inflammation would be a vast improvement. 


\section{Introduction}

Obesity has become a major health burden and is considered a key risk factor for diseases such as diabetes, non-alcoholic fatty liver disease (NAFLD), and a plethora of cardiovascular diseases $(C V D)^{1,2}$. This increased risk has been mainly attributed to the expansion of visceral adipose tissue (vAT), which is associated with inflammation. Lipid accumulation in the liver, known as steatosis, is present in the majority of obese subjects, of which $30 \%$ have biopsy-proven non-alcoholic steatohepatitis $(\mathrm{NASH})^{3}$. NASH is the most progressive form of NAFLD and is characterized by steatosis accompanied by inflammation causing irreversible liver damage and hepatic fibrosis. Extensive fibrosis can lead to cirrhosis, requiring patients to undergo a liver transplantation. Moreover, hepatic inflammation increases the risk of developing hepatocellular carcinoma and increases CVD risk ${ }^{4,5}$. Hepatic macrophages or Kupffer cells play a major role in liver inflammation and are thought to be triggered by an abundance of liver fat and factors such as inflammatory cytokines, oxidative stress, advanced glycation endproducts, and cholesterol ${ }^{6,7}$. However, the exact triggers of hepatic inflammation are not yet understood.

Compared to other AT depots, VAT is considered the main contributor to NAFLD development. Due to its anatomic proximity to the liver and due to the fact that venous drainage from vAT happens via the portal system, vAT could directly deliver fatty acids and inflammatory mediators to the liver ${ }^{8}$. Moreover, portal drainage of AT grafts has been shown to influence insulin sensitivity, possibly affecting NAFLD development ${ }^{9}$. Furthermore, the chronic systemic inflammation associated with vAT expansion may also contribute to hepatic inflammation. During obesity, adipose tissue macrophages (ATMs) accumulate in the vAT of mice and humans ${ }^{10,11}$. In addition to their elevated numbers, ATM phenotype changes during obesity development. vAT from lean subjects typically contains more Mannose Receptor C-type 1 positive $\left(\mathrm{MRC1}^{+}\right) \mathrm{CD} 11 \mathrm{c}^{-}$macrophages frequently described as "alternatively activated" anti-inflammatory M2 macrophages. In comparison, vAT from obese individuals has an abundance of "classically activated" proinflammatory $\mathrm{CD} 11 \mathrm{c}^{+} \mathrm{M} 1$ macrophages, which produce high levels of $T N F$, iNOS and IL12. CD11C ${ }^{+}$macrophages are typically found in crown-like 
structures surrounding dead adipocytes, are associated with insulin resistance, and may contribute to systemic chronic inflammation ${ }^{10}$. However, whether $\mathrm{CD}_{11} \mathrm{c}^{+}$macrophages directly contribute to NASH is unknown. Tordjman et al. demonstrated a positive association between visceral ATM numbers and liver histopathology (steatosis, fibrosis and inflammation score) in morbidly obese subjects ${ }^{12}$. However, which macrophage subset underlies this association and whether macrophages are causally linked to NASH development is unknown. In the current study, we investigated whether ATMs directly cause hepatic inflammation during NASH development. To achieve this, lean mice were transplanted with VAT from either lean donor mice, obese donor mice or obese donor mice from which ATMs in VAT tissue were depleted prior to transplantation. This experimental setup allowed us to investigate whether hepatic inflammation was affected by transplanting AT of obese mice compared to transplanting AT of lean mice. In addition, the exact contribution of ATMs was assessed by depleting ATMs prior to transplantation. Our study reveals a key role of ATMs in hepatic inflammation by amplifying macrophage accumulation in established NASH, possibly via inducing early neutrophil infiltration. 


\section{Materials and methods}

Additional materials and methods are included in the supporting information.

\section{Adipose tissue transplantation}

Epididymal AT derived from male donor C57BL/ $6 \mathrm{Idlr}^{-1-} \mathrm{CD} 45.1$ mice fed a low fat diet(LFD), high fat diet diet (HFD) or HFD in combination with clodronate liposomes injection was transplanted to male C57BL/6 CD45.2 congenic Idlr 1- mice resulting in three groups: lean-transplanted acceptors (LTA), obesetransplanted acceptors (OTA) and ATM-depleted obese-transplanted acceptors (DOTA). In the first experiment, hepatic steatosis and inflammation was induced in $\mathrm{Idll}^{-/}$acceptor mice with a high cholesterol diet (HCD) for four weeks before and eight weeks after AT transplantation ${ }^{13,14}$. In the second experiment, all acceptor mice received standard chow for two weeks.

\section{Flow cytometry}

AT and liver tissues were digested and bone marrow (BM) was flushed from the femur and tibia. Single cell suspensions were stained with a cocktail of antibodies (Suppl. table 7.1).

\section{RNA Isolation, cDNA Synthesis and qRT-PCR}

RNA was isolated from murine VAT and liver for CDNA synthesis followed by quantitative PCR. Primer sequences are given in supplementary table 7.2.

\section{Histology}

Frozen murine liver sections were stained with either oil red $\mathrm{O}$ or with antibodies against macrophages (F4/80), T-cells (CD3), monocytes/neutrophils (CD11B) and neutrophils (NIMP) as previously described $^{13,15}$. Paraffin-embedded VAT and liver sections were stained for Haematoxylin and Eosin or Sirius red to assess hepatic steatosis and fibrosis. 


\section{Liver and plasma cholesterol and triglyceride measurements}

Cholesterol and triglycerides were measured in liver homogenates and plasma as described previously ${ }^{16}$.

\section{Cytokine levels}

AT homogenates of donor AT were used to measure cytokine levels of MCP1, IL-6, CXCL1, IFN- $\gamma$, IL-1 $\beta$, IL-2, IL-4, IL-5, IL-10, IL-12P70, and TNF according to the manufacturer's instructions.

\section{AT culturing}

VAT explants from the three donor groups were cultured. LPS-induced CXCL14 and CXCL16 secretion were measured using ELISA, following manufacturer's instructions.

\section{CD11c and CD11 $\mathrm{c}^{+}$cell sorting and array}

By using fluorescence activated cell sorting (FACS), CD11 $\mathrm{c}^{+}$and CD11c- ATMs were isolated from mice fed either LFD or HFD for 12 weeks for micro-array analysis. Data is presented as fold change (FC) in expression level compared to LFD-fed mice. Genes showing fold changes of at least 1.50 and a P-value of less than 0.05 were considered differentially regulated.

\section{Human vAT and liver gene expression data}

VAT and liver micro-array data was obtained from vAT and liver biopsies which were taken from 74 morbidly obese patients (BMI 35-70) (Suppl. table. 7.3). Correlations were tested by calculating Pearson's correlation coefficient using SPSS statistics version 23 (IBM, USA). After Bonferroni correction to adjust for multiple testing, $\mathrm{P}$-values of $\mathrm{P} \leq 0.004$ were deemed statistically significant. The population was divided into non-NASH (score of $\leq 4$ ) and NASH (a score of $\geq 5$ ) based on the NAFLD activity score. 


\section{Results}

CD11 $\mathrm{c}^{+}$macrophages accumulate in visceral adipose tissue and correlate with hepatic macrophage content

Before transplanting VAT to lean acceptor mice, we examined the effect of HFD feeding and clodronate-mediated macrophage depletion on AT phenotype in non-transplanted mice. Compared to LFD-fed mice, 16 weeks of HFD feeding increased bodyweight over $80 \%$ and VAT and subcutaneous AT (scAT) weights (Suppl. Fig. 7.3A, B). Total immune cell levels were elevated in vAT but not scAT (Suppl. Fig. 7.3C). HFD induced expression levels of $\mathrm{Cd11C}$, Mcp1 (proinflammatory chemokine), Tnf (proinflammatory cytokine) and

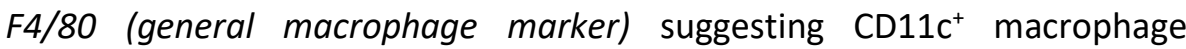
accumulation (Fig. 7.1A). Flow cytometry analysis revealed a large increase in $\mathrm{CD} 11 \mathrm{C}^{+}$macrophages while $\mathrm{CD} 11 \mathrm{C}^{-}$macrophages were increased to a lesser extent. Levels of $\mathrm{CD}^{+}{ }^{+}$T-cells were decreased in VAT by HFD feeding while other immune cells were unaffected (Fig. 7.1B). Interestingly, liver macrophage content correlated significantly with $\mathrm{CD}_{11} \mathrm{c}^{+}$macrophages in vAT but not with CD11c ATMs (Fig. 7.1C). Liver macrophages did not correlate with dendritic cells (DCs), CD8 ${ }^{+} \mathrm{T}$-cells, B-cells or granulocytes, but did show a negative correlation with CD4 ${ }^{+}$T-cells and NK cells in vAT (Suppl. Fig. 7.3D). These results suggest that $C D 11 c^{+} A T M$ numbers are linked to liver macrophage content.

\section{Clodronate liposomes deplete ATMs from vAT of obese mice}

Clodronate liposomes blunted the induction of $\mathrm{F} 4 / 80$ and $\mathrm{Cd} 11 \mathrm{C}$ expression by HFD feeding (Fig. 7.2A). Additionally, clodronate liposomes reduced levels of $\mathrm{CD} 11 \mathrm{c}^{-}$macrophages and normalized levels of $\mathrm{CD}_{11 \mathrm{c}^{+}}$macrophages in obese mice to levels as observed in LFD-fed mice without affecting CD11 $\mathrm{c}^{+}$ DCs (Fig. 7.2B). In agreement, crown-like structures, containing $\mathrm{CD}_{11 \mathrm{c}^{+}}$ cells ${ }^{17}$, were nearly absent after clodronate liposome injection (Fig. 7.2C). ATM depletion resulted in a decrease in Tnf and Ifn- $\gamma$ (macrophage activating cytokine) gene expression, without affecting expression levels of other cytokines such as IL10 (anti-inflammatory cytokine), IL1B (mediator inflammatory response), IL6 (proinflammatory cytokine), Fractalkine (chemokine and leukocyte adhesion) and Cxcl1 (chemotaxis) (Fig. 7.2D). In 
line, ATM depletion did not affect VAT IL6 and CXCL1 protein levels, while MCP1 protein levels were reduced (Fig. 7.2E). Two days after clodronate injection, circulating monocyte levels were normalized, suggesting that that all injected clodronate liposomes were phagocytosed already one day after injection (Suppl. Fig. 7.4A).

A

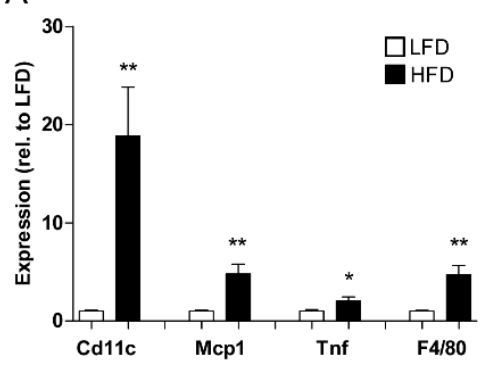

C

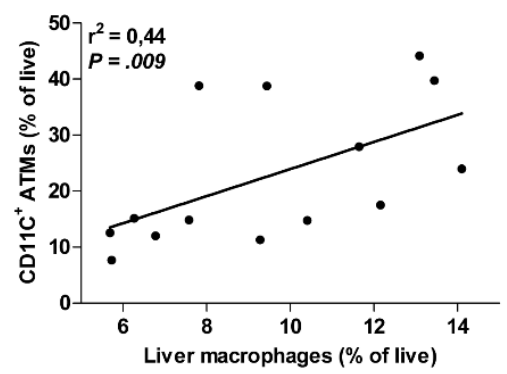

B
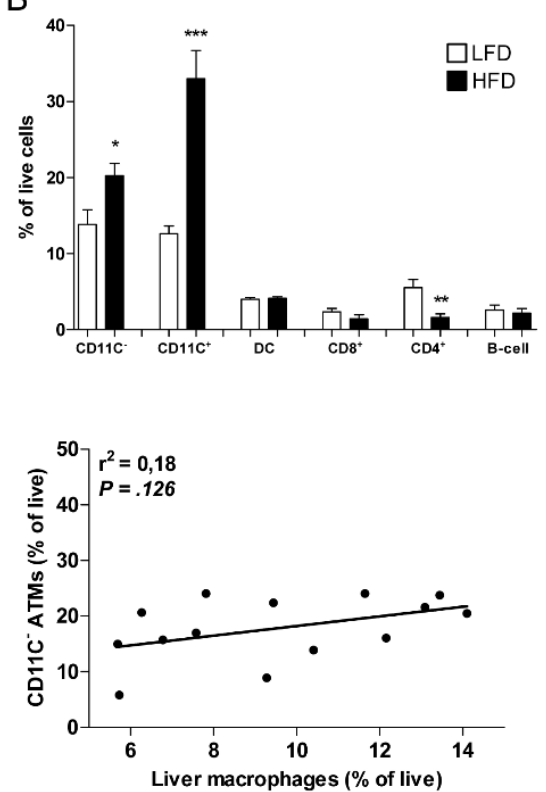

Figure 7.1. Diet-induced obesity induces accumulation of CD11c+ macrophages in visceral adipose tissue which correlates with hepatic macrophages

(A) Gene expression levels of Cd11c, Mcp1, Tnf and F4/80 in vAT of mice fed LFD or HFD for 16 weeks. (B) CD11c- and CD11c+ macrophages, dendritic cells (DC), CD8+ T-cells, CD4+ T-cells and B-cells were determined by flow cytometry and are displayed as percentage of live cells in VAT of LFD- and HFD-fed mice. (C) Correlations of CD11C+ or CD11C- ATMs with liver macrophages measured with flow cytometry. All data are means $\pm \mathrm{SEM} ; \mathrm{n}=7$ per group. ${ }^{*} \mathrm{P}<$ $0.05, * * \mathrm{P}<0.01, * * * \mathrm{P}<0.001$ vs LFD. Spearman's rank correlations based on $\mathrm{n}=14$.

\section{ATMs induce hepatic macrophage accumulation in NASH}

All acceptor Idlr ${ }^{-1-}$ mice received an HCD to induce NASH for 4 weeks before and 8 weeks after transplantation of donor VAT generating the following groups: lean-transplanted acceptors (LTA), obese-transplanted acceptors (OTA) and ATM-depleted obese-transplanted acceptors (DOTA). Body weight development in response to the HCD and surgery was comparable between 
the experimental groups, indicating equal recovery (Suppl. Fig. 7.5A). Transplanted AT was examined at the end of the experiment.
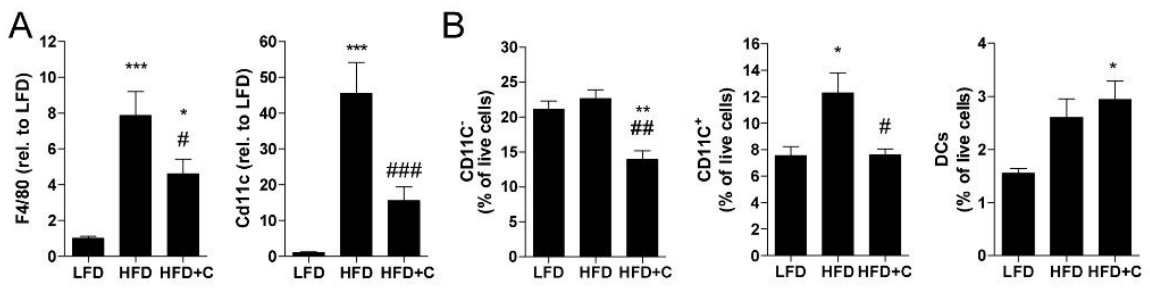

\title{
LFD
}

\author{
HFD
}

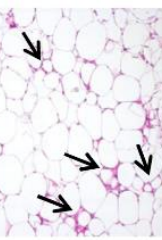

HFD+C
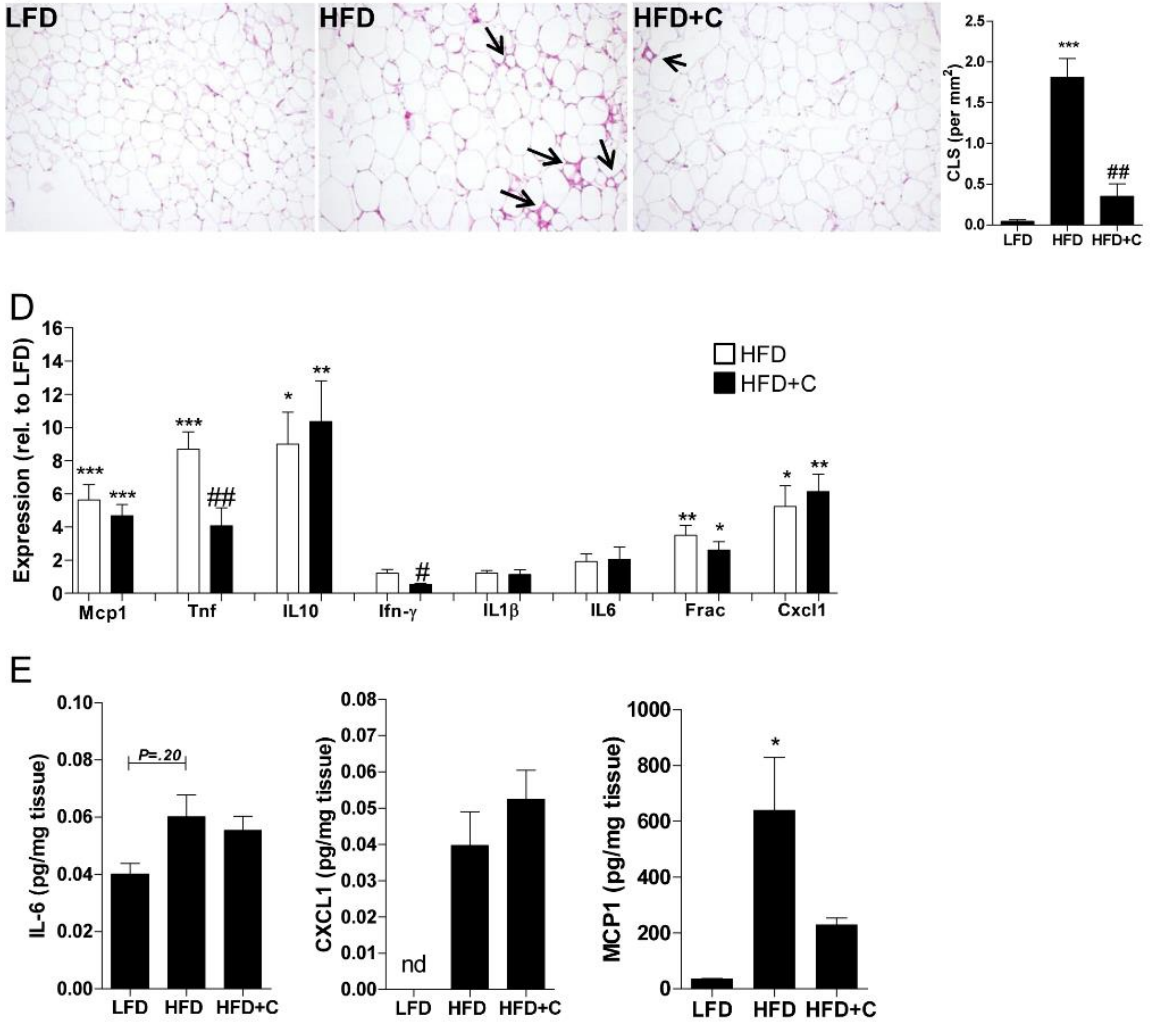

Figure 7.2. Clodronate liposomes deplete ATMs from obese vAT

(A, B) Gene expression levels of F4/80 and Cd11C (A) and CD11C- and CD11C+ macrophage and $D C$ numbers displayed as percentage of live cells determined by flow cytometry (B) in VAT of mice fed LFD, HFD or HFD and injected with clodronate liposomes 48 hours before sacrifice $(\mathrm{HFD}+\mathrm{C})$. (C) Representative pictures of the VAT stained with HE (100x magnification), arrows show crown-like structures, and quantification of these structures. (D, E) Gene expression (D) and protein levels (E) of inflammatory markers in the VAT (nd=not-detectable). All data are means $\pm S E M ; n=4-6$ per group. ${ }^{*} \mathrm{P}<0.05,{ }^{* * *} \mathrm{P}<0.001$ vs LFD. \#P $<0.05, \# \# \mathrm{P}<0.01$ vs HFD. 
Transplanted AT was well vascularized via the peritoneum in each mouse (data not shown). In addition, transplanted AT weight (Suppl. Fig. 7.4B), morphology and necrosis (data not shown) were similar between groups. Moreover, F4/80 and CD11C expression levels of transplanted AT were not significantly different between groups two or eight weeks after transplantation (Suppl. Fig. 7.4C, D). Experiments were performed using CD45.1 donor and CD45.2 acceptor mice. These isoforms of CD45 allowed us to distinguish donor and host cells, but do not differ in functionality. CD45.1 ${ }^{+}$ donor cells were absent in the circulation (Suppl. Fig. 7.5B), liver, spleen, AT and draining lymph nodes of CD45.2 acceptor mice post-transplantation (data not shown), excluding effects of direct migration of donor cells into host tissue. Due to the $H C D$, circulating monocyte and neutrophil levels were elevated before vAT transplantation $(t=0)^{18,19}$. VAT transplantation did not further affect blood monocytes in LTA mice. Interestingly, blood monocytes were decreased in OTA mice, while this effect was not observed in DOTA mice (Suppl. Fig. 7.5C). A similar trend was seen for both Ly6C- (patrolling) and $\mathrm{Ly}_{6 \mathrm{C}} \mathrm{C}^{+}$(inflammatory) monocyte subsets (data not shown). Circulating neutrophil levels were unchanged eight weeks after AT transplantation (Suppl. Fig. 7.5C).

Next, we investigated whether NASH development was affected in OTA or DOTA mice. Liver triglycerides and cholesterol measurements as well as HE and oil red $\mathrm{O}$ stained liver sections showed equal steatosis between the groups (Fig. 7.3A, C, Suppl. Fig. 7.5D-E). Hepatic neutrophil and T-cell numbers did not differ between the groups (Fig. 7.3B). Strikingly, hepatic macrophage content was increased in the OTA mice compared to LTA mice while this was not observed in the DOTA mice (Fig. 7.3D). In line, hepatic F4/80 expression was lower in DOTA mice compared to OTA mice. Other inflammatory genes such as Mcp1, Tnf, Mpo (neutrophil activation marker), Cd11b (myeloid marker present on neutrophils, monocytes and macrophages), and Ly6c (proinflammatory monocyte marker) and Col1a1 (fibrosis marker), were not different between the groups (Fig. 7.3E). Staining with Sirius red to visualize fibrosis revealed mild fibrosis which did not differ between the groups (data not shown). Compared to LTA mice, circulating alanine aminotransferase (ALAT) levels were strongly increased 

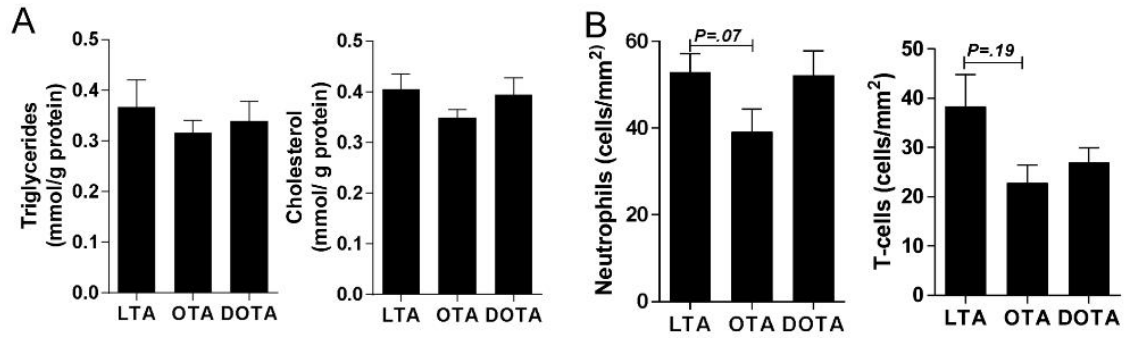

C
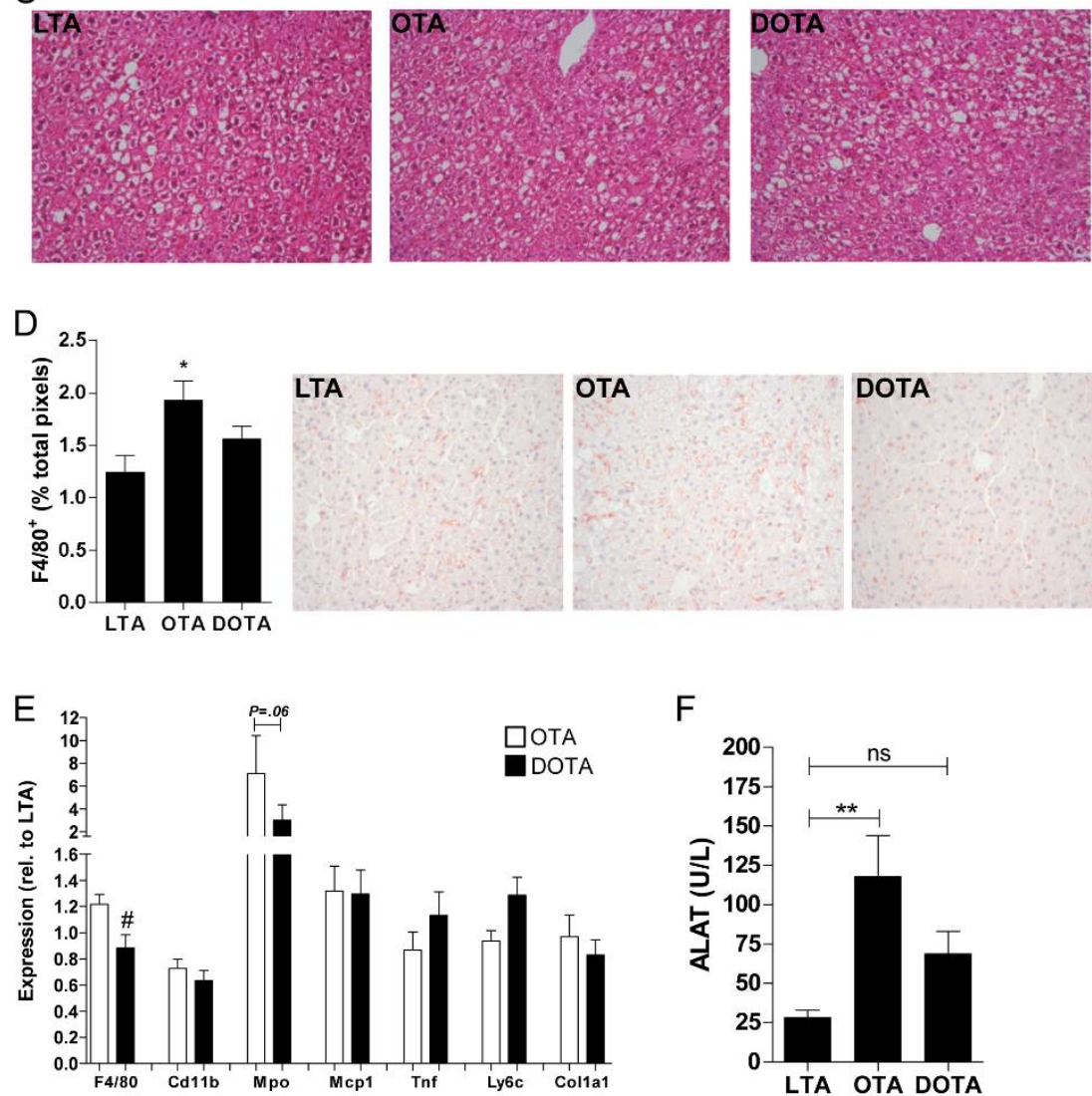

Figure 7.3. Adipose tissue macrophages induce hepatic macrophage accumulation in NASH (A, C) Liver triglyceride and cholesterol levels (A) including representative photos (200x magnification) of the HE stained liver sections (C) of LTA, OTA and DOTA mice fed an HCD for a total of 12 weeks. (B) Quantification of immunohistochemical staining of hepatic neutrophil and T-cell numbers in the LTA, OTA and DOTA mice. (D) Representative photos of the LTA, OTA and DOTA mice livers stained for F4/80 (200x magnification) and the corresponding quantification. (E) Hepatic gene expression levels of inflammatory, immune cell specific and fibrotic markers. (F) Circulating ALAT levels. All data are means $\pm S E M ; n=9-12$ per group. ${ }^{*} \mathrm{P}$ $<0.05$ vs LTA. ${ }^{* * P}<0.05$ vs LTA. \#P $<0.05$ vs OTA. 
in OTA mice, but not in DOTA mice (Fig. 7.3F). Plasma glucose and insulin levels did not differ between groups suggesting no effects on insulin resistance (data not shown). These findings indicate that ATMs induce hepatic macrophage accumulation in NASH contributing to hepatic damage.

A

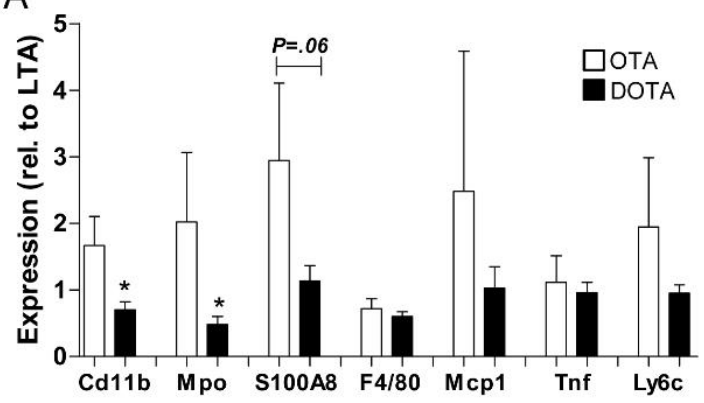

B

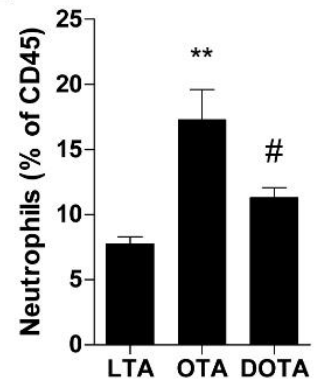

C
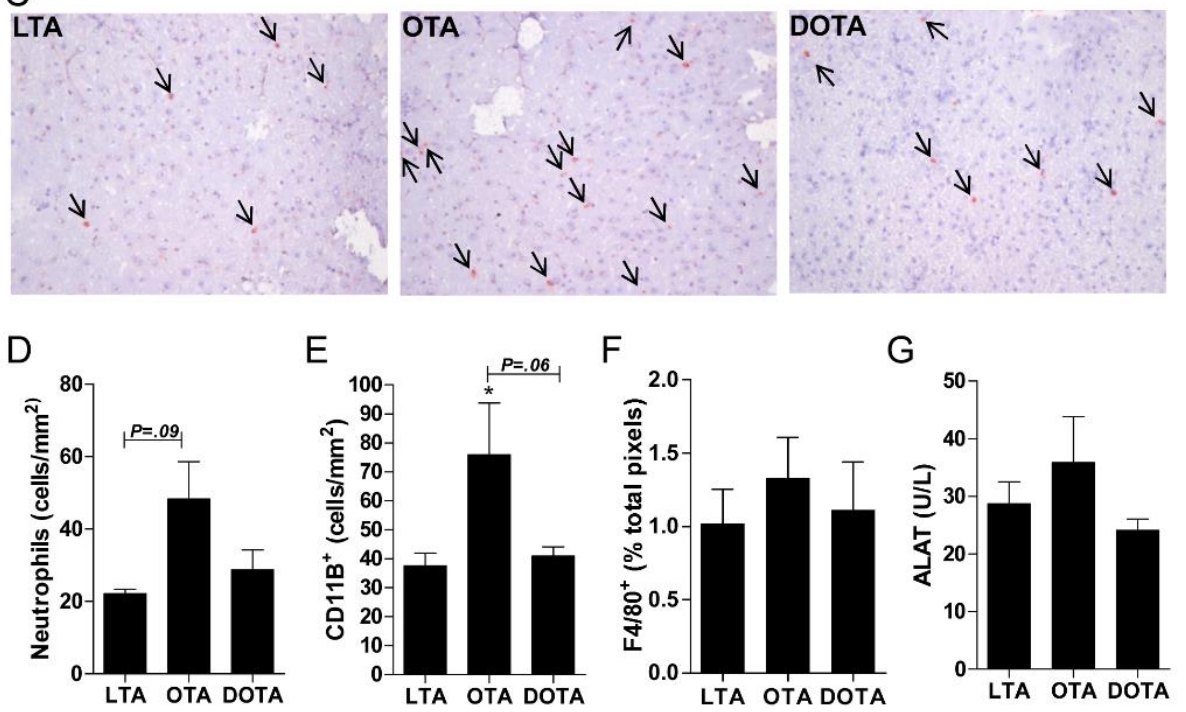

Figure 7.4. Hepatic neutrophil infiltration is triggered by ATMs

$(A, B)$ Hepatic gene expression levels of inflammatory markers $(A)$ and liver neutrophil levels measured by FACS (B) in LTA, OTA and DOTA mice two weeks after transplantation and fed a standard chow diet. (C, D) Representative pictures of hepatic neutrophil staining (200x magnification, arrows show positive cells) (C) and corresponding quantification (D). (E, F) Quantification of CD11B positive cells (E) and F4/80 staining (F) in the liver. (G) Plasma ALAT levels. All data are means \pm SEM; $n=4-5$ per group. ${ }^{*} \mathrm{P}<0.05,{ }^{*} \mathrm{P}<0.01$ vs LTA. \#P<0.05 vs OTA. 


\section{ATMs rapidly induce the recruitment of hepatic neutrophils}

To investigate the mechanisms responsible for increased hepatic macrophage accumulation in OTA mice, we studied the initiating events by performing a short term study. Again, vAT transplantation was performed to generate LTA, OTA or DOTA mice which were maintained on a chow diet. Compared to OTA mice, hepatic expression of the neutrophil marker MPO and of the myeloid marker $C d 11 b$ were decreased in DOTA mice suggesting decreased hepatic neutrophil infiltration. S100A8 (involved in neutrophil recruitment) expression levels tended to be decreased in DOTA mice. No difference was observed in inflammation- and macrophage-related markers such as F4/80, Mcp1, Tnf and Ly6c (Fig. 7.4A). Flow cytometry data showed a clear accumulation of hepatic neutrophils in OTA mice compared to LTA mice and confirmed the reduction of hepatic neutrophils in DOTA mice (Fig. 7.4B). Immunohistochemistry showed a similar but non-significant trend in hepatic

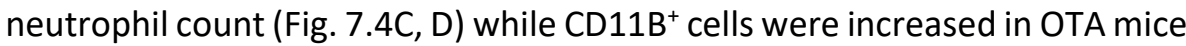
but not in DOTA mice (Fig. 7.4E). At this time point, there was no difference in $\mathrm{F} 4 / 80^{+}$tissue macrophages (Fig. 7.4F). In line, there were no differences in either plasma ALAT (Fig. 7.4G) or lipid levels, or in hepatic lipid levels (Suppl. fig. 7.6A, B). To assess whether lipolysis was affected in donor VAT, gene expression of lipolysis genes (HSL and LPL) in the transplanted AT as well as circulating free fatty acids were measured. No differences were found between groups (data not shown). Compared to LTA mice, OTA mice displayed elevated circulating neutrophils after VAT transplantation whereas in DOTA mice circulating neutrophils decreased (Fig. 7.5A). Circulating monocytes showed a trend towards increased levels in LTA and OTA but not in DOTA mice (Fig. 7.5A). These results suggest that ATMs stimulate neutrophil recruitment, possibly from BM. Therefore, using flow cytometry, we determined levels of BM progenitor cells. Common myeloid progenitor cells (CMPs) were higher in OTA and DOTA mice, albeit not statistically significant. Granulocyte-macrophage progenitor cells

(GMPs), which are derived from CMPs and are neutrophil precursors ${ }^{20}$, were lower in the DOTA mice compared to the OTA mice (Fig. 7.5B), suggesting that ATMs from obese vAT stimulate neutrophil development in BM. 
A
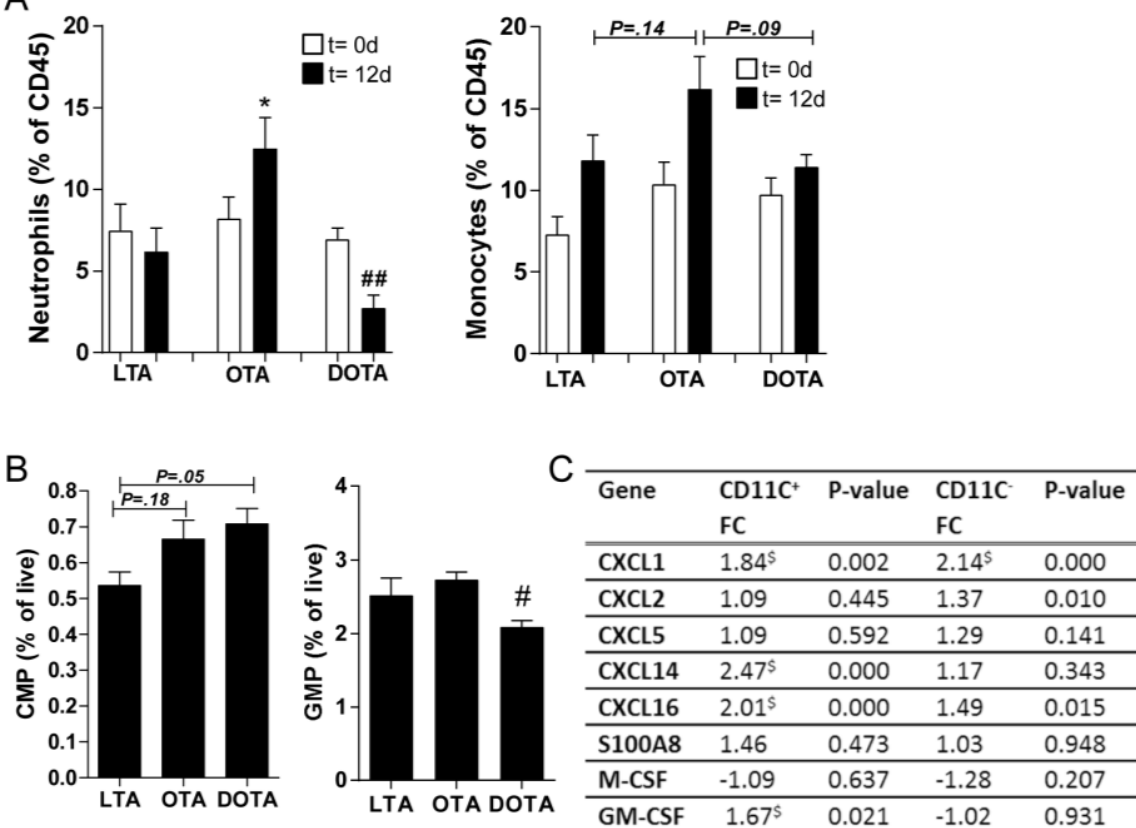

\begin{tabular}{lllll}
\multicolumn{2}{c}{ FC } & \multicolumn{3}{l}{ FC } \\
\hline CXCL1 & $1.84^{\text {s }}$ & 0.002 & $2.14^{\text {s }}$ & 0.000 \\
\hline CXCL2 & 1.09 & 0.445 & 1.37 & 0.010 \\
\hline CXCL5 & 1.09 & 0.592 & 1.29 & 0.141 \\
\hline CXCL14 & $2.47^{\text {S }}$ & 0.000 & 1.17 & 0.343 \\
\hline CXCL16 & $2.01^{\text {s }}$ & 0.000 & 1.49 & 0.015 \\
\hline S100A8 & 1.46 & 0.473 & 1.03 & 0.948 \\
\hline M-CSF & -1.09 & 0.637 & -1.28 & 0.207 \\
\hline GM-CSF & $1.67^{\text {S }}$ & 0.021 & -1.02 & 0.931 \\
\hline G-CSF & $-1.63^{\text {s }}$ & 0.013 & -1.15 & 0.429 \\
\hline & & & &
\end{tabular}
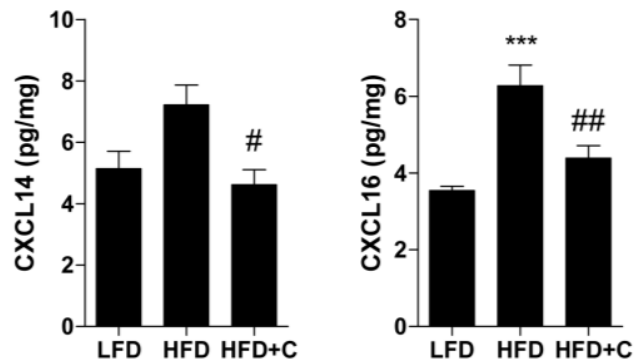

Figure 7.5. $C D 11 c+A T M s$ increase circulating neutrophils and their recruitment from the bone marrow

(A) Circulating neutrophils and monocytes before and 12 days after AT transplantation in LTA, OTA and DOTA mice on a chow diet. (B) Bone marrow FACS data displaying CMP and GMP cells as percentage of live bone marrow cells two weeks after transplantation. (C) Fold changes (FC) in gene expression of a cluster of genes involved in neutrophil chemotaxis in CD11c+ and CD11c- macrophages after HFD feeding. All data are means \pm SEM; $n=4-5$ per group. ${ }^{*} P<0.05$ vs LTA. \#P $<0.05, \# \#>0.01$ vs OTA. \$FC $\geq 1.50$ and $P<0.05$ was considered differentially regulated. (D) CXCL14 and CXCL16 protein levels measured in medium after culturing AT derived from donor mice expressed as pg produced per mg AT. $n=4-6$. Representative data shown of experiment, which was performed 3 times. All data are means $\pm \mathrm{SEM}$; ${ }^{* * *} \mathrm{P}<0.001$ vs LFD. \#P $<0.05, \# \# P<0.01$ vs HFD. 
To determine the mechanism by which ATMs induce neutrophil recruitment, we sorted $\mathrm{CD} 11 \mathrm{c}^{+}$and $\mathrm{CD} 11 \mathrm{c}^{-}$macrophages from VAT derived from LFD- and HFD-fed mice (similar to donor mice). Microarray analysis was performed to investigate qualitative differences in ATMs induced by obesity. Interestingly, several genes involved in neutrophil chemotaxis, such as members of the CXCL and CSF families, were specifically upregulated only in CD11 $\mathrm{c}^{+} \mathrm{ATMs}$ in response to high fat feeding (Fig. 7.5C): $C x C l 14(F C=2.47), C x C l 16(F C=2.01)$ and $\mathrm{Gm}$-csf ( $\mathrm{FC}=1.67)$. Cxcl1 was increased significantly in both $\mathrm{CD} 11 \mathrm{c}^{+}$(Fold Change; $F C=1.84)$ and $C D 11 c^{-}(F C=2.14)$ cells after HFD feeding. In total vAT, HFD feeding increased gene expression of CXCL14 and CXCL16. Depletion of ATMs using clodronate reduced both CXCL14 and CXCL16 expression, but this reduction was only significant for CXCL14 (Suppl. Fig. 7.7A). Taken together, these data show that, in addition to their accumulation in VAT during obesity, $C D 11 c^{+}$cells feature enhanced expression of neutrophil chemo-attractants. Finally, culturing vAT from the 3 different types of donor mice showed that CXCL14 and CXCL16 protein secretion is induced in VAT from obese mice and ATM depletion normalized this secretion to the levels observed in vAT from lean animals (Fig. 7.5D). These results suggest that ATMs are responsible for the secretion of neutrophil chemo-attractants by vAT.

\section{Human CD11c expression in vAT correlates with liver neutrophil and macrophage markers}

To investigate if our findings were translatable to human liver disease, we analyzed hepatic and VAT transcriptomic data of bariatric surgery patients (Suppl. table 7.3). Based on the NAFLD activity score (NAS), subjects were divided into non-NASH (NAS $\leq 4$ ) and NASH (NAS $\geq 5$ ) patients. Although all patients displayed morbid obesity, gene expression of CXCL5, CXCL16 and MCSF was only increased in obese patients with NASH. Other inflammatory genes, including $\mathrm{CD} 11 \mathrm{c}$, tended to be higher in obese patients with NASH (Suppl. table 7.4). Next, we investigated whether macrophage markers in vAT correlated with macrophage and neutrophil markers in the livers of the same individuals (Table 7.1). CD11c gene expression was used as a marker of CD11 $\mathrm{C}^{+}$ATMs, while for CD11 $\mathrm{C}^{-}$ATMs, we analyzed MRC1, a known marker of alternatively activated resident $\mathrm{CD}_{11} \mathrm{C}^{-}$AT macrophages ${ }^{10}$. CD11C 
expression in VAT correlated with hepatic expression of the neutrophil markers MPO ( $\mathrm{R}=0.331 ; \mathrm{P}=0.004)$ and $C D 15(\mathrm{R}=0.328 ; \mathrm{P}=0.004)^{21,22}$. We did not find a correlation between MRC1 in vAT and hepatic MPO, CD15 or CD11B expression. CD11C in vAT did not correlate with hepatic FCGR2A $(R=0.246 ; P=0.035)$, a general macrophage marker, or with $M R C 1(R=0.061$; $\mathrm{P}=0.608$ ) but did show a strong correlation with hepatic $C D 11 \mathrm{c}$ expression $(\mathrm{R}=0.426 ; \mathrm{P}=0.000)$. vAT $M R C 1$ did not correlate with any of these markers in the liver.

Table 7.1. Correlations of CD11c and MRC1 expression in human vAT with neutrophil and macrophage markers in the liver

\begin{tabular}{|c|c|c|c|c|c|c|c|}
\hline & & $\begin{array}{l}\text { MPO } \\
\text { (liver) }\end{array}$ & $\begin{array}{l}\text { CD15 } \\
\text { (liver) }\end{array}$ & $\begin{array}{l}\text { CD11B } \\
\text { (liver) }\end{array}$ & $\begin{array}{l}\text { FCGR2A } \\
\text { (liver) }\end{array}$ & $\begin{array}{l}\text { CD11C } \\
\text { (liver) }\end{array}$ & $\begin{array}{l}\text { MRC1 } \\
\text { (liver) }\end{array}$ \\
\hline \multirow{2}{*}{$\begin{array}{l}\text { CD11c } \\
\text { (VAT) }\end{array}$} & $R$-value & $0.331 *$ & $0.328 *$ & 0.160 & 0.246 & $0.426 *$ & 0.061 \\
\hline & P-value & 0.004 & 0.004 & 0.173 & 0.035 & 0.000 & 0.608 \\
\hline \multirow{2}{*}{$\begin{array}{l}\text { MRC1 } \\
\text { (VAT) }\end{array}$} & R-value & -0.185 & 0.001 & -0.023 & -0.016 & 0.057 & 0.025 \\
\hline & $P$-value & 0.114 & 0.993 & 0.845 & 0.890 & 0.629 & 0.832 \\
\hline
\end{tabular}

R-values and corresponding P-values of the Pearson correlations between CD11c or MRC1 in vAT with MPO, CD15, CD11B, FCGR2A, CD11c and MRC1 in liver. $n=74$. *P-values of $P \leq 0.004$ were deemed statistically significant due to adjustment for multiple testing.

Next, we studied the association of $C D 11 C$ or MRC1 in vAT with neutrophil chemotaxis genes in vAT. Strong correlations were found between $C D 11 \mathrm{C}$ and CXCL2 ( $\mathrm{R}=0.695 ; \mathrm{P}=0.000), C X C L 5(\mathrm{R}=0.565 ; \mathrm{P}=0.000), \mathrm{CXCL8}$ (human homologue of murine $C X C L 1 ; R=0.736 ; P=0.000), \operatorname{CXCL16}(\mathrm{R}=0.504 ; \mathrm{P}=0.000)$, S100A8 ( $R=0.813 ; \mathrm{P}=0.000)$ and $G-C S F(R=0.702 ; P=0.000)$ but not with $G M$ CSF $(\mathrm{R}=-0.016 ; \mathrm{P}=0.895)$ or $\mathrm{M}-\mathrm{CSF}(\mathrm{R}=0.069 ; \mathrm{P}=0.559)$. Conversely, MRC1 did not correlate with any of the chemotaxis markers (Table 7.2). Although numerically outnumbered by ATMs, dendritic cells (DCs) also express CD11c. VAT expression of the dendritic cell marker gene FLT3 did not correlate with any of the investigated genes in the liver and only correlated with CXCL5 
$(R=0.355 ; P=0.002)$ in the vAT (Suppl. table 7.5 and 7.6), arguing against $D C$ involvement ${ }^{23}$. Taken together, these findings are in line with our data showing that $\mathrm{CD} 11 \mathrm{c}^{+}$macrophages in VAT mediate the increased neutrophil chemotaxis and hepatic inflammation.

Table 7.2. Correlations of CD11C and MRC1 expression with neutrophil chemotaxis genes in human vAT

\begin{tabular}{llllllllll}
\hline & $\begin{array}{l}\text { CXCL2 } \\
\text { (vAT) }\end{array}$ & $\begin{array}{l}\text { CXCL5 } \\
\text { (vAT) }\end{array}$ & $\begin{array}{l}\text { CXCL8 } \\
\text { (vAT) }\end{array}$ & $\begin{array}{l}\text { CXCL16 } \\
\text { (vAT) }\end{array}$ & $\begin{array}{l}\text { S100A8 } \\
\text { (vAT) }\end{array}$ & $\begin{array}{l}\text { G-CSF } \\
\text { (vAT) }\end{array}$ & $\begin{array}{l}\text { GM-CSF } \\
\text { (vAT) }\end{array}$ & $\begin{array}{l}\text { M-CSF } \\
\text { (vAT) }\end{array}$ \\
\hline $\begin{array}{l}\text { CD11c } \\
\text { (vAT) }\end{array}$ & R-value & $0.695^{*}$ & $0.565^{*}$ & $0.736^{*}$ & $0.504^{*}$ & $0.813^{*}$ & $0.702^{*}$ & -0.016 & 0.069 \\
\hline & P-value & 0.000 & 0.000 & 0.000 & 0.000 & 0.000 & 0.000 & 0.895 & 0.559 \\
\hline $\begin{array}{l}\text { MRC1 } \\
\text { (vAT) }\end{array}$ & R-value & 0.048 & -0.032 & 0.046 & 0.024 & 0.008 & 0.092 & 0.030 & 0.045 \\
\hline & P-value & 0.685 & 0.787 & 0.696 & 0.838 & 0.943 & 0.435 & 0.798 & 0.701 \\
\hline
\end{tabular}

R-values and corresponding P-values of the Pearson correlations between CD11C or MRC1 with CXCL2, CXCL5, CXCL8, CXCL16, S100A8, G-CSF, GM-CSF and M-CSF in vAT. n=74. *Pvalues of $\mathrm{P} \leq 0.004$ were deemed statistically significant due to adjustment for multiple testing.

\section{Discussion}

Our study shows that transplantation of AT from obese mice rapidly causes elevated circulating neutrophils and hepatic neutrophil infiltration. Increased expression of genes involved in neutrophil recruitment, in CD11c ${ }^{+}$ATMs, probably contributes to hepatic neutrophil accumulation. Furthermore, in an experimental model of $\mathrm{NASH}$, transplanting $\mathrm{CD} 11 \mathrm{c}^{+}$ATM-rich AT of obese mice resulted in more hepatic macrophage accumulation and enhanced liver damage. Depleting ATMs from obese donor AT prior to transplantation inhibited the effects on neutrophil and macrophage accumulation, indicating that $\mathrm{CD} 11 \mathrm{c}^{+}$ATMs directly contribute to hepatic inflammation. Lastly, CD11c expression was associated with neutrophil chemotaxis gene expression in human AT biopsies. Strikingly, AT CD11c expression also correlated with gene expression of neutrophil and macrophage markers in paired human liver biopsies. 
Previously, it has been shown that visceral ATM numbers and liver histopathology (steatosis, fibrosis and inflammation score) are associated in morbidly obese subjects ${ }^{12}$. Using FACS analysis on murine adipose tissue, we now show that specifically $\mathrm{CD} 11 \mathrm{c}^{+}$, but not $\mathrm{CD} 11 \mathrm{c}^{-}$macrophages are associated with hepatic macrophages. Moreover, our microarray data in human AT and liver biopsies confirm this link between CD11c ${ }^{+}$ATMs and hepatic pathophysiology.

Transplanting AT from obese mice, rich in $\mathrm{CD}_{11 \mathrm{c}^{+}}$macrophages, to nonhypercholesteraemic mice rapidly resulted in elevated circulating and hepatic neutrophils levels, but not when transplanting AT from obese mice from which ATMs were depleted prior to transplantation. A potential role of neutrophils in NASH has been previously suggested as MPO deficient mice have reduced hepatic inflammation and attenuated NASH development ${ }^{24}$. However, the increase in hepatic neutrophil accumulation we observed 12 days after AT transplantation did not coincide with macrophage accumulation or elevated liver enzyme levels. Neutrophils are the first cell type to be recruited in response to infections or damage, followed by monocyte recruitment and macrophage accumulation to tissues ${ }^{25}$. Hence, it is possible that neutrophil recruitment is a primary event leading to further liver inflammation. In line, our data show that during NASH development, AT from obese mice enhanced hepatic macrophage accumulation in acceptor mice and increased circulating liver enzyme levels, suggesting enhanced liver damage. Again, these effects were mediated by obesity-induced ATMs since depletion of ATMs before transplantation did not increase macrophage accumulation or ALAT levels. Collectively, these data suggest a certain sequence of events where ATMs trigger the recruitment of neutrophils via enhanced production of chemokines, leading to their accumulation in the liver. Next, these acute events probably lead to hepatic macrophage accumulation resulting in liver damage. In line, Nagareddy et al. previously showed that ATMs can mediate bone marrow production of neutrophils ${ }^{26}$. Moreover, disrupting inflammatory signaling in CD11c expressing cells decreased circulating neutrophil and neutrophil precursor levels in bone marrow. These data argue in favor of a causal role for $\mathrm{CD} 11 \mathrm{c}^{+}$macrophages ${ }^{26}$.

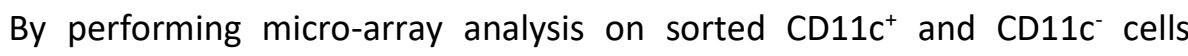
derived from AT of lean and obese mice, we now accurately determined gene 
expression of chemo-attractant proteins in specific macrophage populations instead of in whole AT. Our data showed an increased expression of neutrophil chemotaxis genes in specifically $\mathrm{CD} 11 \mathrm{c}^{+}$macrophages. Most of the upregulated genes in $\mathrm{CD} 11 \mathrm{c}^{+}$macrophages belong to the $\mathrm{CXCL}$ chemokine families which are known to primarily attract neutrophils ${ }^{27}$. In particular CXCL1/CXCL8 and CXCL16 have been well described to recruit neutrophils in vivo, while CXCL14 is considered a strong chemoattractant of neutrophils based on in vitro assays ${ }^{25,27-30}$. Interestingly, du Plessis et al. previously described a correlation between CXCL8 and liver inflammation or NAFLD activity score, further strengthening the importance of this inflammatory protein in liver pathology ${ }^{11}$. Furthermore, inhibition of CXCL14 was shown to reduce hepatic damage and mortality in a murine hepatotoxicity model. However, hepatic immune cell infiltration was not investigated ${ }^{31}$. Interestingly, Wehr et al. showed that inhibition of CXCL16 reduced macrophage infiltration in an inflammatory model of $\mathrm{NASH}^{32}$. Unfortunately, neutrophil levels were not investigated in this study. In addition to gene expression data in specific ATM subsets, we also showed that AT from obese mice displays increased secretion of CXCL14 and CXCL16, while this secretion was blunted when ATMs were depleted. Thus, our data show that in addition to the increased numbers of $\mathrm{CD} 11 \mathrm{c}^{+}$cells in $\mathrm{AT}$, obesity enhanced production of neutrophil chemotaxis proteins in these cells.

Previous human studies found associations between liver histopathology and ATMs in general, but did not investigate $C D 11 c^{+}$and $C D 11 c^{-}$cells separately ${ }^{11}$ ${ }^{12}$. To discriminate between these macrophage subsets, we used $C D 11 c$ expression as a marker of $\mathrm{CD} 11 \mathrm{c}^{+}$macrophages (M1) and $M R C 1$ expression as a marker of $\mathrm{CD} 11 \mathrm{c}^{-}$macrophages (M2). Our data show that AT expression of $C D 11 c$, but not of MCR1, correlated with neutrophil and macrophage markers in the livers of the same subjects. These data indicate that $\mathrm{CD} 11 \mathrm{c}^{+}$ (M1) and not CD11c (M2) ATMs are associated with liver pathology in humans. This notion is in agreement with findings of du Plessis et al. showing that $\mathrm{CD} 11 \mathrm{c}^{+}$cells are more frequent in AT from NASH patients compared to lean and obese/NAFLD patients and are of vital importance in NAFLD to NASH progression ${ }^{11}$. Our human data also confirmed the data of sorted cell murine ATMs showing higher expression of neutrophil chemotaxis genes in $\mathrm{CD}_{11 \mathrm{c}^{+}}$ macrophages after HFD feeding. The expression of the CXCL chemokine 
family, which has similar functions regarding neutrophil chemotaxis in humans, correlated strongly with CD11c but not with MRC1 expression in AT. Moreover, the expression of the chemo-attractant genes, CXCL5, CXCL16 and M-CSF, was elevated in the AT of obese NASH patients compared to obese subjects without NASH. Our microarray data from human tissues also revealed some other genes that may be relevant to NAFLD in humans. In AT, CXCL2 and CXCL5, both involved in neutrophil recruitment and homeostasis, correlated with CD11c expression ${ }^{33-35}$. Interestingly, there was also a strong correlation between CD11C and S100A8 in our human AT data, corresponding with data from Nagareddy et al. describing higher levels of S100A8 and A9 in AT of obese mice when compared to AT of lean mice ${ }^{26}$. The S100 protein family has been implicated in neutrophil recruitment and more specifically the S100A8/9 - TLR4 axis was shown to be involved in ATMinduced myelopoiesis ${ }^{26,36,37}$. Our findings are in agreement with the notion that neutrophil chemotaxis proteins are being expressed by human $\operatorname{CD} 11 \mathrm{c}^{+}$ ATMs. Together with our experimental results in mice, these results suggest that $\mathrm{CD} 11 \mathrm{c}^{+} \mathrm{AT}$ macrophages contribute to neutrophil recruitment to the liver.

In our long term murine experiment, hepatic macrophage content was increased after transplanting AT from obese mice. However, this was not paralleled by an increase of circulating monocytes or neutrophils after eight weeks. Remarkably, we even noted a significant decrease in monocytes after transplantation of AT from obese mice which was not seen in the mice transplanted with ATM-depleted adipose tissue. Possibly, this decrease in circulating monocytes reflects enhanced hepatic recruitment, followed by their differentiation into tissue macrophages. In addition, since all mice received HCD already before performing AT transplantation, circulating monocyte levels were already high at baseline. This high baseline level of circulating monocytes might explain why we did not observe monocytosis after AT transplantation, in contrast with the findings of Nagareddy et al. ${ }^{26}$. Finally, the effects of the transplanted AT on circulating cells and bone marrow may be primarily acute and therefore might have been no longer present after eight weeks ${ }^{18,19}$. This reasoning is strengthened by the fact that we did see increases in monocytes and neutrophils two weeks posttransplantation. Differences with the study of Nagareddy et al. may be 
explained by location of the transplanted AT. In our study, AT was transplanted into the peritoneal cavity while Nagareddy et al. transplanted AT into the subcutaneous space ${ }^{26}$. By transplanting AT to the parietal peritoneum, portal venous drainage of the transplanted AT was prevented in our study. Portal drainage of AT grafts has effects on insulin sensitivity, potentially via portal migration of cells or cytokines to the liver ${ }^{9}$. Indeed, we did not detect any differences between groups in plasma glucose or insulin levels. Therefore, our results point to a systemic effect of the ATMs independent from direct drainage into the portal vein. Unfortunately, our model for NASH, the Idlr-- mouse fed an HCD, did not allow us to investigate other relevant parameters of NASH. This model is excellent for rapidly inducing steatosis and inflammation, but fibrosis is mild and hepatocyte damage characterized by hepatocyte ballooning is limited ${ }^{13,14}$.

An important limitation in our human study is intrinsic to the statistical method employed which can only show associations and is not able to determine causality. Therefore, we can merely state that a change in $C D 11 \mathrm{C}$ expression in AT is associated with expression changes of macrophage or neutrophil genes in liver or neutrophil chemotaxis genes in AT. Protein levels or FACS-sorted individual cell populations were also not obtained from human AT and therefore we were limited to gene expression data, which does not always show a clear relation with protein levels. Therefore, causal relationships can only be assumed based on our murine data. Prospective studies are needed to fully elucidate the contribution of $\mathrm{CD} 11 \mathrm{c}^{+}$ macrophages to NASH progression. However, these studies prove to be challenging to perform as they would require multiple AT and liver biopsies. Therefore, we are currently limited to studies such as our own which can only reveal associations.

In conclusion, obesity induces accumulation of $\mathrm{CD}_{11 \mathrm{c}^{+}}$macrophages in adipose tissue, which produce more neutrophil regulatory and stimulating proteins resulting in elevated circulating neutrophil levels. The resulting neutrophil infiltration might lead to enhanced macrophage accumulation and contribute to NASH development. As both the CXCL and S100 protein family consists of targetable proteins, further investigation into specific inhibitors is warranted. 


\section{Acknowledgments}

We would like to thank Prof. Dr. H. J. Verkade and O.A.H.O. Ronda (University Medical Center Groningen, The Netherlands) for kindly providing part of the animal diets and M.P.H. van de Waarenburg for performing various measurements. 


\section{References}

1. Nguyen DM, El-Serag HB. The epidemiology of obesity. Gastroenterol Clin North Am 2010;39:1-7.

2. Wild $\mathrm{SH}$, Byrne $\mathrm{CD}$. $\mathrm{ABC}$ of obesity. Risk factors for diabetes and coronary heart disease. BMJ 2006;333:1009-11.

3. Festi D, Colecchia A, Sacco T, et al. Hepatic steatosis in obese patients: clinical aspects and prognostic significance. Obes Rev 2004;5:27-42.

4. Than NN, Newsome PN. A concise review of non-alcoholic fatty liver disease. Atherosclerosis 2015;239:192-202.

5. Ekstedt M, Franzen LE, Mathiesen UL, et al. Long-term follow-up of patients with NAFLD and elevated liver enzymes. Hepatology 2006;44:865-73.

6. Tailleux A, Wouters K, Staels B. Roles of PPARs in NAFLD: potential therapeutic targets. Biochim Biophys Acta 2012;1821:809-18.

7. Gaens KH, Niessen PM, Rensen SS, et al. Endogenous formation of Nepsilon(carboxymethyl)lysine is increased in fatty livers and induces inflammatory markers in an in vitro model of hepatic steatosis. J Hepatol 2012;56:647-55.

8. Mirza MS. Obesity, Visceral Fat, and NAFLD: Querying the Role of Adipokines in the Progression of Nonalcoholic Fatty Liver Disease. ISRN Gastroenterol 2011;2011:592404.

9. Rytka JM, Wueest S, Schoenle EJ, et al. The portal theory supported by venous drainageselective fat transplantation. Diabetes 2011;60:56-63.

10. Boutens L, Stienstra R. Adipose tissue macrophages: going off track during obesity. Diabetologia 2016;59:879-94.

11. du Plessis J, van Pelt J, Korf $\mathrm{H}$, et al. Association of Adipose Tissue Inflammation With Histologic Severity of Nonalcoholic Fatty Liver Disease. Gastroenterology 2015;149:63548 e14.

12. Tordjman J, Poitou C, Hugol D, et al. Association between omental adipose tissue macrophages and liver histopathology in morbid obesity: influence of glycemic status. J Hepatol 2009;51:354-62.

13. Wouters K, van Gorp PJ, Bieghs V, et al. Dietary cholesterol, rather than liver steatosis, leads to hepatic inflammation in hyperlipidemic mouse models of nonalcoholic steatohepatitis. Hepatology 2008;48:474-86.

14. Bieghs V, Van Gorp PJ, Wouters K, et al. LDL receptor knock-out mice are a physiological model particularly vulnerable to study the onset of inflammation in non-alcoholic fatty liver disease. PLoS One 2012;7:e30668.

15. Huugen D, Xiao $\mathrm{H}$, van Esch $\mathrm{A}$, et al. Aggravation of anti-myeloperoxidase antibodyinduced glomerulonephritis by bacterial lipopolysaccharide: role of tumor necrosis factor-alpha. Am J Pathol 2005;167:47-58.

16. Shiri-Sverdlov R, Wouters K, van Gorp PJ, et al. Early diet-induced non-alcoholic steatohepatitis in APOE2 knock-in mice and its prevention by fibrates. J Hepatol 2006;44:732-41.

17. Lumeng CN, DelProposto JB, Westcott DJ, et al. Phenotypic switching of adipose tissue macrophages with obesity is generated by spatiotemporal differences in macrophage subtypes. Diabetes 2008;57:3239-46.

18. Swirski FK, Libby P, Aikawa E, et al. Ly-6Chi monocytes dominate hypercholesterolemiaassociated monocytosis and give rise to macrophages in atheromata. J Clin Invest 2007;117:195-205.

19. Drechsler M, Megens RT, van Zandvoort M, et al. Hyperlipidemia-triggered neutrophilia promotes early atherosclerosis. Circulation 2010;122:1837-45. 
20. Gorgens A, Radtke S, Mollmann M, et al. Revision of the human hematopoietic tree: granulocyte subtypes derive from distinct hematopoietic lineages. Cell Rep 2013;3:153952.

21. Kerr MA, Stocks SC. The role of CD15-(Le $(X))$-related carbohydrates in neutrophil adhesion. Histochem J 1992;24:811-26.

22. Amanzada A, Malik IA, Nischwitz M, et al. Myeloperoxidase and elastase are only expressed by neutrophils in normal and in inflamed liver. Histochem Cell Biol 2011;135:305-15.

23. Miller JC, Brown BD, Shay $\mathrm{T}$, et al. Deciphering the transcriptional network of the dendritic cell lineage. Nat Immunol 2012;13:888-99.

24. Rensen SS, Bieghs V, Xanthoulea S, et al. Neutrophil-derived myeloperoxidase aggravates non-alcoholic steatohepatitis in low-density lipoprotein receptor-deficient mice. PLoS One 2012; 7:e52411.

25. Kolaczkowska E, Kubes P. Neutrophil recruitment and function in health and inflammation. Nat Rev Immunol 2013;13:159-75.

26. Nagareddy PR, Kraakman M, Masters SL, et al. Adipose tissue macrophages promote myelopoiesis and monocytosis in obesity. Cell Metab 2014;19:821-35.

27. Cao X, Zhang W, Wan T, et al. Molecular cloning and characterization of a novel CXC chemokine macrophage inflammatory protein-2 gamma chemoattractant for human neutrophils and dendritic cells. J Immunol 2000;165:2588-95.

28. Zhang L, Ran L, Garcia GE, et al. Chemokine CXCL16 regulates neutrophil and macrophage infiltration into injured muscle, promoting muscle regeneration. Am J Pathol 2009;175:2518-27.

29. De Filippo K, Dudeck A, Hasenberg $M$, et al. Mast cell and macrophage chemokines CXCL1/CXCL2 control the early stage of neutrophil recruitment during tissue inflammation. Blood 2013;121:4930-7.

30. Woehrl B, Klein M, Rupprecht T, et al. CXCL16 contributes to neutrophil recruitment to cerebrospinal fluid in pneumococcal meningitis. J Infect Dis 2010;202:1389-96.

31. Li J, Gao J, Yan D, et al. Neutralization of chemokine CXCL14 (BRAK) expression reduces CCl4 induced liver injury and steatosis in mice. Eur J Pharmacol 2011;671:120-7.

32. Wehr A, Baeck C, Ulmer F, et al. Pharmacological inhibition of the chemokine CXCL16 diminishes liver macrophage infiltration and steatohepatitis in chronic hepatic injury. PLoS One 2014;9:e112327.

33. Mei J, Liu Y, Dai N, et al. Cxcr2 and Cxcl5 regulate the IL-17/G-CSF axis and neutrophil homeostasis in mice. J Clin Invest 2012;122:974-86.

34. Zhou SL, Dai Z, Zhou ZJ, et al. Overexpression of CXCL5 mediates neutrophil infiltration and indicates poor prognosis for hepatocellular carcinoma. Hepatology 2012;56:2242-54.

35. Rouault C, Pellegrinelli V, Schilch R, et al. Roles of chemokine ligand-2 (CXCL2) and neutrophils in influencing endothelial cell function and inflammation of human adipose tissue. Endocrinology 2013;154:1069-79.

36. Marenholz I, Heizmann CW, Fritz G. S100 proteins in mouse and man: from evolution to function and pathology (including an update of the nomenclature). Biochem Biophys Res Commun 2004;322:1111-22.

37. Ryckman C, Vandal K, Rouleau P, et al. Proinflammatory activities of S100: proteins S100A8, S100A9, and S100A8/A9 induce neutrophil chemotaxis and adhesion. J Immunol 2003;170:3233-42. 


\section{Supplementary materials and methods}

\section{Adipose tissue transplantation}

Eight-week-old male C57BL/6 $\mathrm{Idlr}^{-1-}$ CD45.1 mice were fed a low fat (LFD; 10 kcal\% fat; D12450J, Research Diets, New Brunswick) or high fat diet (HFD; 60 kcal\% fat; D12492, Research Diets, New Brunswick) for 12 weeks before acting as a visceral adipose tissue (VAT) donor. vAT derived from donor mice fed a LFD, HFD or HFD in combination with clodronate liposomes injection (i.p. $115 \mathrm{mg} / \mathrm{kg}, 48$ hours before sacrifice ${ }^{1}$ ) was transplanted to 18 -week-old male C57BL/6 CD45.2 congenic Idlr $^{-1-}$ mice resulting in the following three groups: lean-transplanted acceptors (LTA), obese-transplanted acceptors (OTA) and ATM-depleted obese-transplanted acceptors (DOTA). For VAT transplantation, acceptor mice were anesthetized using medetomidine (1 $\mathrm{mg} / \mathrm{kg})$ or xylazine $(10 \mathrm{mg} / \mathrm{kg})$ and ketamine $(75 \mathrm{mg} / \mathrm{kg})$ intraperitoneally. Temgesic $(0.05 \mathrm{mg} / \mathrm{kg})$ was subcutaneously injected to relieve pain. Approximately $250 \mathrm{mg}$ of VAT (epididymal fat) of the donor mice was thoroughly rinsed in PBS to remove any traces of clodronate liposomes before transplanting the AT to the peritoneal cavity and suturing it to the parietal peritoneum. In the first experiment, hepatic steatosis and inflammation was induced in Idl ${ }^{-1-}$ acceptor mice with a high cholesterol diet (HCD, $21 \%$ milk butter, $0.2 \%$ cholesterol, $46 \%$ carbohydrates and $17 \%$ casein; SDSdiets \#824171) for four weeks before and eight weeks after vAT transplantation ${ }^{2,3}$. The $\mathrm{Idlr}^{-/-}$mouse rapidly develops steatosis and hepatic inflammation when fed a HCD. The rapid development of hepatic inflammation makes this an ideal mouse model to study the factors that trigger the progression of inflammation in the steatotic liver. However, these mice do not display advanced features of NASH, such as massive fibrosis or hepatocyte ballooning. These features are more commonly observed in less physiological mouse models of $\mathrm{NASH}$, such as feeding mice a methionineand choline- deficient (MCD) diet leading to severe weight loss, rendering the MCD diet model less relevant to study the effects of obesity on NASH development. In the second experiment, all acceptor mice received standard chow and were sacrificed after two weeks. Mice showing signs of aberrant infection or peritonitis based on visual inspection and weight of transplanted AT at sacrifice were excluded. A small group $(n=7)$ of sham operated animals 
was also included in the first experiment, data from this group was similar to data from LTA mice. Mice were housed in standard ventilated cages with enrichment. All procedures were performed during the day of a 12 hour day/night cycle. All performed experiments were approved by the Animal Experiments Committee of Maastricht University.

\section{Flow cytometry}

AT and liver tissue was incubated with Collagenase I (Sigma), Collagenase XI (Sigma), and DNAse (Sigma) in RPMI-20mM HEPES (Gibco) at $37^{\circ} \mathrm{C}$ for 30 min. Hereafter, the dissolved tissue was filtered using a $70 \mu \mathrm{m}$ cell strainer (Greiner) and ice cold PBS. The liver cell suspension was centrifuged at $50 \mathrm{~g}$ for $2 \mathrm{~min}$ and the supernatant was carried over twice. Adipose tissue cell suspension was centrifuged at $1200 \mathrm{rpm}$ for 5 minutes and the floating adipocyte and lipid fraction was removed. Bone marrow was flushed from the femur and tibia using ice cold PBS, and a single cell suspension was created using a $25 \mathrm{G}$ and $18 \mathrm{G}$ needle. Erythrocytes were lysed using lysis buffer $\left(8.4 \mathrm{~g} / \mathrm{L} \mathrm{NH}_{4} \mathrm{CL}\right.$ and $0.84 \mathrm{~g} / \mathrm{L} \mathrm{NaHCO} 3$ in $\left.\mathrm{H}_{2} \mathrm{O}, \mathrm{pH} 7.4\right)$ and the remaining cells were suspended in FACS buffer ( $0,5 \%$ bovine serum albumin and NaN3 in PBS). Blood collected during the study was taken from the hind limb using EDTA lined Microvette tubes (Sarstedt) and at sacrifice by cardiac puncture. To prevent non-specific binding of FC-receptor expressing cells, FC-receptor block (anti-CD16/CD32) was added to cells. Next, a cocktail of antibodies was added (Suppl. table 7.1). Hereafter, erythrocytes were lysed from blood using lysisbuffer. Flow cytometry was performed using a BD FACSCANTO II running FACS Diva 8.0.1 software used for analysis of all flow cytometry data. All FACS gating strategies can be found in the supplementary materials (Suppl. Fig. 7.1 and 7.2) and were validated using fluorescence minus one (FMO) tests.

\section{RNA Isolation, cDNA Synthesis and qRT-PCR}

RNA was isolated from murine vAT and liver using Trizol reagent (Ambion) following manufacturer's instructions. CDNA was synthesized using the iScript cDNA synthesis kit (170-8891; Bio-Rad, Hercules, USA) according to manufacturer's instructions. Gene expression was determined on a CFX96 Touch with CFX manager software (Biorad) using IQ SensiMix SYBR master mix (Bioline, London, UK). The geometric mean of Cyclophillin and Beta2- 
microglobulin was used as reference and the $\Delta \Delta C T$ method was used to calculate expression levels ${ }^{4}$. Primer sequences are given in supplementary table 7.2.

\section{Histology}

Frozen $7 \mu \mathrm{m}$ murine liver sections were stained with either oil red $\mathrm{O}$ or with antibodies against macrophages (rat anti-mouse F4/80, clone $\mathrm{Cl}$ :A3-1; Acris antibodies), T-cells (custom CD3 AB; clone KT3), monocytes/neutrophils (rat anti-mouse $C D 11 B$, clone $M 1 / 70 ; R \& D$ systems) and neutrophils (custom $A B$; clone NIMP-R14) as previously described ${ }^{2,5}$. For the negative controls, the primary antibody was omitted. Photographs were taken with a Jenoptik camera and Progress Capture Pro 2.8.8 software. Neutrophils were counted in 6 microscopical views (200x magnification) while macrophage content was quantified as percentage of positive pixels of the total area using Photoshop CS3 (v10.0). Paraffin-embedded $4 \mu \mathrm{m}$ murine VAT and liver sections were stained for Haematoxylin and Eosin (E; E4382; Sigma-Aldrich) or Sirius red and photos were taken (AT: 100x, liver: 200x magnification) as described above.

\section{Liver and plasma cholesterol and triglyceride measurements}

Murine livers were homogenized in $250 \mu \mathrm{l}$ SET buffer ( $250 \mathrm{mM}$ sucrose, 2 $\mathrm{mM}$ EDTA and $10 \mathrm{mM}$ Tris). Cholesterol and triglycerides in the liver homogenate and plasma were then measured using a colorimetric test (Cholesterol FS'10 and Triglycerides FS 5'ecoline, Diagnostic System GmbH, Holzheim, Germany) as described previously ${ }^{6}$. Liver cholesterol and triglycerides were corrected for protein content by performing a BCA-assay (BCA kit, Sigma-Aldrich, Germany) according to the manufacturer's instructions.

\section{Cytokine levels}

vAT cytokine levels of IL-6, CXCL1, IFN- $\gamma$, IL-1 $\beta$, IL-2, IL-4, IL-5, IL-10, IL-12P70, and TNF were measured using a V-plex Mouse Cytokine Assay kit (Meso Scale Discovery), according to the manufacturer's instructions. MCP1 levels in adipose tissue were detected with a separate V-plex Mouse Cytokine Assay kit (Meso Scale Discovery). 


\section{Plasma glucose, insulin and ALAT measurements}

Plasma glucose levels were determined using an YSI 2300 STAT PLUS Glucose \& L-Lactate analyzer (YSI Life Sciences) following manufacturer's instructions. Insulin levels were measured using the Mouse Metabolic Kit for detection of insulin and leptin (Meso Scale Discovery) according to the manufacturer's instructions. ALAT levels were detected using a reagent kit (DIAGNOSTIC SYSTEMS) on a Cobas Fara Centrifugal Automated Chemistry Analyzer (Roche).

\section{CD11c and $\mathrm{CD}^{-} 1 \mathrm{c}^{+}$cell sorting and array}

$\mathrm{CD} 11 \mathrm{c}^{+}$and $\mathrm{CD} 11 \mathrm{c}^{-}$macrophages were isolated from murine vAT fed either LFD or HFD for 12 weeks using a BD FACSAria I sorter. RNA was isolated and $3 \mathrm{ng}$ total RNA was amplified using the Ovation PicoWTA system V2 (NuGEN). Afterwards, SPIA cDNA was purified using Agencourt RNAClean XP beads (Beckman Coulter) and $2.8 \mathrm{mg}$ was fragmented and labeled using the Encore Biotin module (NuGEN). All labeled samples were hybridized to Mouse Gene 2.1 ST arrays (Affymetrix). Washing, staining and scanning was performed using the GeneTitan Hybridization, Wash, and Stain Kit for WT Array Plates, and the GeneTitan Instrument (Affymetrix). Data were normalized using Expression console software and analyzed using transcriptome analysis console v2.0 from Affymetrix. Data is presented as fold change (FC) in expression level compared to LFD fed mice. Genes showing fold changes of at least 1.50 and a P-value of less than 0.05 were considered differentially regulated.

\section{vAT culturing}

Mice were fed a LFD or HFD for 12 weeks. One group of HFD-fed mice was injected with clodronate liposomes (i.p. $115 \mathrm{mg} / \mathrm{kg}$ ) 48 hours before sacrifice. vAT was excised after sacrifice and cultured in DMEM (4,5 g/L glucose, Lglutamine and pyruvate; Gibco) supplemented with 10\% FBS (GE Healthcare Life Sciences) and $1 \%$ penicillin/streptomycin (Gibco) at $37^{\circ} \mathrm{C}$ on a shaker at $200 \mathrm{rpm}$. The vAT pieces (100-200 mg) were cultured overnight (16 hours) before stimulation with LPS $(10 \mathrm{ng} / \mathrm{ml})$ for 8 hours. At the end of the experiment, medium and tissue were collected. Secreted CXCL14 and CXCL16 
was measured in the medium using ELISA following manufacturer's instructions (R\&D systems). This experiment was performed 3 times. It should be noted that the ELISA kit used for CXCL14 is optimized for human CXCL14 measurement as a murine kit was not available. However, use of this ELISA for measurement of murine CXCL14 has been previously reported due to the high sequence identity between human and murine CXCL14 (two amino acids difference) ${ }^{7}$.

\section{Human AT and liver gene expression data}

VAT and liver micro-array data was obtained from a previously reported study performed by the Department of General Surgery, MUMC (Maastricht, the Netherlands) $)^{8}$. Briefly, liver and vAT biopsies were taken from obese patients (BMI 35-70) who underwent bariatric surgery between 2006 and 2011. Exclusion criteria were: presence of inflammatory (e.g. auto-immune diseases) or degenerative diseases, alcohol consumption of $>10 \mathrm{~g} /$ day, or use of anti-inflammatory drugs. For 74 subjects both vAT and liver micro-array data were available; these subjects were included in analysis and considered study population (Suppl. table. 7.3). Correlations between gene expression in human VAT and liver were tested by calculating Pearson's correlation coefficient and the corresponding P-value using SPSS statistics version 23 (IBM, USA). After Bonferroni correction to adjust for multiple testing, Pvalues of $\mathrm{P} \leq 0.004$ were deemed statistically significant. The population was divided into non-NASH and NASH based on the NAFLD activity score. A score of $\leq 4$ was considered non-NASH while a score of $\geq 5$ was considered NASH. Differences in gene expression were examined using a Student's T-test. This study was approved by the Medical Ethics Board of MUMC, in line with the ethical guidelines of the 1975 Declaration of Helsinki. Written informed consent was obtained from each individual.

\section{Statistical Analysis}

Data was tested for normal distribution using D'Agostino and Pearson omnibus normality test. Accordingly, data was tested using a two-tailed Student's T-test when data was normally distributed or a Mann-Whitney test for non-normally distributed data when comparing two groups or a one-way ANOVA with Tuckey's multiple comparison post-hoc test for normally 
distributed data or a Kruskal-Wallis test with Dunn's multiple comparison post-hoc test when data was not normally distributed when comparing multiple groups. All murine data analyses were performed using GraphPad Prism 5 (La Jolla California, USA), are expressed as the mean \pm SEM and were considered statistically significant at $P \leq 0.05$. 


\section{References}

1. Van Rooijen N, Sanders A. Liposome mediated depletion of macrophages: mechanism of action, preparation of liposomes and applications. J Immunol Methods 1994;174:83-93.

2. Wouters K, van Gorp PJ, Bieghs V, et al. Dietary cholesterol, rather than liver steatosis, leads to hepatic inflammation in hyperlipidemic mouse models of nonalcoholic steatohepatitis. Hepatology 2008;48:474-86.

3. Bieghs V, Van Gorp PJ, Wouters K, et al. LDL receptor knock-out mice are a physiological model particularly vulnerable to study the onset of inflammation in non-alcoholic fatty liver disease. PLoS One 2012;7:e30668.

4. Livak KJ, Schmittgen TD. Analysis of relative gene expression data using real-time quantitative PCR and the 2(-Delta Delta C(T)) Method. Methods 2001;25:402-8.

5. Huugen $\mathrm{D}$, Xiao $\mathrm{H}$, van Esch $\mathrm{A}$, et al. Aggravation of anti-myeloperoxidase antibodyinduced glomerulonephritis by bacterial lipopolysaccharide: role of tumor necrosis factor-alpha. Am J Pathol 2005;167:47-58.

6. Shiri-Sverdlov R, Wouters K, van Gorp PJ, et al. Early diet-induced non-alcoholic steatohepatitis in APOE2 knock-in mice and its prevention by fibrates. J Hepatol 2006;44:732-41.

7. Dai C, Basilico P, Cremona TP, et al. CXCL14 displays antimicrobial activity against respiratory tract bacteria and contributes to clearance of Streptococcus pneumoniae pulmonary infection. J Immunol 2015;194:5980-9.

8. Wolfs MG, Rensen SS, Bruin-Van Dijk EJ, et al. Co-expressed immune and metabolic genes in visceral and subcutaneous adipose tissue from severely obese individuals are associated with plasma HDL and glucose levels: a microarray study. BMC Med Genomics 2010;3:34. 


\section{Supplementary figures and tables}
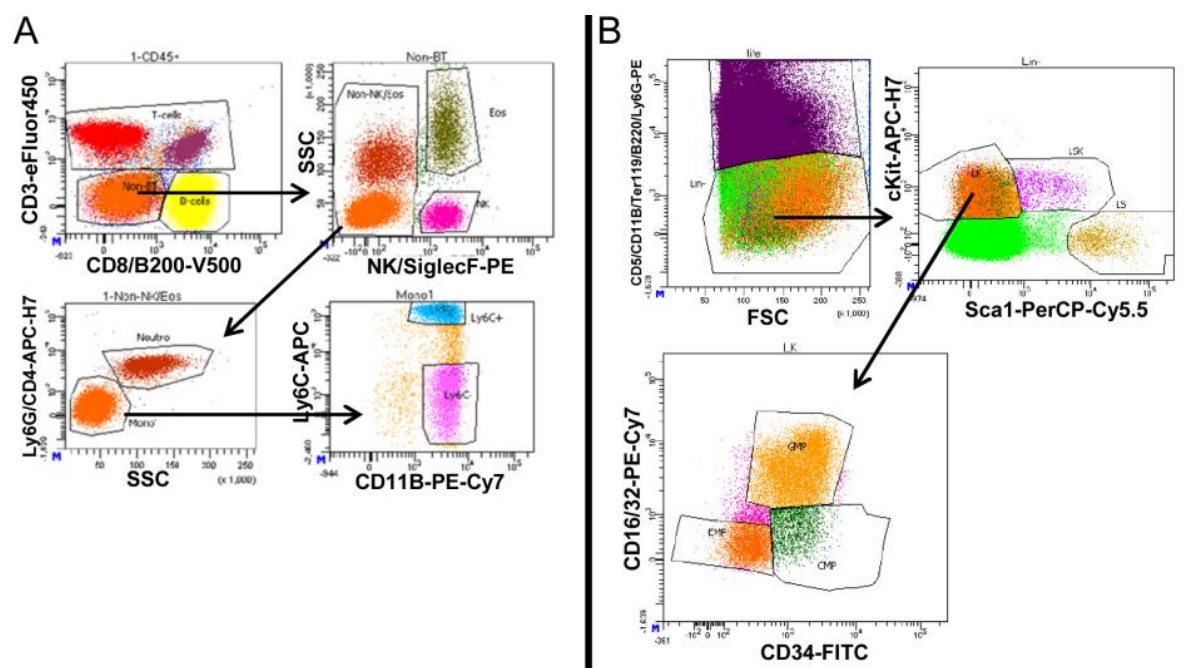

Suppl. Figure 7.1. Gating strategy used for blood and bone marrow FACS analysis

(A) FACS plots showing gating strategy used for blood. First, T-cells and B-cells were excluded using CD3 and B220, respectively. Eosinophils and NK cells were separated from monocytes and neutrophils based on NK1.1 and Siglec-F. Next, neutrophils were discriminated from monocytes using Ly6G. Lastly, monocytes were subdivided in LY6C- (patrolling) and LY6C+ (proinflammatory) monocytes. (B) FACS plots showing gating strategy for bone marrow. Stem cells were distinguished as CD5, CD11B, TER-119, B220, and LY6G negative (Lineage-). Next, lineage- C-Kit+ (LK) cells were subdivided in common myeloid progenitor cells (CMP) and granulocyte-monocyte progenitor cells (GMP) based on CD34 and CD16/32 expression. 

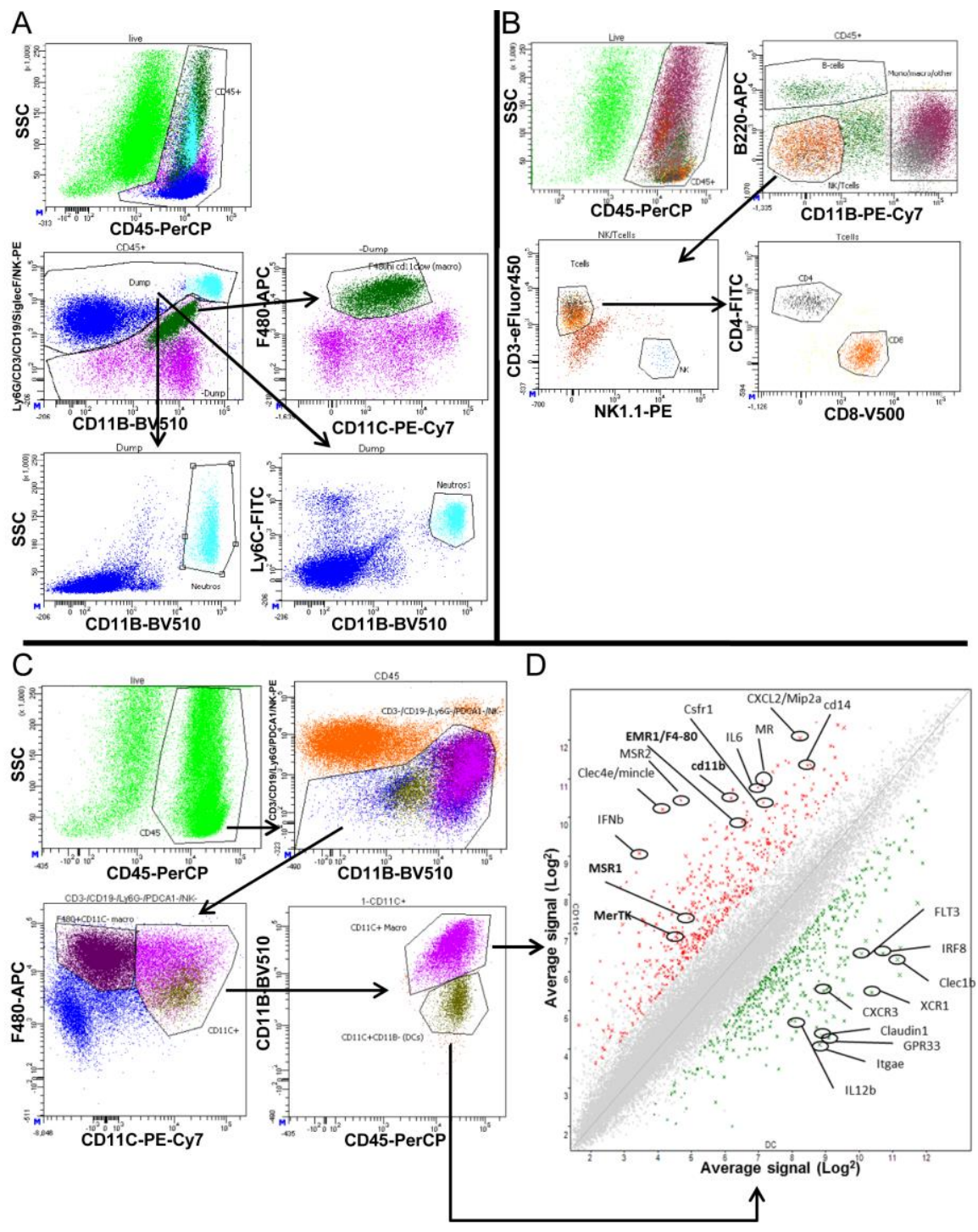

Suppl. Figure 7.2. Gating strategy used for liver and adipose tissue FACS analysis and CD11c ${ }^{+}$ cells gene signature.

(A) FACS plots showing gating strategy used for liver starting from live cells. First, CD45+ cells were divided in Ly6G/CD4/CD19/SiglecF/NK negative or positive cells. Macrophages were identified from the negative cells based on $\mathrm{F} 480$ and $\mathrm{CD} 11 \mathrm{c}$ expression while neutrophils were separated from the positive cells based on the sidescatter (SSC), CD11B and Ly6C expression. (B) FACS plots showing gating strategy used for NK, B- and T-cells in VAT. B-cells were identified using B220 and myeloid cells were identified based on CD11B. Next, non-myeloid or B-cells were identified as NK cells and T-cells based on NK1.1 and CD3, respectively. T-cells were 
further subdivided in CD4- and CD8-positive cells. (C) FACS gating strategy for ATMs. All macrophages and tissue DCs were selected as CD3, CD19, Ly6G, PDCA1 and NK1.1 negative. Next, F480 and CD11c were used to discriminate CD11c- ATMs and CD11 ${ }^{+}$(ATMs and DCs) cells. Lastly, CD11 $\mathrm{c}^{+}$cells were subdivided in $\mathrm{CD} 11 \mathrm{c}^{+}$ATMs and DCs based on CD11B expression. (D) Gene expression signature (as Log2 average signal of microarray data) of FACS sorted $\mathrm{CD} 11 \mathrm{c}^{+}$cells. Using micro-array analysis on FACS sorted cells, we confirmed the CD11 $\mathrm{C}^{+} \mathrm{CD} 11 \mathrm{~B}^{+}$designated cells (CD11 $\mathrm{C}^{+}$ATMs) expressed a macrophage specific gene signature and were ATMs while $C D 11 \mathrm{c}^{+} \mathrm{CD} 11 \mathrm{Blow} / \mathrm{A}^{-} \mathrm{DCs}$ showed enhanced expression of typical DC marker genes and genes involved in DC function. Red dots are higher expressed in $\mathrm{CD} 11 \mathrm{C}^{+} \mathrm{CD} 11 \mathrm{~B}^{+}$cells and green dots are higher expressed in DCs.
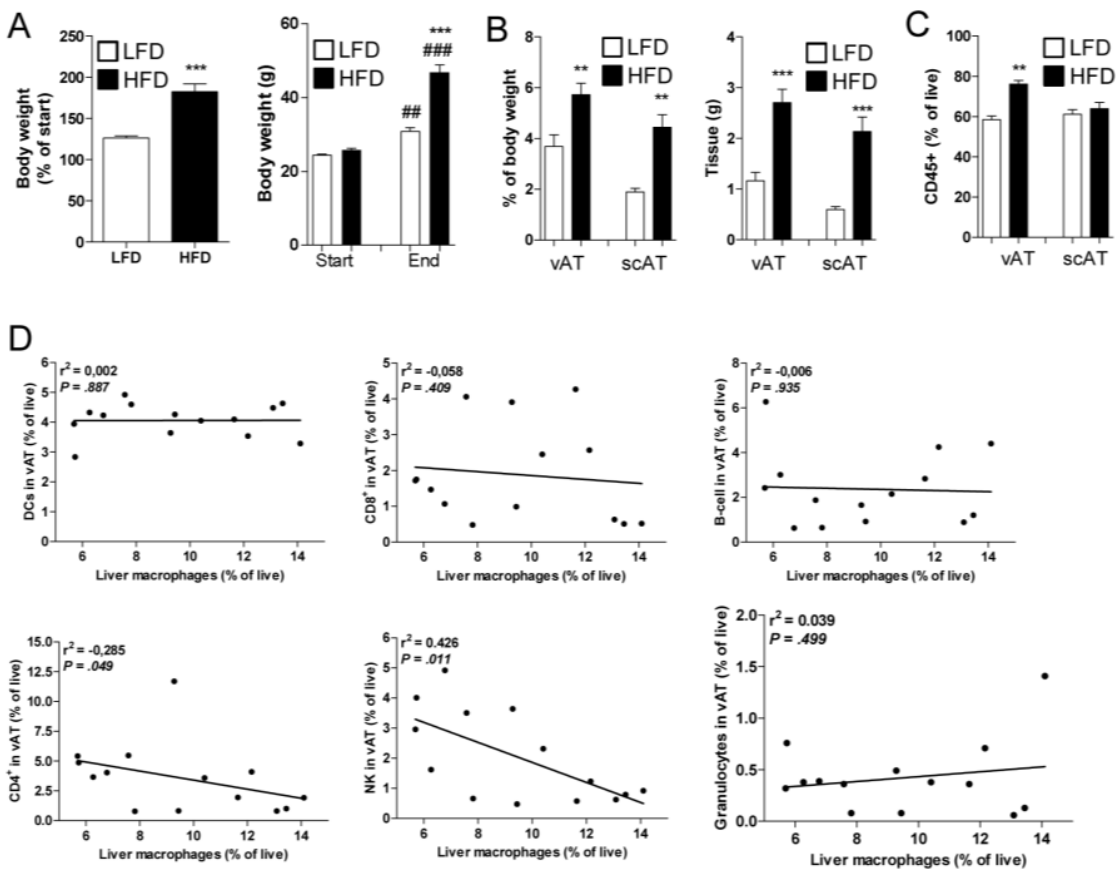

Suppl. Figure 7.3. HFD feeding increases bodyweight, adipose tissue and immune cell levels in AT

(A) Bodyweight in percentage of starting weight and in absolute numbers in mice fed LFD or HFD for 16 weeks. (B) VAT and SCAT as weight percentage of bodyweight and in absolute numbers. (C) Immune cell levels (CD45+ cells) displayed as percentage of living stromal vascular cells in vAT and SCAT of LFD- and HFD-fed mice. (D) Correlations of DCs, CD4, CD8, Bcells, NK cells and granulocytes in vAT with liver macrophages measured with flow cytometry. All data are means $\pm \mathrm{SEM} ; \mathrm{n}=7$ per group. ${ }^{* *} \mathrm{P}<0.01,{ }^{* * *} \mathrm{P}<0.001$ vs LFD. \#\#P<0.01, \#\#P $<0.001$ vs Start. Spearman's rank correlations based on $n=14$. 

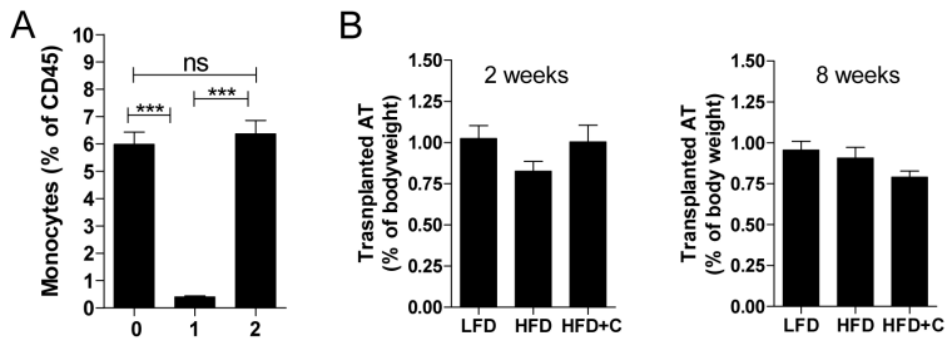

C
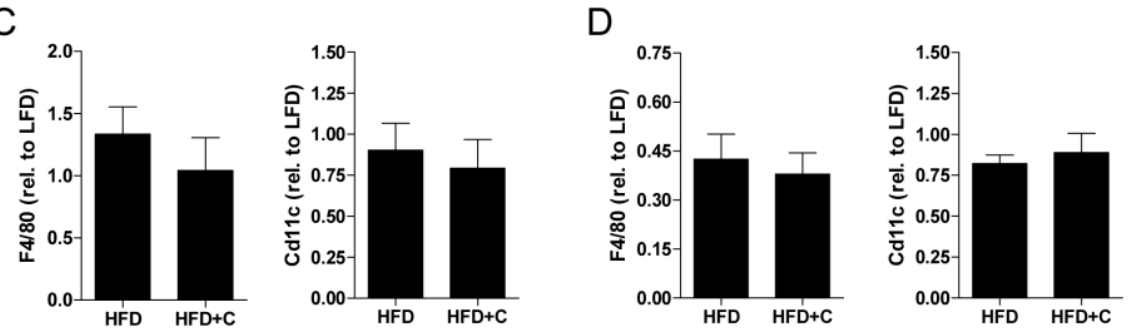

Suppl. Figure 7.4. Circulating monocytes recover rapidly after clodronate injection and vAT depleted CD11 ${ }^{+}$cells are ATMs

(A) Circulating monocyte levels in mice before and one or two days after injection with clodronate liposomes; $n=3-5$ per group. (B-D) Transplanted vAT weight (B) and transplanted vAT F4/80 and CD11C gene expression levels two weeks (C) and eight weeks (D) after transplantation; $n=4-5$ for 2 weeks experiment and $n=9-12$ for 8 weeks experiment. All data are means $\pm S E M ; n=4-6$ per group. ${ }^{*} \mathrm{P}<0.05,{ }^{* * *} \mathrm{P}<0.001$. 
A

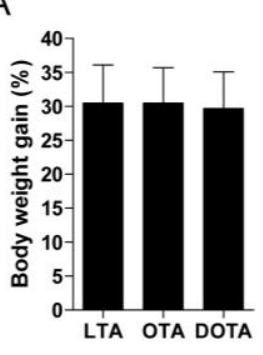

C

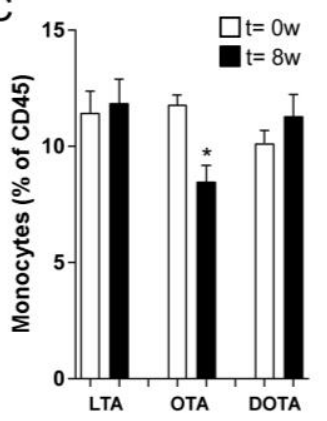

$\mathrm{E}$

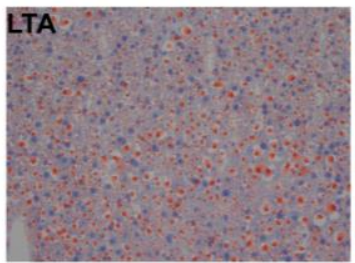

B
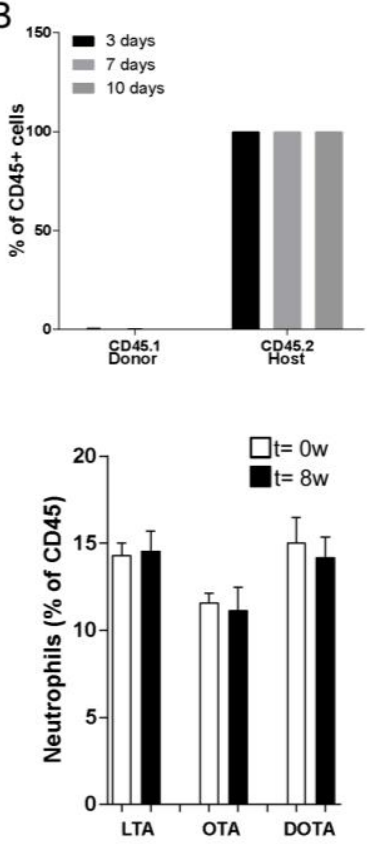

D

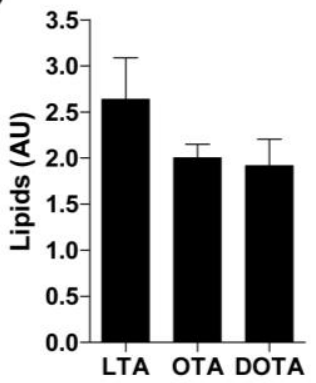

Suppl. Figure 7.5. Circulating immune cells before and after AT transplantation

(A) Bodyweight gain compared to starting weight; $n=10-12$ per group. (B) Percentage of CD45.1 and CD45.2 cells in the circulation after 3,7 and 10 days post $A T$ transplantation; $n=$ 3 per group. (C) Circulating monocyte and neutrophil levels were measured by flow cytometry before $(t=0)$ and 8 weeks after AT transplantation in LTA, OTA and DOTA mice fed an HCD for a total of 12 weeks; $n=6-9$ per group. (D-E) Hepatic lipid levels based on an oil red $O$ staining (D) including representative photos (200x magnification) (E) of LTA, OTA and DOTA mice fed an HCD for a total of 12 weeks; $n=10-12$ per group. All data are means \pm SEM. ${ }^{*} P<0.05$ vs LTA. 
A

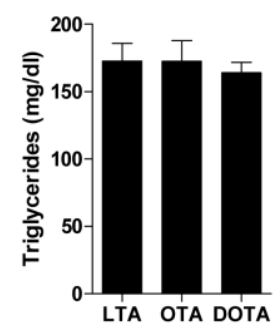

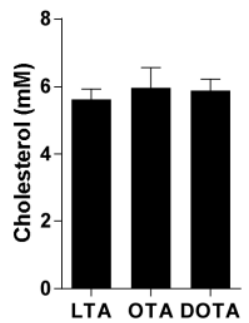

B
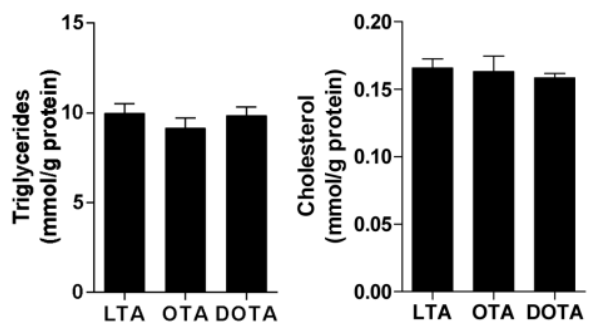

Suppl. Figure 7.6. Depletion of ATMs does not affect plasma or hepatic cholesterol and triglycerides

(A, B) Plasma (A) and hepatic (B) cholesterol and triglyceride levels in LTA, OTA and DOTA mice 2 weeks after transplantation and on chow. All data are means $\pm S E M ; n=4-5$ per group.
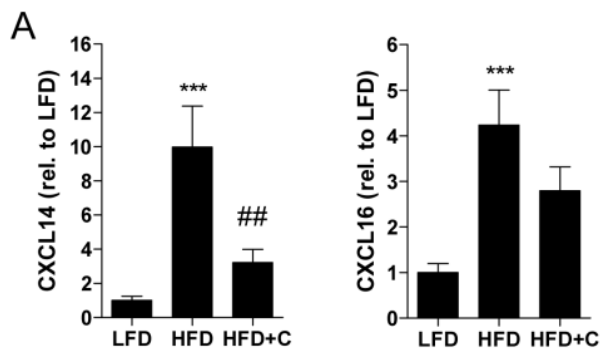

Suppl. Fig. 7.7. ATMs express higher levels of chemokines in obese mice

(A) CXCL14 and CXCL16 gene expression levels measured in VAT from LFD-, HFD- and HFDfed mice injected with clodronate; $\mathrm{n}=10-12$ per group. All data are means $\pm \mathrm{SEM}$; ${ }^{* * * P}<$ 0.001 vs LFD. \#\#P $<0.01$ vs HFD. 
Suppl. Table 7.1. Antibodies used for flow cytometry

\begin{tabular}{lll}
\hline Antibody & Label & Manufacturer \\
\hline \hline & & \\
\hline Blood mix & & \\
\hline CD16/32 & - & eBioscience \\
\hline CD45 & PerCP & Biolegend \\
\hline CD3 & eFluor450 & eBioscience \\
\hline NK1.1 & PE & BD \\
\hline LY6G & APC-CY7 & BD \\
\hline CD11B & PE-CY7 & BD \\
\hline LY6C & APC & Miltenyi \\
\hline CD4 & APC-H7 & BD \\
\hline CD8 & V500 & BD \\
\hline B220 & V500 & BD \\
\hline SIGLECF & PE & BD \\
\hline
\end{tabular}

\begin{tabular}{lll}
\hline Liver / AT1 mix & & \\
\hline CD16/32 & - & eBioscience \\
\hline CD45 & PerCP & Biolegend \\
\hline NK1.1 & PE & BD \\
\hline CD19 & PE & eBioscience \\
\hline LY6G & PE & BD \\
\hline CD3 & PE & eBioscience \\
\hline LY6C & FITC & Miltenyi \\
\hline CD11C & PE-CY7 & eBioscience \\
\hline CD11B & BV510 & Biolegend \\
\hline F4/80 & APC & Biolegend \\
\hline MHC-1I & APC-H7 & eBioscience \\
\hline SIGLECF (Liver only) & PE & BD \\
\hline PDCA1 (AT only) & PE & eBioscience \\
\hline
\end{tabular}

\begin{tabular}{lll} 
AT2 mix & & \\
\hline CD45 & PerCP & Biolegend \\
\hline CD3 & eFluor450 & eBioscience \\
\hline NK1.1 & PE & BD \\
\hline CD11B & PE-Cy7 & BD \\
\hline B220 & APC & eBioscience \\
\hline CD8 & V500 & BD \\
\hline CD4 & FITC & eBioscience \\
\hline
\end{tabular}

\begin{tabular}{lll} 
BM mix & & \\
\hline SCA-1 & PerCP-Cy5.5 & eBioscience \\
\hline C-KIT & APC-H7 & eBioscience \\
\hline CD34 & FITC & eBioscience \\
\hline CD16/32 & PE-CY7 & eBioscience \\
\hline CD5 & PE & eBioscience \\
\hline CD11B & PE & eBioscience \\
\hline TER-119 & PE & eBioscience \\
\hline B220 & PE & BD \\
\hline LY6G & PE & BD \\
\hline & & \\
\hline
\end{tabular}

Antibody cocktails used for blood, liver, vAT and bone marrow. 
Suppl. Table 7.2. Primer sequences used for murine experiment

\begin{tabular}{lll}
\hline Gene & FW primer & RV primer \\
\hline CD11c & GGGAGAAACAAGGGGACA & GTATTCATGGGAAGGCATCG \\
\hline Mcp1 & TTAAAACCTGGATCGGAACCAA & GCATTAGCTTCAGATTTACGGGT \\
\hline Tnf & CATCTTCTCAAATTCGAGTGACAA & TGGGAGTAGACAAGGTACAACCC \\
\hline F4/80 & GGATGTACAGATGGGGGATG & TCTGTGGTGTCAGTGCAGGT \\
\hline IL10 & GCCTTATCGGAATGATCCA & TTTTCACAGGGGAGAAATCG \\
\hline IFNy & ACCTTCTTCAGCAACAGCAA & TCAGCAGCGACTCCTTTTC \\
\hline IL1 $\boldsymbol{\beta}$ & CTGCAGCTGGAGAGTGTGGAT & CACTTTGCTCTTGACTTCTATCTTGTTG \\
\hline Fractalkine & CGCGTTCTTCCATTTGTGTA & TAGCTGATAGCGGATGAGCA \\
\hline CD11b & ATGGACGCTGATGGCAATACC & TCCCCATTCACGTCTCCCA \\
\hline Mpo & GGGCTGCTGGCTATCAATAC & TAGAGCTTCTCCCCATTCCA \\
\hline Ly6c & GGACTGCAGTGCTACGAGTG & AAGGCACTGACGGGTCTTTA \\
\hline S100A8 & AGTGTCCTCAGTTTGTGCAG & ACTCCTTGTGGCTGTCTTTG \\
\hline CXCL1 & CTTGCCTTGACCCTGAAGC & AGGTGCCATCAGAGCAGTCT \\
\hline Col1a1 & TTCAACCAAGAGGTAAAAGATTTACATAA & CACTCCTTCTGTGACTCCAGCTT \\
\hline CXCL14 & CACTGCAGCTTTGTGGACCTC & TCAAGCATACCTCGGGTTTC \\
\hline CXCL16 & GTGTGGGGGAAGCCAAGA & GATGAAGCGTTTGGTGCTCT \\
\hline Cyclophilin & TTCCTCCTTTCACAGAATTATTCCA & TGCTCCTGATGGAAGAGTGG \\
\hline B2-Micro & CTTTCTGGTGCTTGTCTCACTGA & CCGCCAGTGCCATTATGG \\
\hline & & \\
\hline
\end{tabular}

Forward and reverse primer sequences used for qPCR. 
Suppl. Table 7.3. Baseline characteristics of study population used for gene expression correlation analysis

\begin{tabular}{|c|c|c|c|}
\hline & Mean \pm SD $(n=74)$ & Mean \pm SD $(n=49)$ & Mean $\pm S D(n=25)$ \\
\hline & All & Non-NASH & NASH \\
\hline Age (years) & $44.500 \pm 9.828$ & $44.163 \pm 10.315$ & $45.160 \pm 8.961$ \\
\hline Sex (\% male) & 31.1 & 26.5 & 40 \\
\hline Body mass index $\left(\mathrm{kg} / \mathrm{m}^{2}\right)$ & $45.954 \pm 9.329$ & $43.087 \pm 6.677$ & $51.458 \pm 11.215^{*}$ \\
\hline Hemoglobin A1c (\%) & $6.577 \pm 1.441$ & $6.226 \pm 0.944$ & $7.250 \pm 1.941^{*}$ \\
\hline NAFLD activity score & $3.515 \pm 2.663$ & $1.694 \pm 1.698$ & $6.240 \pm 1.615^{*}$ \\
\hline ASAT (IU/L) & $24.583 \pm 12.583$ & $20.809 \pm 10.206$ & $31.680 \pm 13.726^{*}$ \\
\hline ALAT (IU/L) & $26.083 \pm 15.873$ & $21.319 \pm 8.225$ & $35.040 \pm 22.082^{*}$ \\
\hline Cholesterol (mmol/L) & $5.046 \pm 1.107$ & $5.113 \pm 1.163$ & $4.924 \pm 1.011$ \\
\hline LDL (mmol/L) & $3.163 \pm 0.988$ & $3.209 \pm 1.112$ & $3.075 \pm 0.704$ \\
\hline HDL (mmol/L) & $0.987 \pm 0.395$ & $1.065 \pm 0.443$ & $0.838 \pm 0.218^{*}$ \\
\hline Triglycerides (mmol/L) & $2.314 \pm 2.157$ & $2.201 \pm 2.362$ & $2.531 \pm 1.722$ \\
\hline Free fatty acids (mmol/L) & $0.642 \pm 0.310$ & $0.557 \pm 0.266$ & $0.794 \pm 0.330^{*}$ \\
\hline Leukocytes (x109/L) & $7.415 \pm 1.905$ & $7.148 \pm 1.501$ & $7.976 \pm 2.507$ \\
\hline PMNs (\%) & $54.969 \pm 9.681$ & $54.204 \pm 9.554$ & $56.571 \pm 9.983$ \\
\hline Monocytes (\%) & $7.338 \pm 2.123$ & $7.273 \pm 1.969$ & $7.476 \pm 2.462$ \\
\hline Lymphocytes (\%) & $34.230 \pm 8.636$ & $34.681 \pm 8.826$ & $33.286 \pm 8.355$ \\
\hline Eosinophils (\%) & $3.015 \pm 2.095$ & $3.364 \pm 2.263$ & $2.286 \pm 1.488$ \\
\hline
\end{tabular}

Characteristics of patients used for gene expression correlations. Data are means $\pm S D . n=74$. $* \mathrm{P} \leq 0.05$. 
Suppl. Table 7.4. Expression levels of neutrophil and macrophage markers in the liver and of macrophage and neutrophil chemotaxis genes in the VAT of non-NASH and NASH patients.

\begin{tabular}{|c|c|c|c|}
\hline & $\begin{array}{l}\text { Non-NASH (mean } \pm S D) \\
n=49\end{array}$ & $\begin{array}{l}\text { NASH (mean } \pm S D) \\
n=25\end{array}$ & Non-NASH vs NASH (P-value) \\
\hline MPO Liver & $6.68 \pm 0.12$ & $6.8005 \pm 0.18$ & $0.006^{*}$ \\
\hline CD15 Liver & $6.98 \pm 0.19$ & $7.0705 \pm 0.20$ & 0.061 \\
\hline CD11B Liver & $6.99 \pm 0.23$ & $7.0290 \pm 0.26$ & 0.492 \\
\hline FCGR2A Liver & $7.71 \pm 0.14$ & $7.68705 \pm 0.13$ & 0.566 \\
\hline CD11c Liver & $7.02 \pm 0.21$ & $7.0987 \pm 0.26$ & 0.148 \\
\hline MRC1 Liver & $6.61 \pm 0.06$ & $6.6070 \pm 0.06$ & 0.842 \\
\hline CD11c vAT & $7.17 \pm 0.29$ & $7.3115 \pm 0.44$ & 0.114 \\
\hline MRC1 vAT & $6.67 \pm 0.08$ & $6.6625 \pm 0.07$ & 0.517 \\
\hline CXCL2 vAT & $9.09 \pm 1.21$ & $9.4194 \pm 1.50$ & 0.318 \\
\hline CXCL5 vAT & $6.71 \pm 0.11$ & $6.8052 \pm 0.16$ & $0.016^{*}$ \\
\hline CXCL8 vAT & $9.67 \pm 1.91$ & $10.01 \pm 2.32$ & 0.206 \\
\hline CXCL16 vAT & $8.59 \pm 0.23$ & $8.73 \pm 0.22$ & $0.010^{*}$ \\
\hline S100A8 vAT & $11.46 \pm 1.30$ & $12.02 \pm 1.42$ & 0.091 \\
\hline G-CSF vAT & $7.00 \pm 0.39$ & $7.09 \pm 0.52$ & 0.393 \\
\hline GM-CSF vAT & $6.79 \pm 0.22$ & $6.74 \pm 0.14$ & 0.348 \\
\hline M-CSF vAT & $6.83 \pm 0.09$ & $6.91 \pm 0.10$ & $0.002^{*}$ \\
\hline FLT3 vAT & $6.81 \pm 0.14$ & $6.82 \pm 0.17$ & 0.694 \\
\hline
\end{tabular}

Mean gene expression levels of MPO, CD15, CD11B, FCGR2A, CD11C and MRC1 in liver and CD11c, MRC1, CXCL2, CXCL5, CXCL8, CXCL16, S100A8, G-CSF, GM-CSF, M-CSF and FLT3 in vAT of non-NASH and NASH patients. ${ }^{*} \mathrm{P} \leq 0.05$. 


\section{Chapter 7}

Suppl. Table 7.5. Correlations of FLT3 in vAT with neutrophil and macrophage markers in the liver

\begin{tabular}{lccccccc}
\hline & & MPO & CD15 & CD11B & FCGR2A & CD11c & MRC1 \\
& & (liver) & (liver) & (liver) & (liver) & (liver) & (liver) \\
\hline \multirow{2}{*}{ FLT3 (vAT) } & R-value & -0.011 & 0.143 & 0.051 & -0.030 & 0.068 & 0.163 \\
\hline & P-value & 0.924 & 0.223 & 0.665 & 0.802 & 0.563 & 0.166 \\
\hline
\end{tabular}

R-values and corresponding P-values of the Pearson correlations between FLT3, a DC marker, in vAT with MPO, CD15, CD11B, FCGR2A, CD11c and MRC1 in liver. $n=74 .{ }^{*} \mathrm{P} \leq 0.004$.

Suppl. Table 7.6. Correlations of FLT3 with neutrophil chemotaxis genes in VAT

\begin{tabular}{llllllllll}
\hline & & CXCL2 & CXCL5 & CXCL8 & CXCL16 & S100A8 & G-CSF & GM-CSF & M-CSF \\
& (vAT) & (vAT) & (vAT) & (vAT) & (vAT) & (vAT) & (vAT) & (vAT) \\
\hline \multirow{2}{*}{ FLT3 (vAT) } & R-value & 0.111 & $0.355^{*}$ & 0.124 & -0.010 & 0.059 & 0.112 & -0.115 & 0.110 \\
\hline & P-value & 0.345 & 0.002 & 0.294 & 0.934 & 0.621 & 0.341 & 0.329 & 0.352 \\
\hline
\end{tabular}

R-values and corresponding P-values of the Pearson correlations between FLT3 with CXCL2, CXCL5, CXCL8, CXCL16, S100A8, G-CSF, GM-CSF and M-CSF in vAT. $n=74$. ${ }^{*} \leq 0.004$. 


\section{Chapter 8}

\section{Adipose tissue macrophages do not affect atherosclerosis development in mice}

Mitchell Bijnen, José van de Gaar, Maria Vroomen, Marion J. Gijbels, Menno de Winther, Casper G. Schalkwijk and Kristiaan Wouters

Atherosclerosis 281 (2019) 31-37 


\section{Abstract}

\section{Background and aims}

Obese individuals have a higher risk of developing atherosclerosis, possibly driven by adipose tissue (AT) inflammation. We recently showed that AT macrophages (ATMs), which accumulate in the expanding obese AT, produce mediators causing immune cell recruitment from the bone marrow. In the current study, we evaluated whether ATMs are directly involved in atherosclerotic plaque development.

\section{Methods}

Lean $\mathrm{Idll}^{-/}$acceptor mice received visceral AT (VAT) from lean, obese, or ATMdepleted obese Idlr- $^{-1}$ mice. Acceptor mice were fed high cholesterol diet (HCD) for 4 weeks before and 8 weeks after AT transplantation to induce atherosclerosis. Atherosclerotic plaque development was studied 8 weeks after transplantation.

\section{Results}

Transplanting donor VAT from obese mice increased circulating triglycerides and B-cells, but decreased Ly6c monocytes. Plasma cholesterol, Ly6c ${ }^{+}$ monocytes, T-cells, NK-cells and eosinophils were unaffected. Depleting ATMs from obese AT using clodronate liposomes prior to VAT transplantation prevented the increase in triglycerides and B-cells and decrease in Ly6c monocytes, but did increase eosinophils. Circulating CXCL1 was reduced by obese AT transplantation and IFN- $\gamma$ tended to be increased while TNF and IL$1 \beta$ were unaffected. ATM-depleted obese AT transplantation also reduced CXCL1, but increased circulating TNF levels. However, obese AT transplantation with or without depletion of ATMs did not influence atherosclerotic plaque size, phenotype, or stability.

\section{Conclusions}

ATMs from obese VAT do not affect atherosclerotic plaque development or phenotype. 


\section{Introduction}

Over the last few decades, the prevalence of obesity has nearly tripled. In $2016,39 \%$ of the global adult population was overweight and $13 \%$ was obese $^{1}$. Obesity has been associated with diabetes, non-alcoholic fatty liver disease (NAFLD) and cardiovascular disease (CVD). Several studies, including the Framingham heart study, have connected increasing degrees of obesity with increasing rates of coronary heart disease including atherosclerosis, an important cause of $\mathrm{CVD}^{2,3}$.

Atherosclerosis is a progressive disease in which lipids, fibrotic proteins, and immune cells accumulate in the vessel wall of large arteries forming an atherosclerotic plaque. When this plaque ruptures, the vessel is promptly occluded and can cause a myocardial infarction or stroke ${ }^{4}$. Immune cell recruitment and accumulation plays a key role in plaque development. At first, hyperlipidemia, shear stress and circulating cytokines all contribute to endothelial dysfunction resulting in endothelial expression of adhesion molecules. In parallel, cholesterol loaded LDL particles accumulate in the vessel wall, are modified and trigger the endothelium to produce chemokines $^{5}$. Next, circulating neutrophils and monocytes will bind to the endothelial adhesion molecules and are attracted to modified LDL induced chemokines allowing migration into the vessel wall. Neutrophils can there aggravate endothelial dysfunction and attract more monocytes, while monocytes differentiate into macrophages ${ }^{6}$. In the vessel wall, these macrophages take up (modified i.e. oxidized) lipids, recruit more immune cells to the vessel wall and produce extracellular matrix degrading enzymes that increase the risk of plaque rupture ${ }^{7}$. Neutrophils also further stimulate lipid uptake by plaque macrophages and produce both proteases and reactive oxygen species contributing to plaque instability ${ }^{6}$.

Both the expansion of the adipose tissue (AT) as well as the accompanying AT inflammation has been suggested to be responsible for the increased risk of atherosclerosis ${ }^{8,9}$. The expansion of adipose tissue and the accompanying increase in circulating lipids (including cholesterol loaded LDL) is being tackled by lowering lipids and, indeed, this reduces mortality rates ${ }^{10}$. However, simply lowering lipids is not effective enough with two thirds of 
cardiovascular events still occuring ${ }^{10}$. Therefore, it is necessary to investigate the link between AT inflammation and atherosclerosis.

An important driver of AT inflammation are the AT macrophages (ATMs) which accumulate in the visceral AT (VAT) of obese humans and mice ${ }^{11,12}$. In addition to higher macrophage numbers in the obese AT, obese ATMs also differ in phenotype when compared to ATMs in lean AT. The obese ATMs are considered to be more proinflammatory as they produce TNF and iNOS and are typically characterized by expression of CD11C. ATMs found in lean AT produce anti-inflammatory factors such as arginase-1 and IL-10 and are identified based on expression of $\mathrm{MRC1}^{12}$. Recently, we and others demonstrated that the proinflammatory $\mathrm{CD}_{11 \mathrm{C}^{+}}$ATMs express genes involved in myelopoiesis and immune cell recruitment, thereby affecting circulating monocyte and neutrophil levels ${ }^{13,14}$.

Öhman et al. have shown that VAT inflammation accelerates atherosclerosis in $\mathrm{ApoE}^{-/-}$mice and that monocyte chemoattractant protein (MCP1) plays a key role in this VAT stimulated atherogenesis ${ }^{15,16}$. These findings strongly suggest a key role of ATMs in atherosclerosis. Recently, our group transplanted lean, obese or ATM-depleted obese AT to acceptor mice. We demonstrated that inflammatory $\mathrm{CD}_{11} \mathrm{C}^{+}$ATMs directly cause an increase in circulating neutrophils and monocytes, potentially by expression of cytokines such as CXCLs, CSFs and S100A8/A9. This elevated immune cell recruitment resulted in hepatic neutrophil and macrophage accumulation and consequently liver damage ${ }^{13}$. Due to these effects of ATMs on circulating immune cells and systemic inflammation, we investigated whether ATMs directly cause atherosclerotic plaque development.

\section{Materials and methods}

\section{Adipose tissue transplantation}

Procedures and effectiveness of ATM depletion have been previously described ${ }^{13}$. Briefly, eight-week-old male C57BL/6 $\mathrm{Idlr}^{-/-}$mice were fed a low fat (LFD) or high fat diet (HFD) for 12 weeks before acting as an AT donor. One group of HFD-fed donor mice was injected with clodronate liposomes (i.p. $115 \mathrm{mg} / \mathrm{kg}$ ) two days prior to sacrifice to deplete ATMs. AT derived from LFD-fed, HFD-fed or ATM depleted HFD-fed mice was transplanted to 
eighteen-week-old male C57BL/6 $\mathrm{Idlr}^{/-}$mice resulting in the following three groups: lean-transplanted acceptors (LTA), obese-transplanted acceptors (OTA) and ATM-depleted obese-transplanted acceptors (DOTA). Acceptor mice received a high cholesterol diet (HCD) for 4 weeks before and 8 weeks after AT transplantation to induce atherosclerosis. All performed experiments were approved by the Animal Experiments Committee of Maastricht University.

\section{Histology}

Aortic roots were cryosectioned $(7 \mu \mathrm{m})$ and stained for Haematoxylin and Eosin (HE; Sigma-Aldrich) or Sirius red (stains collagen). An experienced mouse pathologist scored plaque phenotype from 0 to 5 based on fibroblasts, necrosis, foam cells, general inflammation, endothelial adhesion, granulocytes, adventitia influx and calcification using the HE sections. Photographs were taken using a Jenoptik camera and progress capture pro 2.8.8 software. Photos of HE (40x magnification) and Sirius red (40x magnification) sections were analysed blindly using computerized morphometry (Leica QWin V3, Cambridge, UK) to quantify plaque size, collagen content and necrotic area. For each mouse, the average plaque size of all three plaques was quantified based on four sections and then summed to determine the total plaque size. Two sections of each plaque were quantified per mouse to calculate an average percentage of plaque collagen content. Cryosections were stained using antibodies against neutrophils (custom antibody; clone NIMP-R14) as previously described ${ }^{17}$. Neutrophils were counted in three sections per mouse (40x magnification) and an average was calculated.

\section{Cytokine levels}

Circulating cytokine levels of IL-6, CXCL1, IFN- $\gamma$, IL-1 $\beta$, IL-2, IL-4, IL-5, IL-10, IL12P70, and TNF were measured using a V-plex Mouse Cytokine Assay kit (Meso Scale Discovery), according to the manufacturer's instructions.

\section{Flow cytometry}

Blood was collected at the end of the study by cardiac puncture. FC-receptor block (anti-CD16/CD32) was added to the blood. Next, a cocktail of 
antibodies was added (Suppl. table 1). Erythrocytes were lysed by adding lysisbuffer $\left(8.4 \mathrm{~g} / \mathrm{L} \mathrm{NH}{ }_{4} \mathrm{CL}\right.$ and $0.84 \mathrm{~g} / \mathrm{L} \mathrm{NaHCO}$ in $\mathrm{H}_{2} \mathrm{O}, \mathrm{pH} 7.4$ ) before measurement. Flow cytometry was performed using a BD FACSCANTO II running FACS Diva 8.0.1 software, which was used for analysis of all flow cytometry data. The FACS gating strategy can be found in the supplementary materials (Suppl. Fig. 8.1).

\section{RNA Isolation, cDNA Synthesis and qRT-PCR}

RNA was isolated from aortic arch tissue using Trizol reagent (Ambion) before cDNA synthesis using the iScript cDNA synthesis kit (170-8891; Bio-Rad, Hercules, USA) following manufacturer's instructions. Gene expression was determined using IQ SensiMix SYBR master mix (Bioline, London, UK) on a CFX96 Touch with CFX manager software (Biorad). The geometric mean of two reference genes, Cyclophillin and Beta2-microglobulin, was used as reference and the $\triangle \triangle C T$ method was employed to calculate expression levels ${ }^{18}$. Primer sequences are given in supplementary table 8.2.

\section{Plasma cholesterol and triglyceride measurements}

Plasma levels of cholesterol and triglycerides were measured using a colorimetric test (Cholesterol FS'10 and Triglycerides FS 5' ecoline, Diagnostic System $\mathrm{GmbH}$, Holzheim, Germany) as previously described ${ }^{19}$.

\section{Statistical Analysis}

A one-way ANOVA with a Tukey's multiple comparison post-hoc test was performed to analyze all data using GraphPad Prism 5. All data are expressed as the mean \pm SEM and were considered statistically significant at $P \leq 0.05$.

\section{Results}

ATMs affect circulating triglycerides, Ly6c monocytes, B-cells and eosinophils, but not cholesterol, Ly6c $\mathrm{c}^{+}$monocytes, T-cells or NK-cells

$\mathrm{HCD}$ feeding resulted in comparable weight gain in all groups both before and after transplantation indicating similar recovery from the AT transplantation surgery (Suppl. Fig. 8.2). While plasma total cholesterol was unaffected by the type of transplanted VAT, triglycerides were increased in 
OTA mice. Depleting ATMs from donor obese AT prior to transplantation prevented this increase in triglycerides in acceptor mice (Suppl. Fig. 8.3A, B). Total circulating monocytes were decreased in the OTA mice, but not in the DOTA mice when compared to LTA mice (previously published data ${ }^{13}$ ). These effects were mainly due to lower patrolling Ly6c monocytes in the OTA mice (Fig. 8.1A). Circulating proinflammatory Ly $6 \mathrm{c}^{+}$monocytes were unchanged and comparable between all groups after 8 weeks of HCD (Fig. 8.1B). Blood neutrophils, T-cells and NK-cells were unaffected by transplantation of obese AT with or without ATMs (Fig. 8.1C, D and previously published data ${ }^{13}$ ). The OTA mice had increased circulating B-cells when compared to LTA or DOTA mice. Eosinophil levels were similar between LTA and OTA mice, but elevated in the DOTA mice when compared to the OTA mice. It is important to note that immune cell levels were already high before the transplantation since the $H C D$, given from 4 weeks prior to transplantation, rapidly induces immune cell recruitment ${ }^{20,21}$.
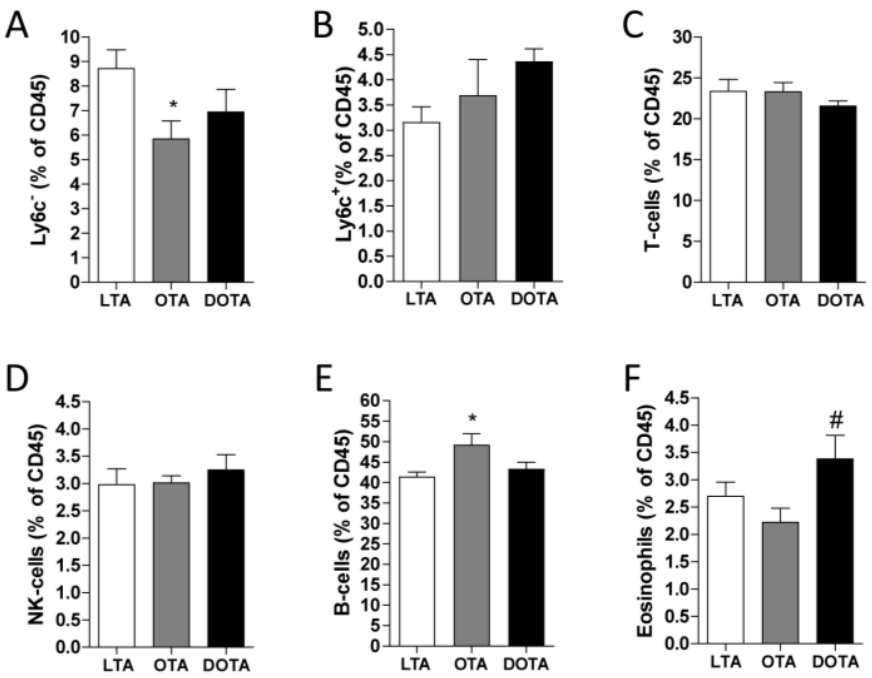

Figure 8.1. Effects of adipose tissue macrophages on circulating immune cell levels Ly6 $c^{+}$monocytes (A), Ly6c- monocytes (B), T-cells (C), B-cells (D), NK-cells (E) and eosinophils $(F)$ in LTA, OTA and DOTA mice 8 weeks after AT transplantation (i.e. after 12 weeks of HCD feeding) presented as percentage of $\mathrm{CD} 45+$ (immune) cells. All data are means $\pm \mathrm{SEM}$. ${ }^{*} \mathrm{P} \leq$ 0.05 vs LTA. \#P $\leq 0.05$ vs OTA. 


\section{Transplantation of obese AT affects circulating cytokines}

To investigate whether AT macrophages affect systemic inflammation, we measured circulating cytokine levels. LTA and OTA mice exhibited similar circulating levels of TNF (proinflammatory cytokine), but the DOTA mice displayed increased circulating TNF levels compared to LTA and OTA mice (Fig. 8.2A). Circulating levels of IL-1 $\beta$ (mediator inflammatory response) did not differ significantly between groups (Fig. 8.2B). CXCL1 (chemotaxis protein) plasma levels were decreased after obese AT transplantation, but not affected by ATMs (Fig. 8.2C). The macrophage activating cytokine, IFN- $\gamma$, tended to be increased in OTA, but not in DOTA mice when compared to LTA mice (Fig. 8.2D).

A

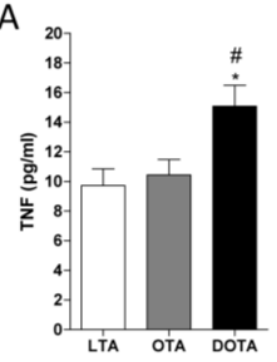

C

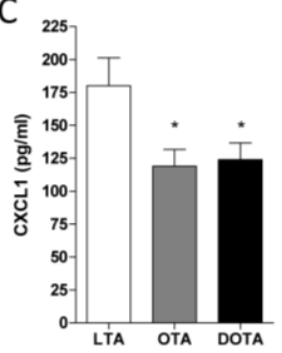

B

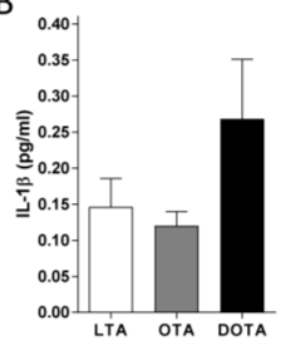

D

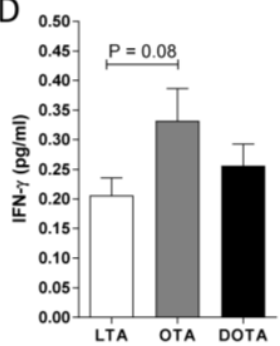

Figure 8.2. Circulating inflammatory cytokines are influenced by adipose tissue macrophages

Plasma levels of TNF (A), IL-1 $\beta$ (B), CXCL1 (C) and IFN- $\gamma$ (D) in LTA, OTA and DOTA mice after AT transplantation and 12 weeks of $H C D$ feeding. All data are means \pm SEM. ${ }^{*} P \leq 0.05$ vs LTA. $\# P \leq 0.05$ vs OTA.

\section{Depletion of ATMs does not prevent atherosclerotic plaque development} Atherosclerotic plaques were characterized 8 weeks after AT transplantation (i.e. after 12 weeks of $H C D$ ). Plaque phenotype was determined by scoring 
plaque severity and complexity and was similar in all groups (Fig. 8.3A). In addition, plaque size, collagen content, and necrotic plaque area did also not differ between the groups (Fig. 8.3B, C). Aortic arch gene expression analysis was similar, indicating no differences in plaque inflammation between groups (Fig. 8.3D). As we previously reported strong effects of ATMs on circulating and hepatic neutrophil levels ${ }^{13}$, we quantified plaque neutrophils. However, neutrophil cell count was similar between all groups 8 weeks after AT transplantation (Fig. 8.3E).
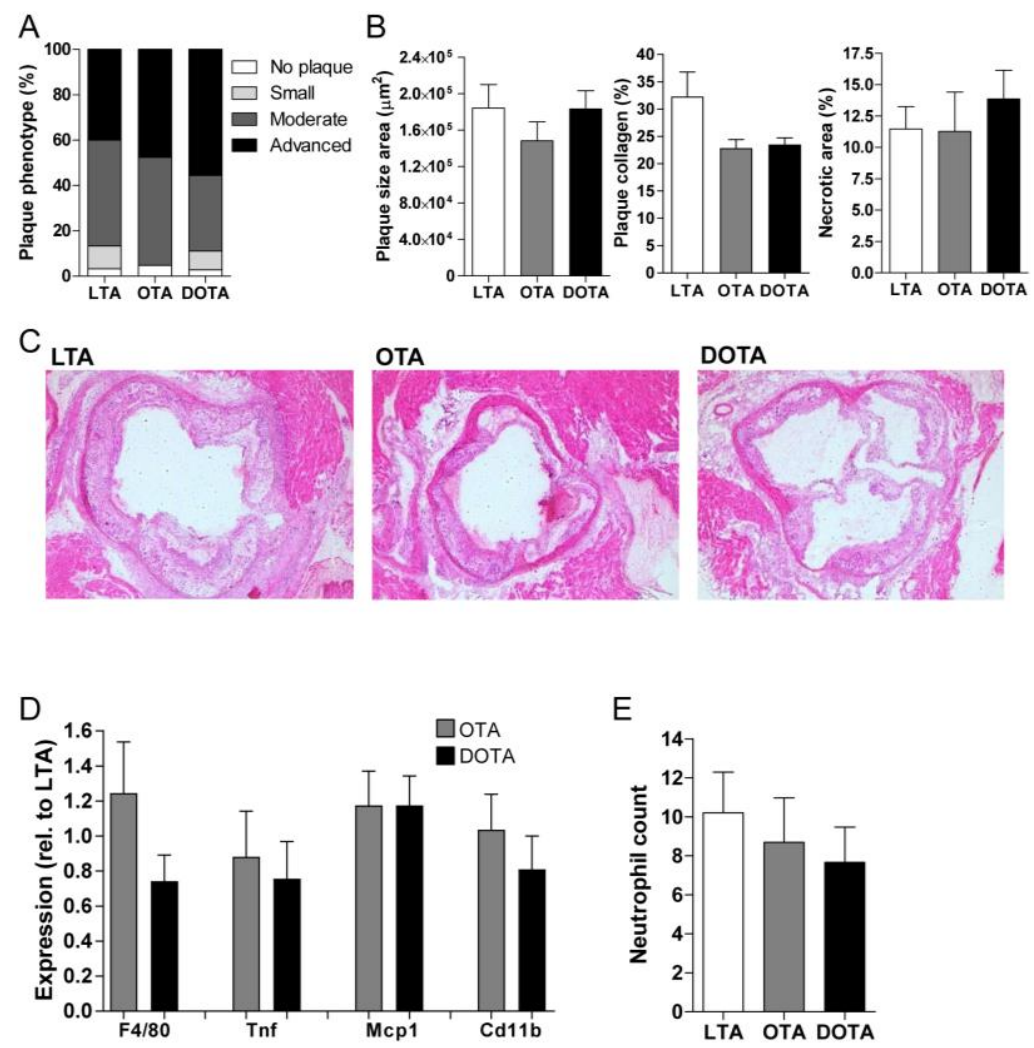

Figure 8.3. The atherosclerotic plaque is unaffected by adipose tissue macrophages

(A) Plaque phenotype graded from 0 to 5 by pathologist. (B, C) Atherosclerotic plaque size, collagen content and necrotic core size $(B)$ and representative images (40x magnification) of HE stained aortic roots (C) in LTA, OTA and DOTA mice 8 weeks after AT transplantation (i.e. after 12 weeks of HCD feeding). (D-E) Aortic arch gene expression levels of inflammatory markers (D) and neutrophil cell count (E) in the atherosclerotic plaque in LTA, OTA and DOTA mice after AT transplantation and 12 weeks of HCD feeding. All data are means \pm SEM. 


\section{Discussion}

The current study showed neither effect of obese AT nor a key role of ATMs on the development of atherosclerosis despite effects on circulating lipids, immune cells and cytokines.

Transplanting obese AT resulted in increased circulating triglycerides and this effect was dependent on ATMs. As both the OTA and DOTA group received similar amounts of adipose tissue and lipolysis gene expression in the donor AT was comparable ${ }^{13}$, the change in triglycerides is likely not due to lipolysis of the donor AT. Potentially, the increase in circulating triglycerides is due to hepatic dysfunction caused by liver damage present in the obese transplanted group. Previously, we observed liver damage in this group, which was reduced when ATMs were depleted before transplantation ${ }^{13}$. This is in line with the effects on plasma triglycerides. Indeed, Alwahsh et al. showed in rats that diet-induced liver damage coincides with increased plasma triglycerides ${ }^{22}$. Furthermore, Corey et al. showed an association of non-alcoholic steatohepatitis (NASH) resolution with reduced triglyceride levels, again demonstrating a link between liver inflammation and damage with triglyceride levels ${ }^{23}$. Interestingly, this increase in circulating triglycerides did not affect atherosclerotic plaque size or phenotype. However, if the observed difference in triglycerides is due to liver damage, only present at a late stage of $\mathrm{NASH}$, it is possible that these changes only occurred at a later stage of atherosclerotic plaque development. Alternatively, the observed difference in total lipid levels may not be large enough to impact plaque development. Moreover, plasma cholesterol, the major driver of experimental NASH, was comparable between all groups.

The levels of most immune cells were not different between the groups. Despite an initial effect of ATMs on neutrophil recruitment from the bone marrow, neutrophils were comparable between all groups 8 weeks after AT transplantation ${ }^{13}$. Total monocytes were lower (most likely due to reduced patrolling Ly $6 c^{-}$monocytes) after transplantation of AT from obese mice and this was not observed when transplanting ATM-depleted AT. The reduction in circulating monocytes might indicate elevated recruitment of monocytes to tissues as we reported higher levels of hepatic macrophages in the obese transplanted group, which are likely monocyte derived ${ }^{13,24}$. Importantly, the 
hypercholesterolemia induced by HCD-feeding triggers monocytosis resulting in elevated monocyte levels in all groups even before transplantation ${ }^{20}$. Notably, circulating B-cells were slightly increased by obese AT transplantation. Current literature supports both an atherogenic and atheroprotective role for B-cells in atherosclerosis ${ }^{25}$. However, as we did not observe any effects on atherosclerosis in our study, the increase in B-cells might not have been sufficiently high to affect the atherosclerotic plaque. Eosinophils were increased only when transplanting ATM-depleted obese AT. Zhang et al. described that eosinophils can promote M2 macrophage polarization in AT, thereby reducing chronic inflammation ${ }^{26}$. Moreover, M2 macrophages are known to recruit eosinophils by expressing chemokines such as CCL17, CCL22 and CCL24 ${ }^{27}$. To our knowledge, effects of specifically ATMs on eosinophils have not been described, but based on the data from Zhang et al., it is conceivable that this interaction does exist and should be further explored.

To assess systemic inflammation, we measured several circulating cytokines. However, 8 weeks after transplantation, obese AT only tended to increase circulating IFN- $\gamma$, an important proinflammatory cytokine important in tissue macrophage differentiation. IFN- $\gamma$ is expressed at high levels in the atherosclerotic plaque and its role in atherosclerosis is a topic of ongoing discussion. Likely, it has a pro-atherogenic role when produced in the plaque $^{28}$, but we found no difference between groups in plaque size or phenotype. However, we only measured IFN $-\gamma$ in the circulation and not in the plaque itself. Furthermore, the effects on circulating levels are subtle and might be transient, therefore not impacting plaque development over time. Levels of TNF, a major proinflammatory cytokine both produced by adipocytes and macrophages, were elevated in the acceptor mice that received ATM-depleted obese AT. In AT, macrophages are the main producers of $\mathrm{TNF}^{29}$. As macrophages were depleted from the obese AT, the elevated TNF plasma levels are therefore most likely caused by increased TNF production in other tissues. CXCL1 (also known as CXCL8 in humans), was measured and found to be decreased by transplantation of obese AT, independent of ATM depletion. CXCL1 is implicated in both neutrophil chemotaxis and monocyte mobilization ${ }^{30,31}$, but lower levels in the obese transplanted groups did not impact atherosclerosis. Collectively, these data 
show that ATMs impact systemic inflammation, but that these changes are not sufficient to alter atherosclerosis development. This is in line with work by Dalmas et al., which showed that intima-media thickness (marker of subclinical atherosclerosis) was unaffected by systemic inflammation or ATM accumulation in obese humans ${ }^{32}$.

We previously showed that the increase in circulating neutrophils and monocytes caused by ATMs resulted in hepatic neutrophil and macrophage accumulation worsening NASH. Interestingly, NASH is associated with cardiovascular disease and over five times as many NASH patients die from CVD than from liver-related causes. Furthermore, a long-term follow up study predicted lower survival of CVD-related diseases when a patient had NASH and this lower survival wasn't present when a patient had only liver steatosis in which there is very little inflammation, suggesting that hepatic inflammation plays a key role in modulating this risk ${ }^{33}$. We observed no effects of ATMs on atherosclerotic plaque size, phenotype, composition or inflammation despite our previously reported effects on hepatic inflammation in the same model ${ }^{13}$. Possibly, the early changes in hepatic neutrophils and later effects on hepatic macrophage accumulation and damage are not sufficient to impact atherosclerotic plaque development. However, a necessary specific sequence of events might also explain the lack of effects of ATMs on atherosclerosis in our experiments. The observed differences in hepatic inflammation and especially liver damage take time to develop and are therefore absent in the early stages of atherosclerotic plaque development. Moreover, the strongest effects on circulating cells and hepatic inflammation are observed early as ATMs recruit neutrophils from the bone marrow and cause neutrophilia followed by hepatic neutrophil infiltration. At a later time point, this early neutrophil infiltration caused elevated hepatic macrophage accumulation and liver damage ${ }^{13}$. However, during the initial and relatively short neutrophilia phase caused by the ATMs, a plaque has not yet fully developed and therefore neutrophils could only impact the early stage of plaque development. Therefore, even though neutrophils have been described to affect atherosclerosis ${ }^{6}$, the transient effect of ATMs on neutrophils might not have impacted atherosclerosis in our model. Indeed, when the plaque has fully developed 8 weeks after 
transplantation, circulating and plaque neutrophil levels are comparable between groups.

Our results are not in line with the work of Öhman et al., which showed effects of VAT transplantation on atherosclerosis. However, there are crucial differences in the methods employed between these studies. In the study of Öhman et al., vAT was transplanted subcutaneously into 4 dorsal (backside) incisions while in the current study the VAT was transplanted into the peritoneal space ${ }^{15}$. Besides the location of the AT transplant, the control group was different as we used a lean transplanted mouse as control while Öhman et al. used a sham operated control group ${ }^{15}$. Lastly, the atherosclerosis model used differed between studies with Öhman et al. employing the non-diet dependent ApoE ${ }^{-/}$model compared to the HCD fed $\mathrm{Idlr}^{-/-}$used in the current study. Indeed, different results have been obtained depending on which model was used when studying atherosclerosis ${ }^{34}$.

In conclusion, proinflammatory ATMs in obese VAT do not affect atherosclerotic plaque development or phenotype despite effects of these ATMs on hepatic inflammation in our model of atherosclerosis. 


\section{References}

1. WHO. Obesity and overweight. http://www.who.int/en/news-room/factsheets/detail/obesity-and-overweight: WHO, 2017.

2. Grundy SM. Obesity, metabolic syndrome, and coronary atherosclerosis. Circulation 2002;105:2696-8.

3. Lakka HM, Lakka TA, Tuomilehto J, et al. Abdominal obesity is associated with increased risk of acute coronary events in men. Eur Heart J 2002;23:706-13.

4. Rader DJ, Daugherty A. Translating molecular discoveries into new therapies for atherosclerosis. Nature 2008;451:904-13.

5. Chen C, Khismatullin DB. Oxidized low-density lipoprotein contributes to atherogenesis via co-activation of macrophages and mast cells. PLoS One 2015;10:e0123088.

6. Soehnlein 0 . Multiple roles for neutrophils in atherosclerosis. Circ Res 2012;110:875-88.

7. Lusis AJ. Atherosclerosis. Nature 2000;407:233-41.

8. Nakamura K, Fuster JJ, Walsh K. Adipokines: a link between obesity and cardiovascular disease. J Cardiol 2014;63:250-9.

9. Mittendorfer B. Origins of metabolic complications in obesity: adipose tissue and free fatty acid trafficking. Curr Opin Clin Nutr Metab Care 2011;14:535-41.

10. Libby P. The forgotten majority: unfinished business in cardiovascular risk reduction. J Am Coll Cardiol 2005;46:1225-8.

11. Wouters K, Gaens K, Bijnen M, et al. Circulating classical monocytes are associated with CD11c+ macrophages in human visceral adipose tissue. Sci Rep 2017;7:42665.

12. Boutens L, Stienstra R. Adipose tissue macrophages: going off track during obesity. Diabetologia 2016;59:879-94.

13. Bijnen $M$, Josefs $T$, Cuijpers I, et al. Adipose tissue macrophages induce hepatic neutrophil recruitment and macrophage accumulation in mice. Gut 2017.

14. Nagareddy PR, Kraakman M, Masters SL, et al. Adipose tissue macrophages promote myelopoiesis and monocytosis in obesity. Cell Metab 2014;19:821-35.

15. Ohman $\mathrm{MK}$, Shen $\mathrm{Y}$, Obimba $\mathrm{Cl}$, et al. Visceral adipose tissue inflammation accelerates atherosclerosis in apolipoprotein E-deficient mice. Circulation 2008;117:798-805.

16. Ohman MK, Wright AP, Wickenheiser KJ, et al. Monocyte chemoattractant protein1 deficiency protects against visceral fat-induced atherosclerosis. Arterioscler Thromb Vasc Biol 2010;30:1151-8.

17. Huugen $\mathrm{D}$, Xiao $\mathrm{H}$, van Esch $\mathrm{A}$, et al. Aggravation of anti-myeloperoxidase antibodyinduced glomerulonephritis by bacterial lipopolysaccharide: role of tumor necrosis factor-alpha. Am J Pathol 2005;167:47-58.

18. Livak KJ, Schmittgen TD. Analysis of relative gene expression data using real-time quantitative PCR and the 2(-Delta Delta C(T)) Method. Methods 2001;25:402-8.

19. Shiri-Sverdlov R, Wouters K, van Gorp PJ, et al. Early diet-induced non-alcoholic steatohepatitis in APOE2 knock-in mice and its prevention by fibrates. J Hepatol 2006;44:732-41.

20. Swirski FK, Libby P, Aikawa E, et al. Ly-6Chi monocytes dominate hypercholesterolemia-associated monocytosis and give rise to macrophages in atheromata. J Clin Invest 2007;117:195-205. 
21. Drechsler $M$, Megens RT, van Zandvoort $M$, et al. Hyperlipidemia-triggered neutrophilia promotes early atherosclerosis. Circulation 2010;122:1837-45.

22. Alwahsh SM, Xu M, Schultze FC, et al. Combination of alcohol and fructose exacerbates metabolic imbalance in terms of hepatic damage, dyslipidemia, and insulin resistance in rats. PLoS One 2014;9:e104220.

23. Corey KE, Vuppalanchi R, Wilson LA, et al. NASH resolution is associated with improvements in $\mathrm{HDL}$ and triglyceride levels but not improvement in LDL or nonHDL-C levels. Aliment Pharmacol Ther 2015;41:301-9.

24. Tacke F. Targeting hepatic macrophages to treat liver diseases. J Hepatol 2017;66:1300-1312.

25. Morris-Rosenfeld S, Lipinski MJ, McNamara CA. Understanding the role of B cells in atherosclerosis: potential clinical implications. Expert Rev Clin Immunol 2014;10:7789.

26. Zhang Y, Yang P, Cui R, et al. Eosinophils Reduce Chronic Inflammation in Adipose Tissue by Secreting Th2 Cytokines and Promoting M2 Macrophages Polarization. Int J Endocrinol 2015;2015:565760.

27. Arango Duque G, Descoteaux A. Macrophage cytokines: involvement in immunity and infectious diseases. Front Immunol 2014;5:491.

28. McLaren JE, Ramji DP. Interferon gamma: a master regulator of atherosclerosis. Cytokine Growth Factor Rev 2009;20:125-35.

29. Surmi BK, Hasty AH. Macrophage infiltration into adipose tissue: initiation, propagation and remodeling. Future Lipidol 2008;3:545-556.

30. Soehnlein O, Drechsler M, Doring Y, et al. Distinct functions of chemokine receptor axes in the atherogenic mobilization and recruitment of classical monocytes. EMBO Mol Med 2013;5:471-81.

31. Kolaczkowska E, Kubes P. Neutrophil recruitment and function in health and inflammation. Nat Rev Immunol 2013;13:159-75.

32. Dalmas E, Kahn JF, Giral P, et al. Intima-media thickness in severe obesity: links with $\mathrm{BMI}$ and metabolic status but not with systemic or adipose tissue inflammation. Diabetes Care 2013;36:3793-802.

33. Ekstedt M, Franzen LE, Mathiesen UL, et al. Long-term follow-up of patients with NAFLD and elevated liver enzymes. Hepatology 2006;44:865-73.

34. Wouters K, Shiri-Sverdlov R, van Gorp PJ, et al. Understanding hyperlipidemia and atherosclerosis: lessons from genetically modified apoe and Idlr mice. Clin Chem Lab Med 2005;43:470-9. 


\section{Supplementary figures and tables}
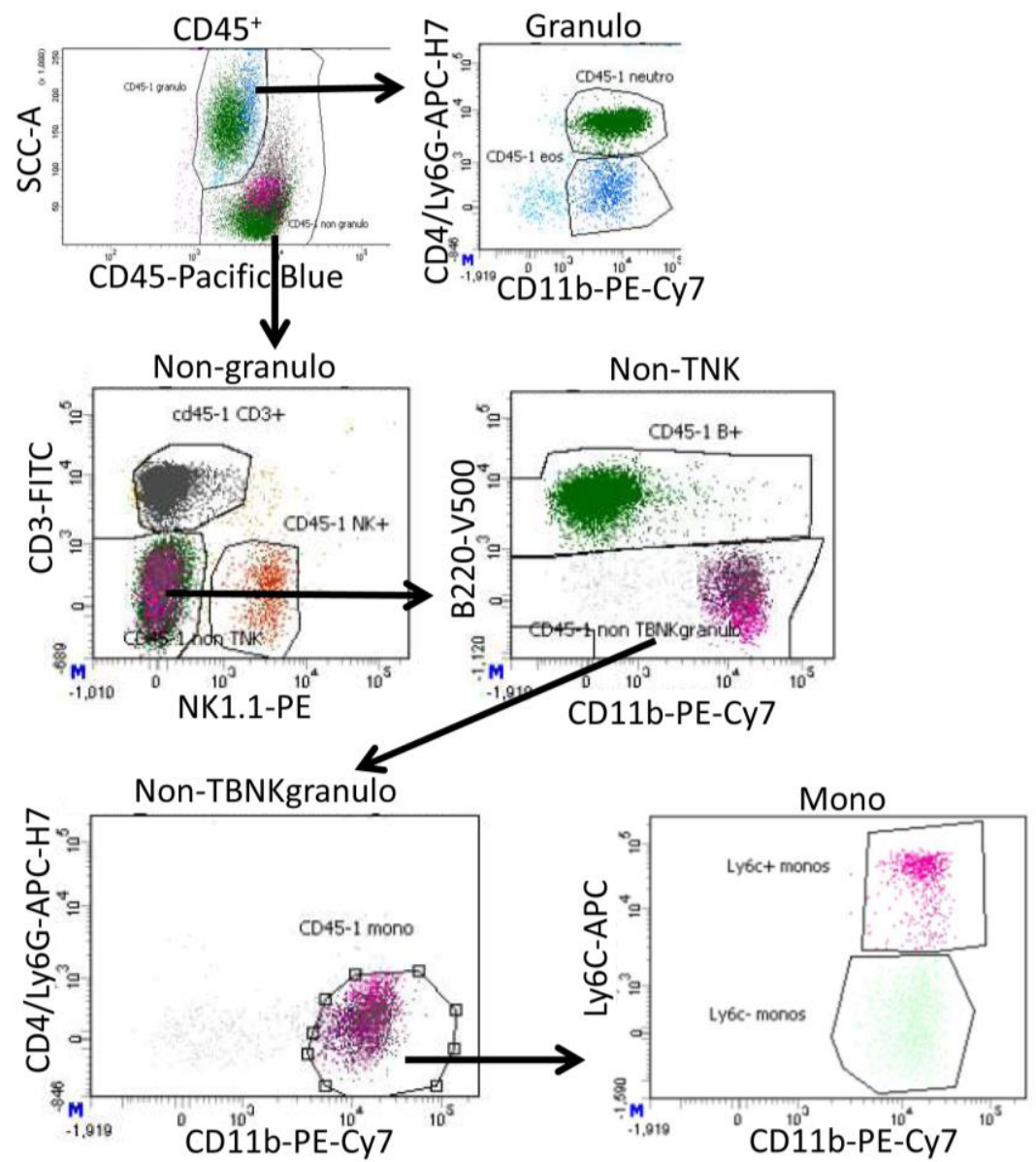

\section{Suppl. Figure 8.1. Flow cytometry gating strategy}

FACS plots showing the gating strategy employed for circulating cells. First, all $\mathrm{CD}^{4} 5^{+}$cells (immune cells) were divided into granular cells and non-granular cells based on sidescatter (SCC). These granular cells were divided into neutrophils (CD11b ${ }^{+} \mathrm{Ly}_{6 \mathrm{G}}{ }^{+}$) and eosinophils (CD11 b+ Ly6G-). The non-granular cells were separated into T-cells based on CD3 expression, NK cells based on NK1.1 expression and a remaining population that was negative for both CD3 and NK1.1. This double negative population (Non-TNK) was divided into B-cells (B220+) and a population negative for CD3, NK1.1 and B220. Monocytes were separated from this population based on high CD11b expression. The monocyte population was then subdivided into Ly6c- (patrolling) and Ly6+ (proinflammatory) monocytes. 


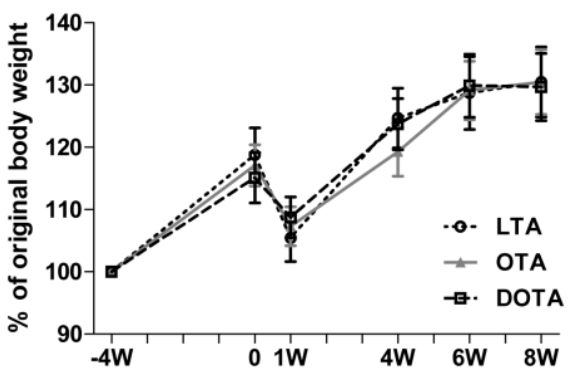

Suppl. Figure 8.2. Obese adipose tissue transplantation does not affect weight gain

Body weight gain before and after adipose tissue transplantation ( $t=0$ weeks) and during HCD feeding. All data are means \pm SEM.

A

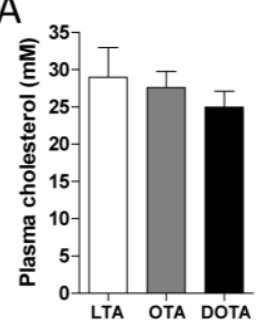

B

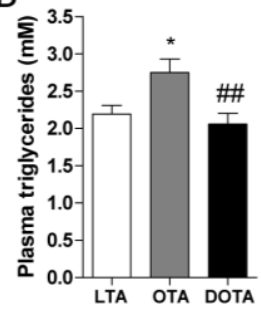

Suppl. Figure 8.3. ATMs affect circulating triglycerides, but not cholesterol

(A, B) Circulating cholesterol (A) and triglyceride (B) levels 8 weeks after AT transplantation (i.e. after 12 weeks of HCD feeding). All data are means \pm SEM. ${ }^{*} P<0.05$ vs LTA. \#\#P $<0.01$ vs OTA. 
Suppl. Table 8.1. Antibodies used for flow cytometry

\begin{tabular}{lll}
\hline Antibody & Label & Manufacturer \\
\hline \hline Blood mix & & \\
\hline CD16/32 & - & eBioscience \\
\hline CD45 & Pacific Blue & Biolegend \\
\hline CD3 & FITC & eBioscience \\
\hline NK1.1 & PE & BD \\
\hline Ly6G & APC-Cy7 & BD \\
\hline CD11B & PE-Cy7 & BD \\
\hline Ly6C & APC & Miltenyi \\
\hline CD4 & APC-H7 & BD \\
\hline B220 & V500 & BD \\
\hline Antbd cockin
\end{tabular}

Antibody cocktail used for blood.

Suppl. Table 8.2. Primer sequences used for gene expression analysis

\begin{tabular}{lll}
\hline Gene & FW primer & RV primer \\
\hline \hline Mcp1 & TTAAAAACCTGGATCGGAACCAA & GCATTAGCTTCAGATTTACGGGT \\
\hline Tnf & CATCTTCTCAAAATTCGAGTGACAA & TGGGAGTAGACAAGGTACAACCC \\
\hline F4/80 & GGATGTACAGATGGGGGATG & TCTGTGGTGTCAGTGCAGGT \\
\hline CD11b & ATGGACGCTGATGGCAATACC & TCCCCATTCACGTCTCCCA \\
\hline Cyclophilin & TTCCTCCTTTCACAGAATTATTCCA & CCGCCAGTGCCATTATGG \\
\hline B2-Micro & CTTTCTGGTGCTTGTCTCACTGA & GTATGTTCGGCTTCCCATTCTC \\
\hline
\end{tabular}

Forward and reverse primer sequences used for qPCR. 


\section{Chapter 9}

Summary and general discussion 


\section{Summary and general discussion}

NAFLD is a progressive liver disease ranging from simple steatosis to the inflammatory NASH, potentially leading to hepatic fibrosis and ultimately cirrhosis ${ }^{1}$. Progression to these later stages is driven by hepatic inflammation, which causes liver damage resulting in liver fibrosis and ultimately liver failure ${ }^{2}$. Moreover, hepatic inflammation is associated with enhanced atherosclerosis, an important cause of myocardial infarction and stroke ${ }^{3}$. Hepatic steatosis sensitizes the liver to induction of inflammation, but it is unclear which factors trigger inflammation and thereby progression of NAFLD.

AGEs may contribute to obesity-related complications such as NAFLD by causing inflammation, mainly by activation of their receptor, RAGE. AGE formation is enhanced during hyperglycemia, hyperlipidemia, oxidative stress and lipid peroxidation, all present in the fatty liver ${ }^{4}$. Hepatic AGE accumulation indeed correlated with hepatic steatosis and inflammation in the livers of NAFLD patients 5 . Furthermore, RAGE-dependent inflammation was demonstrated for hepatocytes ${ }^{5}$. In addition to endogenous AGE formation, high dietary AGE intake may also cause hepatic AGE accumulation $^{6,7}$.

Another important contributor to hepatic inflammation could be the chronic systemic inflammation caused by ATMs accumulating in the expanding AT during the development of obesity ${ }^{8,9}$. A positive association between visceral ATM numbers and hepatic steatosis, inflammation and fibrosis has already been demonstrated in humans ${ }^{10}$. Moreover, inflammatory gene expression in AT was associated with progression and severity of NAFLD and ATMs are likely a major source of the elevated levels of circulating cytokines and chemokines observed in NASH patients ${ }^{11}$. However, it has not been conclusively proven whether ATMs directly cause hepatic inflammation and it is poorly understood how their secreted factors influence hepatic inflammation.

Atherosclerosis is characterized by a similar aetiology as NAFLD with lipid accumulation and inflammatory processes taking place in the vessel wall ${ }^{12}$. 
The conditions in the atherosclerotic plaque are therefore also favourable for AGE-formation. Indeed, higher AGE levels were observed in more inflammatory plaques, which are generally more unstable and prone to rupture causing infarction or stroke when compared to stable plaques. Moreover, a role for RAGE in experimental atherosclerosis has been shown ${ }^{13}$, ${ }^{14}$. Therefore, the AGE-RAGE axis might play a key role in atherosclerosis.

The pro-inflammatory cytokines secreted by ATMs contributing to LGI and potentially impacting the liver might explain the link between obesity and atherosclerosis considering that AT inflammation contributes to atherosclerosis in mice ${ }^{15}$. Moreover, blocking circulating cytokines that might be ATM-derived has beneficial effects on human coronary artery disease ${ }^{16,17}$. However, it has not yet been demonstrated that ATMs directly affect atherosclerotic plaque development.

In this thesis, I describe my research regarding two proposed causes of hepatic inflammation and atherosclerosis:

1. AGEs via their receptor, RAGE

2. Release of inflammatory mediators by obese ATMs

\section{Main findings}

The first chapters focus on the source of hepatic AGEs and their effects on hepatic inflammation and atherosclerosis via RAGE.

Chapter $\mathbf{2}$ describes that hepatic steatosis and hepatocellular injury were positively associated with circulating free AGEs in humans, while inverse associations were observed with circulating protein-bound AGEs. Together with previous work performed in our group, these results suggest an elevated formation of hepatic AGEs in NAFLD. Moreover, a higher breakdown of the formed protein-bound AGEs may result in elevated levels of free AGEs in the circulation. These free AGEs were positively associated with LGI, while SRAGE was not affected by NAFLD and was not associated with LGI. Therefore, the contribution of liver disease to LGI via AGEs is likely independent of RAGE.

Chapter 3 reports that endogenous AGE formation is not the only source of hepatic AGEs, but that they can also accumulate in the plasma and liver due 
to intake of dietary AGEs. The higher hepatic levels caused by a higher AGE intake were accompanied by increased hepatic inflammatory gene expression suggesting effects of AGEs on hepatic inflammation. Interestingly, we were able to reduce circulating and hepatic AGEs by lowering the AGE intake resulting in decreased hepatic inflammatory gene expression. The obtained results demonstrate that dietary AGEs are important contributors to circulating and hepatic AGE and might affect hepatic inflammation. Consequently, AGEs potentially contribute to NAFLD progression and intake should be reduced.

Chapter 4 describes the role of RAGE in hepatic inflammation. RAGE deficiency did not affect systemic or hepatic inflammation or hepatic steatosis in a hyperlipidemic mouse model of NASH. AT expansion was affected by RAGE deficiency, but no effects on AT inflammation were observed. Moreover, RAGE deficiency did not impact atherosclerotic plaque size or phenotype. Additionally, RAGE did not affect circulating or hepatic levels of AGEs. Our results suggest that there is no major role of RAGE in NAFLD progression or atherosclerosis in the employed mouse model.

The next chapters focus on AT inflammation, specifically ATMs, and their effects on hepatic inflammation and atherosclerosis by the release of inflammatory mediators into the circulation.

Chapter $\mathbf{5}$ explains and shows the isolation of immune cells including ATMs from AT and how to quantify the relative numbers of each cell-type and subset within the AT. In addition, it is explained how to determine the quantity of specific membrane-bound markers on the quantified cells.

Chapter 6 makes use of the technique reported in chapter 5 and describes the association between circulating classical monocytes and CD11c $\mathrm{C}^{+} \mathrm{ATM}$ in human vAT. The relation between ATMs and circulating immune cells is further addressed in chapter 7. This chapter describes that CD11 $c^{+}$ATMs in obese AT secrete neutrophil chemotaxis proteins, rapidly causing elevated circulating neutrophils and consequently hepatic infiltration by these cells in mice. Moreover, ATMs of obese AT affected hepatic macrophage accumulation and caused liver damage in an experimental mouse model of NAFLD. In part, our findings were also observed in humans in which CD11c expression was associated with neutrophil chemotaxis gene expression in 
VAT. In addition, CD11c expression in AT correlated with neutrophil and macrophage specific genes in paired human livers. These results suggest that ATMs and the factors they produce contribute to the progression of NAFLD.

Chapter 8 expanded upon our findings in chapter 7 by reporting on the effects of ATMs on atherosclerosis development. Despite the previously reported consequences for the liver and effects on some circulating lipids, immune cells and cytokines, the ATMs did not affect atherosclerosis development.

\section{The AGE-RAGE axis in NAFLD}

AGE accumulation in the liver has been reported previously and hepatic AGEs might be derived from dietary AGEs or endogenously formed ${ }^{5,7}$. In NAFLD patients, especially patients with NASH, AGE accumulation in the liver is increased $^{5}$. Considering the role of oxidative stress, lipid peroxidation and metabolic activity in AGE formation, it is likely that endogenous AGE formation is higher in steatotic and inflammatory livers ${ }^{4,}{ }^{18}$. We now demonstrated an association of hepatic steatosis and hepatocellular injury (two main characteristics of NASH) with circulating free AGEs in a large cohort study (Chapter 2). Protein-bound AGEs were inversely associated with liver pathology. Based on our previous research showing that AT traps AGEs in a RAGE-dependent manner during the development of obesity, we believe that this mechanism may also play a role in the liver, i.e. RAGE-mediated AGE trapping in the steatotic liver ${ }^{19}$. However, we did not observe changes in circulating or hepatic AGEs in our RAGE-deficient mice (Chapter 4). Alternatively, enhanced general protein-breakdown in the liver, which occurs during NAFLD, can contribute to the reduction of circulating protein-bound AGEs by their breakdown and results in elevated circulating free $\mathrm{AGEs}^{20}$. Together with the observed higher hepatic AGE accumulation in NAFLD patients, this supports the hypothesis that more AGEs are formed in the steatotic and inflammatory liver and released into the circulation (Fig. 9.1). An association between free CML and LGI was observed. However, mediation analysis showed that free CML did not contribute a lot to the LGI caused by NAFLD. Most likely, the inability of free CML to activate RAGE is responsible for the only minor contribution of free CML to the association of NAFLD with 
$\mathrm{LGI}^{21}$. Therefore, the association between free $\mathrm{CML}$ and $\mathrm{LGI}$ might be explained by another AGE-mediated inflammatory process in the body, e.g. in the AT.

No BMI-independent association between either liver fat or hepatocullular injury with SRAGE was observed. Moreover, sRAGE was not associated with LGI either. SRAGE is thought to either act as decoy receptor for its ligands, thereby inhibiting RAGE signalling, or is seen as a reflection of AGE-RAGE axis activity $^{22,23}$. However, the main source of SRAGE, particularly during disease, is unknown, making it impossible to determine if sRAGE levels reflect RAGE activation of mainly the liver. Moreover, adiposity seems to have a major impact on circulating SRAGE levels explaining the attenuation of the observed inverse association when adjusted for $\mathrm{BMI}^{19,24}$. Possibly, the activity of RAGE cleaving proteases (e.g. ADAM10) is impaired in obesity, but no data is currently available ${ }^{24,25}$. Therefore, regarding the role of RAGE in liver disease based on our results, we can only conclude that hepatic fat content and hepatocellular injury do not independently affect circulating sRAGE levels and that sRAGE levels do not influence general LGI. In contrast, an inverse correlation between SRAGE and either TNF- $\alpha$ and CRP, two components of our LGI-score has been reported ${ }^{26}$. In comparison to our cohort study, that study used diagnosed NAFLD patients with likely more severe liver disease with potentially increased stimulation of RAGE and a higher release of inflammatory mediators ${ }^{26}$. Furthermore, our LGI-score is a better reflection of $L G I$ than two individual markers, but might contain markers that do not correlate well with RAGE. When performing a similar analyses as their study, we also found that sRAGE correlated with CRP, but not TNF- $\alpha$ in our study population. This suggests that a greater contribution to $L G I$ via RAGE is present in more advanced liver disease.

Dietary AGEs and hepatic inflammation

Next to endogenous formation of AGEs in the liver, hepatic AGEs can be derived from the diet (Fig. 9.1). Previously, we demonstrated that higher dietary protein-bound AGE intake was associated with higher levels of free (and not with protein-bound) AGEs in plasma and urine in a human cohort study ${ }^{27}$. Moreover, biodistribution experiments in mice revealed an 
accumulation of dietary protein-bound $\mathrm{CML}$ in many organs including the liver of mice ${ }^{7}$. Now, we confirmed that alterations in dietary protein-bound AGE intake of three major AGEs (CML, CEL and MG-H1) affects circulating and hepatic free AGE levels in mice (Chapter 3). These data in combination with the aforementioned human cohort study suggest that protein-bound AGEs in the diet are degraded in the intestines and end up as free AGEs in the circulation. Indeed, Alamir et al. revealed that dietary protein-bound CML cannot be absorbed and only digested free $\mathrm{CML}$ derived from dietary $\mathrm{CML}$ can accumulate in organs ${ }^{28}$. In the liver, certain free AGEs can cause hepatic inflammation by binding of RAGE. Indeed, Leung et al demonstrated RAGEdependent hepatic inflammation induced by high AGE feeding in line with our work ${ }^{29}$. Notably, we were also able to reduce hepatic AGE levels and even hepatic inflammation by reducing AGE intake, which opens up the possibility of dietary interventions to prevent AGE-related pathology. The main free AGE capable of binding and activating RAGE is MG-H1 considering it can bind and stimulate RAGE in its free form, unlike $\mathrm{CML}$ and $\mathrm{CEL}^{30}$. Interestingly, hepatic steatosis and inflammation was not associated with free MG-H1 in our human cohort study (Chapter 2). This could suggests that endogenous formation of this AGE is not elevated during NAFLD or that there is another important source of MG-H1 other than the liver. This source might be the intake of dietary AGEs, which will end up in the liver as free MG-H1 and could stimulate inflammation via RAGE.

RAGE in NAFLD and atherosclerosis

After investigating the sources of hepatic AGE accumulation, we studied the contribution of RAGE to hepatic inflammation during NASH development (Fig. 9.2). Despite previous reports describing the importance of RAGE in several other immune-driven liver diseases, we observed no effects of RAGE deficiency on hepatic steatosis and inflammation in our model of NASH (Chapter 4) $)^{31-33}$. However, in many of those other liver diseases, e.g. acetaminophen-induced liver injury, large amounts of damage-associated molecular patterns (DAMPs) are released due to cell injury and death ${ }^{34}$. An important DAMP released upon cell damage is HMGB1, which can bind and activate RAGE signalling and consequently trigger inflammation ${ }^{35,36}$. In our 
murine NASH model, hepatic steatosis and inflammation occurs very fast and inflammation is mainly cholesterol-driven ${ }^{37,38}$. Late stage aspects of NAFLD, such as fibrosis and liver damage are mild and therefore the release of DAMPs is possibly minimal in our model ${ }^{38,39}$. Without sufficient release of DAMPs, binding of RAGE by AGEs is required to induce hepatic inflammation. It is possible that the level of hepatic AGEs produced by endogenous formation in our model is not sufficiently high enough to stimulate RAGE. In addition, the Western type diet contained little AGEs resulting in low circulating and hepatic AGEs in our model of NAFLD (data not shown). This implies that hepatic AGE levels are impacted more by the diet than by endogenous formation, even under conditions favourable for AGE formation, i.e. hepatic steatosis, inflammation and oxidative stress. In line, Leung et al. could only demonstrate an involvement of RAGE in NAFLD when hepatic AGEs were strongly increased by feeding mice a baked diet high in AGEs ${ }^{29}$. When liver damage does occur in the latter stages of NAFLD, which are not sufficiently mirrored in our model, DAMPs such as HMGB1 are released and RAGE could have a superior role to play in NAFLD progression. This fits with our assumption based on the comparison between our human study and the study of Palma-Duran et al. that a greater contribution to LGI via RAGE is present in more advanced liver disease (Chapter 2) ${ }^{26}$.

In our RAGE-deficient mice, we observed a lower bodyweight gain, potentially caused by a decrease in VAT expansion, but this was not accompanied with alterations in AT inflammation (Chapter 4). Ueno et al. reported a similar finding, but in a different model of atherosclerosis development $\left(\mathrm{apoE}^{-/}\right)^{40}$. This effect was also observed in RAGE-deficient mice by Song et al. in high fat diet-induced obesity. In that study, the reduction in VAT mass was associated with increased energy expenditure and less VAT inflammation as $\mathrm{CD} 11 \mathrm{c}^{+}$ATMs were reduced, in contrast with our results ${ }^{41}$. An explanation for disparate effects on AT inflammation might be found in the difference between models. Song et al. used regular C57BL/6 mice and induced obesity using a high fat diet designed to greatly expand adipose tissue mass and cause accumulation of inflammatory ATMs ${ }^{41,42}$. In contrast, we used Idlr-- mice C57BL/6 mice fed a Western type diet, which induces only 
mild obesity ${ }^{38,43}$. Therefore, comparing RAGE-dependent effects on AT inflammation between these models is difficult.

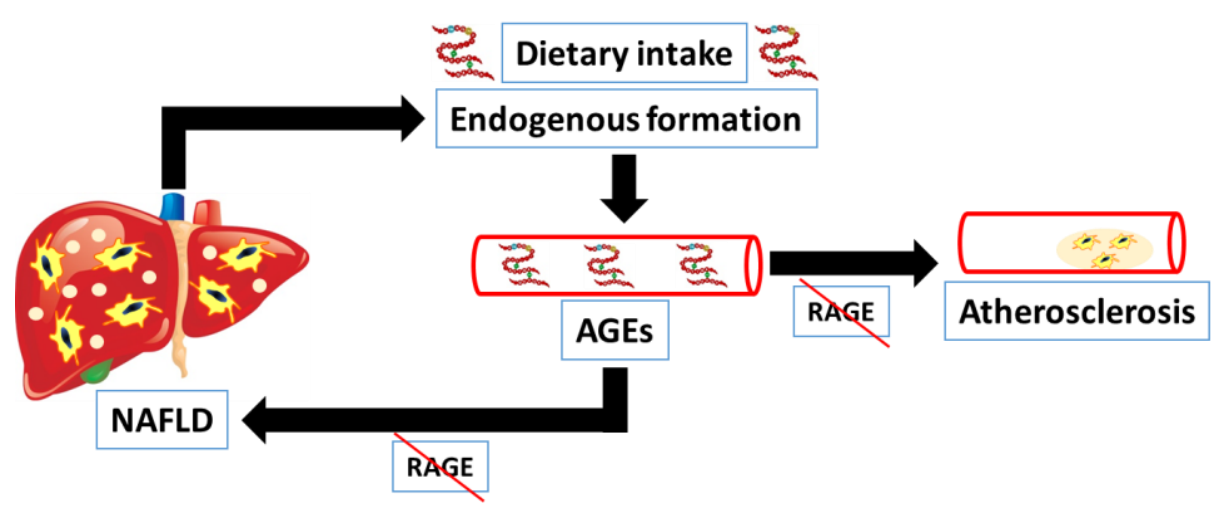

Figure 9.1. Overview of the role of AGEs and RAGE in NAFLD and atherosclerosis

The steatotic and inflamed liver in NAFLD contributes to endogenous AGE formation. The formed AGEs can cause hepatic inflammation, but this might be independent of RAGE. Dietary AGEs end up in the circulation together with the endogenous AGEs and might contribute to NAFLD progression by stimulating hepatic inflammation. Furthermore, AGEs have been shown to accumulate in the atherosclerotic plaque, but no role of RAGE in atherosclerosis was observed.

We investigated the role of RAGE on atherosclerosis in the same hyperlipidemic mouse model (Chapter 4). Similar to our effects on NASH, we did not observe any effects of RAGE deficiency on atherosclerosis (Fig. 9.1). This observation is in line with our data showing no change in monocytosis or hepatic inflammation in this model. In particular monocytosis has been strongly linked to atherosclerosis and RAGE has indeed been shown to only affect diabetic and not hyperlipidemia-associated myelopoiesis ${ }^{44-47}$. The inflammatory component of NAFLD has been linked to atherosclerosis development and CVD-related death ${ }^{3,48}$. As mentioned above, hepatic inflammation was not affected in our RAGE-deficient mice. Therefore, no difference in atherosclerotic plaque development mediated by hepatic inflammation can be expected when comparing the control and RAGEdeficient mice. It is possible that the atherosclerotic plaque is more affected when liver disease is more advanced with elevated systemic inflammation and disturbed liver function such as alterations in lipoprotein metabolism ${ }^{49}$, 
50. At this stage, release of DAMPs due to hepatic injury could potentially stimulate RAGE and contribute to inflammation. Previous studies did report a role of RAGE in atherosclerosis. However, these studies were performed in different animal models of atherosclerosis, mainly diabetes-accelerated atherosclerosis in which AGEs are elevated ${ }^{51}$. The study of Sun et al. does report contradictory results in a more similar model of atherosclerosis, the $\mathrm{Idlr}^{-/-}$mice fed a high fat $\operatorname{diet}^{52}$. However, the difference in diet might explain the discrepancies between results. Particularly the higher fat content of their diet makes the development of atherosclerosis in their model more driven by obesity and AT inflammation and not by cholesterol.

\section{Adipose tissue inflammation during obesity}

Obese AT is not only characterized by lipid-filled hypertrophic adipocytes, but also by an altered immune cell composition. During the development of obesity, the immune cell numbers in the AT increase. Particularly, ATMs increase greatly in numbers by recruitment of monocytes or local proliferation. Moreover, the type of macrophages in the AT changes with a shift towards more pro-inflammatory ATMs characterized by CD11c expression ${ }^{9}$. When studying AT inflammation and ATMs, it is of importance to be able to distinguish AT immune cells including ATM subsets. Therefore, we established a protocol to isolate and phenotype immune cells from the AT using flow cytometry (Chapter 5$)^{53}$. Flow cytometry allows the measurement of several markers per cell simultaneously and this technique was employed in several chapters of this thesis.

The described protocol was used to determine the amount and types of AT immune cells including ATMs in human VAT and SAT. These data were combined with flow cytometry data of circulating cells and correlations between circulating monocytes and ATMs were examined (Chapter 6$)^{54}$. The main finding was an association between circulating classical monocytes and inflammatory CD11 $\mathrm{c}^{+}$ATMs in human vAT. This association suggests that

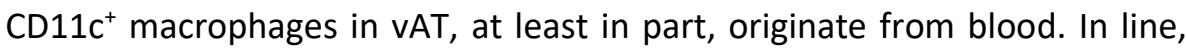
when comparing the migration rate of the different human monocyte subsets, classical monocytes showed the highest migration towards conditioned medium from human $\mathrm{VAT}^{55}$. However, some murine studies 
suggest that local proliferation contributes substantially to the ATM pool in obesity independently from monocyte recruitment. A cell tracking study in mice revealed that macrophages are seeded in the AT during embryogenesis and are maintained by local self-renewal and proliferation ${ }^{56}$. Another study in mice described that ATM recruitment is followed by local proliferation of these monocyte-derived ATMs ${ }^{57}$. It is likely that both recruitment and local proliferation play an important role in human ATM accumulation during obesity, but this has not yet been studied. Moreover, it is possible that the source (recruitment or local proliferation) of ATMs depends on the ATM subset. Indeed, it has been reported that local proliferation mainly contributed to $\mathrm{M} 2$ macrophages and we also observed no association of circulating monocytes with M2 macrophages in our study suggesting that these macrophages depend less on monocyte recruitment ${ }^{54,58}$. Based on our human study data and the aforementioned studies, we considered inflammatory $\mathrm{CD} 11 \mathrm{c}^{+}$macrophages to originate at least in part from circulating classical monocytes (Fig. 9.2).

However, the observed association between monocytes and CD11 $\mathrm{c}^{+}$ATMs might also be explained by potential effects of these ATMs on monocytosis. We indeed found that ATMs contribute to the recruitment of neutrophils and potentially monocytes from the bone marrow (Chapter 7) ${ }^{59}$. ATMs have previously been shown to cause neutrophilia and monocytosis after transplantation of obese AT to lean mice ${ }^{46}$. Now, we revealed enhanced expression of several colony stimulating factors and neutrophil chemotaxis genes during obesity by specifically $\mathrm{CD} 11 \mathrm{c}^{+}$macrophages explaining the observed elevated monocyte and neutrophil levels. 


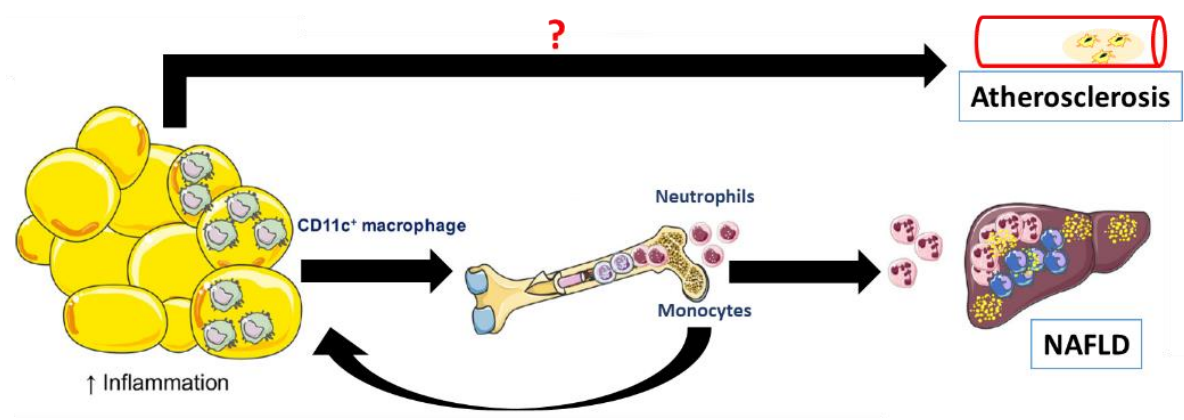

Figure 9.2. Overview of the effects of ATMs on circulating cells and consequently the liver CD11 $\mathrm{c}^{+}$inflammatory ATMs elevate circulating neutrophil and monocyte levels by affecting recruitment from the bone marrow. These increases in circulating cells cause hepatic inflammation due to enhanced hepatic neutrophil infiltration and macrophage accumulation resulting in damage to the liver. Alterations in circulating monocyte levels are also associated with the inflammatory $\mathrm{CD} 11 \mathrm{c}^{+}$macrophage accumulation in the AT. The effects of ATMs in obese AT on atherosclerosis require further investigation. Figure adapted from Pernes et al. (Gut, 2018).

\section{Adipose tissue inflammation and NAFLD}

The elevated circulating immune cells caused by ATMs resulted in increased hepatic neutrophils and at a later stage accumulation of (monocyte derived) macrophages (Chapter 7; Fig. 9.2). We believe that due to the high levels of neutrophils in the circulation, well-perfused organs such as the liver are highly exposed to these neutrophils and therefore prone to extravasation. This should be confirmed in other well-perfused organs, e.g. the kidney. If these organs do not have a high infiltration of neutrophils, it might be a selective process requiring expression of adhesion molecules or release of chemoattractants by the liver. After neutrophils infiltrate the liver, they can cause hepatic inflammation in a myeloperoxidase-dependent manner further attracting immune cells ${ }^{60}$. Indeed, we observed elevated hepatic macrophage accumulation at a later time point. This can be a direct consequence of the inflammation caused by the neutrophils or due to the reported elevated monocyte levels after obese AT transplantation ${ }^{46}$. The increased macrophage levels in the liver were accompanied by higher levels of ALAT, a reflection of liver damage. It has been well described that hepatic inflammation causes hepatic injury and vice versa ${ }^{61,62}$. Therefore, ATMs in obese AT are capable of driving NAFLD progression from steatosis to NASH 
followed by enhanced hepatic injury. Strikingly, we were able to confirm our experimental findings in humans using paired biopsy micro-array data. We observed correlations between the inflammatory CD11 $\mathrm{c}^{+}$ATM subset and neutrophil and macrophage markers in the liver. Associations between ATMs in general and liver histopathology have previously been demonstrated, but no distinction was made between subsets ${ }^{10}$. However, it was shown by du Plessis et al. that the $\mathrm{CD} 11 \mathrm{c}^{+}$macrophage subset is more prevalent in the AT of NASH patients compared to the AT of lean or non-inflammatory NAFLD patients ${ }^{11}$. We also determined significant correlations between the $\mathrm{CD} 11 \mathrm{c}^{+}$ macrophage marker and neutrophil chemotaxis genes in the human AT micro-array data. One of these neutrophil chemotaxis genes, i.e. CXCL8, has previously been implicated in hepatic inflammation and NAFLD progression ${ }^{11}$. Our data combined with the aforementioned studies support our hypothesis that specifically $\mathrm{CD} 11 \mathrm{c}^{+} \mathrm{ATMs}$ contribute to the progression of NAFLD.

Adipose tissue inflammation and atherosclerosis

Despite the effects of ATMs on systemic inflammation and consequently hepatic inflammation, we did not observe an effect of obese AT or specifically ATMs on atherosclerosis (Chapter 8). The strongest effects of ATMs on circulating cells were seen only shortly after AT transplantation. Indeed, circulating neutrophils were normalized 8 weeks after transplantation and plaque neutrophil content was not affected by ATMs. Murphy et al. also showed a peak of circulating monocyte levels at 3 weeks after obese AT transplantation with already a decline present at 4 weeks ${ }^{46}$. Furthermore, it has been shown that over time the plaque macrophages predominantly depend on local macrophage proliferation rather than monocyte influx ${ }^{63}$. The transplantation was performed after 4 weeks of Western type diet feeding, i.e. atherosclerosis development, at which stage the monocyte infiltration might already be less important than local plaque macrophage proliferation. Therefore, despite the described role of neutrophils and monocytes in atherosclerosis, the transient effect of ATMs on neutrophil and monocyte recruitment in our experiment might not have an impact on atherosclerosis ${ }^{44,}$ $45,64,65$. In obesity, the obese AT maintains a constant low-grade inflammatory 
state by production of inflammatory adipokines, while transplantation of obese AT has a temporary effect ${ }^{9}$. This is a limitation of the employed model and could suggest larger effects when there would be a sustained effect of the transplanted obese AT.

Seemingly, the well-perfused liver is more prone to such a transient change in systemic inflammation. The early hepatic neutrophil infiltration caused elevated hepatic macrophage accumulation and liver damage at a later stage (Chapter 7) $)^{59}$. However, these ATM-mediated effects on hepatic inflammation and especially liver damage were only observed 8 weeks after transplantation and atherosclerosis developed simultaneously in our model. Potentially, atherosclerosis could be affected when NAFLD is further progressed with even more damage causing impairment of liver function and secretion of inflammatory mediators contributing to systemic inflammation ${ }^{49,50,66,67}$.

In contrast to our results, general AT inflammation has been reported to affect atherosclerosis in mice, but there are notable differences in the applied methods such as the origin, amount and location of the transplanted AT, the used control group and the model of atherosclerosis ${ }^{15}$. Furthermore, Öhman et al. did not investigate ATMs specifically. Therefore, it is difficult to compare these studies and draw a final conclusion on the effects of ATMs on atherosclerosis (Fig. 9.2).

\section{Future directions}

As described in this thesis, our data suggest that AGEs accumulate in the fatty liver via endogenous formation and dietary intake. In the liver, AGEs might cause hepatic inflammation and potentially contribute to LGI. Future research should be focused on testing the ability to reduce AGE accumulation in the liver. $\alpha$-dicarbonyls, such as methylglyoxal (MGO), are AGE-precursors which are highly reactive and can bind to proteins resulting in the formation of AGEs. They are of major importance in the endogenous formation of $A G E s^{68}$. Several compounds are capable of reducing AGE-precursors. Pyridoxamine is a vitamin B6 analogue capable of trapping $\alpha$-dicarbonyl compounds and thereby inhibiting glycation of proteins ${ }^{69,70}$. Recently, it was shown that pyridoxamine reduced AT inflammation and improved insulin 
sensitivity in obese mice ${ }^{71}$. Aminoguanidine has also been described to react with $\alpha$-dicarbonyls preventing AGE formation ${ }^{72}$. Therefore, it would be of interest to test these compounds in a model of NAFLD to reduce endogenous AGE formation and thereby hepatic inflammation. A human clinical study with overweight subjects receiving pyridoxamine is currently being conducted at our department. In this study, circulating AGEs and immune cells, liver enzymes and LGI markers will be determined, providing information on the effects of AGE lowering on the liver in overweight individuals. Endogenous AGE formation is also affected by the glyoxalase system, which detoxifies $\alpha$-dicarbonyls, mainly MGO, by conversion into $D$ lactate $^{73}$. Our group has access to mice which overexpress human glyoxalase$1^{74}$. It is possible to cross these mice with mice prone to develop NAFLD or feed them a diet (e.g. methionine-choline deficient diet) to induce hepatic inflammation and this will allow us to study whether inhibition of endogenous AGE formation would benefit liver disease. In addition, AGE formation is strongly stimulated by high glucose levels, lipid peroxidation and oxidative stress. Particularly lipid peroxidation and oxidative stress might be reduced by use of anti-oxidants, thereby preventing AGE-formation ${ }^{75}$. Indeed, anti-oxidant therapy e.g. Vitamin $\mathrm{E}$, has beneficial effects on NAFLD, specifically $\mathrm{NASH}^{76}$. However, it is difficult to discern if the positive effects are caused by reduction of AGE formation or via another oxidative stress pathway causing hepatic inflammation.

Another main finding in our thesis is the major impact of dietary AGEs on circulating and hepatic AGEs. Further dietary intervention studies with a focus on the liver are required to confirm that hepatic AGEs are strongly affected by dietary intake and, more importantly, can be reduced with consequently less hepatic inflammation. Currently, a study is ongoing in which mice are fed a regular chow diet, followed by a period of baked chow diet feeding before returning to feeding of a chow diet again. In this experiment, circulating AGEs, hepatic AGEs and hepatic inflammation will be quantified in detail and an increase of these parameters due to high AGE feeding followed by a reversal by lower AGE intake is hypothesized. Moreover, a human clinical study is planned at our department in which subjects will receive either a low or high AGE diet. Many parameters including circulating AGEs and immune cells, liver enzymes and LGI markers 
will be measured. A recent meta-analysis focused on cardiometabolic parameters already reported beneficial effects of low AGE consumption on LGI markers, but liver function or damage was not studied ${ }^{77}$. The aforementioned clinical studies will provide crucial information about favorable effects of AGE reduction on liver disease.

No effects of RAGE deficiency on hepatic steatosis or inflammation was observed in our model of NAFLD. As mentioned, AGE levels or other RAGE ligands, such as HMGB1, might not have been increased sufficiently in our model to stimulate RAGE. In a different model of NAFLD with more liver damage and accompanying fibrosis, e.g. the methionine-choline deficient diet, RAGE could play a more important role due to the higher amount of HMGB1 released ${ }^{43}$. It is of importance to further investigate the role of RAGE in other models of NAFLD considering the AGE accumulation found in steatotic and inflamed livers ${ }^{5}$. However, the possibility that another RAGEindependent mechanism causes AGE-mediated hepatic inflammation should also be considered and studied in the future. Other AGE receptors, e.g. galectin-3 or AGER1 have been implicated in liver disease ${ }^{78,79}$.

A logical next step in our ATM research is testing if blocking of ATM-derived inflammatory mediators, i.e. the neutrophil chemotaxis proteins, reduces systemic and hepatic inflammation. The use of blocking antibodies to inhibit cytokine function has been previously applied in experimental models ${ }^{80}$. Therefore, it seems feasible to perform a new AT transplantation experiment using blocking antibodies to ultimately prove that ATM-derived immune cell attractant proteins contribute to liver pathology. Alternatively, conditional knockout mice could be generated that lack the neutrophil chemotaxis genes in specifically macrophages. However, a pharmaceutical option would be preferred since a major clinical trial has recently demonstrated the feasibility and beneficial effects of such a blocker on CVD outcome in humans ${ }^{16}$.

Surprisingly, we did not observe effects on atherosclerosis despite alterations of hepatic inflammation by ATMs. Possibly, the link between hepatic inflammation and atherosclerosis depends on the underlying cause of these pathologies. Further research needs to be performed and suppression of liver derived inflammatory mediators in a murine model of atherosclerosis would be a potential first step. 


\section{Clinical implications}

The inhibition of the endogenous formation of AGEs and/or the reduction of the AGE load by dietary AGE reduction would be interesting to test in a clinical setting using NAFLD patients. In part, we can use the data obtained from ongoing and planned clinical studies investigating pyridoxamine and low AGE-diets at our department. However, future studies focused on the liver with MRIs and even liver biopsies would be required for definitive evidence that $A G E$ reduction benefits the liver. If successful, reduction of AGE accumulation in the liver could benefit NAFLD patients by reducing hepatic inflammation and therefore the progression of NAFLD towards irreversible liver damage $e^{5,29,81}$.

Successful blocking of ATM-derived inflammatory mediators and thereby reduction of hepatic neutrophil and macrophage content would also open the possibility for therapy in humans. Obese people prone to NAFLD progression could receive anti-inflammatory therapy to prevent hepatic inflammation and its deleterious consequences. Such a strategy has recently been used to combat CVD, which has opened a new avenue of therapy ${ }^{16}$.

\section{Main conclusions}

AGEs can accumulate in the liver by endogenous formation, stimulated by hepatic steatosis and inflammation, but also due to dietary AGE intake. In the liver, AGEs can cause hepatic inflammation, but at low levels this might not be via RAGE. RAGE could play a more important role in more severe liver disease when more ligands for RAGE are produced and released.

Classical monocytes contribute to the pool of inflammatory CD11c ${ }^{+}$ATMs, but these ATMs might also be responsible for recruitment of monocytes and neutrophils from the bone marrow. This recruitment of immune cells by production and release of inflammatory mediators affects the progression of NAFLD. However, ATM-mediated immune cell recruitment does not contribute to the development of atherosclerosis in our murine model. 


\section{References}

1. Stankovic MN, Mladenovic DR, Duricic I, et al. Time-dependent changes and association between liver free fatty acids, serum lipid profile and histological features in mice model of nonalcoholic fatty liver disease. Arch Med Res 2014;45:116-24.

2. Than NN, Newsome PN. A concise review of non-alcoholic fatty liver disease. Atherosclerosis 2015;239:192-202.

3. Ekstedt M, Franzen LE, Mathiesen UL, et al. Long-term follow-up of patients with NAFLD and elevated liver enzymes. Hepatology 2006;44:865-73.

4. Casper GS. Therapeutic Interventions in the Glyc(oxid)ation Pathway. Immunology, Endocrine \& Metabolic Agents in Medicinal Chemistry 2007;7:57-68.

5. Gaens KH, Niessen PM, Rensen SS, et al. Endogenous formation of Nepsilon(carboxymethyl)lysine is increased in fatty livers and induces inflammatory markers in an in vitro model of hepatic steatosis. J Hepatol 2012;56:647-55.

6. N AL, Carbonero F. Impact of Maillard reaction products on nutrition and health: Current knowledge and need to understand their fate in the human digestive system. Crit Rev Food Sci Nutr 2017:1-14.

7. Tessier FJ, Niquet-Leridon $C$, Jacolot $P$, et al. Quantitative assessment of organ distribution of dietary protein-bound 13 C-labeled Nvarepsilon carboxymethyllysine after a chronic oral exposure in mice. Mol Nutr Food Res 2016;60:2446-2456.

8. Calder PC, Ahluwalia N, Brouns F, et al. Dietary factors and low-grade inflammation in relation to overweight and obesity. Br J Nutr 2011;106 Suppl 3:S5-78.

9. Boutens L, Stienstra R. Adipose tissue macrophages: going off track during obesity. Diabetologia 2016;59:879-94.

10. Tordjman J, Poitou C, Hugol D, et al. Association between omental adipose tissue macrophages and liver histopathology in morbid obesity: influence of glycemic status. J Hepatol 2009;51:354-62.

11. du Plessis J, van Pelt J, Korf H, et al. Association of Adipose Tissue Inflammation With Histologic Severity of Nonalcoholic Fatty Liver Disease. Gastroenterology 2015;149:635-48 e14.

12. Lusis AJ. Atherosclerosis. Nature 2000;407:233-41.

13. Jandeleit-Dahm K, Watson A, Soro-Paavonen A. The AGE/RAGE axis in diabetesaccelerated atherosclerosis. Clin Exp Pharmacol Physiol 2008;35:329-34.

14. Hanssen NM, Wouters K, Huijberts MS, et al. Higher levels of advanced glycation endproducts in human carotid atherosclerotic plaques are associated with a rupture-prone phenotype. Eur Heart J 2014;35:1137-46.

15. Ohman $\mathrm{MK}$, Shen $\mathrm{Y}$, Obimba $\mathrm{Cl}$, et al. Visceral adipose tissue inflammation accelerates atherosclerosis in apolipoprotein E-deficient mice. Circulation 2008;117:798-805.

16. Ridker PM, Everett BM, Thuren $\mathrm{T}$, et al. Antiinflammatory Therapy with Canakinumab for Atherosclerotic Disease. N Engl J Med 2017;377:1119-1131.

17. McKellar GE, McCarey DW, Sattar N, et al. Role for TNF in atherosclerosis? Lessons from autoimmune disease. Nat Rev Cardiol 2009;6:410-7.

18. Gaens KH, Stehouwer CD, Schalkwijk CG. Advanced glycation endproducts and its receptor for advanced glycation endproducts in obesity. Current opinion in lipidology 2013;24:4-11. 
19. Gaens KH, Goossens GH, Niessen PM, et al. Nepsilon-(carboxymethyl)lysinereceptor for advanced glycation end product axis is a key modulator of obesityinduced dysregulation of adipokine expression and insulin resistance. Arterioscler Thromb Vasc Biol 2014;34:1199-208.

20. Gaggini M, Carli F, Rosso $C$, et al. Altered amino acid concentrations in NAFLD: Impact of obesity and insulin resistance. Hepatology 2018;67:145-158.

21. Kislinger T, Fu C, Huber B, et al. N(epsilon)-(carboxymethyl)lysine adducts of proteins are ligands for receptor for advanced glycation end products that activate cell signaling pathways and modulate gene expression. J Biol Chem 1999;274:31740-9.

22. Lopez-Diez R, Shekhtman A, Ramasamy R, et al. Cellular mechanisms and consequences of glycation in atherosclerosis and obesity. Biochim Biophys Acta 2016;1862:2244-2252.

23. Gaens $\mathrm{KH}$, Ferreira I, van der Kallen CJ, et al. Association of polymorphism in the receptor for advanced glycation end products (RAGE) gene with circulating RAGE levels. J Clin Endocrinol Metab 2009;94:5174-80.

24. Sebekova K, Krivosikova Z, Gajdos M. Total plasma Nepsilon-(carboxymethyl)lysine and SRAGE levels are inversely associated with a number of metabolic syndrome risk factors in non-diabetic young-to-middle-aged medication-free subjects. Clin Chem Lab Med 2014;52:139-49.

25. Koborova I, Gurecka R, Csongova M, et al. Association between metabolically healthy central obesity in women and levels of soluble receptor for advanced glycation end products, soluble vascular adhesion protein-1, and the activity of semicarbazide-sensitive amine oxidase. Croat Med J 2017;58:106-116.

26. Palma-Duran SA, Kontogianni MD, Vlassopoulos A, et al. Serum levels of advanced glycation end-products (AGEs) and the decoy soluble receptor for AGEs (sRAGE) can identify non-alcoholic fatty liver disease in age-, sex- and BMI-matched normoglycemic adults. Metabolism 2018;83:120-127.

27. Scheijen J, Hanssen NMJ, van Greevenbroek MM, et al. Dietary intake of advanced glycation endproducts is associated with higher levels of advanced glycation endproducts in plasma and urine: The CODAM study. Clin Nutr 2017.

28. Alamir I, Niquet-Leridon C, Jacolot $P$, et al. Digestibility of extruded proteins and metabolic transit of $\mathrm{N}$ epsilon -carboxymethyllysine in rats. Amino Acids 2013;44:1441-9.

29. Leung $C$, Herath $C B$, Jia $Z$, et al. Dietary advanced glycation end-products aggravate non-alcoholic fatty liver disease. World J Gastroenterol 2016;22:8026-40.

30. Xue J, Ray $R$, Singer $D$, et al. The receptor for advanced glycation end products (RAGE) specifically recognizes methylglyoxal-derived AGEs. Biochemistry 2014;53:3327-35.

31. Zeng S, Feirt N, Goldstein M, et al. Blockade of receptor for advanced glycation end product (RAGE) attenuates ischemia and reperfusion injury to the liver in mice. Hepatology 2004;39:422-32.

32. Ekong $\mathrm{U}$, Zeng $\mathrm{S}$, Dun $\mathrm{H}$, et al. Blockade of the receptor for advanced glycation end products attenuates acetaminophen-induced hepatotoxicity in mice. J Gastroenterol Hepatol 2006;21:682-8.

33. Goodwin M, Herath $\mathrm{C}$, Jia Z, et al. Advanced glycation end products augment experimental hepatic fibrosis. J Gastroenterol Hepatol 2013;28:369-76.

34. Huebener P, Pradere JP, Hernandez C, et al. The HMGB1/RAGE axis triggers neutrophil-mediated injury amplification following necrosis. J Clin Invest 2015;125:539-50. 
35. Chen $\mathrm{R}$, Hou $\mathrm{W}$, Zhang $\mathrm{Q}$, et al. Emerging role of high-mobility group box 1 (HMGB1) in liver diseases. Mol Med 2013;19:357-66.

36. Asavarut $\mathrm{P}, \mathrm{Zhao} \mathrm{H}, \mathrm{Gu}$ J, et al. The role of HMGB1 in inflammation-mediated organ injury. Acta Anaesthesiol Taiwan 2013;51:28-33.

37. Mari M, Caballero F, Colell A, et al. Mitochondrial free cholesterol loading sensitizes to TNF- and Fas-mediated steatohepatitis. Cell Metab 2006;4:185-98.

38. Wouters K, van Gorp PJ, Bieghs V, et al. Dietary cholesterol, rather than liver steatosis, leads to hepatic inflammation in hyperlipidemic mouse models of nonalcoholic steatohepatitis. Hepatology 2008;48:474-86.

39. Bieghs V, Van Gorp PJ, Wouters K, et al. LDL receptor knock-out mice are a physiological model particularly vulnerable to study the onset of inflammation in non-alcoholic fatty liver disease. PLoS One 2012;7:e30668.

40. Ueno H, Koyama H, Shoji T, et al. Receptor for advanced glycation end-products (RAGE) regulation of adiposity and adiponectin is associated with atherogenesis in apoE-deficient mouse. Atherosclerosis 2010;211:431-6.

41. Song F, Hurtado del Pozo C, Rosario R, et al. RAGE regulates the metabolic and inflammatory response to high-fat feeding in mice. Diabetes 2014;63:1948-65.

42. van der Heijden RA, Sheedfar F, Morrison MC, et al. High-fat diet induced obesity primes inflammation in adipose tissue prior to liver in C57BL/6j mice. Aging (Albany NY) 2015;7:256-68.

43. Machado MV, Michelotti GA, Xie G, et al. Mouse models of diet-induced nonalcoholic steatohepatitis reproduce the heterogeneity of the human disease. PLoS One 2015;10:e0127991.

44. Poitou C, Dalmas E, Renovato M, et al. CD14dimCD16+ and CD14+CD16+ monocytes in obesity and during weight loss: relationships with fat mass and subclinical atherosclerosis. Arterioscler Thromb Vasc Biol 2011;31:2322-30.

45. Swirski FK, Libby P, Aikawa E, et al. Ly-6Chi monocytes dominate hypercholesterolemia-associated monocytosis and give rise to macrophages in atheromata. J Clin Invest 2007;117:195-205.

46. Nagareddy PR, Kraakman M, Masters SL, et al. Adipose tissue macrophages promote myelopoiesis and monocytosis in obesity. Cell Metab 2014;19:821-35.

47. Nagareddy PR, Murphy AJ, Stirzaker RA, et al. Hyperglycemia promotes myelopoiesis and impairs the resolution of atherosclerosis. Cell Metab 2013;17:695708.

48. Mavrogiannaki AN, Migdalis IN. Nonalcoholic Fatty liver disease, diabetes mellitus and cardiovascular disease: newer data. Int J Endocrinol 2013;2013:450639.

49. Defilippis AP, Blaha MJ, Martin SS, et al. Nonalcoholic fatty liver disease and serum lipoproteins: the Multi-Ethnic Study of Atherosclerosis. Atherosclerosis 2013;227:429-36.

50. Gaudio E, Nobili V, Franchitto A, et al. Nonalcoholic fatty liver disease and atherosclerosis. Intern Emerg Med 2012;7 Suppl 3:S297-305.

51. Barlovic DP, Soro-Paavonen A, Jandeleit-Dahm KA. RAGE biology, atherosclerosis and diabetes. Clin Sci (Lond) 2011;121:43-55.

52. Sun L, Ishida T, Yasuda T, et al. RAGE mediates oxidized LDL-induced proinflammatory effects and atherosclerosis in non-diabetic LDL receptor-deficient mice. Cardiovasc Res 2009;82:371-81.

53. Wetzels S, Bijnen M, Wijnands $E$, et al. Characterization of Immune Cells in Human Adipose Tissue by Using Flow Cytometry. JoVE 2018:e57319. 
54. Wouters K, Gaens K, Bijnen M, et al. Circulating classical monocytes are associated with CD11c+ macrophages in human visceral adipose tissue. Sci Rep 2017;7:42665.

55. Pecht T, Haim Y, Bashan N, et al. Circulating Blood Monocyte Subclasses and LipidLaden Adipose Tissue Macrophages in Human Obesity. PLoS One 2016;11:e0159350.

56. Amano SU, Cohen JL, Vangala P, et al. Local proliferation of macrophages contributes to obesity-associated adipose tissue inflammation. Cell Metab 2014;19:162-171.

57. Zheng $C$, Yang $Q$, Cao J, et al. Local proliferation initiates macrophage accumulation in adipose tissue during obesity. Cell Death Dis 2016;7:e2167.

58. Haase J, Weyer $\mathrm{U}$, Immig K, et al. Local proliferation of macrophages in adipose tissue during obesity-induced inflammation. Diabetologia 2014;57:562-71.

59. Bijnen $M$, Josefs $T$, Cuijpers I, et al. Adipose tissue macrophages induce hepatic neutrophil recruitment and macrophage accumulation in mice. Gut 2017.

60. Rensen SS, Bieghs V, Xanthoulea S, et al. Neutrophil-derived myeloperoxidase aggravates non-alcoholic steatohepatitis in low-density lipoprotein receptordeficient mice. PLoS One 2012;7:e52411.

61. Koyama Y, Brenner DA. Liver inflammation and fibrosis. J Clin Invest 2017;127:5564.

62. Alisi A, Carsetti R, Nobili V. Pathogen- or damage-associated molecular patterns during nonalcoholic fatty liver disease development. Hepatology 2011;54:1500-2.

63. Robbins CS, Hilgendorf I, Weber GF, et al. Local proliferation dominates lesional macrophage accumulation in atherosclerosis. Nat Med 2013;19:1166-72.

64. Chistiakov DA, Grechko AV, Myasoedova VA, et al. The role of monocytosis and neutrophilia in atherosclerosis. J Cell Mol Med 2018;22:1366-1382.

65. Soehnlein O. Multiple roles for neutrophils in atherosclerosis. Circ Res 2012;110:875-88.

66. Haukeland JW, Damas JK, Konopski Z, et al. Systemic inflammation in nonalcoholic fatty liver disease is characterized by elevated levels of CCL2. J Hepatol 2006;44:1167-74.

67. Bieghs V, Rensen PC, Hofker MH, et al. NASH and atherosclerosis are two aspects of a shared disease: central role for macrophages. Atherosclerosis 2012;220:287-93.

68. Singh R, Barden A, Mori T, et al. Advanced glycation end-products: a review. Diabetologia 2001;44:129-46.

69. Booth AA, Khalifah RG, Hudson BG. Thiamine pyrophosphate and pyridoxamine inhibit the formation of antigenic advanced glycation end-products: comparison with aminoguanidine. Biochem Biophys Res Commun 1996;220:113-9.

70. Voziyan PA, Hudson BG. Pyridoxamine as a multifunctional pharmaceutical: targeting pathogenic glycation and oxidative damage. Cell Mol Life Sci 2005;62:1671-81.

71. Maessen DE, Brouwers O, Gaens KH, et al. Delayed Intervention With Pyridoxamine Improves Metabolic Function and Prevents Adipose Tissue Inflammation and Insulin Resistance in High-Fat Diet-Induced Obese Mice. Diabetes 2016;65:956-66.

72. Thornalley PJ. Use of aminoguanidine (Pimagedine) to prevent the formation of advanced glycation endproducts. Arch Biochem Biophys 2003;419:31-40.

73. Thornalley PJ. Glyoxalase I--structure, function and a critical role in the enzymatic defence against glycation. Biochemical Society transactions 2003;31:1343-8. 
74. Hanssen NM, Brouwers O, Gijbels MJ, et al. Glyoxalase 1 overexpression does not affect atherosclerotic lesion size and severity in ApoE-/- mice with or without diabetes. Cardiovasc Res 2014;104:160-70.

75. Engelen L, Stehouwer CD, Schalkwijk CG. Current therapeutic interventions in the glycation pathway: evidence from clinical studies. Diabetes Obes Metab 2013;15:677-89.

76. Singal AK, Jampana SC, Weinman SA. Antioxidants as therapeutic agents for liver disease. Liver Int 2011;31:1432-48.

77. Baye E, Kiriakova V, Uribarri J, et al. Consumption of diets with low advanced glycation end products improves cardiometabolic parameters: meta-analysis of randomised controlled trials. Sci Rep 2017;7:2266.

78. Butscheid $M$, Hauptvogel $P$, Fritz $P$, et al. Hepatic expression of galectin-3 and receptor for advanced glycation end products in patients with liver disease. J Clin Pathol 2007;60:415-8.

79. Zhuang A, Yap FY, Bruce C, et al. Increased liver AGEs induce hepatic injury mediated through an OST48 pathway. Sci Rep 2017;7:12292.

80. Rider P, Carmi Y, Cohen I. Biologics for Targeting Inflammatory Cytokines, Clinical Uses, and Limitations. Int J Cell Biol 2016;2016:9259646.

81. Leung $C$, Herath $C B$, Jia $Z$, et al. Dietary glycotoxins exacerbate progression of experimental fatty liver disease. J Hepatol 2014;60:832-8. 
Samenvatting 


\section{Samenvatting}

In de laatste 20-30 jaar is de prevalentie van obesitas verdrievoudigd tot $13 \%$ van de wereldwijde populatie. Obesitas wordt gekenmerkt door een te hoge opstapeling van lipiden in het vetweefsel, vaak als het gevolg van een verstoorde verhouding tussen energie inname en energieverbruik. Het vetweefsel is daardoor niet langer in staat om alle lipiden op te slaan en daardoor vindt er een verhoging van circulerende lipiden plaats. Deze overtollige lipiden komen vervolgens terecht in allerlei weefsels, waaronder de lever. Vetopstapeling in de lever is een van de eerste en belangrijkste karakteristieken van non-alcoholische leververvetting (ook non-alcoholic fatty liver disease of NAFLD genoemd). Het voorkomen van NAFLD is samen met (en mogelijk ten gevolge van) obesitas flink gestegen en wordt nu geschat op 20-30\% van de Westerse populatie. NAFLD is een progressieve leverziekte die varieert van alleen steatose tot zeer ernstige leverontsteking en uiteindelijk levercirrhose met leverfalen als gevolg. Het ontstaan van leverontsteking is een belangrijke stap in de progressie van NAFLD. De aanwezigheid van ontsteking in de lever leidt namelijk tot leverschade, hetgeen levercirrhose en op de lange termijn leverfalen tot gevolg heeft. Daarnaast is leverontsteking geassocieerd met een verhoogd risico op aderverkalking (atherosclerose), de belangrijkste oorzaak van een hart- en herseninfarct. Ook bij aderverkalking is er namelijk een opstapeling van vet en vindt er een ontsteking plaats. Bij aderverkalking gebeurt dit in de vaatwand van een bloedvat en wordt er een zogenaamde atherosclerotische lesie gevormd die bestaat uit lipiden en ontstekingscellen. Deze lesie groeit vanwege de ontsteking en kan scheuren. Als dit gebeurt, kan de afgescheurde lesie het bloedvat blokkeren hetgeen tot een infarct leidt. Mogelijk draagt de ontstoken lever bij aan de ontwikkeling van aderverkalking door het vrijgeven van ontstekingsfactoren in het bloed.

Het is dus van groot belang om de mogelijke oorzaken van leverontsteking te achterhalen om zo therapie te ontwikkelen die de progressie van NAFLD kan voorkomen.

Versuikerde eiwitten, genaamd advanced glycation endproducts (AGEs), kunnen mogelijk bijdragen aan obesitas-gerelateerde complicaties zoals 
leverontsteking. AGEs kunnen namelijk binden aan de receptor of advanced glycation endproducts (RAGE). Deze binding veroorzaakt een activatie van het ontstekingsprogamma van cellen. De AGE vorming in het lichaam is versneld in verschillende omstandigheden zoals verhoogde suiker of lipiden levels in het bloed of de aanwezigheid van oxidatieve stress. Dit zijn allemaal omstandigheden die veel voorkomen in de vervette lever. Er is inderdaad een verband gevonden tussen de hoeveelheid vetstapeling en ontsteking en de aanwezigheid van AGEs in de lever van NAFLD patiënten. Ook is aangetoond dat er in levercellen ontsteking kan plaatsvinden door stimulering van de RAGE-receptor met AGEs. Naast vorming van AGEs in de lever, kan er ook een opstapeling van AGEs plaatsvinden in de lever door verhoogde inname van AGEs uit het dieet. Het is echter niet bekend of AGEs direct leverontsteking kunnen veroorzaken en of de progressie van NAFLD gestimuleerd wordt door de activatie van RAGE in de lever.

In de atherosclerotische lesie is er ook een versnelde AGE accumulatie mogelijk vanwege de gunstige omstandigheden voor AGE-vorming vergelijkbaar met de lever, met name veroorzaakt door ontstekingscellen. Er zijn dan ook hogere niveaus van AGEs aangetoond in atherosclerotische plaques waarin meer ontsteking plaatsvindt. Daarnaast is er aangetoond dat RAGE bijdraagt aan het ontstekingsproces dat een rol speelt in experimentele aderverkalking. Vandaar dat de interactie tussen AGE en RAGE mogelijk belangrijk is bij het ontstaan of verergeren van aderverkalking.

Een andere belangrijke oorzaak van leverontsteking is mogelijk de chronische systemische ontsteking veroorzaakt door bepaalde ontstekingscellen in het vetweefsel, namelijk de vetweefselmacrofagen. Deze ontstekingscellen accumuleren in het vetweefsel tijdens de ontwikkeling van obesitas. Het is eerder aangetoond dat er een verband is tussen het aantal macrofagen in het vet en de ernst van leverziekte bij patiënten. Daarnaast is gerapporteerd dat vetweefselmacrofagen waarschijnlijk de voornaamste bron van de verhoogde ontstekingsfactoren in het bloed van patiënten met ernstige leverontsteking zijn. Wat de precieze relatie is tussen vetweefselmacrofagen en ontstekingscellen in het bloed is nog niet geheel duidelijk. Ook is nog niet bekend of vetweefselmacrofagen een directe invloed hebben op het ontstaan van leverontsteking en wat de onderliggende mechanismen zouden zijn. 
Wel is aangetoond dat ontstekingsfactoren geproduceerd door vetweefselmacrofagen bijdragen aan laag-gradige ontsteking in het lichaam. Daarom hebben ze mogelijk niet alleen effect op de lever, maar ook op aderverkalking. In muizen is inderdaad aangetoond dat vetweefselontsteking bijdraagt aan de ontwikkeling van aderverkalking. Men heeft zelfs beschreven dat het blokkeren van ontstekingsfactoren, die waarschijnlijk van vetweefselmacrofagen afkomstig zijn, gunstige effecten heeft op hart- en vaatziekten in mensen. Echter is nog niet aangetoond dat vetweefselmacrofagen direct de ontwikkeling van aderverkalking beïnvloeden.

In dit proefschrift, beschrijf ik twee mogelijke oorzaken van leverontsteking en aderverkalking:

1. AGEs via hun receptor, RAGE.

2. Secretie van ontstekingsfactoren door vetweefselmacrofagen in obees vetweefsel.

\section{Bevindingen van dit proefschrift}

De eerste hoofdstukken focussen op de bron van AGEs in de lever en de effecten van deze AGEs op leverontsteking en aderverkalking via RAGE.

In hoofdstuk twee wordt beschreven dat in mensen leververvetting en leverschade positief geassocieerd zijn met vrije AGEs in het bloed. Daarentegen waren circulerende eiwitgebonden AGEs negatief geassocieerd met leververvetting en leverschade. Samengenomen met eerder werk dat aantoonde dat AGEs stapelen in de buurt van lipiden en ontsteking in de lever suggereren deze associaties een verhoogde vorming van AGEs in de lever tijdens NAFLD. Daarnaast zou een verhoogde afbraak van de gevormde eiwitgebonden AGEs in proefpersonen met meer leververvetting en leverschade kunnen leiden tot een verhoogde hoeveelheid vrije AGEs in het bloed. Deze vrije AGEs waren positief geassocieerd met laag-gradige systemische ontsteking, terwijl soluble RAGE (sRAGE), een circulerende vorm van de receptor voor AGEs, niet beïnvloed leek door NAFLD en niet geassocieerd was met laag-gradige ontsteking. Daarom lijkt de bijdrage van leverziekte aan 
laag-gradige inflammatie in het lichaam via AGE-vorming onafhankelijk van RAGE.

Hoofdstuk drie bevestigt dat endogene vorming niet de enige bron is van AGEs in de lever. Het voeren van een dieet laag of hoog in AGEs aan muizen ging namelijk gepaard met respectievelijk verlaagde of verhoogde AGE niveaus in het bloed en de lever. De lagere of hogere AGE niveaus in de lever bracht een verlaagde of verhoogde genexpressie van ontstekingsfactoren in de lever met zich mee. Deze resultaten demonstreren dat AGEs in het dieet een belangrijke bijdrage leveren aan de totale hoeveelheid AGEs in het lichaam en mogelijk leverontsteking kunnen beïnvloeden. Dit betekent dat AGEs kunnen bijdragen aan de progressie van NAFLD en de inname ervan dus moet worden verminderd.

In hoofdstuk vier wordt de rol van RAGE in leverontsteking en aderverkalking beschreven. Het ontbreken van RAGE in een muismodel voor NAFLD had geen effect op systemische of leverontsteking of leververvetting. Expansie van het vetweefsel was wel verminderd door het gebrek aan RAGE, maar effecten op ontsteking in het vetweefsel werden niet waargenomen. Daarnaast had het gebrek aan RAGE geen effect op meerdere aspecten van aderverkalking zoals de grootte van de lesie of de hoeveelheid ontsteking. Ook het niveau van AGEs in het bloed of in de lever werd niet beïnvloed door de aan- of afwezigheid van RAGE. Onze resultaten suggereren daarom dat er geen grote rol is voor RAGE in de progressie van NAFLD of aderverkalking in het toegepaste muismodel.

De volgende hoofdstukken focussen op ontsteking in het vetweefsel en met name op vetweefselmacrofagen en de effecten daarvan op leverontsteking en aderverkalking door de productie van ontstekingsfactoren.

In hoofdstuk vijf en zes wordt de isolatie en kwantificatie van immuuncellen, waaronder vetweefselmacrofagen, uit humaan vetweefsel beschreven en toegepast door de link tussen circulerende immuuncellen en vetweefselmacrofagen te onderzoeken. Het onderzoek toonde aan dat er een associatie is tussen klassieke monocyten (circulerende immuuncellen) in het bloed en zogenaamde $\mathrm{CD} 11 \mathrm{c}^{+}$positieve macrofagen in het vetweefsel. Dit soort macrofagen draagt sterk bij aan ontstekingsprocessen. De relatie tussen vetweefselmacrofagen en circulerende immuuncellen is verder 
onderzocht in hoofdstuk zeven met behulp van een experimenteel muizenmodel dat ons heel specifiek de rol van vetweefselmacrofagen laat onderzoeken. De resultaten van deze experimenten lieten zien dat CD11 $\mathrm{c}^{+}$ vetweefselmacrofagen in obees vetweefsel ontstekingsfactoren produceren die snelwerkende immuuncellen, zogenaamde neutrofielen, aantrekken vanuit het beenmerg. Dit leidt tot een snelle verhoging van deze immuuncellen in het bloed en vervolgens tot een verhoogde neutrofiel infiltratie van de lever. Daarnaast verhogen vetweefselmacrofagen uit obees vetweefsel de hoeveelheid macrofagen in de lever, hetgeen op de lange termijn tot leverschade leidde in een experimenteel muismodel voor NAFLD. Onze bevindingen zagen we voor een deel ook terug in mensen. Met behulp van een maatstaf voor $\mathrm{CD}_{11} \mathrm{c}^{+}$macrofagen is er een associatie aangetoond tussen deze macrofagen en factoren die neutrofielen aantrekken in humaan vetweefsel. Ook was er een associatie tussen $\mathrm{CD} 11 \mathrm{c}^{+}$macrofagen in humaan vetweefsel en een representatie van de hoeveelheid neutrofielen en macrofagen in de levers van dezelfde mensen. Deze resultaten suggereren dat vetweefselmacrofagen ontstekingsfactoren produceren die bijdragen aan een verhoging van ontstekingscellen in het bloed en de progressie van NAFLD.

Hoofdstuk acht gaat verder op onze bevindingen in hoofdstuk zeven en beschrijft de effecten van vetweefselmacrofagen op de ontwikkeling van aderverkalking. Ondanks de eerder beschreven effecten op de lever en een aantal effecten op circulerende lipiden, immuuncellen en ontstekingsfactoren, hadden vetweefselmacrofagen geen effect op de ontwikkeling van aderverkalking.

\section{Conclusie}

AGEs kunnen opstapelen in de lever door endogene vorming, gestimuleerd door leververvetting en ontsteking, maar ook door de opname van AGEs uit de voeding. In de lever kunnen AGEs ontsteking veroorzaken, maar mogelijk niet direct via RAGE. RAGE heeft daarnaast ook geen invloed op de ontwikkeling van aderverkalking in het door ons gebruikt experimenteel model. 
Klassieke monocyten dragen bij aan de hoeveelheid ontsteking stimulerende $\mathrm{CD} 11 \mathrm{c}^{+}$macrofagen in het vetweefsel. Echter zijn deze macrofagen mogelijk verantwoordelijk voor de rekrutering van monocyten en neutrofielen uit het beenmerg door het vrijgeven van ontstekingsfactoren hetgeen de progressie van NAFLD kan beïnvloeden. De vetweefselmacrofaag gemedieerde aantrekking van immuuncellen heeft desalniettemin geen effect op de ontwikkeling van atherosclerose in het door ons gebruikt model. Meer onderzoek is nodig om de precieze invloed van vetweefselmacrofagen op hart- en vaatziekten te achterhalen. 


\section{Valorisation}




\section{Valorisation}

Obesity is a major risk factor for the development of NAFLD and CVD, while NAFLD itself is also associated with enhanced CVD risk ${ }^{1-3}$. The work described in this thesis provides knowledge about the complex interplay between obesity, NAFLD and CVD. This is of great relevance considering the detrimental impact of these diseases on quality of life and all-cause mortality and the great economic burden on society due to the high costs of current therapies to treat liver disease and CVD ${ }^{4,5}$.

The obtained results from the first part of this thesis indicate that both endogenous formation of AGEs and dietary intake of AGEs contribute to hepatic AGE accumulation. These AGEs might cause liver inflammation and contribute to low-grade inflammation. Hepatic inflammation and chronic low-grade inflammation are major factors in the progression of NAFLD toward irreversible liver damage and are associated with CVD ${ }^{3,6}$. Therefore, prevention of inflammation could be of great benefit to people at risk for developing severe liver disease or atherosclerosis. Our results imply that both endogenous formation and dietary intake of AGEs are targets for intervention to combat inflammation. As previously described, there are several compounds capable of reducing endogenous AGE formation including the vitamin B6 analogue pyridoxamine. This compound can trap $\alpha$ dicarbonyl compounds; major precursors in the formation of $\mathrm{AGEs}^{7}, 8$. In mice, pyridoxamine has already shown beneficial effects on AT inflammation and insulin sensitivity ${ }^{9}$. A study with pyridoxamine is under active clinical investigation in obese individuals with insulin sensitivity and microvascular function as primary outcomes. In this study, markers for liver injury will be assessed. If successful in reducing liver damage, pyridoxamine could be a safe supplementation for people at risk of cardiometabolic disease. Medical doctors and pharmaceutical companies will be informed about the outcomes of the pyridoxamine trial.

Results described in this thesis showed that dietary AGEs contribute to the overall level of circulating and hepatic AGEs. Therefore, reduction of dietary AGEs by changing dietary habits is an option to reduce the accumulation of AGEs throughout the body. Vlassara et al. have previously performed dietary 
intervention studies focused on a reduction in AGE consumption and observed reduced oxidative stress and inflammation ${ }^{10}$. Current ongoing clinical studies aim to determine if a diet low in AGEs has beneficial effects on liver disease, insulin sensitivity and CVD. These studies will give insight into the importance of striving for a low AGE diet. At this moment, it will be highly challenging to actually reduce AGE levels in the diet of the general population, as it would require cooperation of food producers and a largescale campaign to inform the public. Healthy eating is already stimulated via many channels: the internet, books, YouTube videos, cooking channels, etc. When the ongoing trials proof that low levels of dietary AGEs are beneficial, more awareness about the benefits of a low AGE diet should be created.

In the second part of this thesis, detrimental effects of ATMs on systemic inflammation and liver disease are described. Inhibition of the detrimental effects of ATMs could be a viable option for therapy to prevent the progression of NAFLD in obese individuals. The ATMs secrete factors (CXCLs, CSFs, S100A8/9) that recruit immune cells from the bone marrow contributing to hepatic inflammation. These soluble factors are present in the circulation, which makes them targetable by blocking antibodies. As such, blocking antibodies to inhibit cytokine, e.g. CXCL14, function could be developed, as previously shown in both experimental models and even humans ${ }^{11}$. Another option to prevent cytokine function is the inhibition of its receptor. This has previously been shown to be a viable option for liver disease with the CCR2/CCR5 antagonist, Cenicriviroc ${ }^{12}$. Although it has been recently demonstrated in a major clinical trial that the cytokine IL-1 $\beta$ can be blocked in humans and that this can have beneficial effects on cardiovascular outcome, this therapy was non-specific and compromised the immune system resulting in increased infections and infection-related death ${ }^{13}$. Therefore, the blocking of cytokines that have more specific functions, such as CXCL14, will provide a more specific and thus safer approach.

Another interesting approach could be the modulation of specific ATMs, i.e. $\mathrm{CD}_{11 \mathrm{c}^{+}}$ATMs, to suppress their proinflammatory functions, such as the production of cytokines that recruit immune cells. In this thesis, we have described an association between classical monocytes and CD $11 \mathrm{c}^{+}$ATMs revealing their possible origin. Moreover, we determined that it are these specific $\mathrm{CD} 11 \mathrm{c}^{+}$ATMs that contribute to systemic inflammation and NAFLD 
progression. However, more knowledge is required about the development, maintenance and modulation of macrophages in general to be able to modulate specific macrophage subsets in tissues. Fortunately, the so-called macrophage niches are currently the subject of intense research efforts. The macrophage niches are a relatively new concept which postulates that tissue macrophages, e.g. the ATMs, are dependent on environmental cues for their development, maintenance and tissue-specific functions ${ }^{14}$. These cues are thought to be derived from the stromal cells surrounding the macrophages within tissues. These stromal cells proposedly provide a 3D anchoring scaffold for the macrophages and nurture them by cell-cell contact and production of cytokines and metabolites ${ }^{14,15}$. This interaction between macrophages and stromal cells needs to be further investigated, but potentially consists of many targetable proteins. Affecting these proteins could allow suppression of specific macrophages, such as the proinflammatory $\mathrm{CD} 11 \mathrm{c}^{+}$macrophages, in the AT. This would mitigate one of the main limitations of current immunotherapy, namely specificity.

Besides targeting the ATMs and the factors they produce, the knowledge obtained about the release of cytokines from ATMs could be crucial for biomarker development. A panel of cytokines (CXCLs, CSFs and S100 proteins) could be measured in people at risk of cardiometabolic disease. Elevated levels of these markers could suggest an inflammatory state in the AT making the development and presence of advanced NAFLD more likely. Currently, the gold standard to diagnose NASH is still an invasive liver biopsy, which still has several limitations. If a combination of cytokine levels could give an indication of the presence of NASH, it would be a major advancement in the diagnosis of NAFLD. Of course, this needs to be tested and validated in large studies wherein sensitivity and specificity of these markers needs to be determined. The biomedical industry is very interested in developing a noninvasive method to diagnose NASH. If successful, the use of such a biomarker panel could be rapidly widespread.

It is clear that many years of additional research are required to translate the described research, as presented in this thesis, into therapy and/or biomarkers. By publishing many of the findings of this fundamental research, an important step towards valorisation has been made. 


\section{References}

1. Mirza MS. Obesity, Visceral Fat, and NAFLD: Querying the Role of Adipokines in the Progression of Nonalcoholic Fatty Liver Disease. ISRN Gastroenterol 2011;2011:592404.

2. Lakka HM, Lakka TA, Tuomilehto J, et al. Abdominal obesity is associated with increased risk of acute coronary events in men. Eur Heart J 2002;23:706-13.

3. Ekstedt M, Franzen LE, Mathiesen UL, et al. Long-term follow-up of patients with NAFLD and elevated liver enzymes. Hepatology 2006;44:865-73.

4. Bloom DE, Cafiero, E.T., Jané-Llopis, E., Abrahams-Gessel, S., Bloom, L.R., Fathima, S., Feigl,, A.B. G, T., Mowafi, M., Pandya, A., Prettner, K., Rosenberg, L., Seligman, B., Stein, A., \& Weinstein, C. The Global Economic Burden of Non-communicable Diseases. Geneva: World Economic Forum. 2011.

5. M.L. Bots IV. Hart- en vaatziekten in Nederland 2017: Europese vergelijking van impact van risicofactoren op het aantal verloren levensjaren in goede gezondheid in Nederland 2017.

6. Tailleux A, Wouters K, Staels B. Roles of PPARs in NAFLD: potential therapeutic targets. Biochim Biophys Acta 2012;1821:809-18.

7. Booth AA, Khalifah RG, Hudson BG. Thiamine pyrophosphate and pyridoxamine inhibit the formation of antigenic advanced glycation end-products: comparison with aminoguanidine. Biochem Biophys Res Commun 1996;220:113-9.

8. Voziyan PA, Hudson BG. Pyridoxamine as a multifunctional pharmaceutical: targeting pathogenic glycation and oxidative damage. Cell Mol Life Sci 2005;62:1671-81.

9. Maessen DE, Brouwers $\mathrm{O}$, Gaens $\mathrm{KH}$, et al. Delayed Intervention With Pyridoxamine Improves Metabolic Function and Prevents Adipose Tissue Inflammation and Insulin Resistance in High-Fat Diet-Induced Obese Mice. Diabetes 2016;65:956-66.

10. Uribarri J, Woodruff S, Goodman S, et al. Advanced glycation end products in foods and a practical guide to their reduction in the diet. J Am Diet Assoc 2010;110:91116 e12.

11. Rider P, Carmi Y, Cohen I. Biologics for Targeting Inflammatory Cytokines, Clinical Uses, and Limitations. Int J Cell Biol 2016;2016:9259646.

12. Tacke F, Weiskirchen R. An update on the recent advances in antifibrotic therapy. Expert Rev Gastroenterol Hepatol 2018:1-10.

13. Ridker PM, Everett BM, Thuren $\mathrm{T}$, et al. Antiinflammatory Therapy with Canakinumab for Atherosclerotic Disease. N Engl J Med 2017;377:1119-1131.

14. Guilliams M, Scott CL. Does niche competition determine the origin of tissueresident macrophages? Nat Rev Immunol 2017;17:451-460.

15. T'Jonck W, Guilliams M, Bonnardel J. Niche signals and transcription factors involved in tissue-resident macrophage development. Cell Immunol 2018. 


\section{Dankwoord}




\section{Dankwoord}

Vier jaar! Dat is de tijd die mij gegund is om mijn promotieonderzoek te doen en onderdeel te zijn van de fenomenale afdeling Interne Geneeskunde. Die vier jaar zijn omgevlogen door de leuke atmosfeer en fantastische collega's. Elke dag ben ik dan ook met veel plezier naar het werk gekomen om mijn onderzoek uit te voeren, vaak samen met anderen. De buitengewone werksfeer en natuurlijk het eindresultaat van deze vier jaar werk, dit proefschrift, was niet mogelijk zonder de inzet van het team Interne Geneeskunde, collega's van andere afdelingen, coauteurs en vele anderen. Bij deze wil ik dus iedereen bedanken die bijgedragen heeft aan mijn proefschrift!

Beste Casper, enorm bedankt voor de geweldige begeleiding tijdens mijn promotieonderzoek. De manier waarop jij de onderzoeksgroep leidt is inspirerend. Je leiderschap is één van de belangrijkste redenen waarom er een geweldige sfeer is op de afdeling en ik dagelijks met veel plezier naar het werk kwam. Het is duidelijk dat jij geeft om je mensen en een zeer toegankelijk persoon bent. Dat is erg waardevol en heeft mij veel steun geboden! Je deur stond altijd voor mij open en dat waardeerde ik ontzettend. Daarnaast ben je een echte top wetenschapper, waarvan ik enorm veel geleerd heb. Zonder je kennis en expertise was dit proefschrift onmogelijk. Nogmaals bedankt!

Beste Kristiaan, er is zo veel om jou dankbaar voor te zijn. Ten eerste natuurlijk dat jij mij de mogelijkheid hebt gegeven om het beschreven promotieonderzoek uit te voeren. Daarnaast bedankt voor de fantastische dagelijkse begeleiding die je mij gegeven hebt. Altijd kon ik bij jou terecht en maakte je tijd voor mij. Altijd! Dat is heel belangrijk voor mij geweest, nooit stond ik er alleen voor. Net als je passie en enthousiasme voor de wetenschap die simpelweg ongelofelijk en inspirerend is. Ik heb dagelijks erg genoten van al onze wetenschappelijke discussies en leuke gesprekken. Nog waardevoller waren je kritische opmerkingen en de manier waarop je mij motiveerde. Ook de vele kansen die je voor mij hebt gecreëerd met 
betrekking tot samenwerkingen en publicaties ben ik ontzettend dankbaar voor. Idem voor alle mooie reizen die ik dankzij jou heb mogen maken, die zijn onvergetelijk. Het mag duidelijk zijn dat dit proefschrift zonder jou niet mogelijk was. Ik zie dit werk dus niet als mijn proefschrift, maar als ons proefschrift. Bedankt voor alles!

De leden van de leescommissie, Prof. dr. Jogchum Plat, Prof. dr. Ronit ShiriSverdlov, Prof. dr. Bart Staels, Prof. dr. ir. Sander Kersten en dr. Ger Koek, wil ik graag bedanken voor het kritisch lezen en beoordelen van mijn proefschrift. Daarnaast wil ik Prof. dr. Ronit Shiri-Sverdlov en dr. Ger Koek bedanken voor hun bijdrage als lid van mijn CARIM mentor comité.

Beste Suzan, van helemaal het begin (de bacheloropleiding) tot helemaal het einde (onze promotie) hebben we alles tegelijkertijd doorgemaakt. Vooral de afgelopen vier jaar hebben we zoveel samen gedaan. Grote en kleine experimenten in Hasselt en Maastricht, zoveel besprekingen, samen erg leuke discussies en gesprekken gehad, samen gelachen en samen veel leuke dingen gedaan. $\mathrm{lk}$ vond het ontzettend leuk dat er altijd iemand was die vanaf het begin hetzelfde doormaakte. Ik kon ook altijd op je rekenen voor hulp en steun. Tot aan het einde, tot aan onze promoties. Daar wil ik je enorm voor bedanken, dus bedankt. Voor alles!

Beste Mathias en Nynke, mijn paranimfen, mijn collega's, mijn vrienden, ontzettend bedankt voor de geweldige tijd samen op de afdeling Interne Geneeskunde. Ik heb erg genoten van de leuke discussies over van alles en nog wat, de gezellige avonden op het werk of daarbuiten, de fitnessavonden, het hardlopen en simpelweg alle tijd die we samen hebben doorgebracht. Ook door jullie ben ik elke dag met veel plezier naar het werk gekomen. Het is een eer om jullie als paranimfen aan mijn zijde te hebben en ik wens jullie heel veel succes met het afronden van jullie eigen $\mathrm{PhD}$ en verdere toekomst.

Dear Ying, thank you for being one of the best roommates ever. I really enjoyed our daily discussions and you are one of the kindest people I have ever met. I would also like to thank you for your help with statistics; your statistical knowledge is amazing! 
Beste Kim, heel erg bedankt voor de gezellige tijden. Vanaf het begin heb ik genoten van je aanwezigheid en je enthousiasme over alles. Wetenschap, hardlopen, feestjes!

Beste Armand, erg mooi dat jij het team bent komen versterken. Bedankt voor alle leuke en soms serieuze gesprekken, vooral tijdens het hardlopen!

Dear Tate, thank you for increasing the fun factor at our department and even at FHML in general! We had some good times, thanks for that!

Dear Wenji, thank you for the fun conversations and introducing me to some interesting Chinese traditions and dishes.

Dear Xiaodi, I wish you good luck with your PhD and thank you for continuing some of the work started by me!

Beste Amée, we zijn niet heel lang kamergenoten geweest, maar toch bedankt voor de korte maar gezellige tijd!

Beste Ine en Evelien, ook jullie waren er alleen de laatste maanden van mijn PhD bij, maar toch hebben we zeker leuke gesprekken gehad samen. Bedankt!

Beste Katrin, jij was een top kamergenoot in het jaar dat je bij ons was. Bedankt dat je altijd naar mij luisterde en ik heb erg gelachen met jou! Vaak gingen onze gesprekken nergens over, maar dat maakte het zo geweldig. Heel erg bedankt voor de goede tijden!

Natuurlijk wil ik ook alle analisten bedanken die het lab draaiende houden en ook ontzettend veel bijdragen aan de leuke sfeer op de werkvloer. Beste Vicky, bedankt voor alle organisatorische taken die je uitvoert! Als ik iets nodig had, dan regelde jij het! Bedankt daarvoor! Beste Margee, bedankt voor het uitvoeren van metingen, het genotyperen en natuurlijk de adviezen wat betreft Western blotting. Beste Petra, bedankt voor de antwoorden op al mijn (wetenschappelijke en levens) vragen en de gezellige gesprekken. Beste Marjo, bedankt voor je bijdrage aan veel van de hoofdstukken in dit proefschrift. Je hebt tientallen AGE metingen en ELISA metingen voor mij gedaan. Ontzettend bedankt!

Beste Maria, heel erg bedankt voor je belangrijke bijdrage aan dit proefschrift. Veel van de kleuringen zijn namelijk van jouw hand en daarnaast heb jij mij de immunohistochemie aangeleerd. Bedankt daarvoor en voor de gezelligheid natuurlijk. 
Beste José, je bijdrage aan het onderzoek beschreven in dit proefschrift is ontzettend groot. Bijna bij elk groot experiment ben jij betrokken geweest en ik heb veel van jou geleerd. Daarnaast was je altijd bereid mij met alles te helpen, dat heb ik altijd erg gewaardeerd. En ook bedankt voor de gezelligheid en alle levenslessen!

Beste Jean, ook jou moet ik voor zeer veel dingen bedanken. Voor de geweldige atmosfeer op de afdeling, de leuke stapavonden, borrels en congresbezoeken. Voor de vele AGE metingen die je gedaan hebt voor het onderzoek in dit proefschrift. Voor de wetenschappelijke discussie, maar ook de leuke gesprekken die we gehad hebben. Daarnaast ook nog bedankt voor de motivatie die jij mij gegeven hebt bij het sporten, vooral bij het hardlopen! Ten slotte wil ik je bedanken voor het ontwerpen van de mooie omslag van dit proefschrift!

Beste Marleen, bedankt voor al je hulp wanneer ik die maar nodig had, met name bij problemen met betrekking tot statistiek. Je bijdrage aan het CODAM hoofdstuk is dan ook cruciaal geweest. Daarnaast wil ik je bedanken voor je kritische vragen bij alle besprekingen, dit heeft altijd veel bijgedragen aan de discussie!

Beste Nordin, jou moet ik om verschillende redenen bedanken. Ten eerste heb ik veel van jou geleerd over het doen van wetenschappelijk onderzoek tijdens mijn stageperiode bij jou. Dit heeft mij ontzettend geholpen en een aantal van de dingen die je mij geleerd hebt, pas ik nu nog altijd toe. Daarnaast wil ik je bedanken voor de rol die jij gespeeld hebt bij het verkrijgen van mijn werk als PhD bij de afdeling Interne Geneeskunde. Kristiaan zal mij niet voor niets gevraagd hebben. Ten slotte wil ik je bedanken voor alle positieve woorden en steun die je mij geboden hebt tijdens mijn promotieonderzoek. Daar ben ik zeer dankbaar voor!

Beste Boy, ook jij bedankt voor je bijdrage aan alle besprekingen en de leuke sfeer op de afdeling! 
Beste Katrien, je voorgaand werk is van groot belang geweest voor dat van mij. Het heeft mij erg geholpen en daarnaast kon ik altijd bij jou terecht als ik er vragen over had. Bedankt!

Beste Coen, bedankt voor het altijd (zeer snel) kritisch lezen van mijn manuscripten en voor natuurlijk je belangrijke bijdrage aan het onderzoek van de afdeling Interne Geneeskunde als hoofd van de afdeling.

Daarnaast wil ik een aantal collega's bedanken waar ik een hele leuke tijd mee gehad heb tijdens de eerste jaren van mijn PhD. Dionne, Stijn, Monica, Elizabeth en Hanneke. Heel erg bedankt voor de gezellige tijden zowel op het werk als buiten het werk. De feestjes en de stapavonden waren altijd top! Ook Yvo wil ik bedanken voor de leuke tijd in de eerste jaren en voor de interessante wetenschappelijke discussies.

Dear Meli, thank you for being a great roommate even though it was only temporary. You were always very nice and I enjoyed our (deep) conversations.

Beste Annemieke, bedankt dat je mij bij het onderwijs hebt betrokken. Dat was een leerzame ervaring en leuk om te doen.

Beste Adriaan, ook jou wil ik bedanken dat je mij al vanaf het begin bij het onderwijs betrokken hebt. Daarnaast waardeerde ik altijd je wetenschappelijke adviezen, je kritische vragen en de leuke gesprekken die we gehad hebben.

Ook wil ik de collega's van De Maastricht Studie, die regelmatig op bezoek kwamen, bedanken voor de leuke tijd op de afdeling Interne Geneeskunde. Ben, Marnix, Pauline, Tan Lai, Sytze en Yuri. Bedankt!

Naast de afdeling Interne Geneeskunde, wil ik ook graag mensen van een aantal andere afdelingen bedanken. Zonder deze samenwerkingen was een groot deel van dit proefschrift namelijk niet mogelijk. 
Beste Sander, bedankt voor je waardevolle input tijdens besprekingen en natuurlijk voor het delen van data waar ik veelvuldig gebruik van heb gemaakt.

Ook de afdeling Humane Biologie, met name Kenneth Verboven en Johan Jocken, wil ik bedanken voor het uitvoeren van de klinische studies en aanleveren van samples die ik heb gebruikt voor dit proefschrift.

De samenwerking met Pathologie is ook erg belangrijk geweest voor dit proefschrift. Beste Erwin, bedankt voor je begeleiding bij de flow cytometrie, de vermakelijke gesprekken en alle hulp bij de flow experimenten. Marion, bedankt voor het scoren van de levercoupes en de atherosclerotische plaques! Beste Erik, bedankt voor de goede samenwerking tussen onze afdelingen, je adviezen en je bijdrage als lid van mijn CARIM mentor comité. Beste Jack, bedankt voor de software voor het kwantificeren van de vele histologische afbeeldingen. Beste Pieter, bedankt voor de introductie die geleid heeft tot mijn nieuwe baan en natuurlijk bedankt voor het advies over Marseille! De samenwerking met Pathologie ging ook naast het werk verder. Beste Margaux, deze keer in het Nederlands, omdat je dat liever hebt. Heel erg bedankt voor alle leuke tijden bij de CARIM/PhD academy evenementen, de borrels, zelfs op congres en natuurlijk de stapavonden in Maastricht! Kim, ook jij bedankt voor de gezellige avonden op de universiteit en in de binnenstad! Jan, thank you for the great times when partying and your advice about Marseille! Graag wil ik ook Kosta, Elke en Thomas bedanken voor de hulp in het lab en de leuke tijden bij de CARIM evenementen.

De afdeling Experimentele Cardiologie ben ik ook dankbaar, omdat ik daar veel geleerd heb over het uitvoeren van wetenschappelijk onderzoek tijdens mijn master. Beste Blanche, heel erg bedankt voor de goede begeleiding en leerzame wetenschappelijke discussie. Dear Tim, you were a great supervisor that seemed to know everything. I learned a lot from you. Thanks! Beste Rick, Wouter en Kevin, ook jullie bedankt voor de leerzame ervaring en dat ik af en toe iets kon lenen indien nodig tijdens mijn PhD. Dear Monika, thank you for not only the great time at Cardiology, but also the fun times after at many different parties! 
De buren van Tumor Immunologie wil ik ook allemaal bedanken voor de leuke sfeer op de afdeling en de goede samenwerking wat betreft de labs. Wilfred, Birgit, Niken, Ying en Roel; fijn dat ik altijd even iets kon lenen en kon rekenen op hulp van jullie kant.

Ook de collega's van MDL ben ik dankbaar voor de leuke gesprekken in de kweeklabs of de random gesprekken op de gang en in de koffiekamer. Heike, Montserrat, Lisa en Zsa Zsa. Bedankt!

Beste Nicky, Mindy, Tendai, Stijn, Ilona en Aniek, bedankt voor de gezelligheid en jullie bijdrage aan mijn onderzoek. Ik heb met veel plezier met jullie samen gewerkt. Nicky, het is erg leuk dat jij bij de buren aan de slag bent gegaan!

Uiteraard wil ik alle coauteurs heel erg bedanken voor hun bijdrage aan mijn manuscripten. Zonder jullie data, wetenschappelijke input en waardevolle opmerkingen was dit proefschrift niet mogelijk!

Graag wil ik Richard, Rik, Mandy, Clarice, Anouk en alle overige medewerkers van het CPV bedanken voor hun belangrijke bijdrage aan dit proefschrift.

Beste Pieter, bedankt voor alle hulp wat betreft de IT-problemen die ik had met het werk. Deze waren dankzij jou altijd snel verholpen!

Beste Eddy, bedankt voor het rondbrengen van alle bestellingen en het verspreiden van gezelligheid door de gehele universiteit.

Zonder de steun van de Hartstichting en de vele donaties aan dit goede doel was het uitgevoerde wetenschappelijk onderzoek en dit proefschrift niet mogelijk. Graag wil ik dus de Hartstichting en haar donoren heel erg bedanken! 
I would also like to thank all of my new colleagues at the Centre d'Immunologie de Marseille-Luminy for their help and support with my new research. The first few months have been wonderful thanks to all of you!

Naast het werk, heb ik tijdens mijn promotietraject altijd kunnen genieten van het gezelschap van mijn familie en vrienden. Daar ben ik zeer dankbaar voor. Natuurlijk tel ik een groot deel van de al eerdergenoemde collega's als vrienden, hetgeen ik erg blij mee ben. Nogmaals bedankt!

Daarnaast wil ik graag mijn Biomedische Wetenschapsvrienden bedanken voor de gezellige momenten de afgelopen jaren. Het is erg leuk dat we, ondanks dat we niet bepaald meer in de buurt wonen, toch nog elk jaar leuke momenten hebben. Yannick, Sascha, Arjan, Roel, Gideon, Donja, Onne en Miriam; Bedankt!

Beste Steven, we kennen elkaar al zo lang! Zeker 20 jaar! Ongelofelijk! Al die jaren ben ik blij geweest jou als beste vriend (en wat mij betreft als broer) te hebben. Ook de afgelopen vier jaar tijdens mijn promotieonderzoek ben je er altijd voor mij geweest. Elke week luisterde je naar mijn verhalen over het werk en hadden we de leukste discussies. Daarnaast hebben we samen heel veel top momenten gehad de laatste jaren. En ja, Marokko was zeker nog beter met jou erbij! Ontzettend bedankt!

Beste Nadir, jij bent niet alleen familie, maar ook een goede vriend. Bedankt dat ik altijd op je kan rekenen en voor de leuke avonden en reizen. Malta en Marseille waren top!

Lieve papa en mama, ontzettend bedankt voor alles dat jullie voor mij doen. Zonder jullie onvoorwaardelijke steun was dit proefschrift niet mogelijk en ik waardeer het ontzettend dat jullie mij altijd mijn eigen keuzes laten maken. Het was daarnaast erg fijn dat ik elk weekend bij jullie als het ware thuis kon komen. Bedankt!

Lieve zussen, Tamara, Chantal en Michele, ook jullie wil ik bedanken voor alle steun en liefde de afgelopen jaren. Jullie staan altijd voor mij klaar en de 
tijd die ik heb doorgebracht met jullie en jullie lieve kinderen is ontzettend belangrijk voor mij geweest de afgelopen jaren. Bedankt!

Lieve familie, jullie zijn mijn motivatie en dit proefschrift is voor jullie!

Dear Femke, thank you for all your love and support during my PhD and when finishing this thesis. I am very thankful that you are always there for me, that you are so understanding and push me when needed. We have already had many great moments together and I am sure that many more will follow. I feel very lucky that we are in love in every way. Danke! 


\section{Curriculum Vitae}




\section{Curriculum Vitae}

Mitchell Bijnen was born on 14-09-1991 in Maastricht, the Netherlands. He graduated from secondary school (Bonnefantencollege, Maastricht) in 2009. He studied Biomedical Sciences, the bachelor followed by the master, from 2009-2014 at Maastricht University. The specialization chosen during his master was Cardiovascular Biology and Medicine with internships performed at Internal Medicine and Experimental Cardiology. From 2014 till 2018, he worked as a PhD student at the department of Internal Medicine, Maastricht University, under supervision of Prof. Dr. Casper Schalkwijk and Dr. Kristiaan Wouters. During his PhD, he acquired the CARIM Postdoctoral Talent Fellowship to fund the first year of his postdoctoral research. This postdoctoral research is performed at the Centre d'Immunologie de Marseille-Luminy (Marseille, France) in the group of Dr. Marc Bajénoff. 
$\underline{\text { Scientific output }}$ 


\section{List of publications}

- M Bijnen, J van de Gaar, M Vroomen, MJ Gijbels, M de Winther, CG Schalkwijk, K Wouters. Adipose tissue macrophages do not affect atherosclerosis development in mice. Atherosclerosis 281 (2019) 31-37. (IF=4.47).

- $\quad$ M Bijnen, N Beelen, S Wetzels, J van de Gaar, M Vroomen, E Wijnands, JL Scheijen, MPH van de Waarenburg, MJ Gijbels, JP, Cleutjens, EAL Biessen, CDA Stehouwer, CG Schalkwijk, K Wouters. RAGE deficiency does not affect non-alcoholic steatohepatitis and atherosclerosis in Western type diet-fed

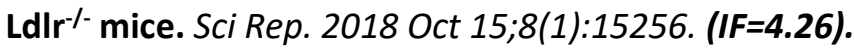

- K Verboven, K Wouters, K Gaens, D Hansen, M Bijnen, S Wetzels, CDA Stehouwer, GH Goossens, CD Schalkwijk, EE Blaak, JW Jocken. Abdominal subcutaneous and visceral adipocyte size, lipolysis and inflammation relate to insulin resistance in male obese humans. Sci Rep. 2018 Mar 16;8(1):4677. (IF=4.85).

- M Bijnen* S Wetzels*, E Wijnands, EAL Biessen, CG Schalkwijk, K Wouters. *Contributed equally. Characterization of immune Cells in human adipose tissue by using flow cytometry. J Vis Exp. 2018 Mar 6;(133). (IF=1.23).

- R Verjans*, T Peters*, FJ Beaumont, R van Leeuwen, $T$ van Herwaarden, W Verhesen, C Munts, $\underline{M}$ Bijnen, $M$ Henkens, J Diez, $U$ de Windt, FA van Nieuwenhoven, M van Bilsen, MJ Goumans, S Heymans, A González, B Schroen. *Contributed equally. MicroRNA-221/222 Family Counteracts Myocardial Fibrosis in Pressure Overload-Induced Heart Failure. Hypertension. $2018 \mathrm{Feb}$;11(2):280-288. (IF=6.86).

- M Bijnen, T Josefs, I Cuijpers, C J Maalsen, J van de Gaar, M Vroomen, E Wijnands, SS Rensen, JWM Greve, MH Hofker ${ }^{\dagger}$, EAL Biessen, CDA Stehouwer, CG Schalkwijk, K Wouters. ${ }^{\dagger}$ Deceased. Adipose tissue macrophages induce hepatic neutrophil recruitment and macrophage accumulation in mice. Gut. 2017 Oct 26. pii: gutjnl-2016-313654. (IF=16.66).

- K Wouters, K Gaens, M Bijnen, K Verboven, J Jocken, S Wetzels, E Wijnands, D Hansen, $M$ van Greevenbroek, A Duijvestijn, EAL Biessen, EE Blaak, CDA Stehouwer, CG Schalkwijk. Circulating classical monocytes are associated 
with CD11 ${ }^{+}$macrophages in human visceral adipose tissue. Sci Rep. 2017 Feb 15;7:42665. (IF=4.85).

\section{Additional manuscripts}

- K Wouters*, YHAM Kusters*, M Bijnen, S Wetzels, PBC Linssen, K Gaens, AJHM Houben, P Joris, J Plat, ME Kooi, CJH van der Kallen, RP Mensink, K Verboven, J Jocken, D Hansen, EE Blaak, CDA Stehouwer, CG Schalkwijk. *Contributed equally. NK cells in human visceral adipose tissue contribute to obesity-associated insulin resistance through macrophage polarization and low-grade inflammation. Under revision at Cell Metabolism.

- $\quad$ M Bijnen, M van Greevenbroek, $C$ van der Kallen, JL Scheijen, MPH van de Waarenburg, CDA Stehouwer, K Wouters, CG Schalkwijk. Hepatic fat content and liver enzymes are associated with circulating free and protein-bound advanced glycation endproducts, which are associated with low-grade inflammation: The CODAM study. Submitted.

- M Bijnen, S Wetzels, JL Scheijen, MPH van de Waarenburg, J van de Gaar, CDA Stehouwer, K Wouters, CG Schalkwijk. Higher dietary advanced glycation endproduct intake increases circulating advanced glycation endproducts, hepatic advanced glycation endproducts and hepatic inflammation. In preparation.

- N Simons, M Bijnen, K Wouters, SS Rensen, F Rutters, JM Dekker, MMJ van Greevenbroek, G Nijpels, LM 't Hart, CJH van der Kallen, NC Schaper, CG Schalkwijk, CDA Stehouwer, MCGJ Brouwers. Soluble E-Selectin is a liverderived endothelial marker that is associated with non-alcoholic fatty liver disease. In preparation.

- K Wouters, M Bijnen, T Josefs, I Cuijpers, J van de Gaar, M Vroomen, E Wijnands, S Wetzels, JJG van Wegberg, K Gaens, EAL Biessen, CDA Stehouwer, CG Schalkwijk. CD11 ${ }^{+}$macrophages are recruited to adipose tissue early during the development of obesity, resemble dendritic cells and display a mixed $\mathrm{M} 1 / \mathrm{M} 2$ profile in mice. In preparation. 


\section{Presentations}

- 8th Joint Diabetes and Metabolism Research Symposium 2018 (Maastricht; Oral)

- European Fatty Liver Conference 2018 (Vaals; Poster)

- NVVI Annual Meeting 2017 (Noordwijkerhout; Poster)

- Internal Medicine day 2017 (Maastricht; Poster)

- VIB conference: Macrophage biology in the single-cell era (Ghent; Poster)

- Keystone Symposia: Integrating Metabolism and Immunity (Dublin; Poster)

- EASL International Liver Conference 2017 (Amsterdam; Poster)

- Joint BSI and NVVI Congress 2016 (Liverpool; Poster)

- Internal Medicine day 2016 (Maastricht; Poster)

- European Association for the Study of Diabetes (EASD) 2016 Annual Meeting (Munich; Oral)

- International Symposium on the Maillard Reaction 2015 (Tokyo; Poster)

\section{Awards and grants}

- Internal Medicine day 2018 Best publication prize

- The $8^{\text {th }}$ Network of Immunology Frontier (NIF) Winter School on Advanced Immunology travel grant

- CARIM Postdoctoral Talent Fellowship 2018 (53.000 euro)

- Internal Medicine day 2017 Best poster prize

- European Association for the Study of Diabetes (EASD) annual meeting 2016 travel grant

- European Association for the Study of the Liver (EASL), School of Hepatology: Liver immunology travel grant 
Abbreviations 


\section{Abbreviations}

$\begin{array}{ll}\text { 3-DG } & \text { 3-Deoxyglucosone } \\ \text { AGE } & \text { Advanced glycation endproduct } \\ \text { ALAT } & \text { Alanine aminotransferase } \\ \text { ASAT } & \text { Aspartate aminotransferase } \\ \text { AT } & \text { Adipose tissue } \\ \text { ATM } & \text { Adipose tissue macrophage } \\ \text { BM } & \text { Bone marrow } \\ \text { BMDM } & \text { Bone marrow-derived macrophage } \\ \text { BMI } & \text { Body mass index } \\ \text { CD } & \text { Cluster of differentiation } \\ \text { CEL } & \text { NE-(1-carboxyethyl)lysine } \\ \text { CLS } & \text { Crown-like structure } \\ \text { CML } & \text { NE-(carboxymethyl)lysine } \\ \text { CMP } & \text { Common myeloid progenitor } \\ \text { CODAM } & \text { Cohort on diabetes and atherosclerosis Maastricht } \\ \text { CRP } & \text { C-reactive protein } \\ \text { CSF } & \text { Colony-stimulating factor } \\ \text { CXCL } & \text { Chemokine (C-X-C motif) ligand } \\ \text { dAGE } & \text { Dietary advanced glycation endproduct } \\ \text { DC } & \text { Dendritic cell } \\ \text { DOTA } & \text { ATM-depleted obese-transplanted acceptor } \\ \text { eGFR } & \text { Estimated glomerular filtration rate } \\ \text { eLF\% } & \text { Estimated liver fat percentage } \\ \text { FACS } & \text { Fluorescence-activated cell sorting } \\ \text { FC } & \text { Fold change } \\ \text { FLI } & \text { Fatty liver index } \\ \text { FMO } & \text { Fluorescence minus one } \\ \text { FSC } & \text { Forward-scatter } \\ \text { GGT } & \text { Gamma-glutamyl transferase } \\ \text { GLO } & \text { Glyoxalase } \\ \text { GMP } & \text { Granulocyte-macrophage progenitor cells } \\ \text { GO } & \end{array}$




$\begin{array}{ll}\text { GSH } & \text { Glutathione } \\ \text { H\&E } & \text { Haematoxylin and eosin } \\ \text { HbA1C } & \text { Hemoglobin A1c } \\ \text { HCD } & \text { High cholesterol diet } \\ \text { HDL } & \text { High-density lipoprotein } \\ \text { HFD } & \text { High fat diet } \\ \text { HFHC } & \text { High fat, high cholesterol } \\ \text { HOMA-IR } & \text { Homeostasis model assessment insulin resistance } \\ \text { IFN } & \text { Interferon } \\ \text { IGM } & \text { Impaired glucose metabolism } \\ \text { IL } & \text { Interleukin } \\ \text { KO } & \text { Knockout } \\ \text { LDL } & \text { Low-density lipoprotein } \\ \text { LDLR } & \text { Low-density lipoprotein receptor } \\ \text { LE } & \text { Liver enzyme } \\ \text { LFD } & \text { Low fat diet } \\ \text { LGI } & \text { Low-grade inflammation } \\ \text { LPS } & \text { Lipopolysaccharide } \\ \text { LTA } & \text { Lean-transplanted acceptor } \\ \text { MFI } & \text { Mean fluorescence intensity } \\ \text { MG-H1 } & \text { N }{ }^{\delta} \text {-(5-hydro-5-methyl-4-imidazolon-2-yl)-ornithine } \\ \text { MGO } & \text { Methylglyoxal } \\ \text { NAFLD } & \text { Non-alcoholic fatty liver disease } \\ \text { NAS } & \text { NAFLD activity score } \\ \text { NASH } & \text { Non-alcoholic steatohepatitis } \\ \text { NGM } & \text { Normal glucose metabolism } \\ \text { NK } & \text { Natural killer } \\ \text { OTA } & \text { Obese-transplanted acceptor } \\ \text { PB-CEL } & \text { Protein-bound CEL } \\ \text { PB-CML } & \text { Protein-bound CML } \\ \text { PB-Pentosidine } & \text { Protein-bound Pentosidine } \\ \text { PMN } & \text { Polymorphonuclear leukocytes } \\ \text { RAGE } & \text { Receptor of advanced glycation endproducts } \\ \text { ROS } & \end{array}$




$\begin{array}{ll}\text { SAA } & \text { Serum amyloid A } \\ \text { SAT } & \text { Subcutaneous adipose tissue } \\ \text { SEM } & \text { Standard error of the mean } \\ \text { SRAGE } & \text { Soluble RAGE } \\ \text { SSC } & \text { Side-scatter } \\ \text { SVF } & \text { Stromal vascular fraction } \\ \text { T2DM } & \text { Diabetes mellitus type 2 } \\ \text { UPLC-MS/MS } & \text { Ultra-performance liquid chromatography tandem } \\ & \text { mass spectrometry } \\ \text { VAT } & \text { Visceral adipose tissue } \\ \text { WBC } & \text { White blood cell } \\ \text { WKS } & \text { Weeks } \\ \text { WT } & \text { Wild type } \\ \text { WTD } & \text { Western type diet }\end{array}$


